\title{
DEVELOPMENT OF A COAL CLEANING CONTROL SYSTEM
}

for

\section{FINAL REPORT}

PETC TPO: Shelby Roger.

by

H.N. Conklo,

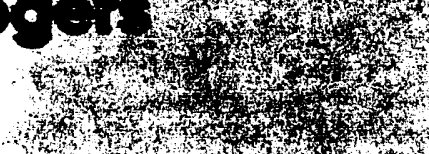

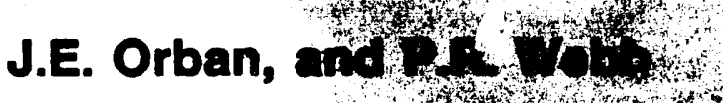
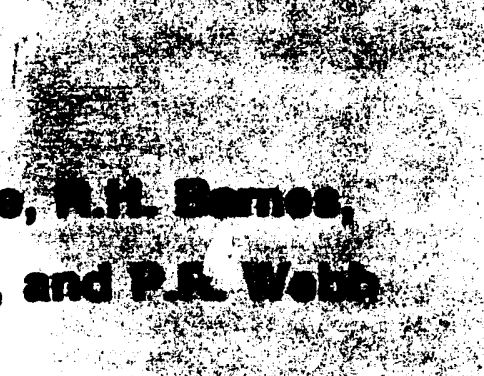

- Battelle

Culumbus Division

jo5 King ivenue

Columbus. Omo tran-xes

MASTER
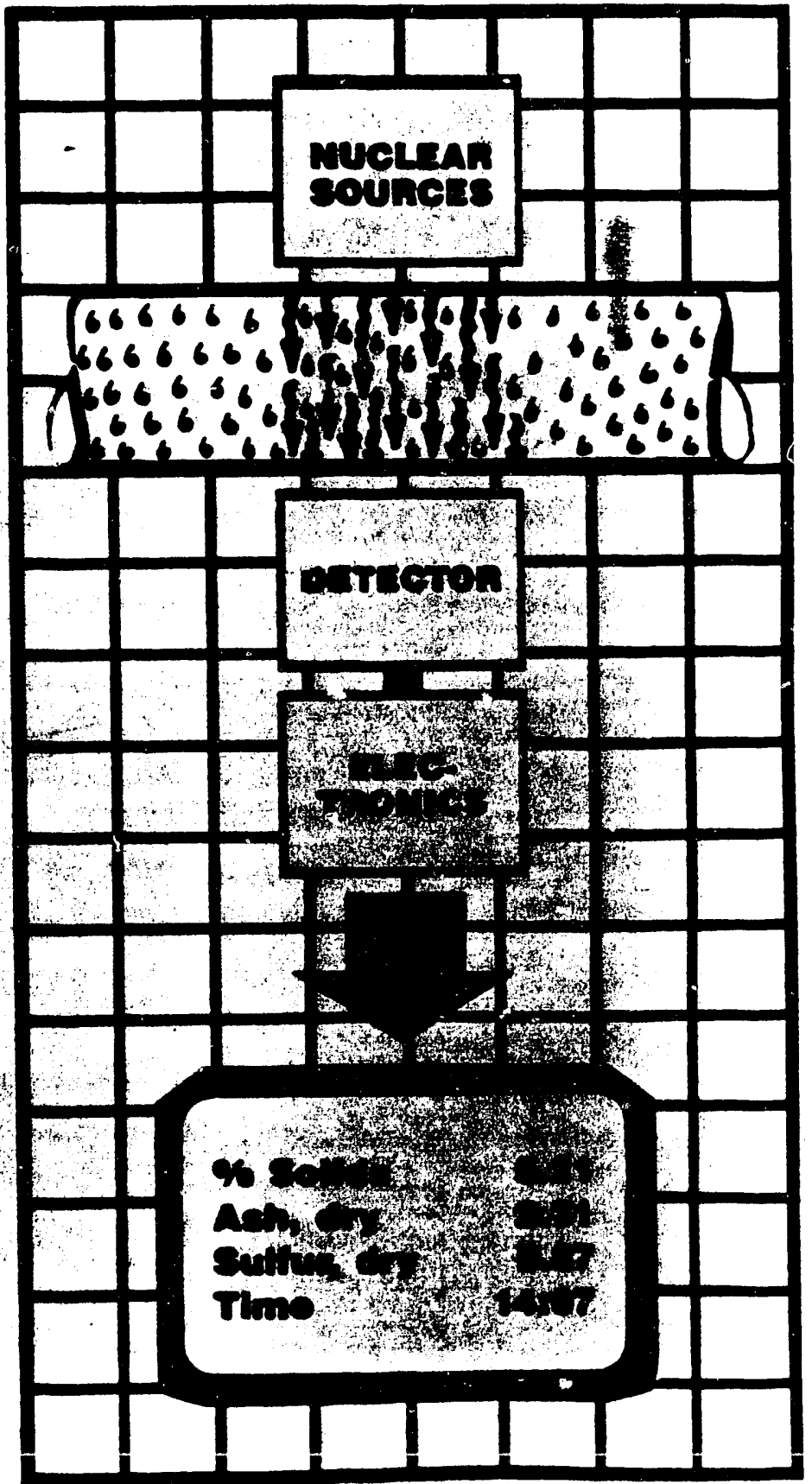


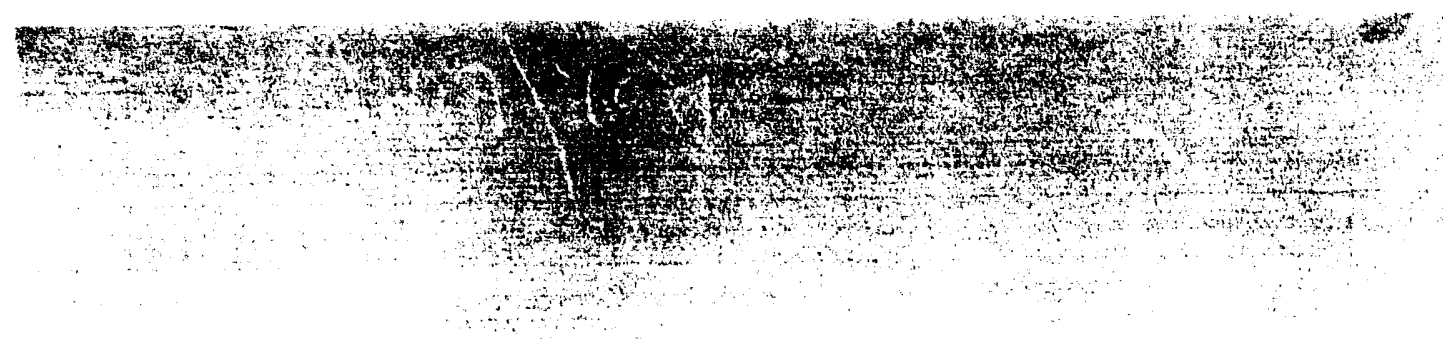

\section{DISCLAIMER}

This report was prepared as an account of work sponsored by an agency of the United States Government. Neither the United States Government nor any agency thereof, nor any of their employees, makes any warranty, express or implied, or assumes any legal liability or responsibility for the accuracy, completeness, or usefulness of any information, apparatus, product, or process disclosed, or represents that its use would not infringe privately owned rights. Reference herein to any specific commercial product, process, or service by trade name, trademark, manufacturer, or otherwise does not necessarily constitute or imply its endorsement, recommendation, or favoring by the United States Government or any agency thereof. The views and opinions of authors expressed herein do not necessarily state or reflect those of the United States Government or any agency thereof.

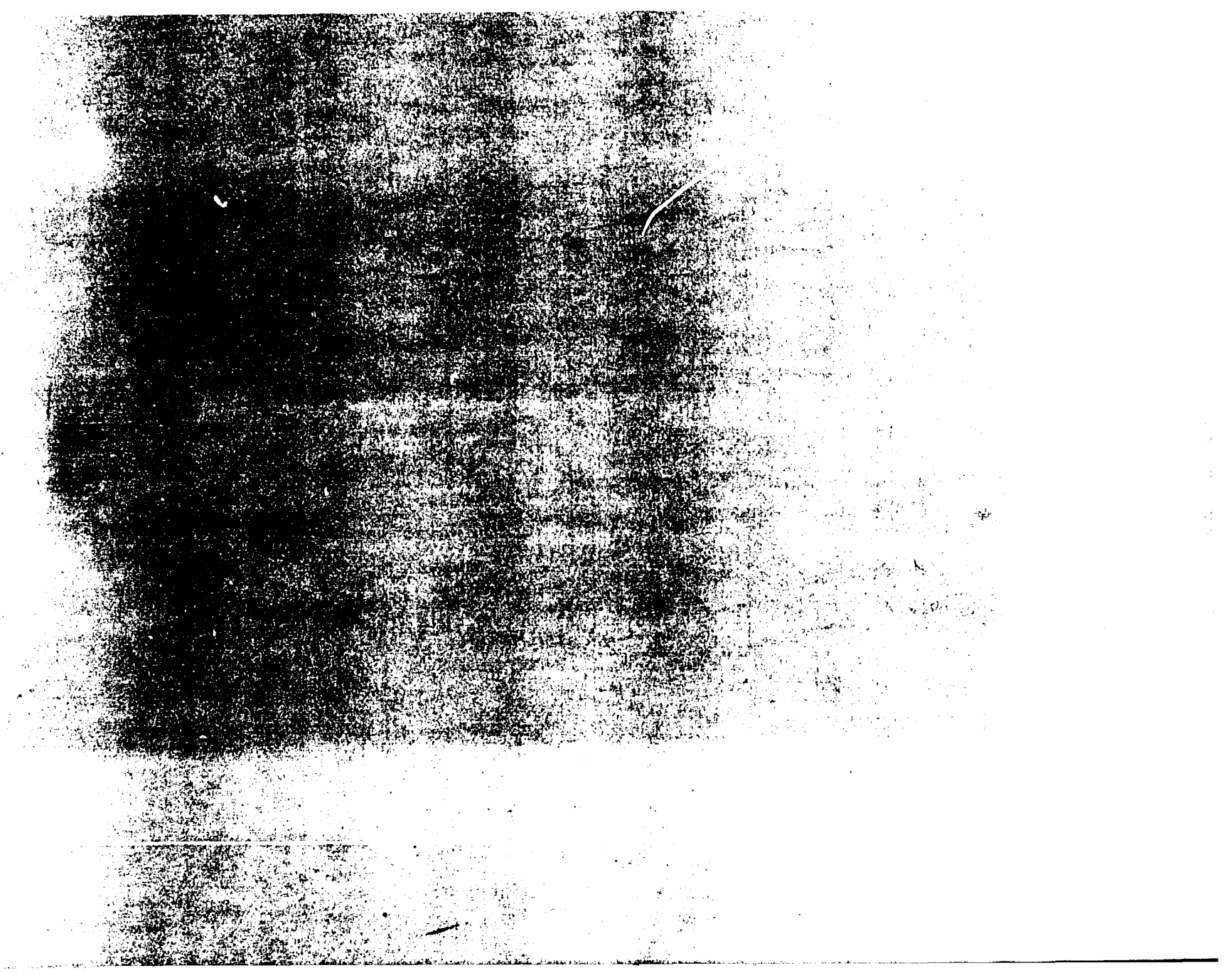




\section{EXECUTIVE SUMMARY}

Today most coals cleaned by advanced or conventional processes are cleaned in an aqueous slurry. In order to optimize cleaning efficiency and better control cleaning operations, more rapid feedback on the coals' ash and sulfur content--while still in the slurry, is required. Recognizing this need, the U.S. Department of Energy selected the Battelle-Electric Power Research Institute-Science Applications International Corporation team to evaluate and develop on-line slurry ash, percent solids, and sulfur analysis instrumentation and process control technology.

\section{Project Objective}

The project's objectives were (1) to develop an accurate, versatile, easy to use, on-line coal slurry analyzer and (2) to develop control strategies for analysis, control, and optimization of advanced and conventional coal-cleaning plants.

\section{Scope of Work}

The project's scope included (1) the installation of a slurry test loop, ash, percent solids, and sulfur instruments; (2) evaluation of instrument accuracy with various coals, under various slurry conditions; and (3) assessment of the cost and benefits to be derived from on-line analysis and control.

\section{Analysis Target Specifications}

Instrument accuracy targets were based on ASTM reproducibility limits for standard ash, percent solids, and sulfur determinations. The targets were: 
Ash:

Percent Solids:

Sulfur: \pm 0.5 percent standard error for coals with less than 12 percent ash, and

\pm 1 percent ash standard error for greater than 12 percent ash

\pm 1 percent solids standard error

\pm 0.1 percent sulfur standard error for coals with less than 2 percent total sulfur, and

\pm 0.2 percent sulfur standard error for coals with 2 percent more sulfur.

These standards were based on ASTM reproducibility limits for ash (03174-82), moisture (02961), and sulfur (03177-84).

An alternative sulfur target, based on ASTM D4239 Method A, was used as a more realistic sulfur goal. The specification was

\pm 11 percent of dry sulfur valve (plus an allowable bias of 0.03 percent sulfur).

\section{Equipment and Procedures}

The coal slurry analyzer below consists primarily of the following four instruments: a high-energy gamma gauge (HEGG) and a low-energy gamma gauge (LEGG), together referred to as the dual energy gamma gauge (DEGG), a prompt gamma neutron activation analyzer (PGNAA), and a Micro Motion (MM) mass flow meter.

\section{Coal Slurry Analyzer}

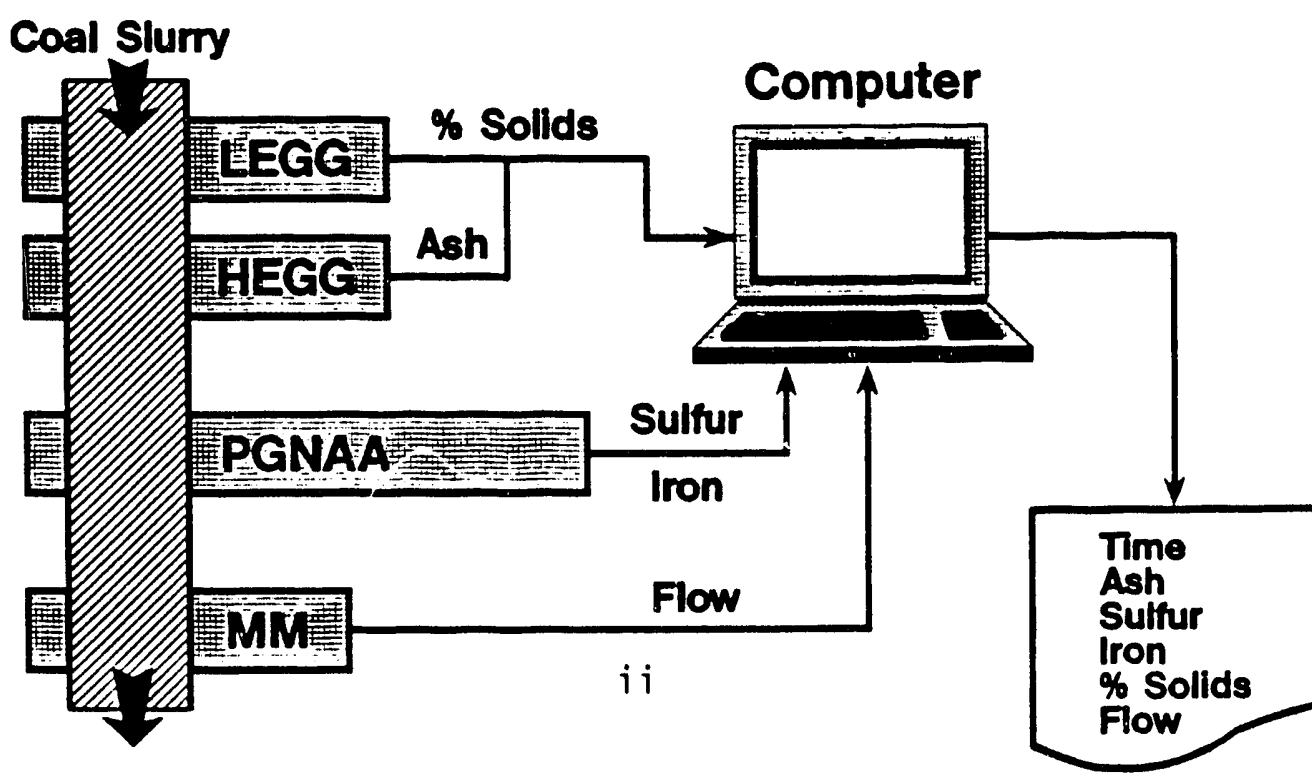

Flow 
The first two are specially modified densitometers which worked on the principle of gamma-ray attenuation. The signal produced is proportional to the slurry density and composition. They are used to predict ash and slurry percent solids. The PGNAA unit produces a gamma-ray spectra resulting from the neutron activation of the coal slurry. The spectra provide quantitative information on coal composition and the concentration of specific elements in the slurry. It is used to predict sulfur and iron. The MM flow meter produces a signal proportional to mass flow rate.

\section{Results}

The instruments allow rapid, accurate analysis of various coal slurries. Over typical ranges of ash (10 to 25 percent), sulfur ( 3 to 6 percent), percent solids (5 to 20 percent), and ash composition (10 to 40 percent iron-oxide-in ash), the three units allow analysis of ash, percent solids, and sulfur within the project's target accuracy specifications (see below).

\section{Ash Analyzer}

The DEGG is versatile, easy-to-use, and well suited to on-line analysis and control. Analysis times are short, allowing nearly instantaneous prediction of ash levels. The unit appears applicable to many major conventional and advanced fine-coal cleaning processes. The major coal slurry properties affecting ash prediction are ash composition and air. Varying sulfur levels, percent solids (above 5 percent), and particle sizes (below 20 mesh) have only minor effects.

Ash Level. The DEGG and PGNAA can be used to estimate ash content with a standard error less than 1 percent $\{0.15$ to 0.9 percent depending on the correlation method selected) over ash levels typically encountered in advanced and conventional cleaning processes, e.g., 5-20 percent ash and 30-50 percent ash. Separate ash prediction correlations are required for each ash range to maintain prediction error within the project's error target (see figure on next page). 


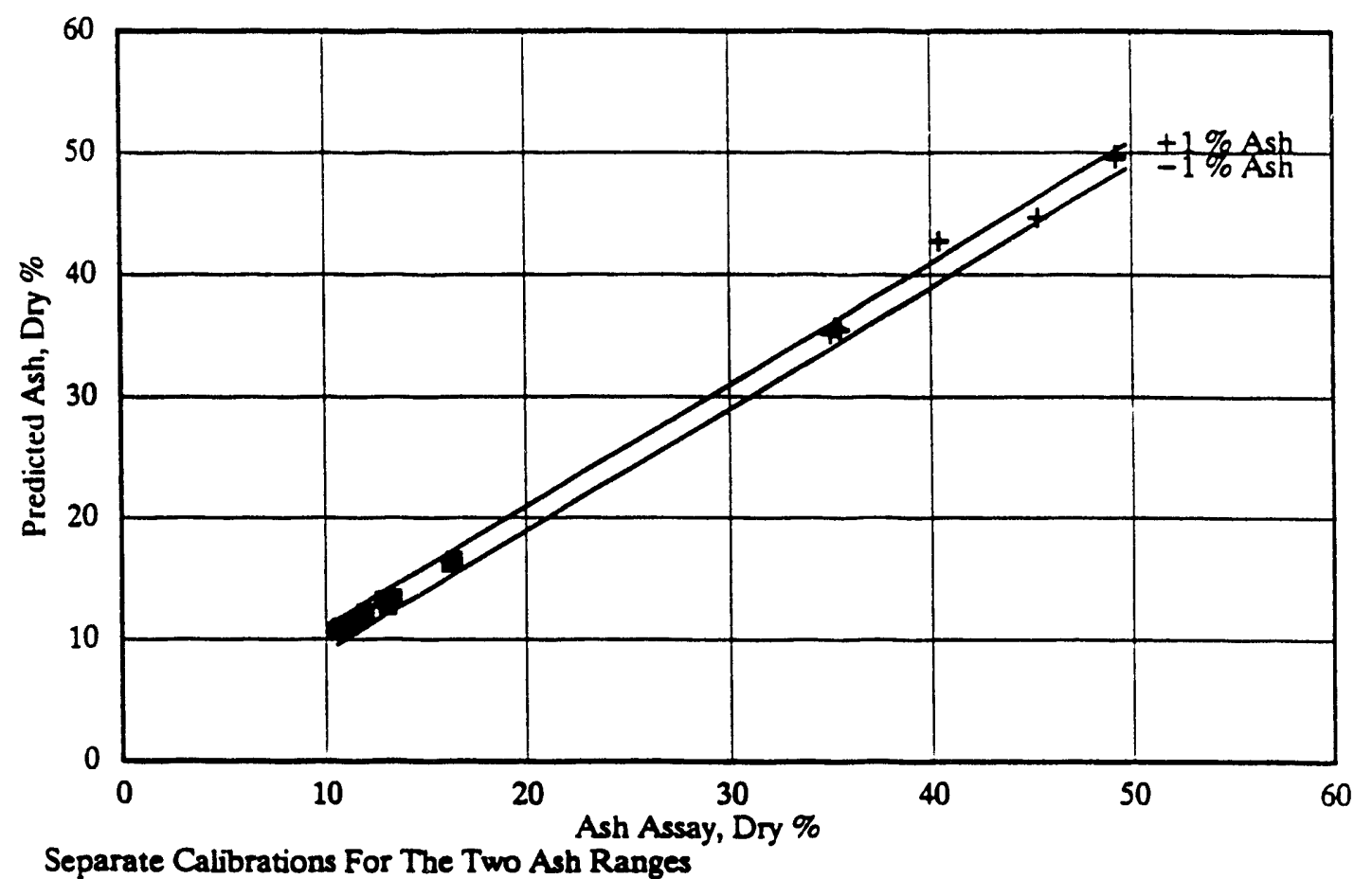

Separate Calibrations For The Two Ash Ranges

Sulfur Level. Varying sulfur levels did not significantly affect ash prediction. Adding a sulfur-correction term resulted in a slight improvement in ash prediction.

Percent Solids. Percent solids, ranging from 5 to 20 percent, did not dramatically affect ash prediction accuracy, e.g., a standard error 0.8 of ash was achieved over this percent-solids range. However, further improvement to 0.6 percent ash error was possible by including a percent-solids correction term. Greater error was encountered with extremely low ( $<5$ percent) percent solids levels.

Iron Level. Varying levels of iron $(0.2$ to 0.9 percent iron, wet basis in slurry) could be tolerated while keeping ash standard-error levels below 1 percent. Greater accuracy ( 0.15 percent ash) was possible using prediction equations incorporating an iron correction term. (Iron levels can be obtained from the PGNAA instrument.) 
Larger standard errors were encountered when much larger iron variations, as between clean coal (10 to 17 percent ash, 10 to 15 percent solids, 0.2 to 0.9 percent iron, wet basis) and refuse stream ( 35 to 50 percent ash, 5 to 20 percent solids, 0.2 to 0.7 percent iron, wet basis) were encountered. Results with slurries doped with magnetite $\left(\mathrm{Fe}_{3} \mathrm{O}_{4}\right)$ to simulate heavy media operations showed excessively high error levels.

Particle Size. Varying levels of particle size, from -20 mesh to -100 mesh, did not noticeably affect ash prediction. Smaller sizes are not anticipated to cause problems. The upper limit was not established, but coal particles $3 / 4$ inch or larger are anticipated to be unsuitable.

Coal Type. Variations in the coal composition between different coal types resulted in standard errors in the range of 2 to 5 percent ash. Individual correlation by coal type was required to achieve standard-error levels below the 1 percent ash target.

\section{Percent Solids Analyzer}

The HEGG percent-solids system is very similar to the DEGG-based ash analyzer. Both were combined for process control and costs/benefits analysis. The major slurry properties affecting percent solids accuracy were excessively high iron levels, as experienced with magnetite-containing streams and air.

Solids Level. The HEGG, DEGG, or PGNAA can be used to predict solids with a standard error less than 1 percent $(0.5$ to 0.9 percent, depending on the correlation method selected) over a reasonably broad range of percent solids ( 5 to 20 percent) ash, and ash composition. The range can be broadened to cover a 10 to 50 percent ash level, while maintaining acceptable accuracy, by including correlations for ash, iron, and sulfur levels. The accuracy achieved is noted on the following figure. 


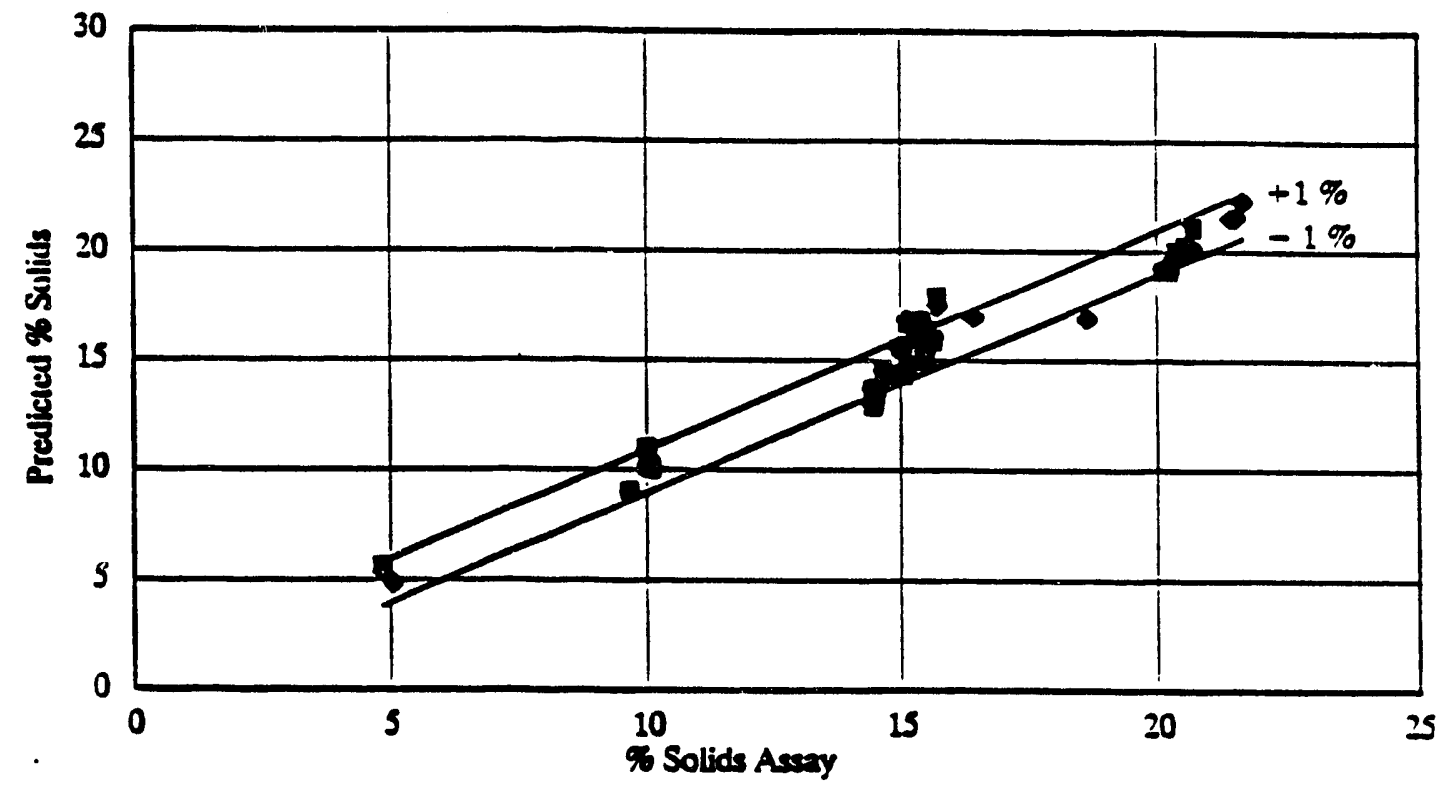

Ash Level. Minor effect over 5 to 40 percent range with constant ash composition levels.

Sulfur Level. Minor effect over 1 to 5 percent sulfur.

Iron Level. Varying levels of iron ( 0.2 to 0.9 percent iron, wet basis in slurry) had only a minor effect. Larger variations, as experienced with magnetite caused unacceptably large errors.

Particle Size. Varying particle size, -20 mesh and -100 mesh, had minimal impact. Smaller sizes should also be acceptable. Particle size upper limit has not been identified, but particles larger than $3 / 4$ inch are anticipated to be unacceptable.

Coal Type. Variation in coal type caused minor variations--tied to ash composition differences. Coal-by-coal correlations, or ash and iron-correction equations, should allow acceptable accuracies. 


\section{Sulfur Analyzer}

The PGNAA can be readily employed for on-line analys is and control. Although analysis times, at 5 minutes per analysis, are longer than the DEGG, they are considerably shorter than the lag time associated with most sulfur control actions (e.g., changing cell level, reagent dosage, specific gravity,

- vortex finder level, etc.). The unit appears applicable to all major finecoal cleaning processes. But, like the DEGG, it cannot be applied directly to magnetite-containing streams or froth stream. The major slurry properties affecting sulfur prediction were sulfur, iron, chlorine, percent solids, and air.

Sulfur Level. The PGNAA can be used to predict dry sulfur content with an error less than 11 percent of the assay value over sulfur level typically encountered in advanced and conventional cleaning processes, e.g., 3 to 6 percent dry sulfur range (see figure below).

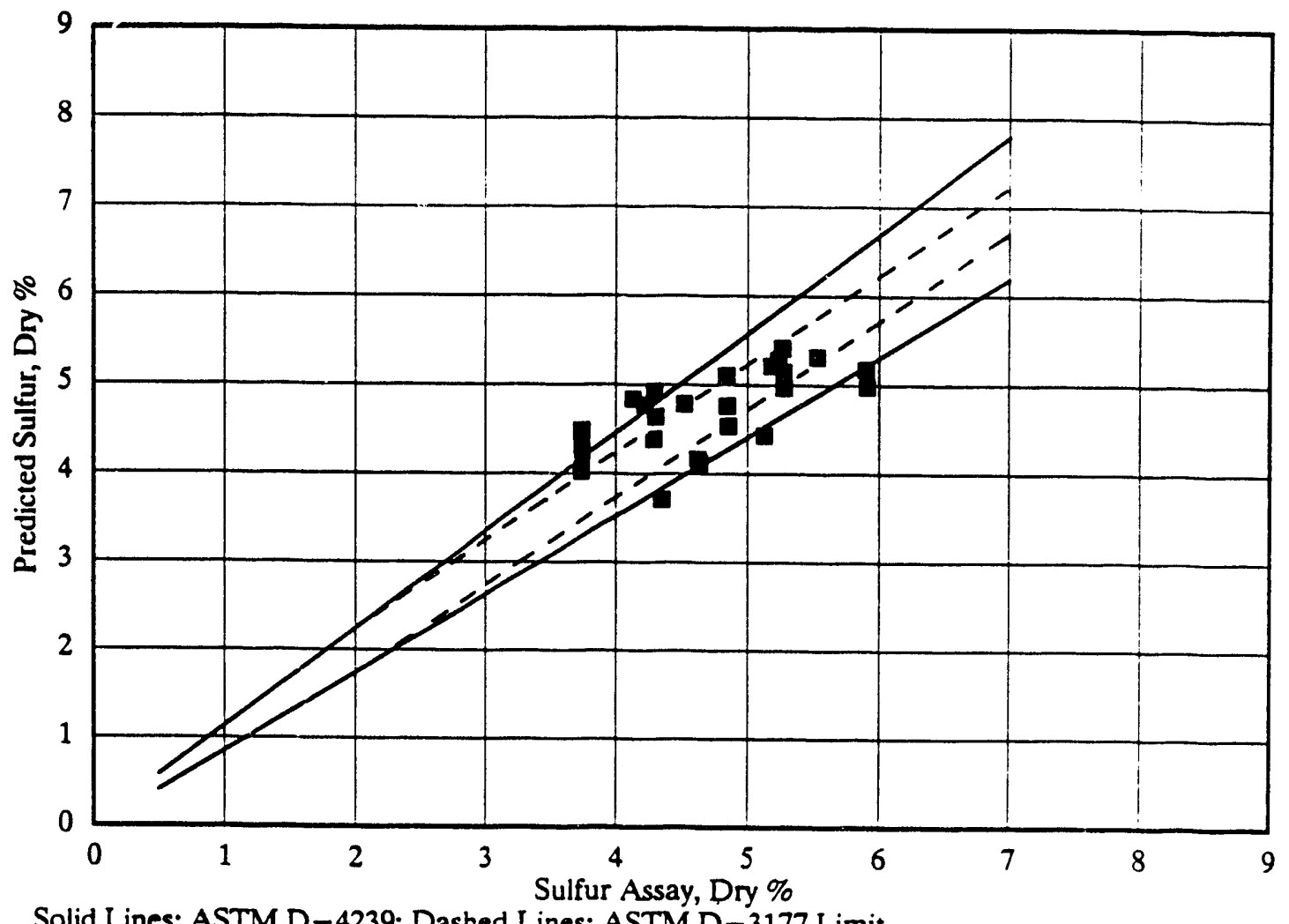

Solid Lines: ASTM D-4239; Dashed Lines: ASTM D-3177 Limit 
Accurate predictions over a lower sulfur range ( 1 to 3 percent dry sulfur) should be obtainable with proper calibration.

Iron Level. Varying iron levels had a dramatic effect on sulfur prediction. However, ihrough incorporation of an iron-correction term in the sulfur prediction algorithm, this effect was minimized. Analysis of coal with up to 4 percent iron should not be a problem. However, magnetite-rich streams, with excessively high iron levels, cannot be analyzed accurately without a separate calibration.

Chlorine Level. Chlorine had an even more pronounced effect on sulfur prediction. However, over levels typically experienced in coal preparation service, this effect can be satisfactorily handled with the chlorine-correction term in the sulfur prediction algorithm. Analysis of coal with up to 0.5 percent chlorine should not present a problem.

Ash Level. Minor effect over a 10 to 50 percent ash range.

Percent Solids. PGNAA testing indicated that operations should be limited to a 10 percent or greater percent soijds range. Testing was successful onlv over a 10-20 percent solids range. Limited testing indicates that a 1-10 percent level may be acceptable if coal composition was reasonably constant.

Particle Size. Minor effect for -20 mesh and smaller particles. The upper limit was not established. However, particles larger than $3 / 4$ inch will probably not be acceptable.

Coal Type. Variations in the coal composition may require separate calibrations for different coals. 


\section{Process Control Applications}

Analysis indicates that the instruments should be applicable to the following advanced cleaning processes: flotation, heavy-liquid cyclones, and oil agglomeration (see below).

\begin{tabular}{lll} 
Cleaning Processes & \multicolumn{1}{c}{ Applicability } & \multicolumn{1}{c}{ Ratoionale } \\
Advanced flotation & $\begin{array}{l}\text { Yes for feed or } \\
\text { refuse; product } \\
\text { possibly after de- } \\
\text { aeration }\end{array}$ & $\begin{array}{l}\text { Particle size (-200 mesh) and } \\
\text { composition are acceptable. } \\
\text { Existence of air bubbles is a } \\
\text { problem. Analysis of froth after } \\
\text { de-aeration may be possible. } \\
\text { Analysis of feed, or refuse stream, } \\
\text { should be acceptable. }\end{array}$ \\
$\begin{array}{l}\text { Heavy-liquid } \\
\text { cyclone }\end{array}$ & $\begin{array}{l}\text { Yes for non- } \\
\text { chlorinated liquids }\end{array}$ & $\begin{array}{l}\text { Particle size (-200 mesh) and } \\
\text { composition are acceptable. } \\
\text { Chlorinated compounds could } \\
\text { interfere with sulfur prediction. }\end{array}$ \\
0il agglomeration & $\begin{array}{l}\text { Yes for non- } \\
\text { chlorinated } \\
\text { agglomerating agents }\end{array}$ & $\begin{array}{l}\text { Particle size (-200 mesh) and } \\
\text { composition are acceptable. } \\
\text { Chlorinated compounds could } \\
\text { interfere with sulfur prediction. }\end{array}$
\end{tabular}

For flotation, control must be based on the feed and refuse streams. In limited testing, a small quantity of air was added to the test loop to simulate froth flotation. The air allowed excessive levels of gamma ray radiation to reach the DEGG and PGNAA detectors. However, the feed to the flotation cell and the tailings underflow, which do not contain excessive air levels, should be readily analyzed. Since tailing-stream analys is is used for on-line control, the coal slurry analyzer should allow effertive control. In addition, froth analysis after de-aeration is a possibility.

The analyzer is also applicable to many, but not all, conventional processes such as heavy-media cyclones, concentrating tables, water-only cyclones, and froth flotation (see below). 


\section{Cleaning Process}

Jig

Heavy-media bath

Heavy-media cyclone

Concentrating table

Water-only cyclone

Froth flotation
Applicability

No

No

Probable

Possible

Yes

Yes for feed or refuse, product possible after deaeration

\section{Rationale}

Coal particle size, $6 i_{i}, n \times 0$, too large.

Coal particle size, $2-1 / 2 \times 1 / 2$ inch, too large, and product and refuse streams may contain too much iron.

Particle size may be too large: feed sizes range from $3 / 4 \times 28$ mesh (too large) to $1 / 4 \times 28$ mesh (may be acceptable, but not proven). Product and refuse streams can be analyzed only after magnetite removal; direct analysis impossible because of iron content.

Particle size $(-3 / 8$ inch or $-1 / 4$ inch) may be acceptable (not demonstrated). Coal composition and iron content, should be acceptable.

Size (-28 mesh), composition, and iron content should be acceptable.

Particle size ( -28 mesh) and composition are acceptable. Existence of air bubbles is a problem. Analys is of froth after de-aeration is possible; feed or refuse stream analysis should be acceptable.

The strong effect of excessive iron levels on the DEGG and PGNAA makes heavy media applications difficult. It appears the unit is not suitable for analysis of the slurries directly from heavy-media baths or cyclones. However, after the magnetite has been removed from the product or refuse streams (i.e., after the drain and rinse screens) acceptable analysis should be possible. Therefore, DEGG control of a heavy-media system should be possible. 


\section{Cost/Benefits}

Estimated cost for an installed DEGG ash and percent solids analyzer is $\$ 27,000$, and $\$ 44,000$ for an installed PGNAA sulfur analyzer. Control system costs depend on the degree of complexity, ranging from $\$ 10,000$ for a simple system to $\$ 100,000$ or more for a sophisticated control system. Greater plant control should allow operation at ash and sulfur levels closer to the buyer's product specification. For example, to consistently produce a 12 percent ash coal, the target cleaning value can be increased from a typical $\mathrm{n}^{-}$-control 10 percent ash cleaning target to a 11.5 percent ash target. Greater ash levels result in reduced overcleaning. The closer match between plant operation and specification means greater product consistency and less clean coal is given away. In addition, because of greater yield, fewer tons of coal need be mined and less refuse needs be disposed--while still meeting plant output requirements. The potential savings of on-line analysis and control are shown below. Cost/benefit projections indicate that on-line analysis and control is economically attractive. For a typical advanced

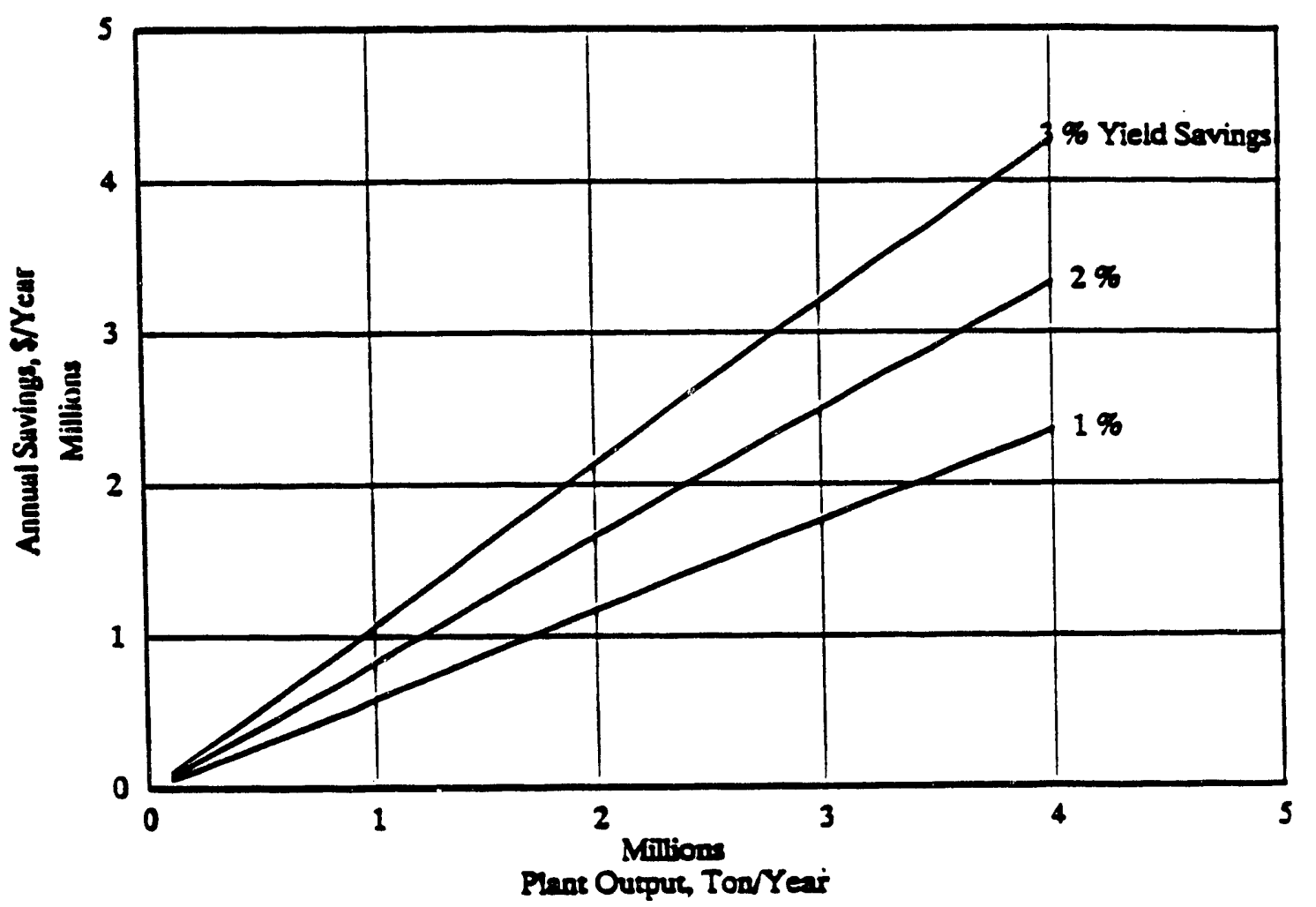


cleaning process (flotation), savings are sufficient to pay back the analyzer, control system, and installation costs within 4 to 10 months. For a conventional system (water-only cyclone), payback periods range from 5 to 8 months. Typically, investments with payback periods of less than 18 months are considered excellent financial opportunicies.

\section{Recommendations}

Based on the experimental data generated and cost/benefits analyses, the following recommendations are made:

(1) Generate longer-term accuracy data with more coals, over typical slurry processing conditions.

(2) Test the DEGG/PGNAA analyzer in an actual coal cleaning piant control mode. Determine effectiveness, estimate costs for the control system and installation, and document savings achieved.

(3) Replace the HEGG with a state-of-the-art cesium 137 densitometer, and modify a similar unit as an americium densitometer. Such a replacement should allow greater accuracy (due to improved electronics), lower gamma-ray emissions (due to smaller nuclear sources), and lower instrument costs. Test the effectiveness of new electronics, and re-estimate DEGG analyzer costs.

(4) Replace the PGNAA amplifier and multi-channel analyzer with new state-of-the-art equipment. These replacements should allow greater accuracy (due to more precision division of the PGNAA spectrum, better spectrum stabilization, and improved electronics) and ready integration with on-line data acquisition, sulfur prediction, and control systems. Test the effectiveness of new electronics, and re-evaluate PGNAA analyzer costs.

(5) Identify the maximum coal particle size consistent with accurate slurry analysis. 
EXECUTIVE SUMMARY .................... i

SECTION 1 INTRODUCTION ..................... 1

Background ..................... 1

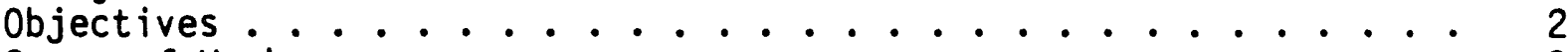

Scope of Work .................... 3

SECTION 2 TECHNOLOGY DESCRIPTION . ............... 4

Ash and Percent Solids Analysis .............. 4

Sulfur and Iron Analysis ................. 10

Flow Rate Analysis ................. 16

SECTION 3 EQUIPMENT AND PROCEDURES . ............... 17

Test Loop . . . . . . . . . . . . . . . . . . 17

High-Energy Gamma Gauge ................... 21

Low Energy Gamma Gauge ................... 22

Prompt Gamma Neutron Activation Analyzer ............ 22

Micro-Motion Mass (MM) Flow Meter .............. 27

Data Acquisition System ............... 27

Nuclear Safety .................... 32

Test Procedures .................... . . 32

Analytical Procedures ................... 33

Ash . . . . . . . . . . . .... 34

Percent Solids .................. 35

Sulfur ..................... 35

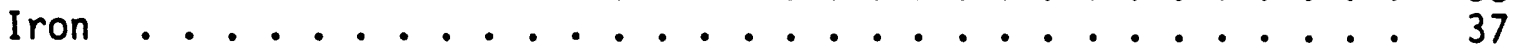

SECTION 4 EXPERIMENTAL RESULTS .................. 38

Accuracy Target Specifications ............... 38

Summary of Experiments ................. 39

Percent Ash Results .................... 43

Accuracy Achieved ................... 43 43

Tests conducted ................... 48

Conclusions ....................... 58

Percent Solids Results ................... 60

Accuracy Achieved .................. 60

Test Conducted .................. 63

Conclusions ..................... 70

Sulfur Results .................... 72

Accuracy Achieved ................ 72

Test Conducted ................. 75

Conclusion ...................... 91

SECTION 5 PROCESS CONTROL APPLICATIONS . . . . . . . . . . . 95

Applicable Cleaning Processes ............. 95

Development of Process-Control Strategies ......... 98

Advanced Coal Flotation ............... . . 98

Water-Only Cyclones ................ 110 


\title{
TABLE OF CONTENTS
}

\author{
(Continued)
}

$\underline{\text { Page }}$

SECTION 6 COST/BENEFIT ANALYSIS . . . . . . . . . . . . . . 116

Analyzer Costs....................... 116

Percent Solids Analyzer ................... . 116

Cost for Sulfur Analyzer . . . . . . . . . . . . . . 118

Cost of Control Hardware/Software . . . . . . . . . . . . 119

Benefits of On-Line Analysis and Control . . . . . . . . . . 120

Ash Control ..................... 120

Sulfur Control . . . . . . . . . . . . . . . . . . 124

Cost/Benefit Assessment for Advanced Froth Flotation . . . . . . . . 131

Cost/Benefit Assessment for Conventional Water-Only Cyciones . . . . 135

SECTION 7 CONCLUSIONS AND RECOMMENDATIONS . . . . . . . . . . . . 139

Conclusions . . . . . . . . . . . . . . . . . . 139

Ash . . . . . . . . . . . . . . . . . 139

Percent Solids ...................... 140

Sulfur and Iron...................... . . 140

Control Strategies .................... 142

Cost/Benefit ...................... 142

Recommendations .................... 142

SECTION 8 REFERENCES . . . . . . . . . . . . . . . . . . 146

APPENDIX A ASH AND PERCENT SOLIDS ANALYSIS

APPENDIX B SULFUR AND IRON ANALYSIS

APPENDIX C DATA ACQUISITION SYSTEM

APPENDIX D CHEMICAL ANALYSES OF TEST COALS

APPENDIX E PROCESS-CONTROL STRATEGIES 


\section{LIST OF TABLES}

Page

TABLE 1. LINEAR ATTENUATION GAMMA-RAY COEFFICIENTS . . . . . . . 6

TABLE 2. SUMMARY OF EXPERIMENTS CONDUCTED . . . . . . . . . . . . . . . 40

TABLE 3. USEABLE AND COMPATIBLE DATA . . . . . . . . . . . . . 43

TABLE 4. PREDICTIVE ASH FORMULAS EVALUATION . . . . . . . . . . . . . 45

TABLE 5. EFFECT OF SLURRY PROPERTIES ON ASH PREDICTION...$\cdots$

TABLE 6. PREDICTIVE PERCENT SOLIDS FORMULAS EVALUATION . . . . . . . . 61

TABLE 7. EFFECT OF SLURRY PROPERTIES ON PERCENT SOLIDS PREDICTION . . . 73

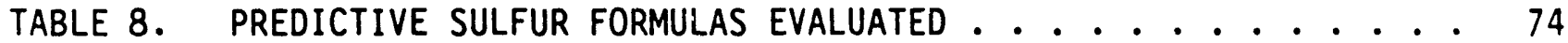

TABLE 9. SULFUR PREDICTION BASED ON SEPARATE ANALYSIS OF RUNS 40,41, 42, AND 43 ................................. 82

TABLE 10. SULFUR PREDICTION BASED ON RUNS 40-43 DATA .......... . . 84

TABLE 11. IRON PREDICTION BASED ON SEPARATE ANALYSES OF RUNS $40,41,42$, AND 43 DATA . . . . . . . . . . . . . . 89

TABLE 12. IRON PREDICTION BASED ON RUNS 40-43 DATA . . . . . . . . 90

TABLE 13. EFFECT OF SLURRY PROPERTIES IN SULFUR AND IRON PREDICTION • . 94

TABLE 14. APPLICABILITY OF THE COAL SLURRY ANALYZER FOR ADVANCED AND CONVENTIONAL CLEANING PROCESS . . . . . . . . . . . . . . 96

TABLE 15. ESTIMATED ANNUAL SAVINGS POSSIBLE WITH COAL ASH SLURRY

ANALYZER • • • • • • • • • • • • • • • • • • • • • • • • • • . 124

TABLE 16. ESTIMATED ANNUAL SAVINGS POSSIBLE WITH COAL SLURRY SULFUR

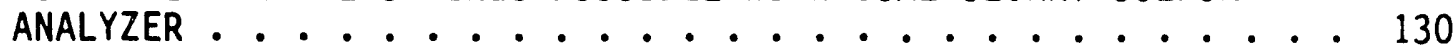

\section{LIST OF FIGURES}

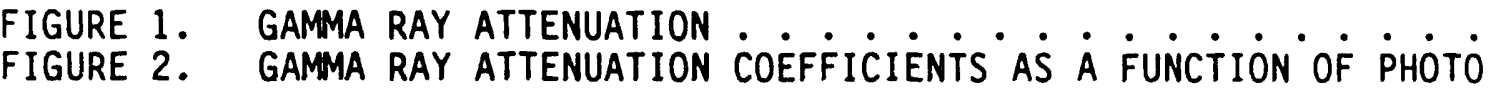
ENERGY AND ATOMIC NUMBER ................. 6

FIGURE 3. THREE STAGES OF PGNAA ANALYSIS . . . . . . . . . . . . . . 11

FIGURE 4. PGNAA ENERGY SPECTRUM USING A Ge(Li) DETECTOR . . . . . . . . . 13

FIGURE 5. PGNAA ENERGY SPECTRUM OF OHIO 4A COAL USING A NaI DETECTOR .14

FIGURE 6. SULFUR WINDOW ENCOMPASSES SEVERAL NON-SULFUR ELEMENTS ..... 15

FIGURE 7. SCHEMATIC OF ANALYZER TEST LOOP WITH DUAL-ENERGY GAMMA GAUGE AND PROMPT GAMMA NEUTRON ACTIVATION ANALYSIS INSTRUMENTS • • 18

FIGURE 8. ASH AND SULFUR ANALYZER SCHEMATIC SHOWS HOW IMPORTANT COAL

DATA ARE OBTAINED .................. 19

FIGURE 9. THE TEST LOOP FACILITY . . . . . . . . . . . . . . . . 20

FIGURE 10. HEGG SCHEMATIC ........................ 21

FIGURE 11. THE HIGH-ENERGY GAMMA GAUGE IN TEST LOOP . . . . . . . . . . . . 23

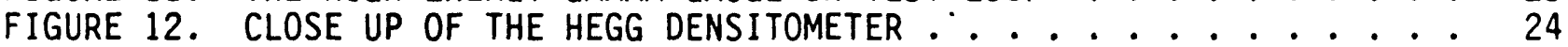

FIGURE 13. LEGG SCHEMATIC ....................... 25

FIGURE 14. THE LOW-ENERGY GAMMA GAUGE . . . . . . . . . . . . . . 26 


\section{LIST OF FIGURES}

(Continued)

Page

FIGURE 15. THE PROMPT GAMMA NEUTRON ACTIVATION ANALYZER IN THE COAL SLURRY TEST LOOP . . . . . . . . . . . . . . . 28

FIGURE 16. CLOSE UP OF THE PGNAA . . . . . . . . . . . . . . . . . . . . . . . . 29

FIGURE 17. THE MICRO-MOTION MASS FLOW METER ................ 30

FIGURE 18. DATA ACQUISITION SYSTEM ..................... 31

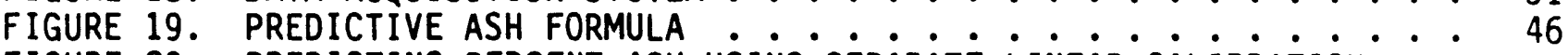

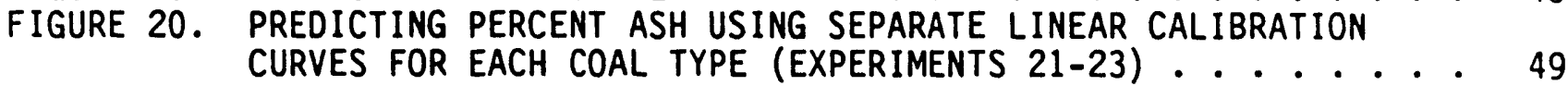

FIGURE 21. RUN 37 MEASURED AND PREDICTED DRY ASH CONTENT WITH \pm 1

PERCENT ACCURACY LIMITS ........... . . . . 52

FIGURE 22. RUN 38 ESTIMATED ASH CONTENT AS A FUNCTION OF TIME $\ldots . . . . \quad . \quad 53$

FIGURE 23. RUNS 40-42 PREDICTED DRY ASH CONTENT . . . . . . . . . . . . 55

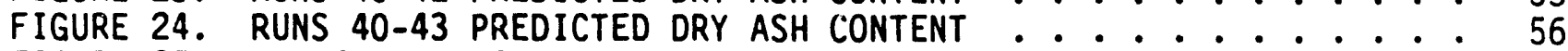

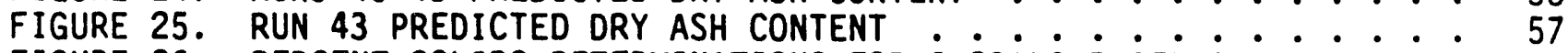

FIGURE 26. PERCENT SOLIDS DETERMINATIONS FOR 6 COALS BASED ON A SINGLE CALIBRATION CURVE OBTAINED FROM OHIO-CLEANED COAL . . . . . . 64

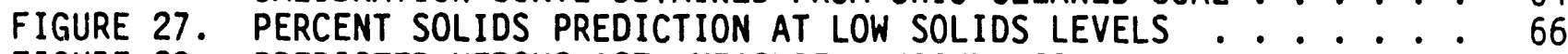

FIGURE 28. PREDICTED VERSUS ASTM MEASURED PERCENT SOLIDS FOR TESTS 37

AS A FUNCTION OF TIME •... 68

FIGURE 30. RUN 38 ESTIMATED PERCENT SOLIDS AS A FUNCTION OF TIME . . . . 69

FIGURE 31. PREDICTED PERCENT SOLIDS FOR RUNS 40-43............. 71

FIGURE 32. PGNAA COUNTS RISE LINEARLY WITH SULFUR CONTENT IN RUN 4

WITH ELKHORN COAL .................... . 77

FIGURE 33. COMPARISON OF KENTUCKY (RUN 25) AND OHIO (RUN 24) MEASURED

SULFUR COUNTS ....................... 79

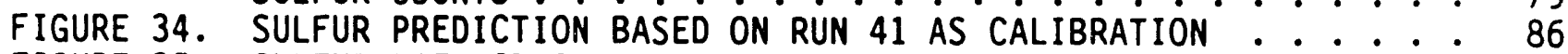

FIGURE 35. SULFUR PREDICTION BASED ON RUN 41 CALIBRATION WITH EXTRAPOLATED POINTS REMOVED ............... . . 87

FIGURE 36. RUNS 40-43 IRON PREDICTION ................. 92

FIGURE 37. EFFECT OF TAILINGS ASH CONTENT ON FLOTATION YIELD AT CONSOLIDATION COAL COMPANY . . . . . . . . . . . . . 99

FIGURE 38. CONTROL STRATEGY USED AT OAKY CREEK COAL PTY., LTD

FIGURE 39. VARIATION OF ASH IN CLEANED COAL

FIGURE 40. POTENTIAL SAVINGS FROM ON-LINE ANALYSIS AND CONTROL $\ldots . . . \quad . \quad 125$ 


\section{ACRONYMS AND ABBREVIATIONS}

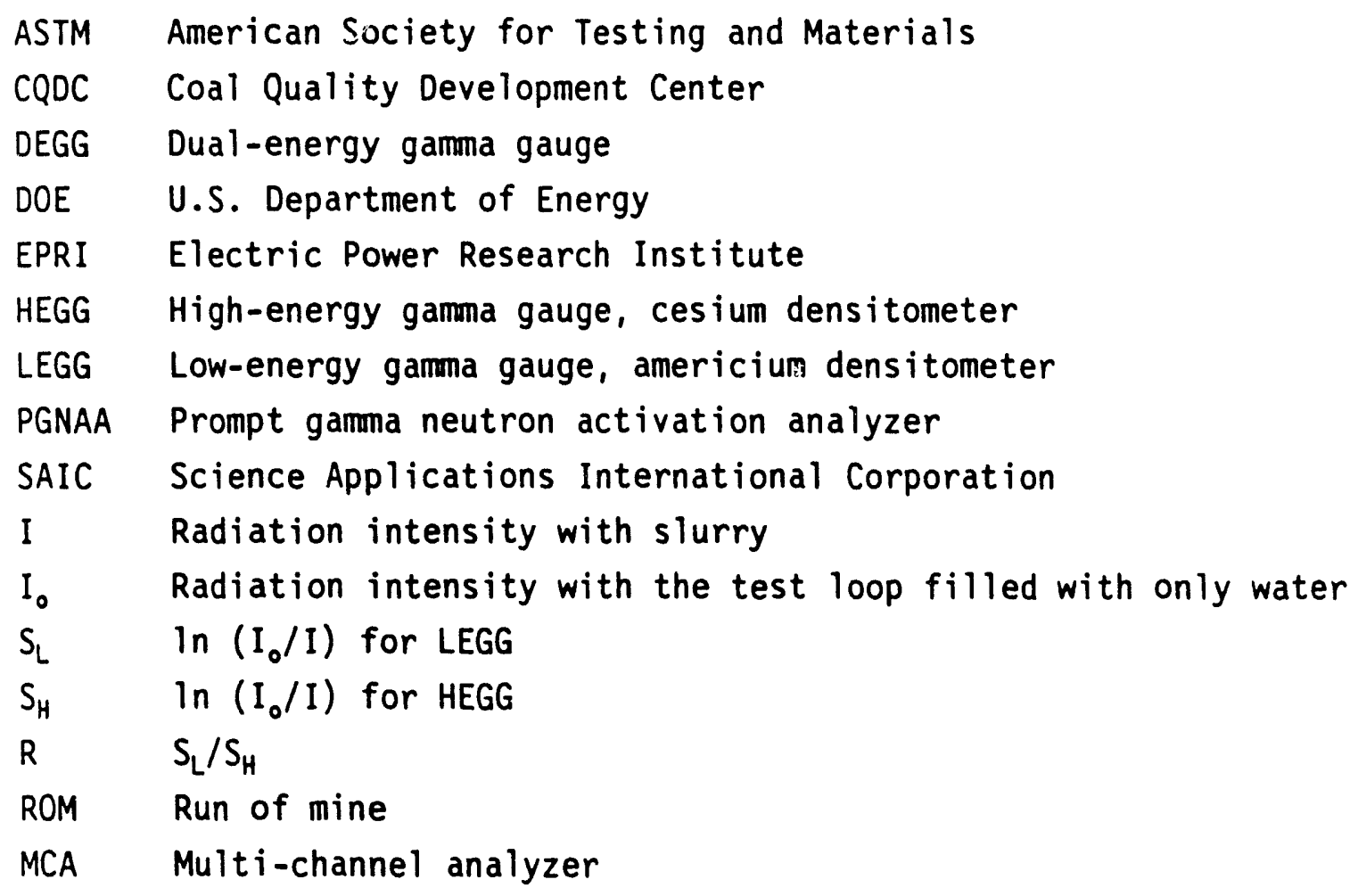




\section{FINAL REPORT \\ CONTRACT NO. DE-AC22-87PC79879 \\ DEVELOPMENT OF A COAL CLEANING CONTROL SYSTEM}

This report summarizes Battelle's effort to evaluate and develop technology for on-line analysis of coal slurries and associated methods to use on-line analysis for coal-cleaning process control. Specifically, the report. describes the coal slurry analysis technology, equipment and procedures, results, process control, and cost and benefits. The report is organized into the following eight sections:

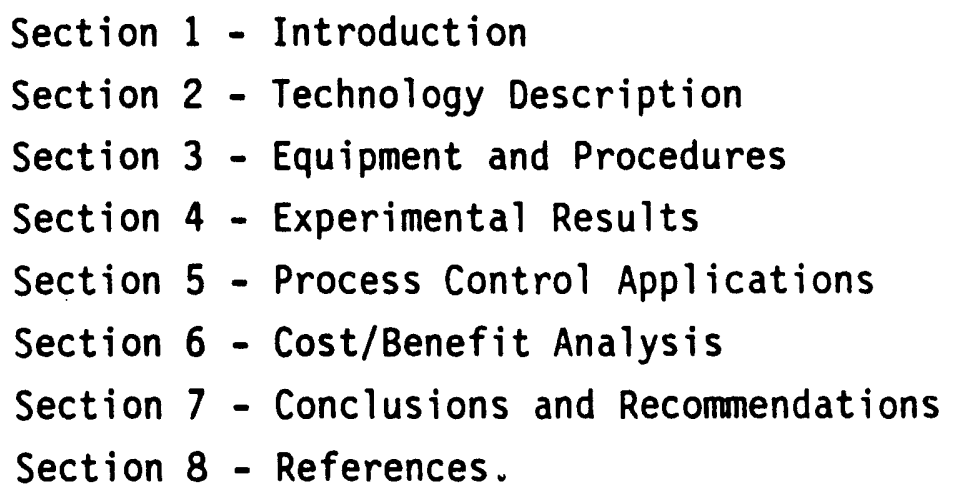

In addition, the following five appendices are included: Ash and Percent Solids Analysis, Suifur and Iron Analysis, Data Acquisition, Chemical Analysis of Test Coals, and Process-Control Strategies.

\section{SECTION 1 INTRODUCTION}

Presented below is a discussion of the background that led to the initiation of this project, along with project objectives and scope of work.

\section{Background}

The U. S. Department of Energy's Coal Preparation program strives to develop improved coal beneficiation technology. The program goal is to develop a knowledge base with which industry can produce economically competitive and environmentally acceptable coal products. DOE, in recognizing 
the need for new physical and chemical cleaning processes and improved instrumentation, issued a Program Research and Development Announcement (PRDA) for "Advanced Techniques for Coal Preparation" on February 17, 1987. Battelle responded, with the Electric Power Research Institute (EPRI), to the "Ancillary Operations" area. The project was accepted and work began in September, 1987. Specifically, the program sought to test and revelop prototype instruments for the on-line analys is of ash, percent solids, and sulfur and the evaluation of techniques for incorporating the slurry analyzer into an integrated control system.

EPRI, like DOE, has been instrumental in the advancement of coal cleaning technology. EPRI recognized early the potential value of on-iine coal analysis for the coal preparation industry. They contracted with the Science Applications International Corporation (SAIC) to develop a set of instruments to determine critical coal properties in coal slurries. In this effort SAIC developed a slurry test loop and prototype ash, percent solids, and sulfur analysis instruments. A limited amount of data were also generated which showed that the instruments had the potential to provide accurate, inexpensive analytical and process control tools. Due to budgetary constraints, the EPRI program was curtailed during the development effort and work was suspended. Battelle and EPRI recognized this DOE PRDA as an opportunity to continue the development of this important coal-cleaning tool.

\section{Objectives}

The objectives of this project were (1) to develop an accurate, versatile, easy to use, on-line, coal slurry analyzer and (2) to develop control strategies for analysis, control, and optimization of advanced and conventional coal-cleaning plants. 


\section{Scope of Work}

The project was originally organized into two phases, I-Development, and II-Coal Quality Development Center Testing. The first phase was planned to generate basic data on the analyzer and how best to apply it for on-line control. The second phase of the project was intended to generate detailed data on the applicability of the analyzer in a real-world coal cleaning plant environment using near-commercial scale cleaning equipment at EPRI's Coal Quality Development Center (CQDC).

However, during Phase I, it became clear that the technology was not yet ready for commercial-scale testing. Additional work was needed to resolve mechanical and electronic problems and improve accuracy. Therefore, a request for a change in project scope was made in November, 1988. Formal acceptance was received and work restarted in May, 1989. The new scope eliminated Phase II and concentrated on test-loop scale development with the focus on improved accuracy. Specifically, the project was re-directed toward generating data on the analyzer instruments: how accurate could they be, how well could they work over the range of interest to advanced and conventional fine-coalcleaning applications, and how best to apply them for on-line control. 


\section{SECTION 2 TECHNOLOGY DESCRIPTION}

Presented below is a description of the technology used for coal slurry analysis; the discussion includes analysis for ash and percent solids, sulfur and iron, and flow rate.

\section{Ash and Percent Solids Analysis}

The basis for ash and percent solids analysis was gamma ray attenuation. The principle is shown schematically in Figure 1 below.

\section{$\%$ Solids and Ash Prediction Related to Gamma Ray Attenuation}

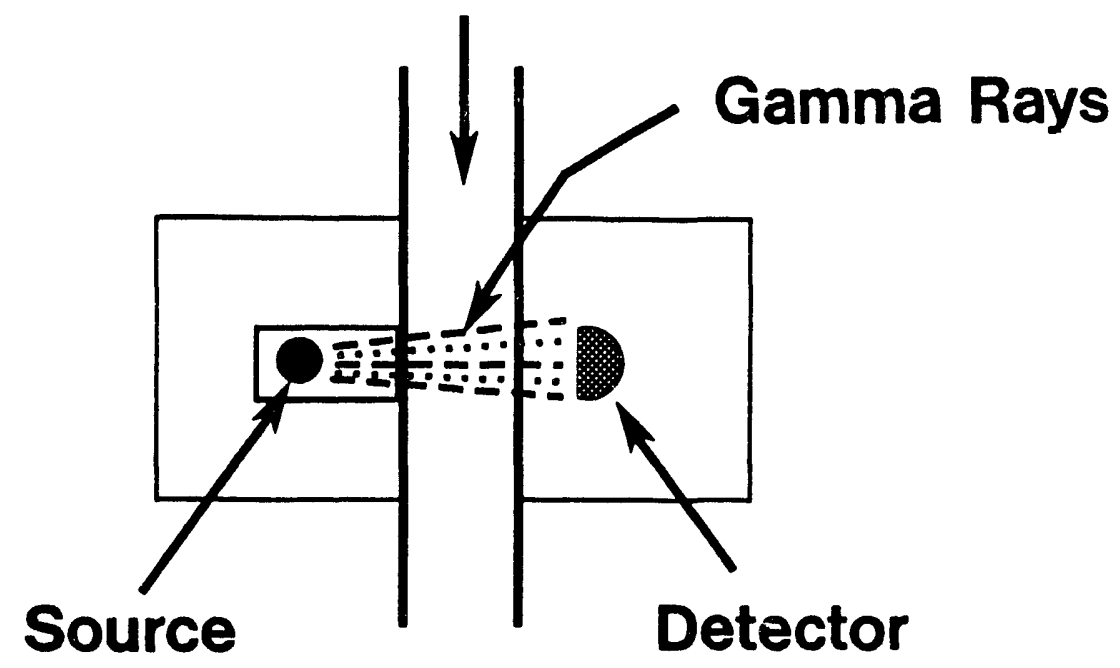

\section{Attenuation $=$ Function (Density, Composition, Thickness, Geometry)}

Figure 1. GAMMA RAY ATTENUATION

Basically, a nuclear source, such as cesium or americium, was placed near the slurry pipe. Emitted gamma rays were directed through the slurry and intercepted by the detector. The degree of attenuation depended on the slurry 
composition, density, and thickness. This relationship is defined by Beer's law:

$$
I=I_{0} e^{-\rho \mu(E) T}
$$

or

$$
\left(\frac{I_{0}}{I}\right)=e^{\rho \mu(E) T}
$$

or,

$$
S=\ln \left(I_{0} / I\right)=\rho \mu(E) T
$$

where

$$
\begin{aligned}
& \text { I = radiation intensity under test conditions } \\
& \text { I。 = radiation intensity with only water } \\
& \rho=\text { slurry density } \\
& \mu(E) \quad=\text { gamma ray attenuation coefficient, a function of solids } \\
& \text { composition and gamma ray energy } E \text {. } \\
& T=\text { Thickness across radiation path (i.e., diameter of the } \\
& \text { test loop pipe) } \\
& S \quad=\ln \left(I_{0} / I\right)
\end{aligned}
$$

In this equation, $\boldsymbol{\mu}$ represented a composite attenuation coefficient. it was represented as:

$$
\mu=\sum \omega_{i} \mu_{i}(E)
$$

where

$$
\begin{aligned}
& \omega_{i}=\text { weight fraction of element } i \\
& \mu_{i}(E)=\text { attenuation coefficient of element } i \text { at energy } E .
\end{aligned}
$$

As shown in Table 1 below, and Figure 2, different gamma-ray energy sources have different element by element attenuation coefficients. 
TABLE 1. LINEAR ATTENUATION GAMMA-RAY COEFFICIENTS

\begin{tabular}{ccc}
\hline & $\begin{array}{c}\text { Low Energy } \\
60 \mathrm{keV} \\
\text { Linear } \\
\text { Attenuation } \\
\text { Coefficient, } \\
\mathrm{cm}^{2} / \mathrm{g}\end{array}$ & $\begin{array}{c}\text { High Energy } \\
662 \mathrm{Kev} \\
\text { Linear }\end{array}$ \\
Element & $\begin{array}{c}\text { Attenuation } \\
\text { Coefficient, } \\
\mathrm{cm}^{2} / \mathrm{g}\end{array}$ \\
\hline $\mathrm{H}$ & 0.326 & \\
$\mathrm{C}$ & 0.176 & 0.1540 \\
$\mathrm{~N}$ & 0.182 & 0.0778 \\
$\mathrm{O}$ & 0.191 & 0.0776 \\
$\mathrm{Na}$ & 0.228 & 0.0778 \\
$\mathrm{Mg}$ & 0.258 & 0.0745 \\
$\mathrm{Al}$ & 0.280 & 0.0768 \\
$\mathrm{Si}$ & 0.322 & 0.0751 \\
$\mathrm{~S}$ & 0.404 & 0.0778 \\
$\mathrm{~K}$ & 0.560 & 0.0780 \\
$\mathrm{Ca}$ & 0.648 & 0.0762 \\
$\mathrm{Ti}$ & 0.752 & 0.0793 \\
$\mathrm{Fe}$ & 1.200 & 0.0750 \\
& & 0.0739 \\
\hline
\end{tabular}

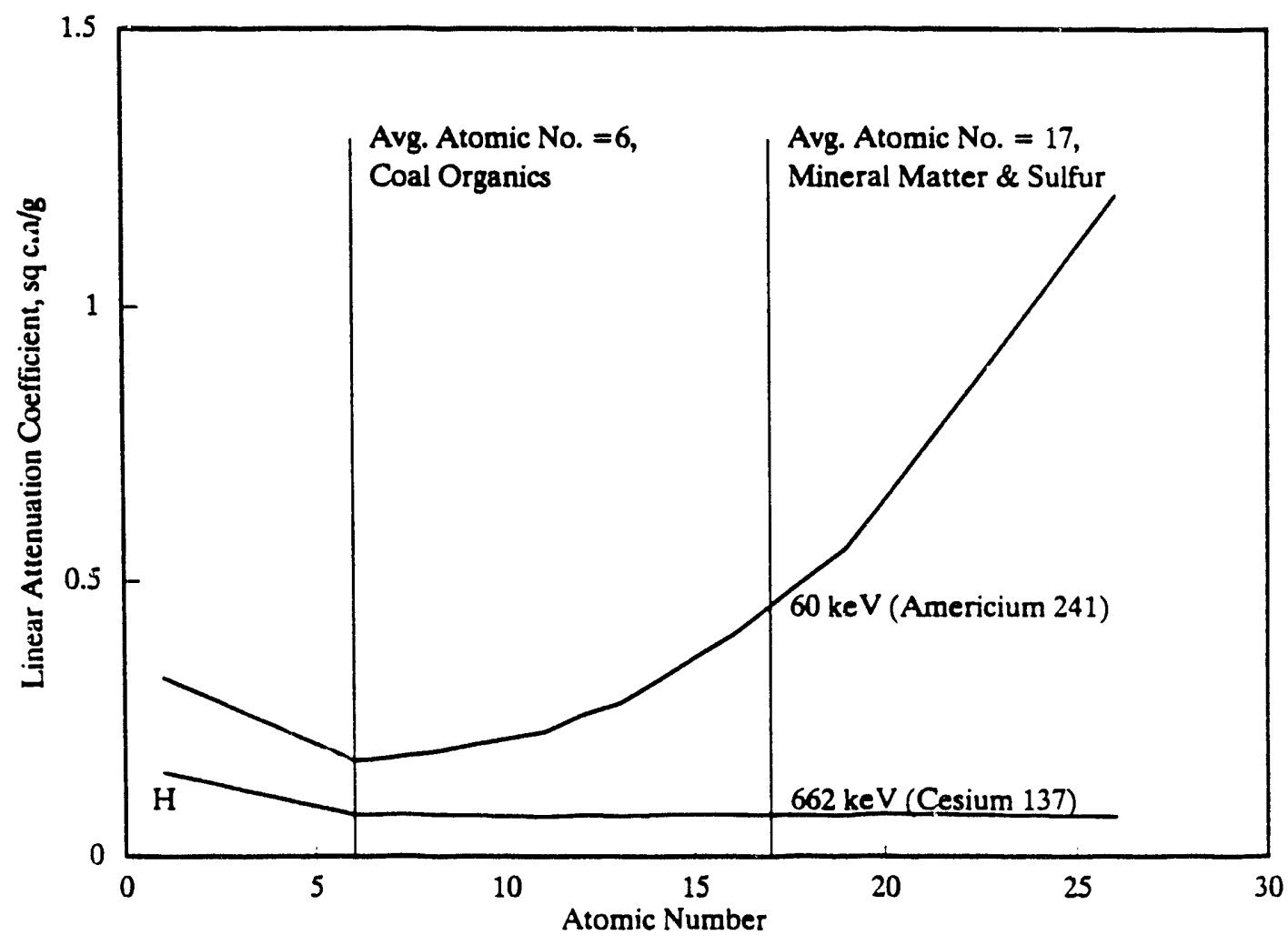

FIGURE 2. GAMMA RAY ATTENUATION COEFFICIENTS AS A FUNCTION OF PHOTO ENERGY AND ATOMIC NUMBER 
With cesium-137 (Cs-137) at $652 \mathrm{keV}$ energy, the low-atomic-number elements ( $H$, $C, N$, and 0 representing combustible materials) and high-atomic-number elements ( $\mathrm{Al}, \mathrm{Si}, \mathrm{S}$, and $\mathrm{Fe}$, representing ash) had similar attenuation coefficients. At lower energy levels, such as with americium-241 (Am-241) at $60 \mathrm{keV}$, the coefficients differed greatly. The high atomic-number elements were much stronger absorbers (attenuate more) than the low-atomic-number group. Therefore, the composite attenuation coefficient for coal was simplified by subdividing it into ash (mineral matter) and combustibles, fractions, or

$$
\mu=\omega a \cdot \mu a+\omega c \cdot \mu c
$$

where

$$
\begin{aligned}
& w a=\text { weight fraction ash } \\
& w c=\text { weight fraction combustibles } \\
& \mu a=\text { attenuation coefficient ash } \\
& \mu c=\text { attenuation coefficient combustible. }
\end{aligned}
$$

Substituting $\boldsymbol{\mu}$, as defined in equation (5), into equation (3) and rearranging gave

$$
\frac{S}{\rho T}=w a \cdot \mu a+u c \cdot \mu c
$$

Defining $S_{L}$ as $\ln \left(I_{0} / I\right)$ for the a low energy source $(\leq 60 \mathrm{keV})$ and $S_{H}$ for a high energy source $(>300 \mathrm{keV})$, the ratio of $S_{L} / S_{H}$ was

$$
\frac{S_{L} / \rho T}{S_{H} / \rho T}=\frac{w a \cdot \mu a_{L}+w c \cdot \mu c_{L}}{w a \cdot \mu a_{H}+w c \cdot \mu c_{H}}
$$

Note that by this division, $\rho T$, canceled out. Therefore, the expression was insensitive to slurry density and thickness. Equation (7) was then solved for wa, the weight fraction ash, as 


$$
w a=\frac{w c \cdot \mu c_{H}-\left(S_{H} / S_{L}\right) \cdot w c \cdot \mu c_{L}}{\left(\frac{S_{H}}{S_{L}}\right) \cdot \mu a_{L}-\mu a_{H}}
$$

or

$$
\text { wa }=\frac{a-\left(S_{H} / S_{L}\right) \cdot \beta}{\left(\frac{S_{H}}{S_{L}}\right) \cdot \gamma-\delta}
$$

Since $\delta$ equaled $\mu a_{H}$ which was a very small number (typically around 0.3 $\mathrm{cm}^{2} / \mathrm{g}$ ), it was, as a further simplification, assumed to be zero, allowing wa to be expressed as

$$
w a=A+B\left(\frac{S_{L}}{S_{H}}\right)
$$

Expanded forms include:

$$
w a=A+B\left(\frac{S_{L}}{S_{H}}\right)+C\left(\frac{S_{L}}{S_{H}}\right)^{2}+D\left(S_{H}\right)
$$

It was found in the test program that ash was also sensitive to iron (Fe) and percent solids. Therefore, this equation was further expanded as:

$$
w a=A+B\left(\frac{S_{L}}{S_{H}}\right)+C\left(w_{F \bullet}\right)+D\left(\frac{S_{L}}{S_{H}} \cdot w_{F e}\right)+E\left(S_{H}\right)+F\left(w_{S} / S_{H}\right)
$$

Where $w_{F_{e}}$ and $w_{S}$ were the weight fractions of iron and sulfur in the slurry (wet basis). The $w_{\mathrm{Fe}}$ and $w_{s}$ information was produced by the PGNAA instrument. 
Further details of this derivation are provided in Appendix $A$. Following this reasoning, ash was estimated based on the signal from a lowenergy gamma gauge (LEGG) with an americium-241 (Am-241) source and a highenergy gamma gauge (HEGG) with a cesium-137 (Cs-137) source.

The deviation of the slurry percent solids equation followed similar logic. However, for a high-energy gamma ray source

$$
\mu \mathrm{a} \simeq \mu \mathrm{c} \simeq \mu
$$

Therefore, re-arranging equation (3) and solving for $\rho$ gave

$$
\rho=S_{H} / \mu T
$$

The slurry density, $\rho$, was a function of $\rho_{w}$ (density of water), $w_{s}$ (weight fraction solids), $w_{\Downarrow}$ (weight fraction water), and $\rho_{s 0}$ (solids density).

$$
\rho=\frac{\rho_{w} \rho_{S O}}{w_{s} \rho_{y}+w_{w} \rho_{s o}}
$$

substitution of $\rho$ from (13) into (14) gave

$$
w_{S}=\frac{\left\{\left(\frac{S_{H}}{T}\right)-\rho_{N} w_{H}\left[\mu_{H_{H}}-\mu_{C_{H}}\right]\right\}}{\left[\rho_{W} \mu_{C_{H}}+\left(\frac{S_{H}}{T}\right)\left(\frac{\rho_{V}}{\rho_{S O}}\right)\right]}
$$

or, assuming the solids density could be assumed a constant, and $\rho$ equals 1 ,

$$
w_{S}=C+D \cdot S_{H} .
$$

An expanded form of this equation was

$$
w_{S}=C+D \cdot\left(S_{Y}\right)+E\left(S_{Y}\right)^{2}+E\left(S_{L} / S_{Y}\right)
$$


It was found in the test program that percent solids was also slightly sensitive to iron and ash content. Therefore, the following expanded form was tested:

$$
w_{S}=C+D\left(S_{H}\right)+E(w a)+F\left(w_{F e}\right)+E\left(S_{H} \cdot w a\right)+F\left(S_{H} \cdot w_{F e}\right)
$$

Since ash was not directly available, the following expression using DEGG and PGNAA information was developed:

$$
w_{S}=C+D\left(S_{H}\right)+E\left(w_{F_{0}}\right)+F\left(S_{L}\right)+G\left(w_{S}\right)
$$

Where $w_{a}, w_{F_{0}}$, and $w_{s}$ were the weight fractions of ash (dry basis), iron (wet basis) and sulfur (wet basis).

More details of the theory behind the ash and percent solids instruments are included in Appendix $A$, and more details on the equipment and procedures are provided in Section 3.

\section{Sulfur and Iron Analysis}

The method of Prompt Gamma Neutron Activation Analysis (PGNAA) can best be described by illustration (see Figure 3). Briefly, a source of fast neutrons from the PGNAA nuclean source, californium-252 ( $C f-252$ ), was positioned near the slurry pipe. Depending on the concentration of the coal slurry, a fraction of the fast neutrons was slowed down to "thermal" energies and was captured by the nuclei of the various coal constituents. The probability of capture by a specific atomic nucleus depended on its "nuclear affinity" to the neutron and was measured by a quantity called capture cross section. The nucleus that captured the neutron emitted, within a very short time $\left(10 \cdot 10^{-9} \mathrm{sec}.\right)$, characteristic gamma rays which provided quantitative characteristic "signatures" of the various atomic nuclei. Most of these gamma rays were of high energy and readily penetrated the coal slurry and 


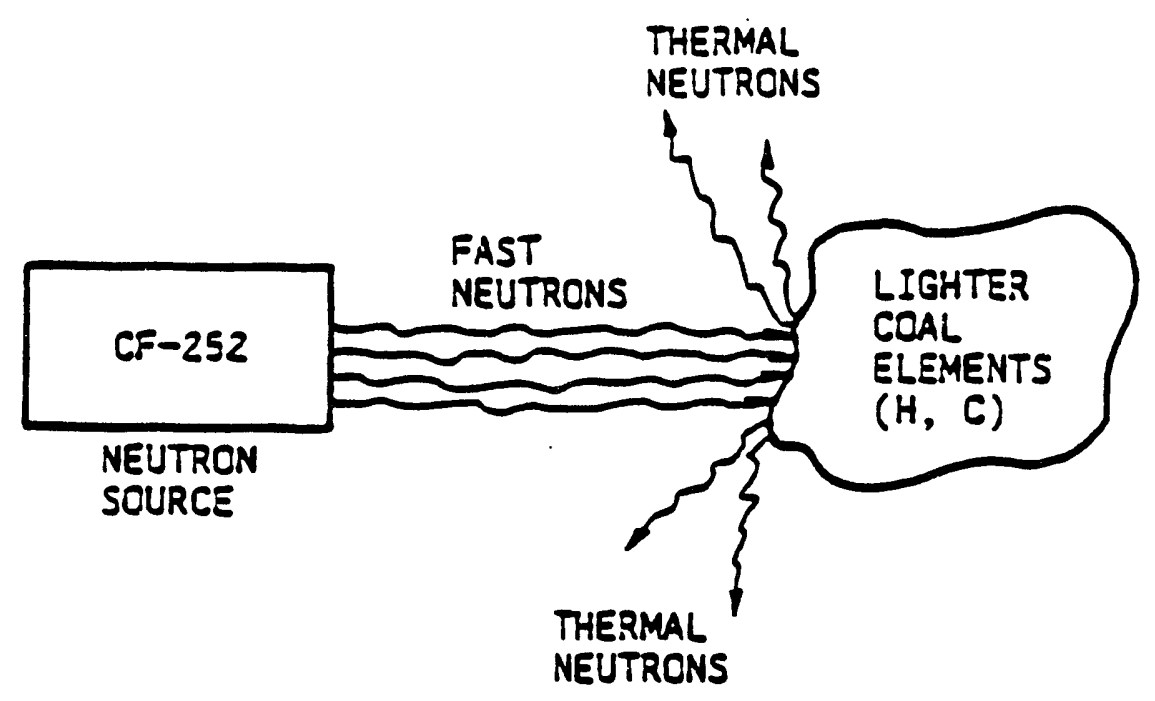

A) THERMALIZATION OF FAST NEUTRONS
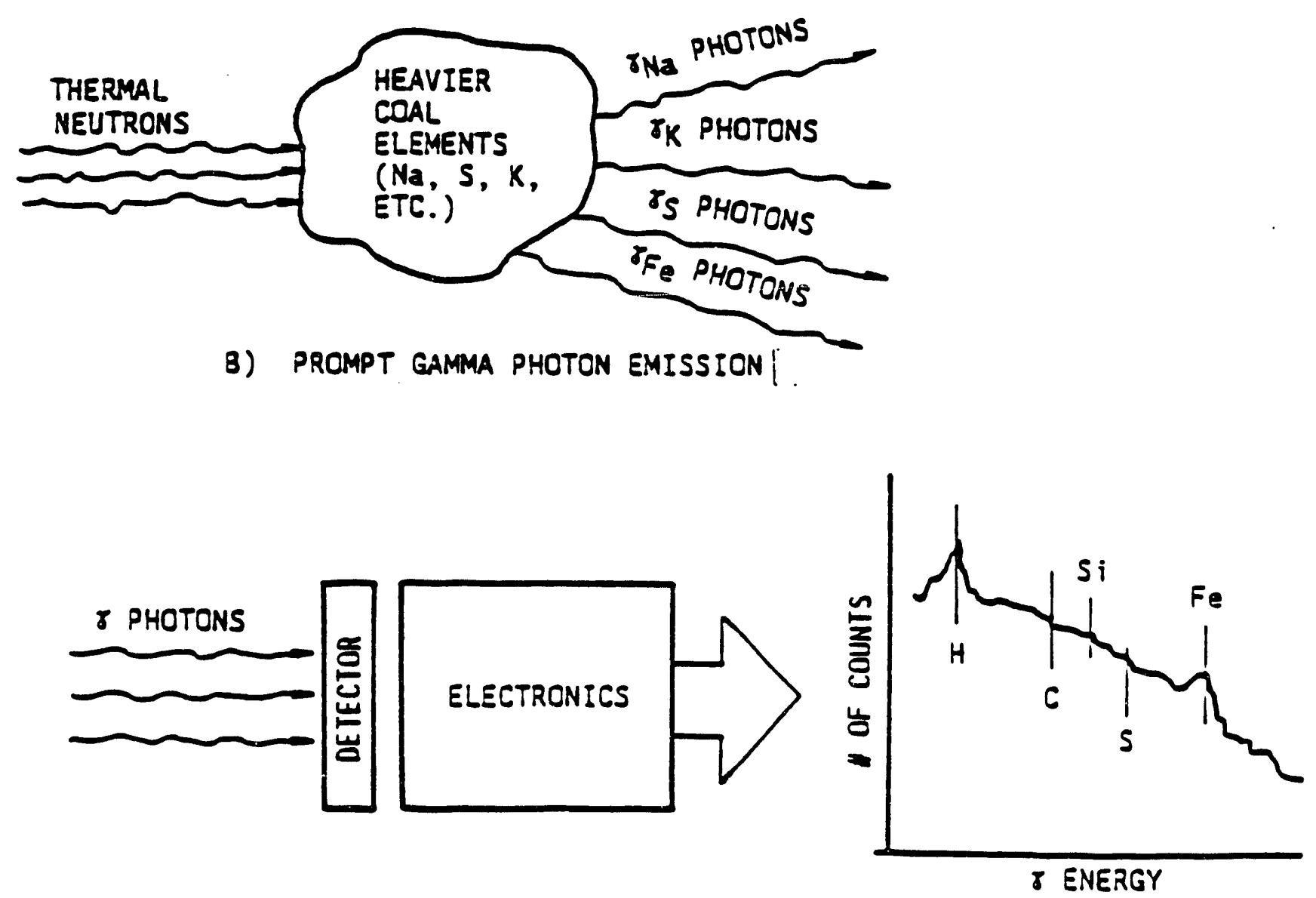

$\checkmark$ OETECTION,

C) SIGNAL CONOITION`NG, ANO HISTCGRAM OEVELOPMENT 
containment pipe. In the analyzer a medium-resolution sodium-iodide (NaI) detector was placed outside the coal slurry pipe and detected the gamma rays. Since rays of different energy were emitted and captured, it was possible to construct a spectrum of the number of rays detected associated with their energy levels. To determine the concentration of the coal constituents, such as sulfur and iron, required a spectral analys is of the detected gamma rays.

The method for interpreting the gamma ray spectra from the PGNAA was fairly complex. The gamma rays were first detected, amplified and sorted. The shape of the resultant spectrum depended to a large degree on the type of detector used. Shown in Figure 4 is a coal slurry spectrum using a high resolution lithium-germanium, Ge- $(L i)$, detector. This spectrum was produced in an earlier EPRI program (1). The elements generated clear, distinct peaks similar in some ways to a gas chromatogram. The spectrum produced in this program was generated using a medium-resolution sodium-iodide (NaI) detector. The gamma-ray intensities were sorted into 512 energy "channels" to produce the spectrum shown in Figure 5. Clearly the spectrum was dampened and individual elements (except for the clearly identifiable hydrogen peak around channel 95) could not be readily observed. However, the information necessary to predict elemental composition was still contained in the spectrum. The area around sulfur in Figure 4 is shown in Figure 6 . Examination revealed that sulfur was not alone; the sulfur region also included peaks from many other elements, primarily chlorine and iron. Therefore, the final sulfur prediction equation included corrections to account for the influences of chlorine and iron on sulfur.

To make a sulfur prediction, the area under each peak was related to the elemental composition of the slurry. Using multiple linear regression, a five-part equation for slurry wet sulfur content was developed. Numerous calibration tests, where sulfur, chlorine, iron, and slurry percent solids were varied, provided the data necessary to determine the correlation constants. 
13

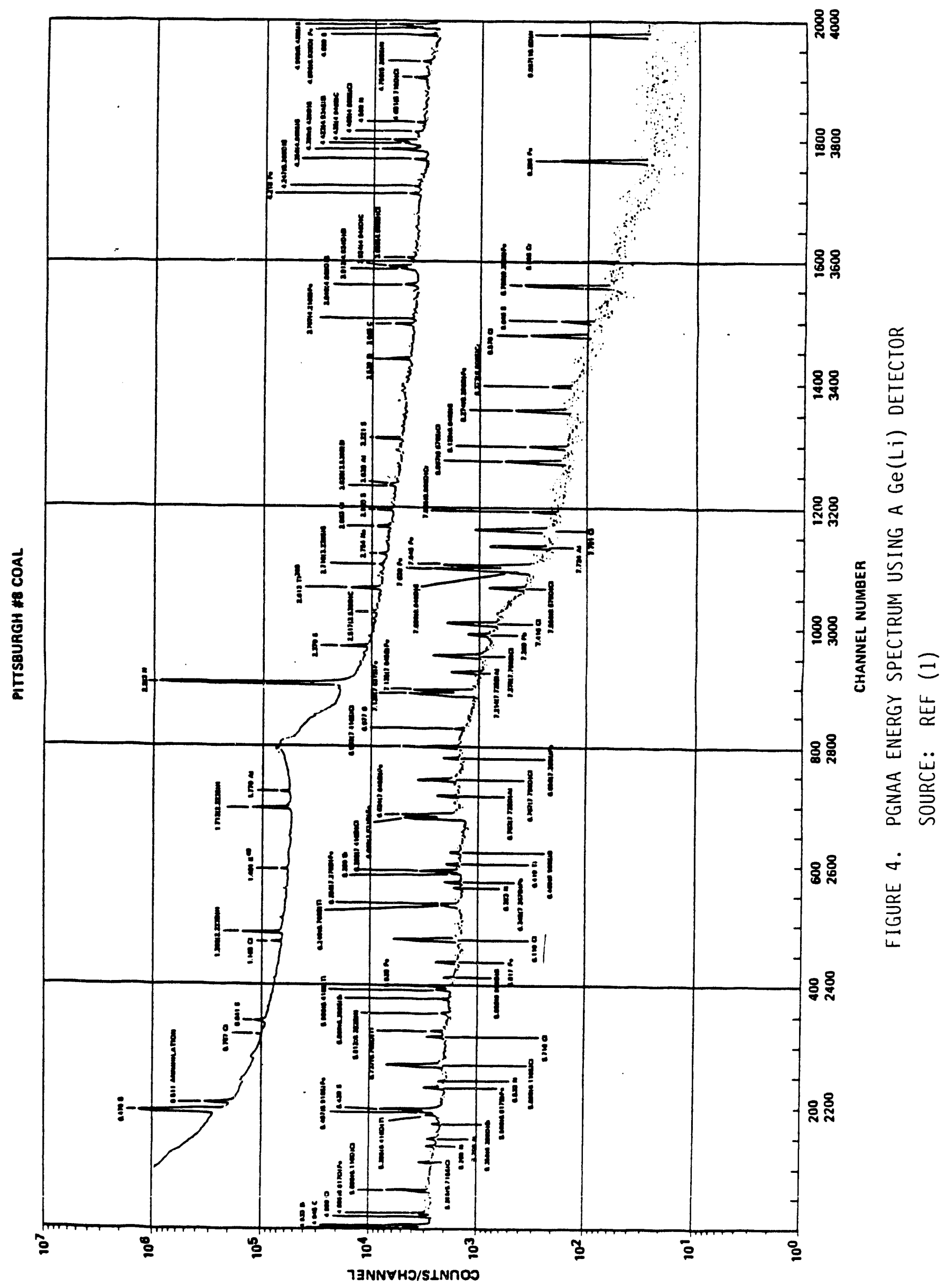




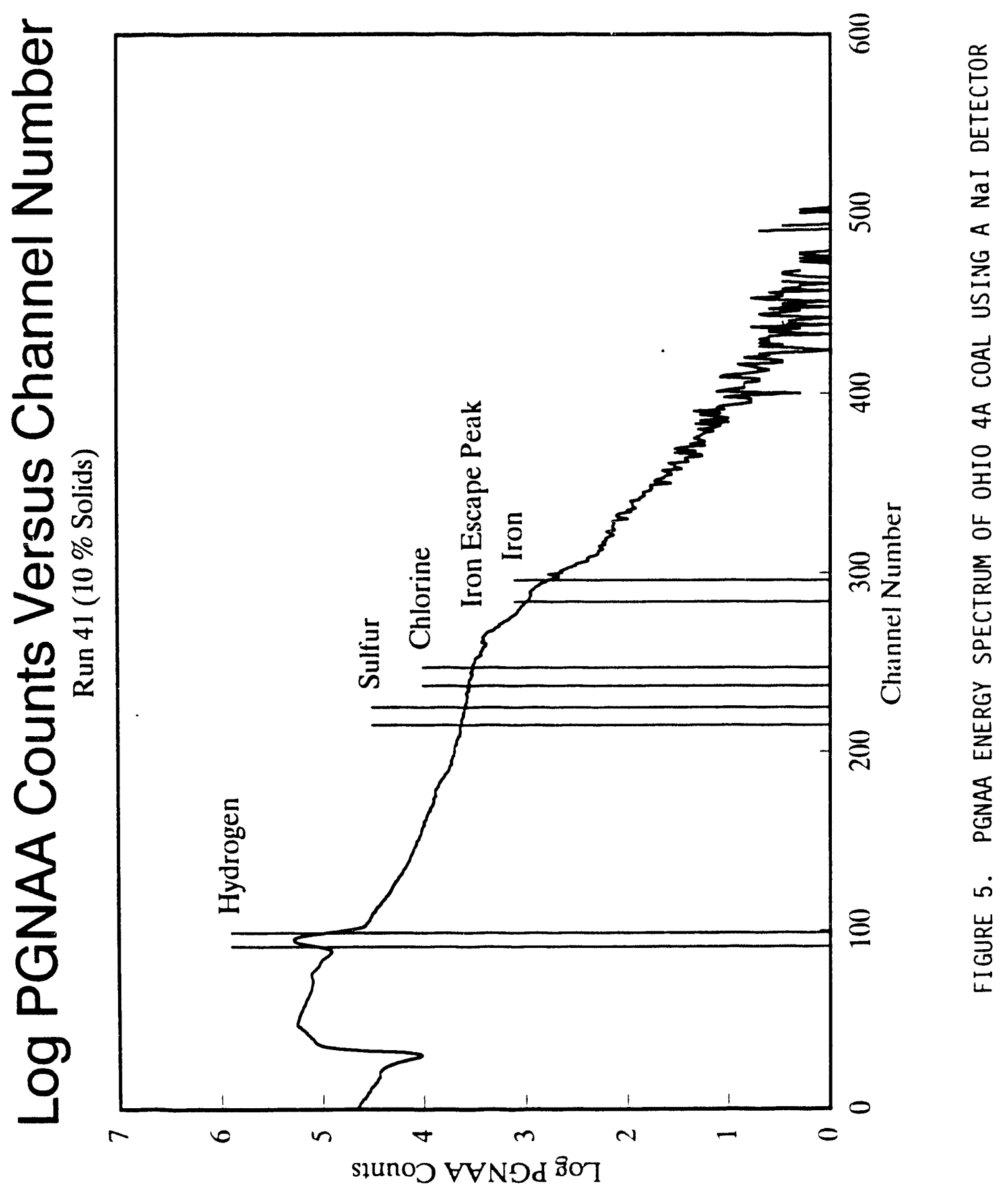




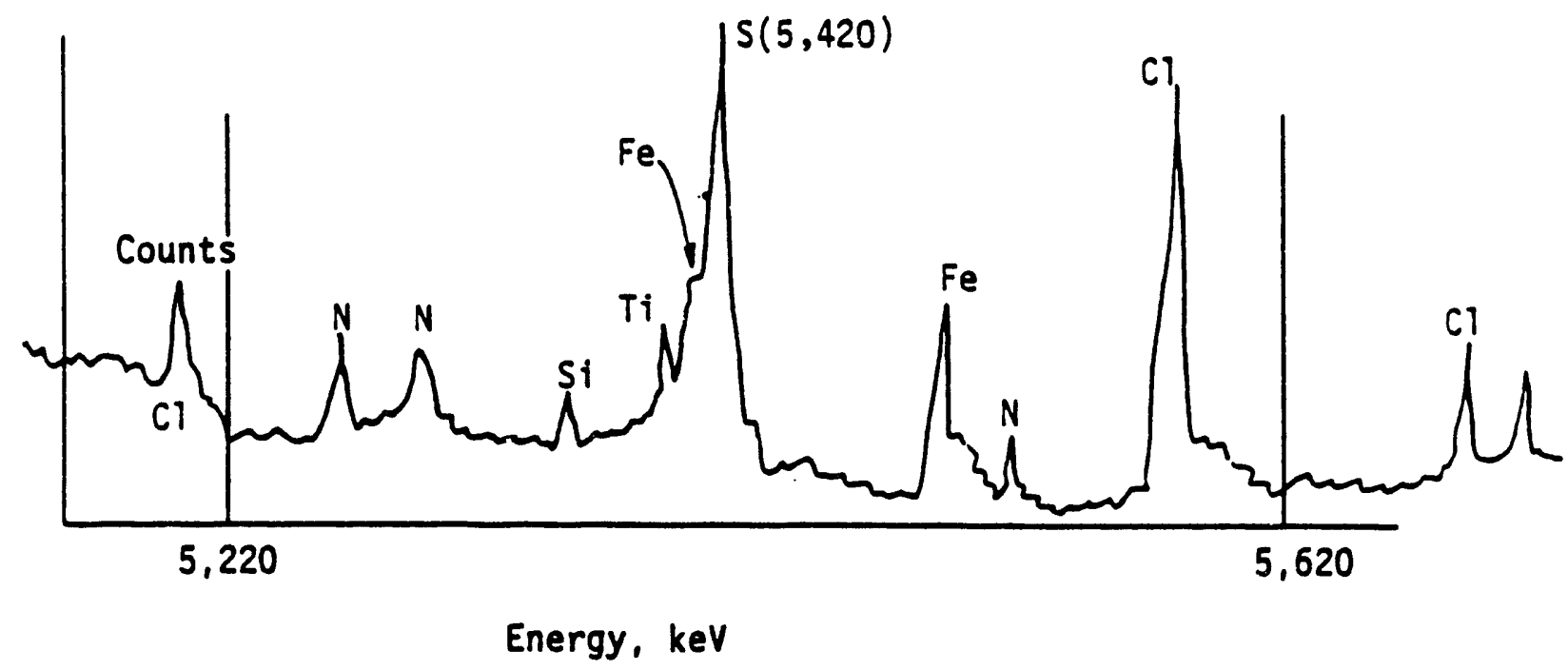

FIGURE 6. SULFUR WINDOW ENCOMPASSES SEVERAL NON-SULFUR ELEMENTS

The wet sulfur and iron content of the slurry was estimated by the following formulas:

Sulfur $=\mathrm{D}+\mathrm{E} \cdot\left(\mathrm{H}_{\text {counts }}\right)+\mathrm{F} \cdot\left(\mathrm{S}_{\text {counts }}\right)+\mathrm{G} \cdot\left(\mathrm{Cl}_{\text {counts }}\right)+H \cdot\left(\mathrm{Fe}_{\text {counts }}\right)$
Iron $=\mathrm{I}+\mathrm{J} \cdot\left(\mathrm{H}_{\text {counts }}\right)+\mathrm{K} \cdot\left(\mathrm{S}_{\text {counts }}\right)+L \cdot\left(\mathrm{Cl}_{\text {counts }}\right)+M \cdot\left(\mathrm{Fe}_{\text {counts }}\right)$

where

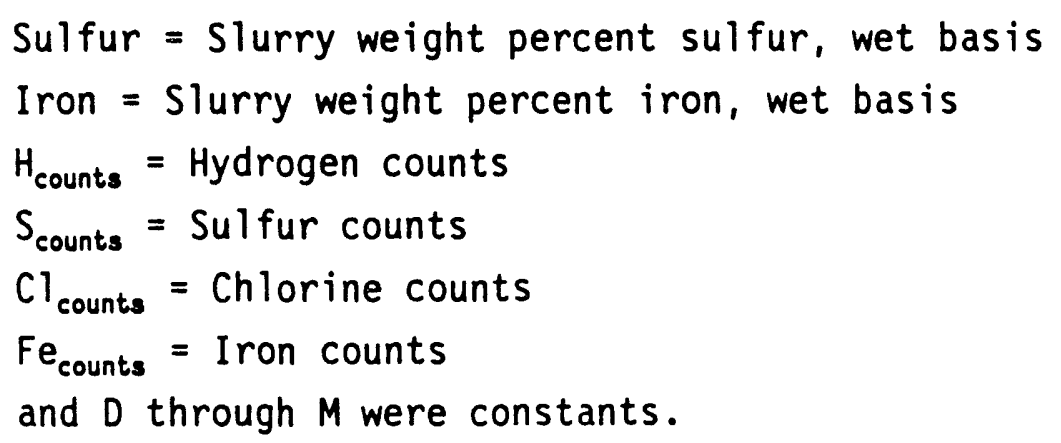

The wet sulfur and iron concentrations were converted to the dry basis by dividing by the predicted percent solids. More specific details of the calculation procedure are provided in Appendix B. 


\section{Flow Rate Analysis}

The mass flow rate was determined by measuring the vibration of a $U$ tube through which the entire slurry flow is passed. The flow tube, see below, acted as spring-mass system. The entire assembly therefore vibrated as a balanced tuning fork. The flow measurement was taken by two magnetic position sensors, one on each leg of the U-tube. During each cycle of vibration the sensors, acting as switches, independently determined when each leg crossed the center position. Mass moving down the input leg of the U-tube moved through areas of increasingly higher tube velocities and therefore was accelerated to these higher velocities by the tube. The force generated by accelerating this mass, which was in opposition to the tube vibration, tended to delay this side of the U-tube from its normal (no-flow) position. The sensor on this leg, therefore, detected the center crossing slightly behind schedule. Conversely, on the output side, mass moving through areas of decreasing tube velocity experienced a deceleration, thereby generating a force on the $U$-tube in the direction of vibration. This force tended to advance the tube ahead of its normal (no-flow) position. The sensor on this side therefore detected the center crossing slightly ahead of schedule. The time relationship between these two signals was proportional to mass flow rate. The yicro Motion mass flow meter is a commercially available unit. The flow rates predicted are considered to have a standard error of 1.0 percent.

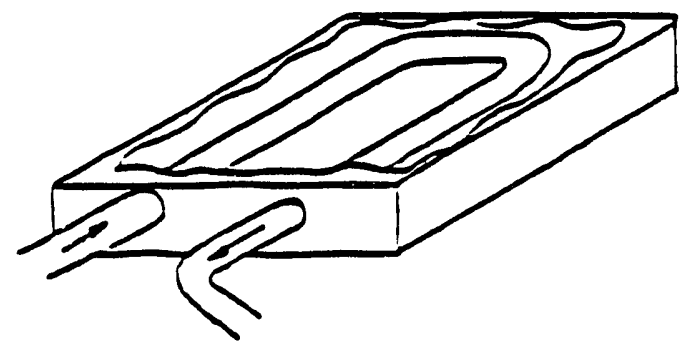

Schematic of Micromotion Unit Used to Measure Mass Flow Rate 


\section{SECTION 3 EQUIPMENT AND PROCEDURES}

Presented below is a summary of the experimental equipment and procedures. The discussion includes the test loop and instruments, the data acquisition system, nuclear safety, test procedures, and analytical procedures.

\section{Test Loop}

The slurry test loop was installed at Battelle's West Jefferson, Ohio, pilot plant facility (about 20 minutes drive from Battelle's main Columbus Ohio, location). The unit was adjacent to Battelle's pilot-scale coal cleaning plant. Needed ancillary equipment such as pumps, tanks, dewatering equipment, etc. were used to support the testing task. The facility is shown schematically in Figures 7 and 8 and in a photograph in Figure 9. The system included a 500-gal. holding tank equipped with a crude heat exchanger. One hundred feet of $1 / 2$-inch copper tubing was coiled inside the tank walls and was fed with $6 \mathrm{gal} / \mathrm{min}(\mathrm{gpm})$ of cooling water. The tank was also equipped with a 1-HP twin-propeller agitator. Water was circulated through the test loop at 250-300 gpm with a centrifugal pump equipped with a variable speed control. The test loop included the following four instruments:
(1) High-Energy Gamma Gauge (HEGG)
(2) Low-Energy Gamma Gauge (LEGG)
(3) Prompt Gamma Neutron Activation Analyzer (PGNAA)
(4) Micro-Motion (MM) Mass Flow Meter.

The slurry leaving the pump passed through the 6-inch test loop piping and traveled downward through the four instruments and then returned to the tank. (Appropriate valves were included to allow either downflow or upflow through the analyzers.) In addition, the system included a data logging and analys is computer system which recorded the analyzer output signals and converted them into predicted ash, percent solids, sulfur, and iron levels. 


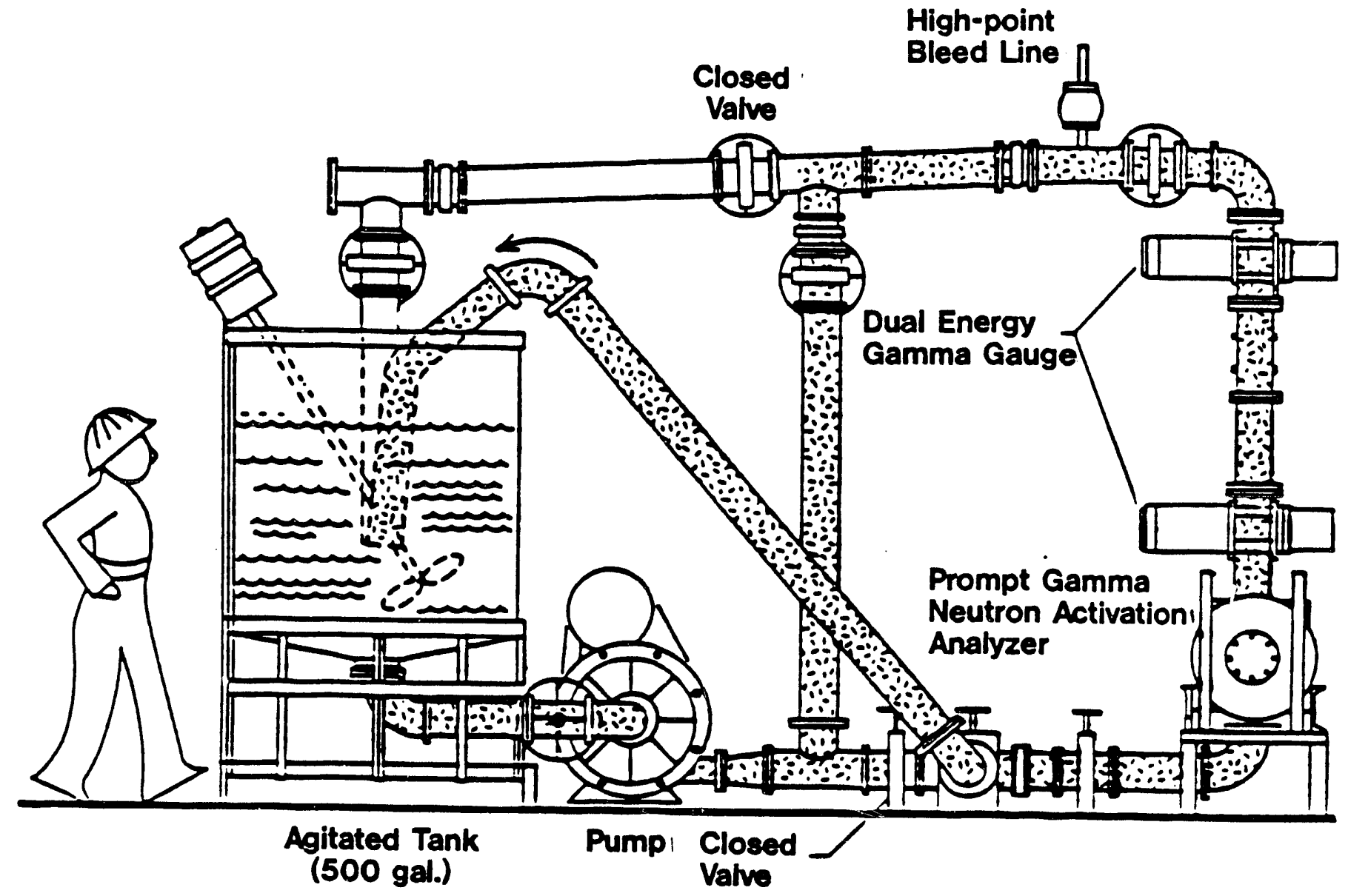

FIGURE 7. SCHEMATIC OF ANALYZER TEST LOOP WITH DUAL-ENERGY GAMMA GAUGE AND PROMPT GAMMA NEUTRUN ACTIVATION ANALYSIS INSTRUMENTS 


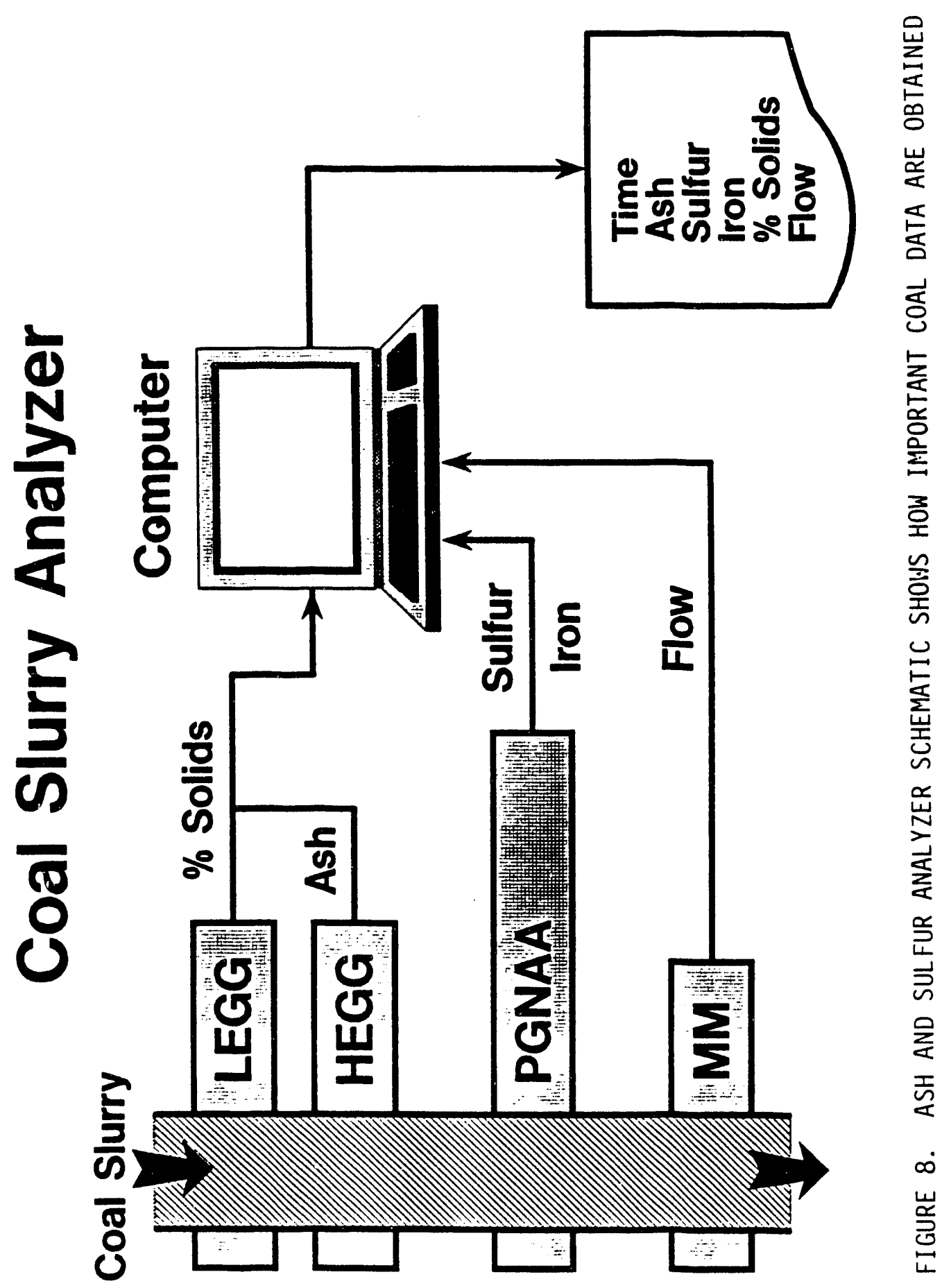




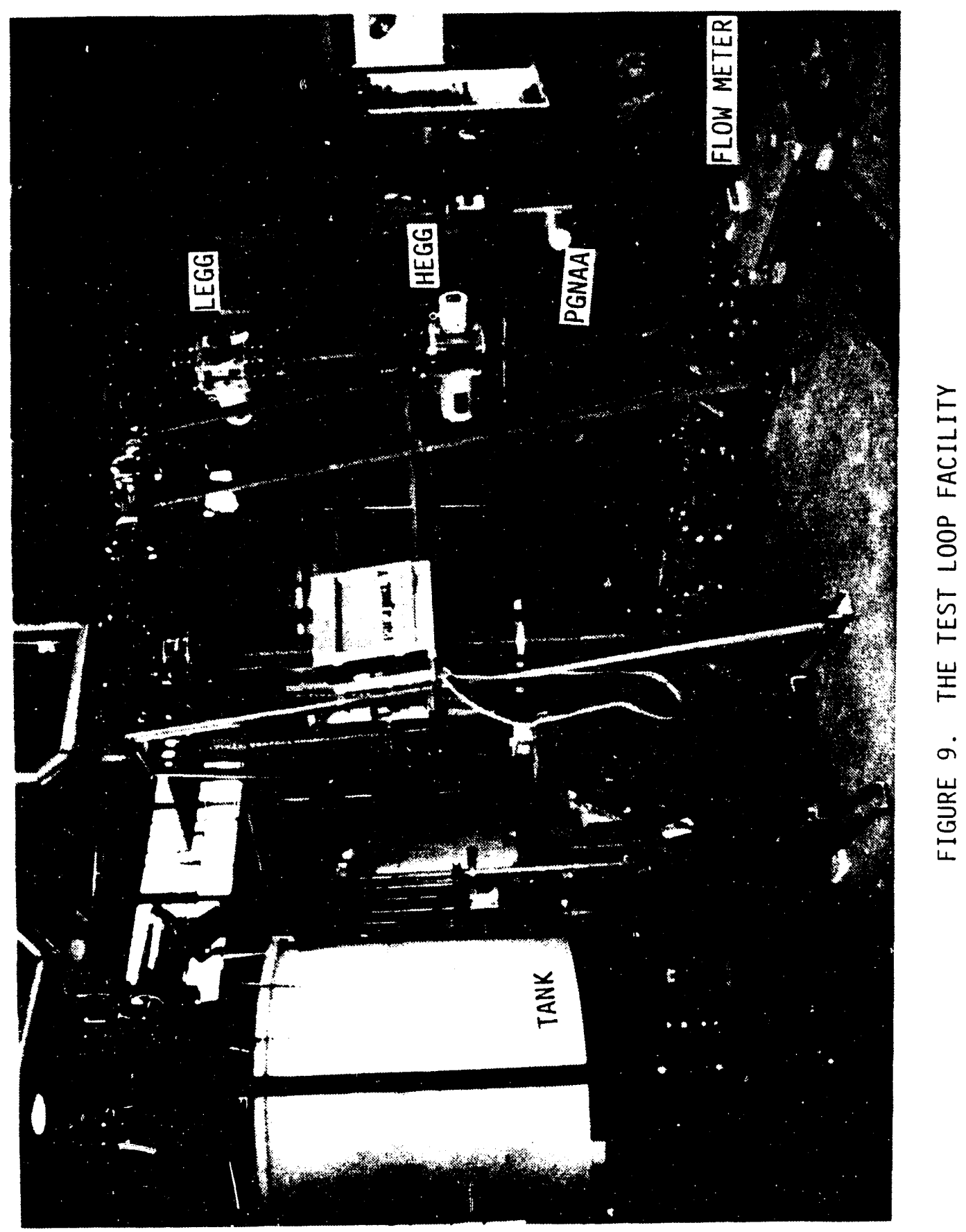




\section{High-Energy Gamma Gauge}

The High-energy gamma gauge (HEGG) was a modified SGH Series Texas Nuclear cesium densitometer. It is shown schematically in Figure 10 below.

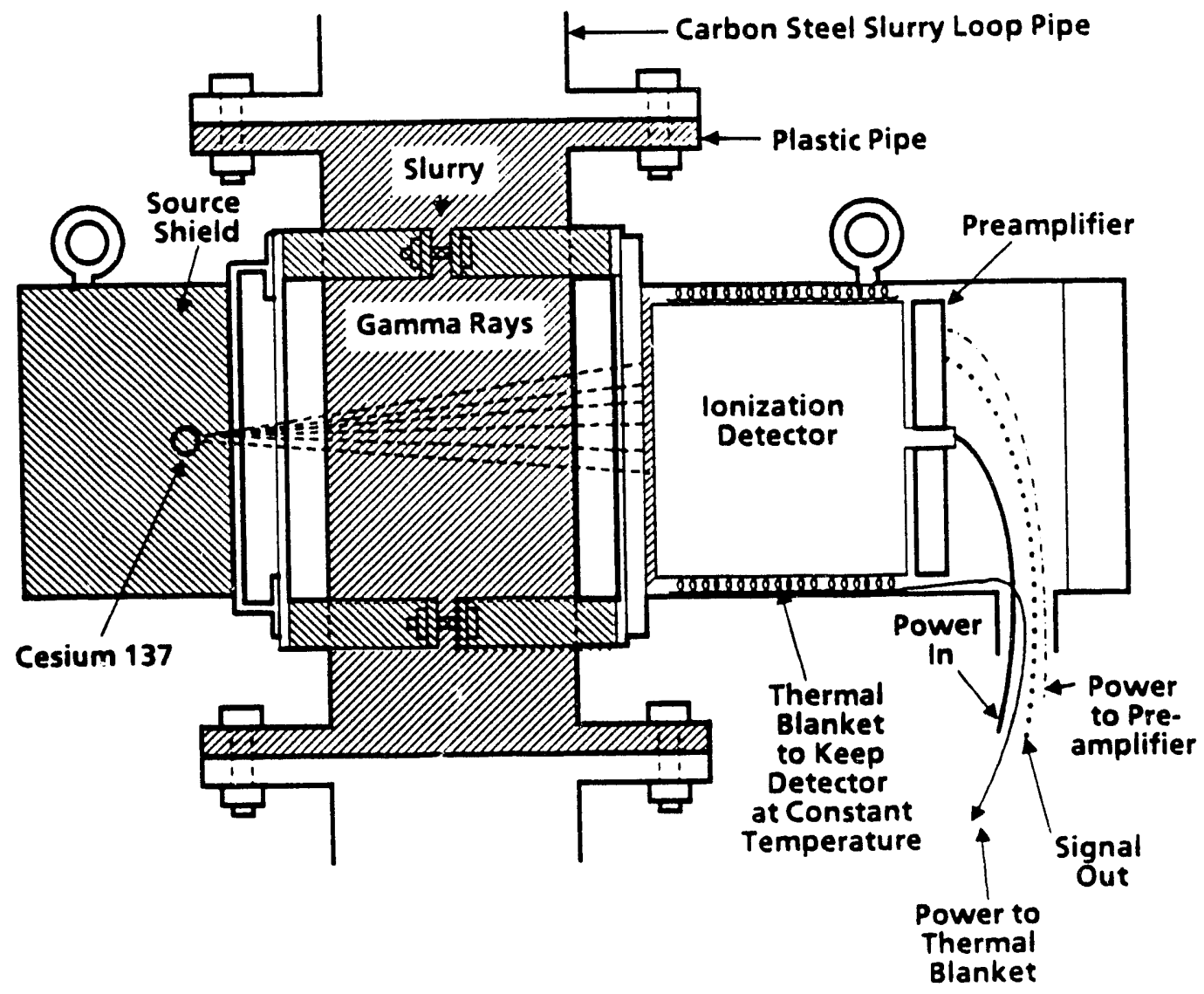

FIGURE 10. HEGG SCHEMATIC

Modifications to the densitometer included replacement of the standard 0.2 curie cesium-137 source with a 1-curie source, and modification of the processing electronics. The HEGG was used to determine the slurry percent solids. More details of the actual unit and the modification made are provided in Appendix A. The source used was considered a high energy source because of its $660 \mathrm{keV}$ gamma energy. The source was contairied in a large lead shield container and was attached to a 6 -inch plastic pipe in the test loop. Opposite the source was a ion-chamber detector. The output from the detector 
was sent to a pre-amplifier which produced a $0-10$ volt signal (referred to as $I_{H}$ ). The gauge is shown in a photograph of the test loop in Figure 11 and in a closeup photograph in Figure 12.

\section{Low Energy Gamma Gauge}

The Low-energy gamma gauge (LEGG) was a more extensively modified SGH Series Texas Nuclear cesium densitometer. It is shown schematically as Figure 13. The changes include replacement of the cesium-137 source with a 5curie americium-241 source, replacement of the standard source shield with a smaller customized shield, modification of the processing electronics, and modification of the source shield bracket to allow the source to be moved closer to she slurry pipe. It was used, along with the HEGG, to predict slurry ash content. (The two analyzers were referred to as the dual-energy gamma gauge, [DEGG].) It was considered a low energy source because of its $60-k e V$ gamma energy. The source was contained in a small lead shield container and attached just above the HEGG on the same 6-inch p? istic pipe in the test loop. Opposite the source was a ion chamber detector. The output from the detector was sent to a separate pre-amplifier which pinduced another 0 to 10 volt signal (referred to a $I_{L}$ ). A close up photograph of the LEGG is shown in Figure 14.

\section{Prompt Gamma Neutron Activation Analyzer}

The Prompt gamma neutron activation analyzer (PGNAA) was used to determine the sulfur and iron content of the coal slurry. The analyzer contained a $20 \mu \mathrm{g}, 11$ millicurie source of californium-252 (Cf-252). This source was a very strong neutron emitter (in contrast to the other two sources which were gammil-ray emitters). The source, which had a 2.55 year useful life was replaced at the beginning of the project. It was contained in a large borated-paraffin filled shield. The unit was made in a clam-shell type arrangement. To install, the unit was opened into two sections, positioned to surround the 6-inch plastic pipe holding the HEGG and the LEGG, then closed together. The neutrons from the californium passed through the coal slurry. 


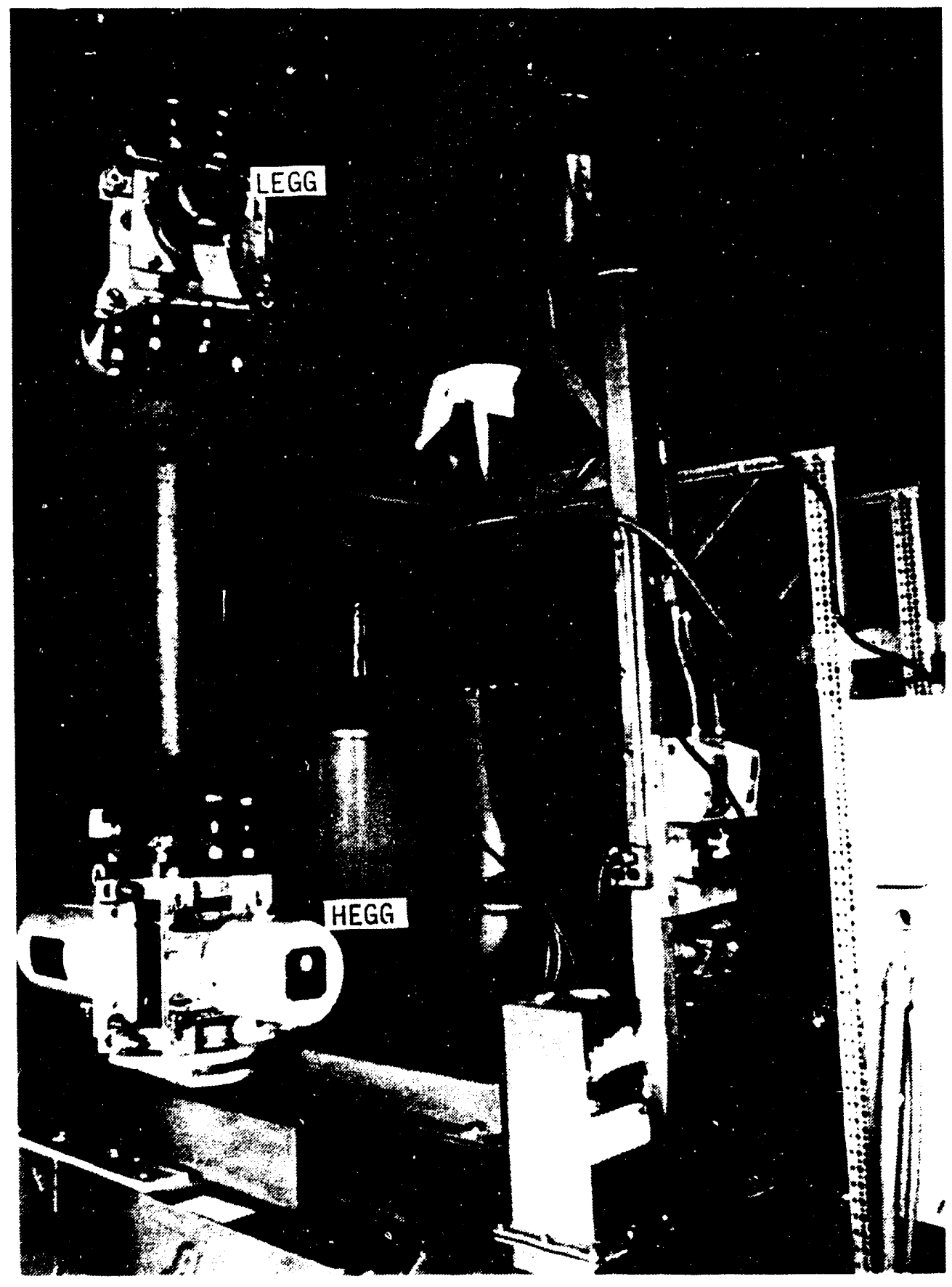

FIGURE 11. THE HIGH-ENERGY GAMMA GAUGE IN TEST LOOP 


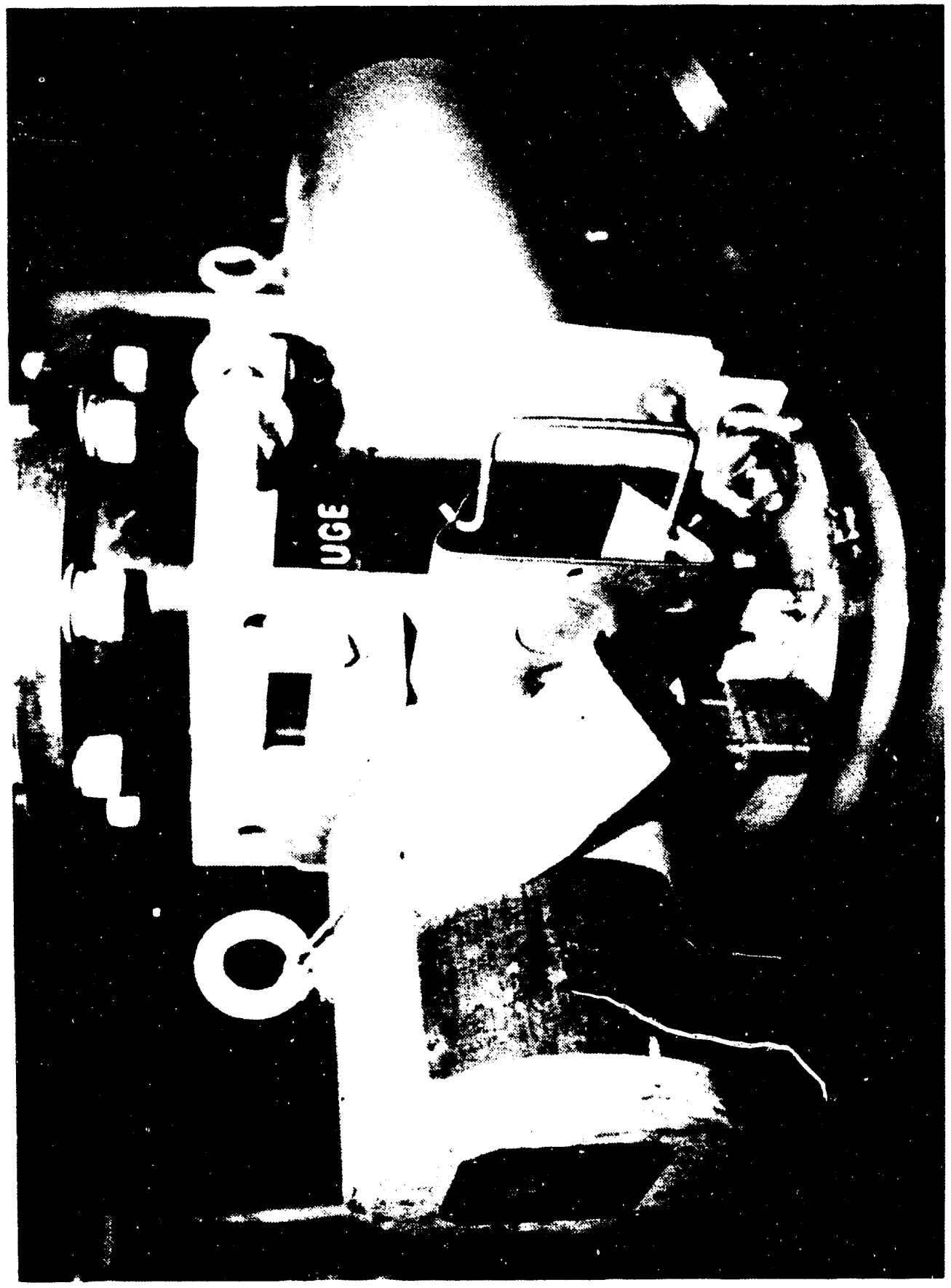

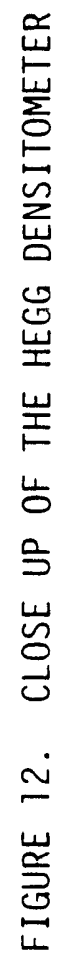




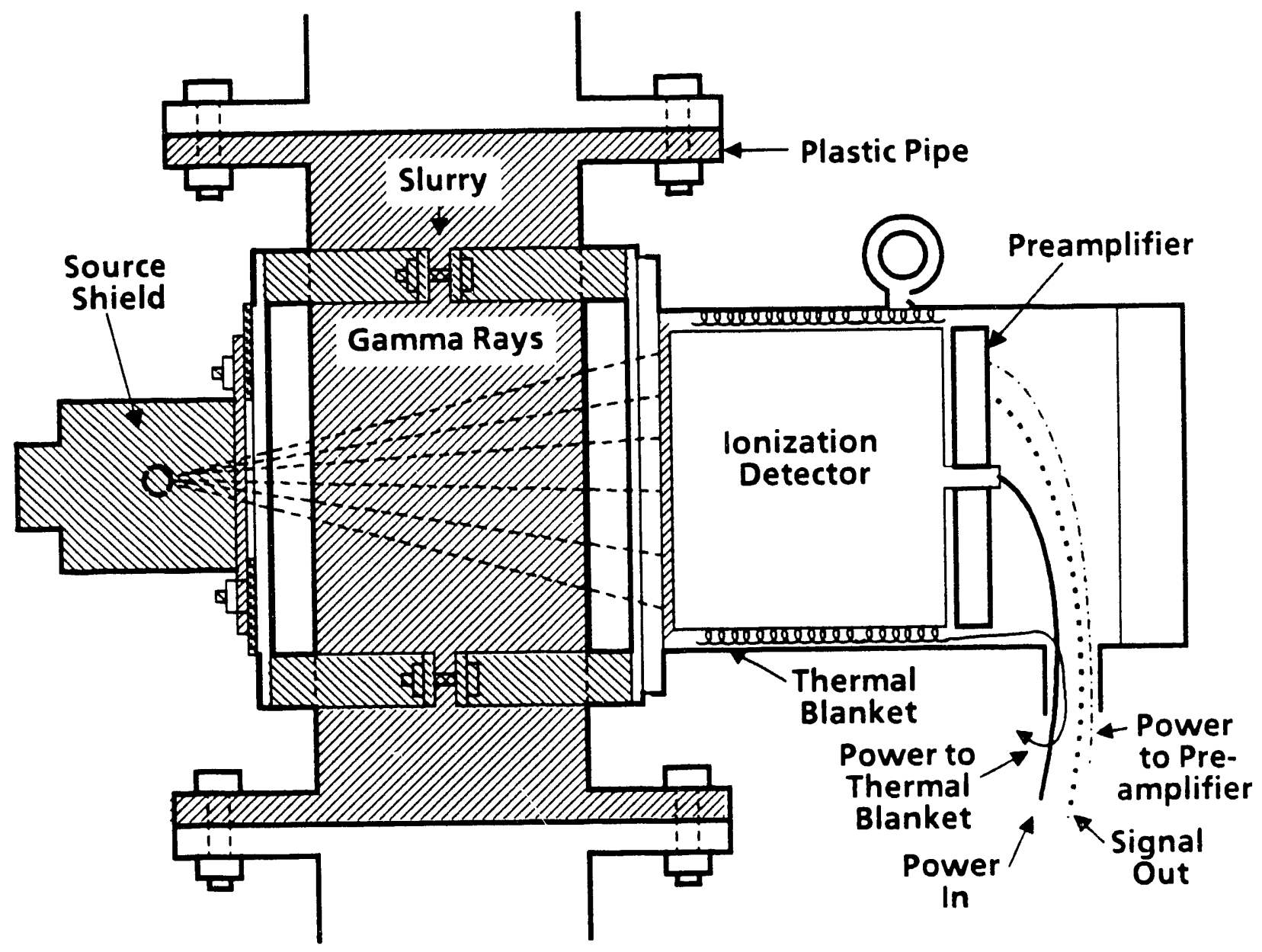

Figure 13. LEGG Schematic 


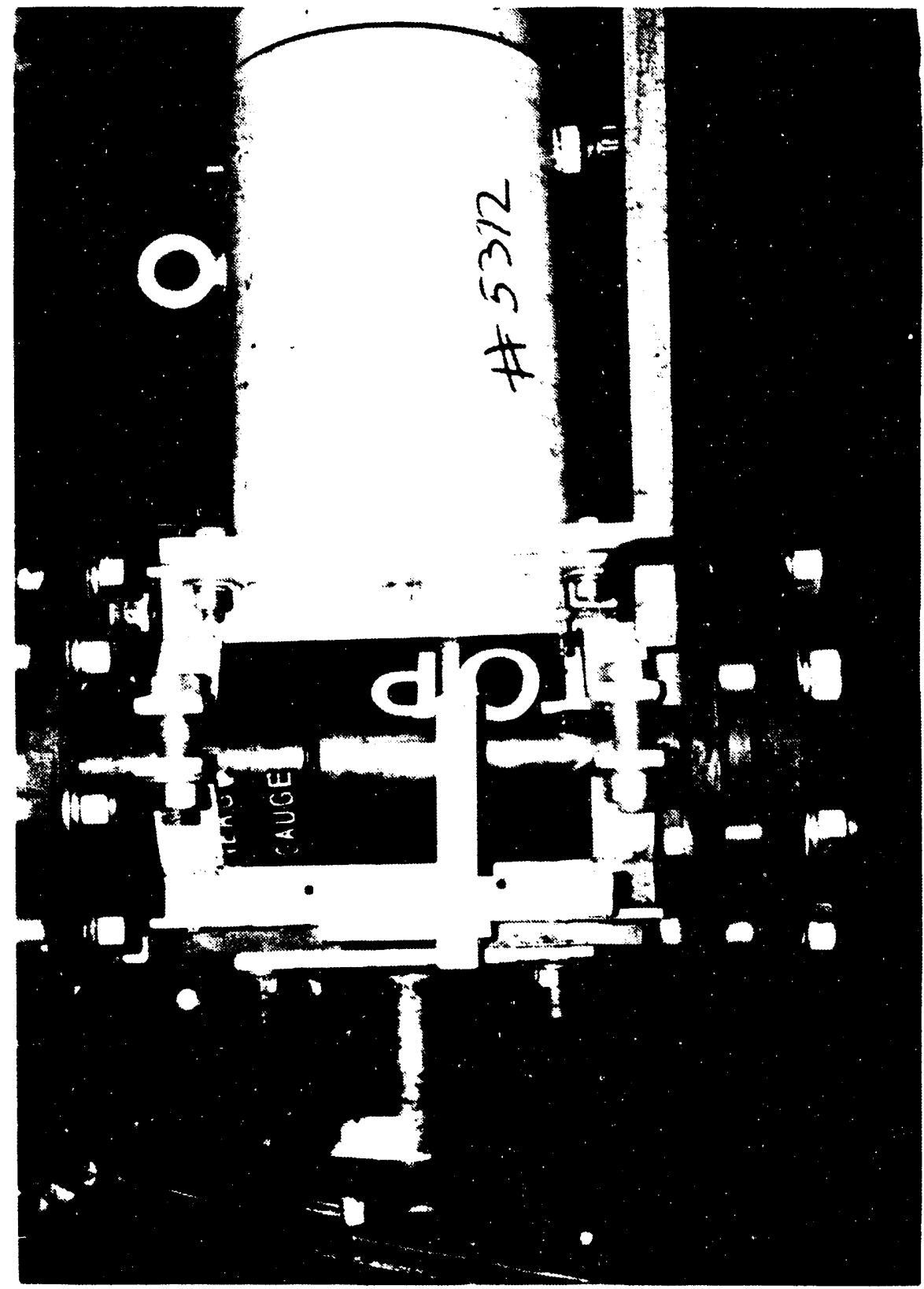

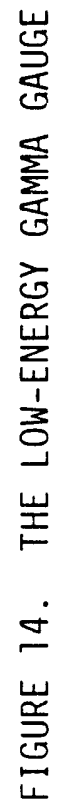


The radiation was detected by a sodium iodide detector and converted into electrical signals using a photomultiplier tube. These signals were amplified and displayed on a Multi-Channel Analyzer (MCA). The output from the MCA was sent to the data acquisition system. More detail on the PGNAA system is provided in Appendix $B$. The position of the PGNAA analyzer in relation to the DEGG is shown in Figure 15. The PGNAA instrument is shown in a close up photograph in Figure 16.

\section{Micro-Motion Mass (MM) Flow Meter}

The final instrument in the test loop was a commercial mass flow meter. A photograph of the Micro-Motion mass flow meter is presented in Figure 17 .

\section{Data Acquisition System}

The original data acquisition and analysis program supplied by EPRI/SAIC could not be made to function properly. After extended efforts in the beginning of the project, the computer system was deemed inoperable. Subsequent operations were achieved by a combination of manual and semiautomated methods. This proved unsatisfactory so a simple data acquisition system was installed. The system was designed based on a Compaq PC, Keithley data acquisition System 500 hardware, and Laboratory Technologies Corporation's LabTech Notebook data acquisition software. The system is shown schematically in Figure 18. Voltage signals from the HEGG and the LEGG and the millivolt signal from a Chromel-Alumel thermocouple came into the Keithley System 500 box. These signals underwent analog-to-digital conversion and amplification and were sent via a special Keithley cable to a card placed inside the PC. The PGNAA produced not a voltage but a series of digital counts representing the gamma-ray spectrum. This consisted of a "count" value ranging from one to hundreds of thousands for each of 512 channels (which corresponded to different energy levels in the gamma-ray spectrum). These signals were sent from the Multi-Channel Analyzer via a "serial" communication 


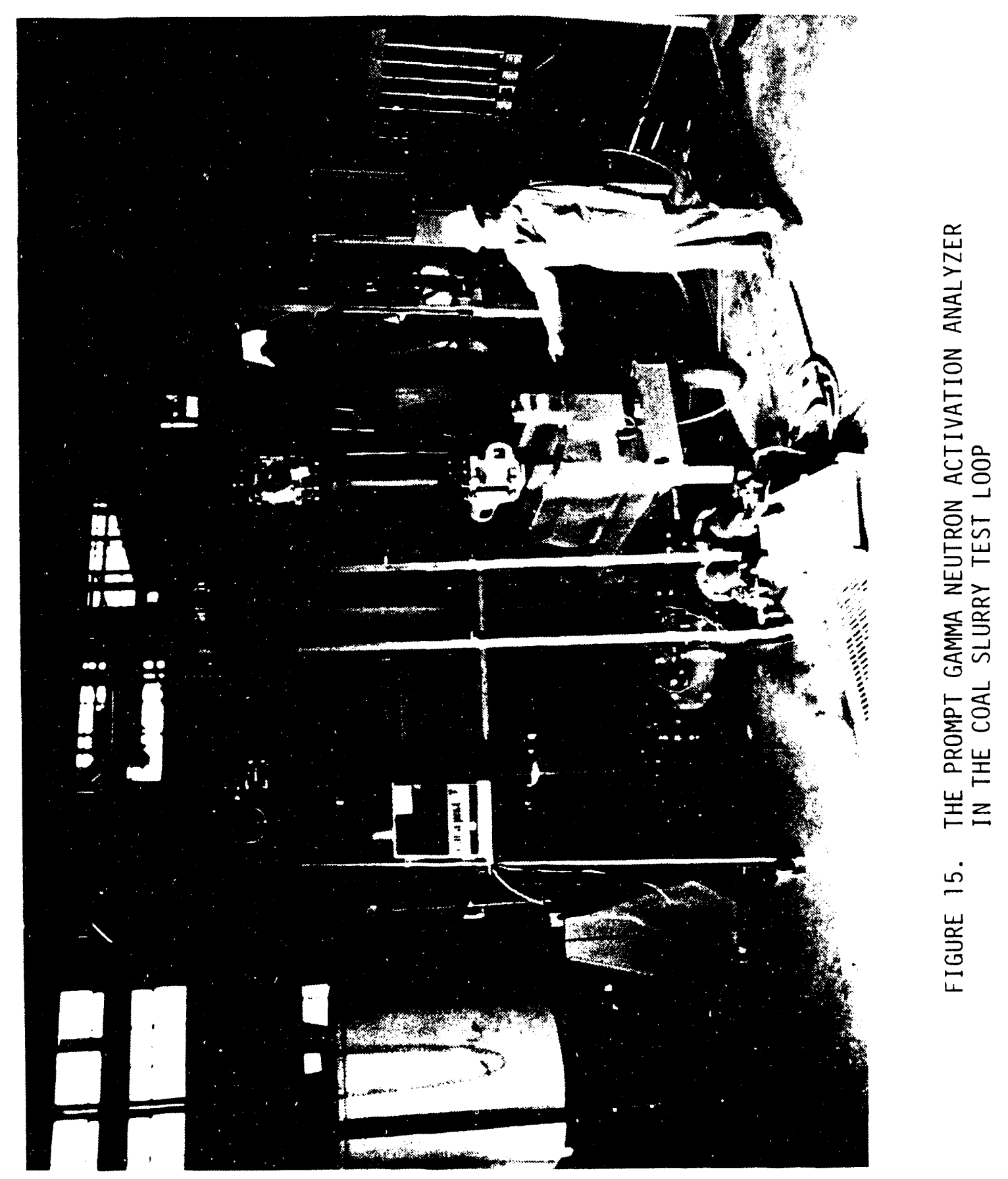




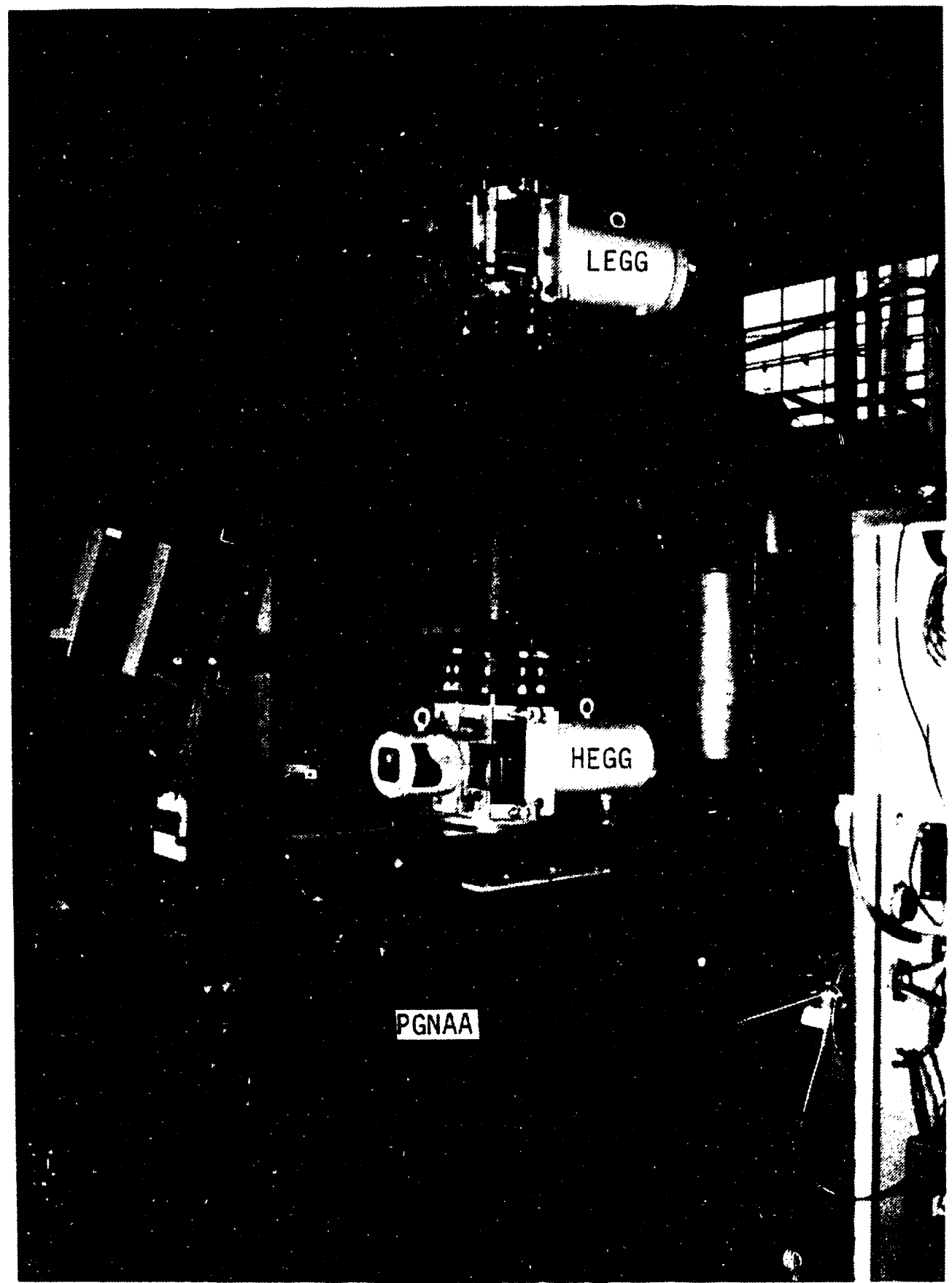

FIGURE 16. CLOSE UP OF THE PGNAA 


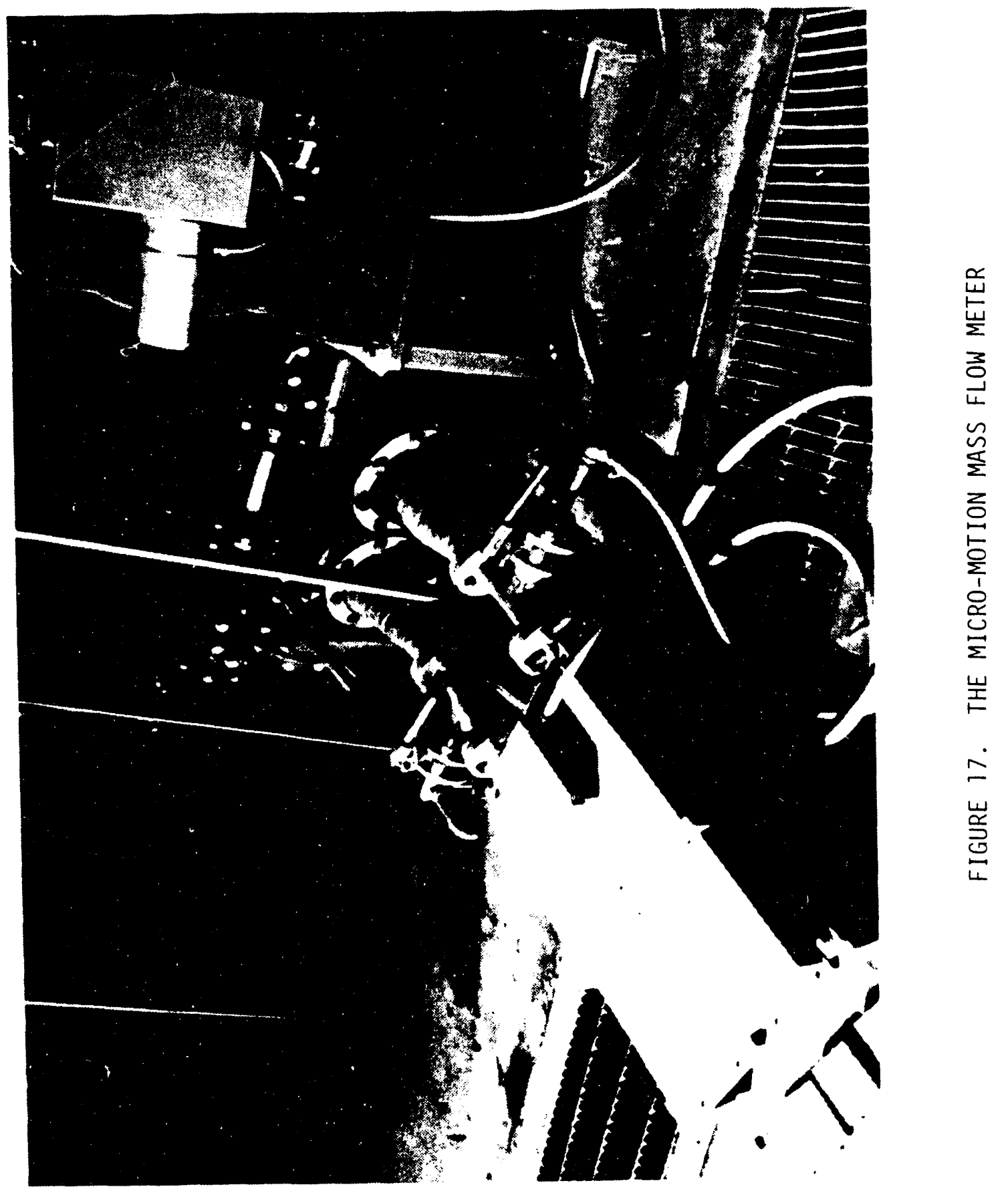




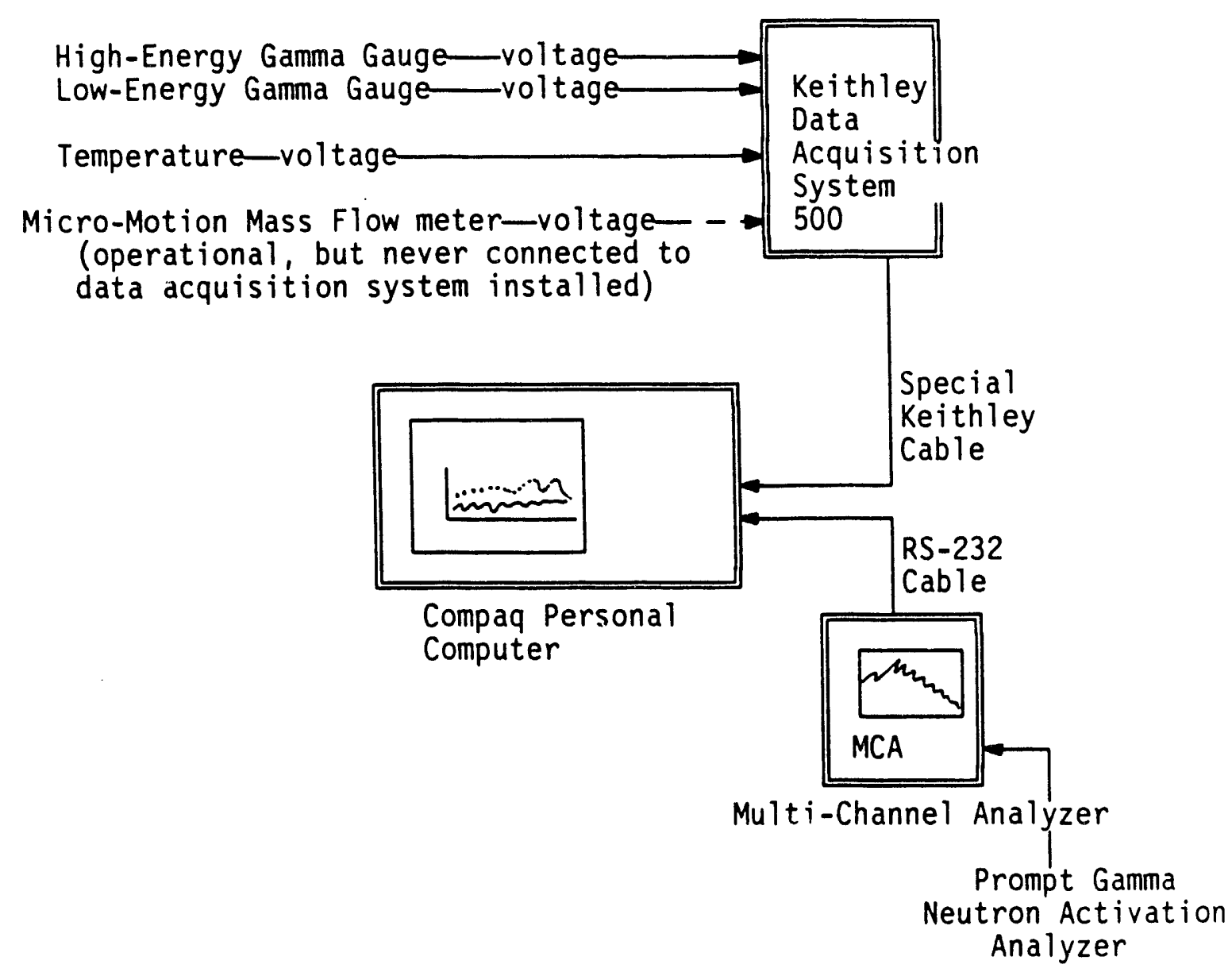

FIGURE 18. DATA ACQUISITION SYSTEM

cable under the "RS-232" protocol. The signals entering the PC were interpreted by the LabTech Notebook software.

The software was set up to receive each signal at a constant frequency (e.g., sampling rate of once every second of the HEGG, LEGG, and thermocouple and once each 5 minutes for the PGNAA spectrum). The signals were converted to percent ash, percent solids, and a first approximation of sulfur, and displayed on the monitor and stored on disk. Greater detail and specific information for each data input are provided in Appendix $C$. 


\section{Nuclear Safety}

The DEGG and PGNAA were designed such that radiation losses were minimal. In general, personnel can work in the vicinity of nuclear gauge without special notices, barricades, etc., if the source emits less than 1millirem per hour (mrem/h) of radiation. Radiation emission maps for the DEGG and PGNAA instruments indicated that emissions, both gamma ray and neutron, were below $1 \mathrm{mrem} / \mathrm{h}$ level. These levels were with the shields in place surrounding the slurry pipe and the pipe was filled with water. Naturally, if the nuclear sources were removed from their protective enclosures, radiation levels would be excessive. Therefore, all source handling and instrument installation should be conducted only by trained radiation safety personnel.

As an extra precaution, radiation badges, one for gamma rays and one for neutrons, were worn by all test personnel during the program. Monthly checks of the badges did not indicate any exposure over the 1-1/2 year installation, shakedown, and test period.

\section{Test Procedures}

All testing followed a test matrix designed to acquire the maximum amount of useful information during each test. The objectives of the run and test conditions were set and noted on a data worksheet. Information was logged on the data sheet (and backed up for several final runs with an automatic data logging system).

Prior to each run, the voltage levels of each densitometer with only water, $i . e ., I O_{H}$ and $I O_{L}$, were recorded with the test loop in the static mode (i.e., without the pump in operation).

Next, the recirculation pump was turned on to full flow (approximately $300 \mathrm{gpm}$ ) and a series of PGNAA spectra were obtained, again with only water. The location of the hydrogen peak was determined by noting the number of counts in Channels 94,95 , and 96 . If the maximum peak count 
level was not found in Channel 95, the high voltage input to the PGNAA photo multiplier tube was adjusted to move the peak to its proper location. Once stabilized, a series of three water-only spectra were recorded to establish a baseline.

Finaliy, a series of different materials were added to the tank. These materials included the three test coals, high-ash refuse from the cleaning of Pennsylvania and Ohio $4 A$ coals, sulfur $(S)$, sodium chloride $(\mathrm{NaCl})$, silicon oxide $\left(\mathrm{SiO}_{2}\right)$, aluminum oxide $\left(\mathrm{Al}_{2} \mathrm{O}_{3}\right)$, and iron oxide $\left(\mathrm{Fe}_{2} \mathrm{O}_{3}\right)$. Chemical analysis of these coals and two refuse materials are provided in Appendix $D$. Tests usually included multiple percent solids levels (useful for both the HEGG calibration and percent solids prediction, and wet sulfur and wet-iron levels need for the PGNAA calibration and evaluation). Other tests involved varying the ash level either by addition of high-ash refuse or by the addition of individual ash species simulated by the addition of $\mathrm{SiO}, \mathrm{Al}_{2} \mathrm{O}_{3}$, and $\mathrm{Fe}_{2} \mathrm{O}_{3}$.

Analytical samples were withdrawn 20 to 30 minutes after addition of each material. On-line prediction of the ash and percent solids content (possible after installation of the data acquisition system) showed that the system reached equilibrium within a few minutes. This time lag was due to the mixing conditions in the slurry test loop, not the instruments. HEGG and LEGG lag was only a few seconds.

At the end of each run, the data were transferred onto an electronic data base and trends analyzed. Samples were prepared and sent for chemical analysis.

\section{Analytical Procedures}

Several times throughout the test, slurry samples were withdrawn for chemical analysis. In most cases, two samples were withdrawn simultaneously. These were measured for slurry density and then percent solids. Each sample was filtered and dried on site for determination of slurry percent sulids. 
The percent solids analysis procedures included the following three steps: (1) determine the weight of the slurry sample, (2) filter through a vacuum buchner filter and record the filtrate and wet cake weights, and (3) dry the wet cake at $105 \mathrm{C}$ in a laboratory drying oven and note dry weight. Percent solids were calculated as:

$$
\% \text { Solids }=\frac{\text { dry cake, } g}{\text { dry cake }+ \text { filtrate }+ \text { water lost during drying, } g} \times 100
$$

The dried cake was their packaged in 8-oz plastic bottles and sent to the Chicago offices of Commercial Testing and Engineering Co. Requested analyses included short proximate (ash, moisture, sulfur, and Btu), ultimate ( $C, H, N$, $\mathrm{O}, \mathrm{S}, \mathrm{Cl}$ ), and one or more ash components, primarily $\mathrm{SiO}_{2}, \mathrm{Al}_{2} \mathrm{O}_{3}$, and $\mathrm{Fe}_{2} \mathrm{O}_{3}$. Not all analyses were obtained for every run. In virtually all tests, however, ash, sulfur, and iron were determined.

The precision of each test sample was important as the analytical results provide the basis for calibration of the instruments. The coal slurry analyzer prediction accuracy could be no better than the precision of the analytical value used to calibrate the instruments. Analytical procedure accuracy for each of the important areas is discussed below.

$\underline{\text { Ash }}$

The standard multi-hour furnace burnout procedure was described by ASTM procedure 03174 . The repeatability and reproducibility intervals are:

\begin{tabular}{lcc} 
& Repeatability, $\%$ & Reproducibility, $\%$ \\
\cline { 2 - 3 } & 0.2 & 0.3 \\
No carbonates present & 0.3 & 0.5 \\
$\begin{array}{l}\text { Cals with more than 12\% } \\
\text { ash containing carbonate }\end{array}$ & 0.5 & 1.0 \\
and pyrite. & &
\end{tabular}


A standard error of 1-percent ash was used as the ash target throughout the project since most of the coals tested had 12 percent or more ash.

\section{Percent Solids}

The ASTM procedure for total moisture, D2961, was defined for -8 mesh coal. The technique is not well designed for very high moisture levels as typically found in coal slurries. The ASTM procedure, which is based on oven drying at $107 \pm 3 \mathrm{C}$, has a repeatability (within lab) precision of 0.3 percent and reproducibility (between $1 a b$ ) of 0.5 percent solids. The bias of the test has not been determined. For high-moisture slurries, a practical error of 1 percent was considered good. A standard error of 1 percent (bias plus the standard deviation of the difference between the ASTM value and the predicted value) was used as the percent solids target specifications throughout this project.

\section{Sulfur}

ASTM 03177 was the basis for the original sulfur accuracy target. It is based on wet chemical analys is of $\mathrm{BaSO}_{4}$. This procedure, although highly accurate, is not routinely used by modern coal laboratories. The repeatability and reproducibility standards are ${ }^{(2)}$ :

\section{Repeatability, $\quad$ Reproducibility, $\%$}
Coal containing less than $2 \%$ sulfur
0.05
0.10
Coal containing more than $2 \%$ sulfur
0.10
0.20

The standard sulfur analys is techniques uses a high temperature combustion method (i.e., LECO determination) described in ASTM procedure D4239. The precision obtained varies by detection procedure ${ }^{(2)}$ (see below). 
Method A

Acid Base Titration Procedure

\section{Method B \\ Iodimetric Titration \\ Procedure}

Repeatability,\%

Reproducibility,\%
$0.06+0.03 x$
$0.03+0.11 x$
$0.08 x$
$0.08+0.09 x$
Method C Infrared Absorption Procedure

Note " $X "$ is the average of duplicate samples for sulfur determination.

For example, using Method $A$, repeatability and reproducibility are further described in the following examples from the ASTM manual(2).

Repeatability: "Duplicate analysis for total sulfur gave values of 1.52 and 1.57 percent. The average sulfur of the duplicate analys is value is 1.55 percent and the calculated repeatability is $0.11[0.06+$ $0.03(1.55)]$. The difference between the two sulfur values is 0.05 and does not exceed the 0.11 [calculated limit]; therefore, these two values are acceptable at the 95 percent confidence level."

Reproducibility: "Duplicate analysis for total sulfur in one laboratory gave an average value of 3.81 percent and a value of 4.00 percent was obtained in a different laboratory. The between-laboratory average sulfur value is 3.91 percent, the calculated interval [allowable reproducibility limit] is 0.46 percent $[0.03+0.11(3.91)]$, and the difference between the different laboratory values is 0.19 percent. Since this difference is less than ine calculate interval, these two values are iceptable at the 95 percent confidence level. 
A standard error of $0.03+0.11$ - (sulfur assay) was used as an alternative, less demanding sulfur target throughout this project.

Iron

The ASTM accuracy limit for iron in coal was derived from the determination of the iron oxide $\left(\mathrm{Fe}_{2} \mathrm{O}_{3}\right)$ level in the coal ash. This determination can be made by atomic absorption (AA) or X-ray fluorescence. Determinations in this program were made by the more standard $A A$ method defined in ASTM D3682. In the procedure, the coal was ashed and fused with lithium tetraborate followed by final dissolution in $\mathrm{HCl}$ and determination of $A A$ emissions. The repeatability and reproducibility limits were 1 and 2 percent, respectively, over the moisture-free $\mathrm{Fe}_{2} \mathrm{O}_{3}$-in-ash range of 5 to 50 percent. At an average ash content of 11 percent and a 25 percent $\mathrm{Fe}_{2} \mathrm{O}_{3}$ in ash level, the $\mathrm{Fe}_{2} \mathrm{O}_{3}$ in the coal was 2.75 percent, or 1.92 percent iron in the coal (since $\mathrm{Fe}_{2} \mathrm{O}_{3}$ is 69.94 percent iron). If the $\mathrm{Fe}_{2} \mathrm{O}_{3}$-in-ash accuracy can vary \pm 2 percent (e.g. $25 \pm 2$ ), the iron level could vary from 2.07 to 1.77 percent or \pm 0.15 percent iron. At 50 percent ash and 20 percent $\mathrm{Fe}_{2} \mathrm{O}_{3}$-in-ash level, this same accuracy limit results in $a \pm 0.70$ percent iron in coal limit. The standard error limit was calculated as:

Standard Error for Iron in = Coal

$$
(\mathrm{Ash}) \cdot\left(\mathrm{Fe}_{2} \mathrm{O}_{3} \text { in Ash }\right) \cdot\left(\frac{2}{\mathrm{Fe}_{2} \mathrm{O}_{3} \text { in Ash }}\right) \cdot 0.6994=1.4 \cdot \text { Ash }
$$

This standard error was used as the iron target throughout this project. This standard error level was also approximately equal to \pm 10 percent of the iron level in the coal. 


\section{SECTION 4 EXPERIMENTAL RESULTS}

Presented below is a summary of experimental results for the coal slurry analyzer; discussed are:

- Accuracy target specifications

- Summary of experiments

- Percent ash results

- Percent solids results

- Sulfur and iron results.

\section{Accuracy Target Specifications}

The level of accuracy needed for successful application of the slurry analyzer depends on the application. Lower accuracy levels will be acceptable for certain control purposes. Contact with users and researchers in the coal preparation industry indicated that instruments with less than ASTM (standard test laboratory) accuracy levels could still be valuable tools for achieving improved cleaning-plant performance. However, to provide a guide in the analyzer development, target specifications, in terms of standard error, were set at standard laboratory levels.

The target specifications were:

(1) Ash. Based on ASTM D3174, measure weight percent ash, with no greater than \pm 0.5 percent standard error for 0 to 12 percent ash coal and \pm 1.0 percent error for coals with greater than 12 percent ash

(2) Percent Solids. Based on ASTM D2961, measure weight percent solids, with no greater than \pm 1 percent standard error.

(3) Sulfur. Based on ASTM D3177, measure weight percent sulfur, with no greater than \pm 0.2 percent standard error: based on D4239, $\pm 0.03+0.11 \cdot$ (sulfur) standard error. 


\section{Summary of Experiments}

Table 2 describes some of the characteristics of the 43 experiments conducted. The primary study objectives were to gather data needed to evaluate (1) the accuracy of the dual energy gamma gauge (DEGG) for estimating ash content and percent solids and the PGNAA for estimating sulfur and iron content, (2) the effect of slurry properties on instrument performance, (3) suitability for heavy-media applications, and (4) suitability for flotation applications.

Data from Runs 0-4 provided basic information on the system. Runs 5-9 and 15 evaluated a calibration procedure where coal and water were placed in thin plastic boxes lowered into the test loop for the purpose of generating calibration data--this procedure proved ineffective. Run 10 along with Run 0 generated extensive data for percent solids calibration and evaluation data. Runs 11-27 provided data on the effect of coal composition on percent solids, ash, and sulfur predictions.

Data from Runs 28-33, and 36 were used to provide baseline information on the effect of silicon, aluminum, carbon, iron, sulfur, chlorine, and nitrogen on the PGNAA spectrum. Runs $34,35,37$, and 38 provided information on all three properties of interest. Run 39 provided information on the background spectrum of the PGNAA with the californium source retracted and removed. Runs 40-43 provided information on the effect of sulfur, iron, and chlorine on ash, percent solids, sulfur, and iron predictions.

Initial analysis of the data indicated a serious problem with ash prediction results. A thorough instrument check indicated that the low-energy densitometer (LEGG) pre-amplifier was operating erratically. It was replaced after Experiment 36 and the accuracy of ash predictions was improved. After successful tests with Runs 37 and 38 the project's scope of work was altered. No new experimentation was conducted for 6 months. When the project was restarted in May of 1989, several additional changes to the electronics were 
TABLE 2. SUMMARY OF EXPERIMENTS CONDUCTED

\begin{tabular}{|c|c|c|}
\hline $\begin{array}{c}\text { Run } \\
\text { Number }\end{array}$ & Coal Type (a) & Test Variables ${ }^{(b)}$ \\
\hline 0 & Ohio - Cleaned & $\begin{array}{l}\% \text { Solids }=0,4,6,8,10,12,15,16 \\
\text { pump speed }(\%)=20,60,100\end{array}$ \\
\hline 1 & Ohio - Cleaned $\left(+\mathrm{Al}_{2} \mathrm{O}_{3}\right)$ & $\%$ Ash $=0,10,20,30,40$ \\
\hline 2 & Ohio - Cleaned & $\%$ Solids $=0,4,8,11,14$ \\
\hline 3 & Illinois \#6 - Cleaned & $\%$ Solids $=0,5,9,12,15$ \\
\hline 4 & Kentucky - Cleaned & $\%$ Solids $=0,5,9,14,17$ \\
\hline $5-9$ & Ohio - Cleaned & Box calibration experiments \\
\hline 10 & Ohio - RaW & $\%$ Solids $=0,1, \ldots, 5,10,14,19,20$ \\
\hline 11 & Ohio - Cleaned $\left(+\mathrm{Al}_{2} \mathrm{O}_{3}\right)$ & $\%$ Ash $=0,10,20,30,40$ \\
\hline 12 & Ohio - Cleaned $\left(+\mathrm{SiO}_{2}\right)$ & $\%$ Ash $=0,10,20,30,40$ \\
\hline 13 & Ohio - Cleaned $\left(+\mathrm{Fe}_{2} \mathrm{O}_{3}\right)$ & $\%$ Ash $=0,10,20,30,40$ \\
\hline 14 & Ohio - Cleaned $\left(+\mathrm{Fe}_{2} \mathrm{O}_{3}\right)$ & $\%$ Ash $=0,10,20,30,40$ \\
\hline 15 & Ohio - Cleaned & Box calibration experiment \\
\hline 16 & Ohio - Cleaned $\left(+\mathrm{SiO}_{2}\right)$ & $\%$ Ash $=0,10,20,30,40$ \\
\hline 17 & Ohio - Cleaned $\left(+\mathrm{Al}_{2} \mathrm{O}_{3}\right)$ & $\%$ Ash $=0,10,20,30,40$ \\
\hline 18 & Kentucky - Cleaned $\left(+\mathrm{Al}_{2} \mathrm{O}_{3}\right)$ & $\%$ Ash $=0,5,20,30,40$ \\
\hline 19 & Kentucky - Cleaned $\left(+\mathrm{SiO}_{2}\right)$ & $\%$ Ash $=0,5,20,30,40$ \\
\hline 20 & Kentucky - Cleaned $\left(+\mathrm{Fe}_{2} \mathrm{O}_{3}\right)$ & $\%$ Ash $=0,5,20,30,40$ \\
\hline 21 & Ohio - Cleaned (+ mixed ash) & $\%$ Ash $=0,10,20,30,40$ \\
\hline 22 & I11\#6 - Cleaned (+ mixed ash) & $\%$ Ash $=0,10,20,30,40$ \\
\hline 23 & Kentucky - Cleaned (+ mixed ash) & $\%$ Ash $=0,5,20,30,40$ \\
\hline
\end{tabular}


TABLE 2. SUMMARY OF EXPERIMENTS CONDUCTED (Continued)

Run Number
Coal Type (a)
Test Variables ${ }^{(b)}$

\begin{tabular}{|c|c|c|}
\hline 24 & Ohio - Cleaned & $\%$ Solids $=0,3,5,10,15,20$ \\
\hline 25 & Kentucky - Cleaned & $\%$ Solids $=0,1,2,3,5,10,15$ \\
\hline 26 & Ohio - Cleaned (+ magnetite) & $\%$ Solids $=0,5,8,10,13$ \\
\hline 27 & Low Ash Coal (+ mixed ash) & $\begin{array}{l}\% \text { Ash }=0,6,8,10,16 \\
\% \text { Solids }=0,3,5,6\end{array}$ \\
\hline 28 & $\mathrm{SiO}_{3}$ in Water $(\mathrm{C})$ & Silicon concentration \\
\hline 29 & $\mathrm{Al}_{2} \mathrm{O}_{3}$ in Water & Aluminum concentration \\
\hline 30 & Graphite in Water & Carbon concentration \\
\hline 31 & $\mathrm{Fe}_{2} \mathrm{O}_{3}$ in Water & Iron concentration \\
\hline 32 & $\mathrm{H}_{2} \mathrm{SO}_{4}$ in Water & Sulfur concentration \\
\hline 33 & $\mathrm{HCl}$ in water & Chlorine concentration \\
\hline 34 & Ohio - Cleaned (+ refuse) & $\%$ Solids $=5 ; \%$ Ash $=11,15,20,25$ \\
\hline 35 & Ohio - Cleaned (+ refuse) & $\begin{array}{l}\% \text { Ash }=11,15,20,25 \\
\% \text { Solids }=5,5.5,6 \text {, and } 6.5\end{array}$ \\
\hline 36 & $\mathrm{HNO}_{3}$ in Water & Nitrogen concentration \\
\hline 37 & Ohio - Cleaned (+ refuse) & $\%$ Ash $=11-17$ \\
\hline 38 & Ohio - Cleaned (+ refuse) & $\begin{array}{l}\% \text { Ash }=11-21 \\
\% \text { Solids }=9-12\end{array}$ \\
\hline 39 & $\begin{array}{l}C f^{252} \text { Source Retracted and } \\
\text { Removed }\end{array}$ & PGNAA background spectrum \\
\hline 40 & $\begin{array}{l}\text { Ohio }-\mathrm{Cl}_{\text {eaned }} \\
\left(+\mathrm{S}, \mathrm{Fe}_{2} \mathrm{O}_{3}, \text { and } \mathrm{NaCl}\right)\end{array}$ & $\begin{array}{l}\% \text { Solids }=10,15 \\
\% \text { Ash }=11,12,13 \\
\% \text { Sulfur (wet) } 0.4,0.5,0.7,0.8 \text { also } \\
\text { variable iron and chlorine }\end{array}$ \\
\hline
\end{tabular}


TABLE 2. SUMMARY OF EXPERIMENTS CONDUCTED (Continued)

\begin{tabular}{|c|c|c|}
\hline $\begin{array}{c}\text { Run } \\
\text { Number }\end{array}$ & Coal Type $(a)$ & Test Variables ${ }^{(b)}$ \\
\hline 41 & $\begin{array}{l}\text { Ohio - Cleaned } \\
\left(+\mathrm{S}, \mathrm{Fe}_{2} \mathrm{O}_{3}, \text { and } \mathrm{NaCl}\right)\end{array}$ & $\begin{array}{l}\% \text { Solids }=10,15,20 \\
\% \text { Ash }=11,12,13 \\
\% \text { Sulfur (wet) }=0.4,0.6,0.7,0.8,0.9 \\
\text { also variable iron and chiorine }\end{array}$ \\
\hline 42 & $\begin{array}{l}\text { Ohio - } \mathrm{Cleaned} \\
\left(+\mathrm{S}, \mathrm{Fe}_{2} \mathrm{O}_{3}, \text { and } \mathrm{NaCl}\right)\end{array}$ & $\begin{array}{l}\% \text { Solids }=5,10,15 \\
\% \text { Ash }=11,12,13,16 \\
\% \text { Sulfur (wet) }=0.2,0.4,0.5,0.6 \text { also } \\
\text { variable iron and chlorine }\end{array}$ \\
\hline 43 & Gob (+ Cleaned Coal, S) & $\begin{array}{l}\% \text { Solids }=5,10,15 \\
\% \text { Ash }=50,45,40,35 \\
\% \text { Sulfur (wet) } 0.1,0.3,0.4,0.6,0.8,0.9\end{array}$ \\
\hline
\end{tabular}

(a) Ohio 4A coal: Waterloo Coal Company, Jackson County, Ohio

111 \#6: Illinois No. 6 coal; Peabody Coal Company, No. 10 mine, Christian County, Illinois

Kentucky: Elkhorn coal, Bethlehem Mines, Pike County, Kentucky

Refuse: High ash reject from the cleaning of Pittsburgh coal from the Homer City, $P A$, coal cleaning plant.

Gob: High ash refuse from cleaning Ohio $4 A$ coal

See Appendix $D$ for detailed chemical analyses.

(b) Levels indicated are nominal or rounded to nearest percent. Percent ash is gi\%en on a dry basis.

(c) Tests 28-32, 36 and 39 were conducted to generate data for use in PGNAA analysis. 
made to allow further improvements in the analyzer's accuracy. Therefore not all of the data generated were usable and not all were compatible. Listed below, in Table 3 , is a summary of the useable and compatible experiments. The experimental results presented next are limited to the usable and compatible runs noted in Table 3 .

\section{TABLE 3. USEABLE AND COMPATIBLE DATA}

Percent Ash

Percent Solids

Sulfur and Iron

tests.
Runs $0-36$ are not always compatible;

Run 37 and 38 are useable and compatible;

Runs 40-43 are useable and compatible.

Runs $0-30$ are useable and compatible;

Runs 40-43 are useable and compatible.

Runs 0-36 are valid and compatible, but only limited parts of the PGNAA spectrum data were recorded. Therefore, this data can not be used in conjunction with subsequent

Runs 37-43 are useable and compatible.

\section{Percent Ash Results}

\section{Accuracy Achieved}

To achieve the greatest accuracy possible, several modifications/ improvements in the equipment and the prediction formulas were made. The equipment modifications included:

- Replacement of the LEGG analysis pre-amplifier

- Reduction of interference signals to the LEGG and HEGG

- Reduction of LEGG noise levels

- Elimination of signal bias

- Automatic recording and time averaging via a data acquisition system. 
These changes allowed progressive improvement in the predicted-ash standard error throughout the course of the project. In addition, to the equipment modification, new runs were conducted (Runs 40-43) to provide data for evaluating alternative prediction formulas. The theory behind these predictive formulas are described in Section 2 and in Appendix A.

The results from the accuracy improvement evaluation were significant. The standard error for ash predicted from Runs 40-42 data dropped from 0.9 to 0.15 percent ash. The various predictive formulas evaluated are shown in Table 4 and their effect in Figure 19. Runs 40-42 were conducted to generate data for accuracy improvement modelling. They were conducted with Ohio $4 \mathrm{~A}$ coal at varying ash, sulfur, and percent solids levels, modified by the addition of sulfur, iron oxide $\left(\mathrm{Fe}_{2} \mathrm{O}_{3}\right)$ and sodium chloride $(\mathrm{NaCl})$. As such, they represent a broad range of solids, sulfur, iron, and chlorine levels in the coals. Their composition was also similar to that tested in Runs 37 and 38 . The Runs 40-43 results show that significantly better ash prediction accuracy was possible by expanding the number of terms included in the ash predictive formula. (Note, data for Runs 1-38 were made using a formula of type Ash $\left.=A+B\left[S_{L} / S_{H}\right]\right)$. The best standard error achieved, without correcting for iron or sulfur levels, was 0.58 percent ash. The formula used was:

$$
\begin{aligned}
& \text { Ash, dry basis }=39.63-14.88\left(\mathrm{~S}_{L} / S_{H}\right)+1.81\left(\mathrm{~S}_{L} / S_{H}\right)^{2}+45.93\left(\mathrm{~S}_{H}\right) \\
& \text { (Runs } 40-42)
\end{aligned}
$$

The standard error could be improved, by using an iron correction term, to 0.19 percent ash. The modified formula used was:

$$
\begin{aligned}
& \text { Ash, dry basis }=11.78-0.31\left(\mathrm{~S}_{L} / \mathrm{S}_{H}\right)-14.41(\mathrm{Fe})+3.65\left(\mathrm{~S}_{L} / \mathrm{S}_{H}\right)(\mathrm{Fe}) \\
& \text { (Runs } 40-42)
\end{aligned}
$$

where $\mathrm{Fe}$ is the iron content in the slurry expressed on a wet basis. 


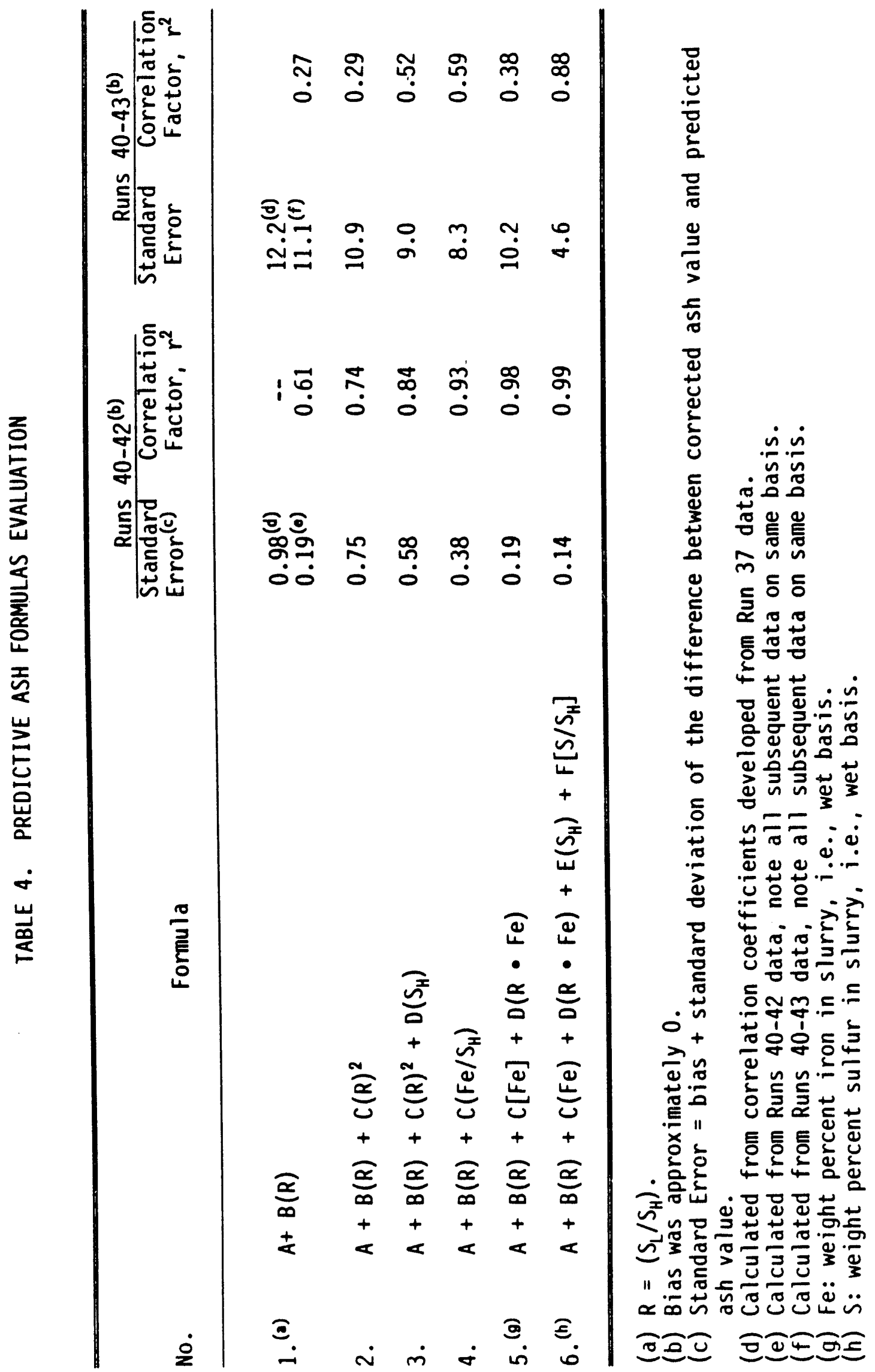




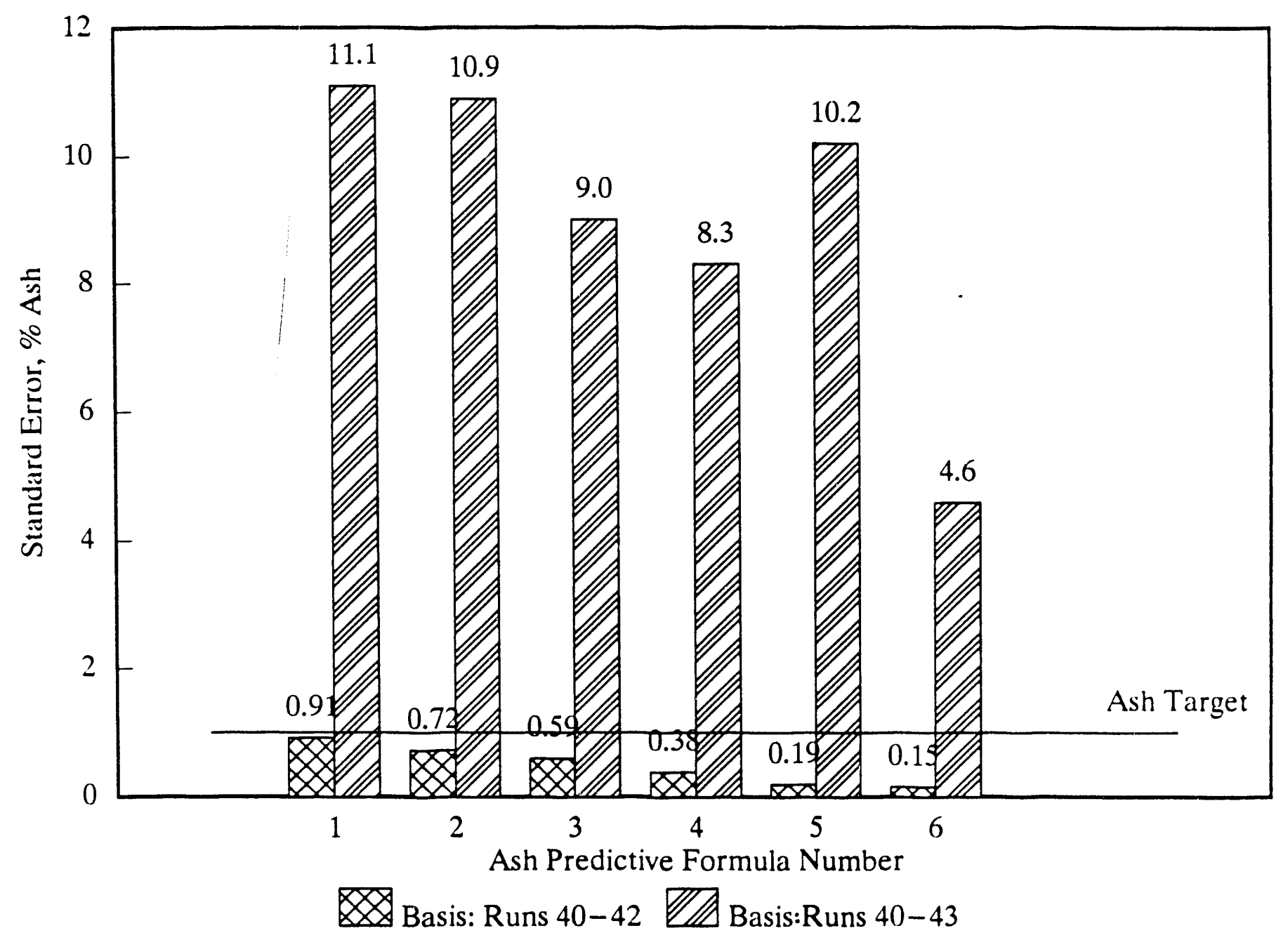

FIGURE 19. PREDICTIVE ASH FORMULA 
Run 43 was made with high ash refuse (called "gob") to which clean coal and sulfur were added. The ash content ranged from 35 to 50 percent. As noted in Table 4, no formula allows prediction of the ash content, over the 10 to 50 percent ash range covered in Runs 40-43, with a standard error meeting the project's \pm 1 percent target. The best level achieved, 4.6 percent ash, was obtained using a formula correcting for percent solids (e.g., $S_{H}$ ), iron, and sulfur. The formula was:

$$
\begin{aligned}
\text { Ash, dry basis }=-16.11 & +12.05\left(\mathrm{~S}_{L} / \mathrm{S}_{H}\right)-186.10(\mathrm{Fe})+25.23\left(\mathrm{~S}_{L} / \mathrm{S}_{H}\right)(\mathrm{Fe}) \\
\text { Runs } 40-43 & +721.24\left(\mathrm{~S}_{H}\right)-1.36(\mathrm{~S}) /\left(\mathrm{S}_{H}\right)
\end{aligned}
$$

where $\mathrm{Fe}$ and $\mathrm{S}$ were the percent iron and sulfur in the slurry, respectively, expressed on a wet basis. These values are produced by the PGNAA instrument.

If the range of ash content was restricted to the 35 to 50 percent ash range found in Run 43 alone, the analysis could satisfactorily predict the ash level. Using the standard formula (No. 3 in Table 4 ) the error was 2.2 percent ash. Using an ash and sulfur corrected formula (No. 6), the standard error was 0.81 percent ash.

These results indicate that the ash analyzer was capable of predicting ash within the project's ash target ( \pm 1 percent ash) when the ash range was limited to narrow band. However, since these ranges, 10 to 20 percent ash, or 35 to 50 percent ash, are typical of preparation plant operation (i.e., 10 to 20 percent ash is typical of the product stream and 35 to 50 percent ash is typical of the refuse stream) this does not present a serious limitation to the ash analyzer.

While ash accuracy was the most significant single factor, other factors which could impact the usefulness of the analyzer were studied. 


\section{Tests Conducted}

A series of runs was colducted to determine the effect of slurry properties on ash prediction ability; they were

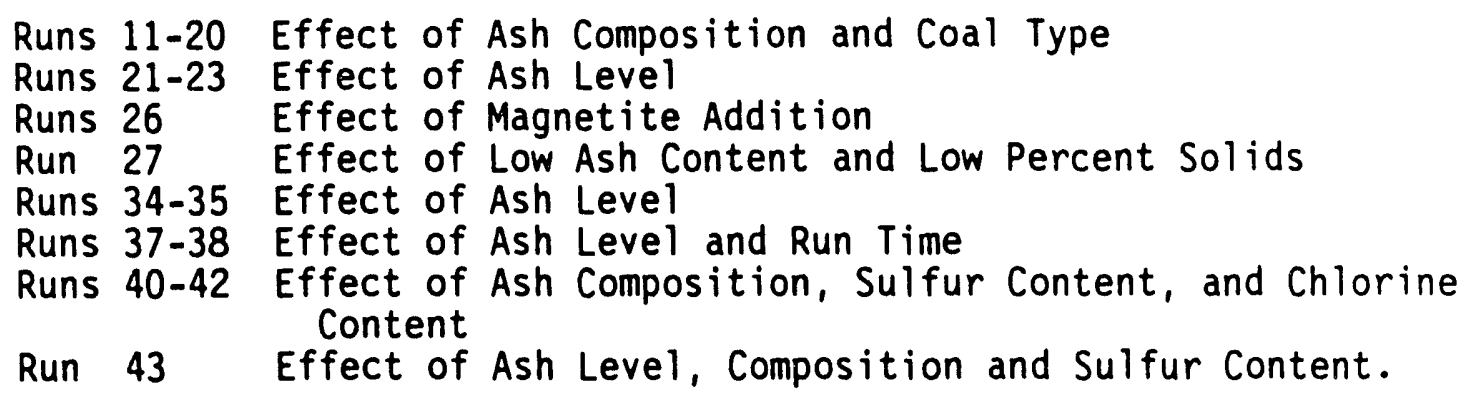

Each is discussed briefly below.

Runs 11-20. In this series of runs, Ohio 4A coal (Runs 11-14) and Kentucky Elkhorn coal (Runs 18-20) were mixed with $\mathrm{Al}_{2} \mathrm{O}_{3}$, or $\mathrm{SiO}_{2}$, or $\mathrm{Fe}_{2} \mathrm{O}_{3}$ and the ash content increased from the nominal feed coal starting value to 10,20 , 30 , and 40 percent total ash, see Table 2 . It was found that each run could be satisfactorily correlated upon itself, but that the results could not be applied to other runs. Ash prediction equations, with iron correction, were able to predict ash with a 5 percent standard error. This was far beyond the target accuracy goal. Therefore, it was concluded that only coals with reasonably consistent ash composition could be successfully analyzed by the DEGG technique.

Runs 21-23. In this series, Ohio 4A (Run 21), I1linois No. 6 (Run 22), and Kentucky (Run 23) coals were tested at ash levels of approximately 10, 20,30, and 40 percent. Mixtures of $\mathrm{Fe}_{2} \mathrm{O}_{3}, \mathrm{Al}_{2} \mathrm{O}_{3}$, and $\mathrm{SiO}_{2}$ were added in the proper proportions to increase ash content while keeping the ash composition reasonably constant. Feed percent solids were maintained at a constant level of 5 percent. The results are shown in Figure 20. Separate ash correlations were developed for each of the three coals using a correlation equation in the form of Formula No. $1\left[A s h=A+B\left(S_{L} / S_{H}\right)\right]$. As noted in the figure, the predicted ash values fell within or near the target levels. When all the data were combined, the composite standard error was still outside the 


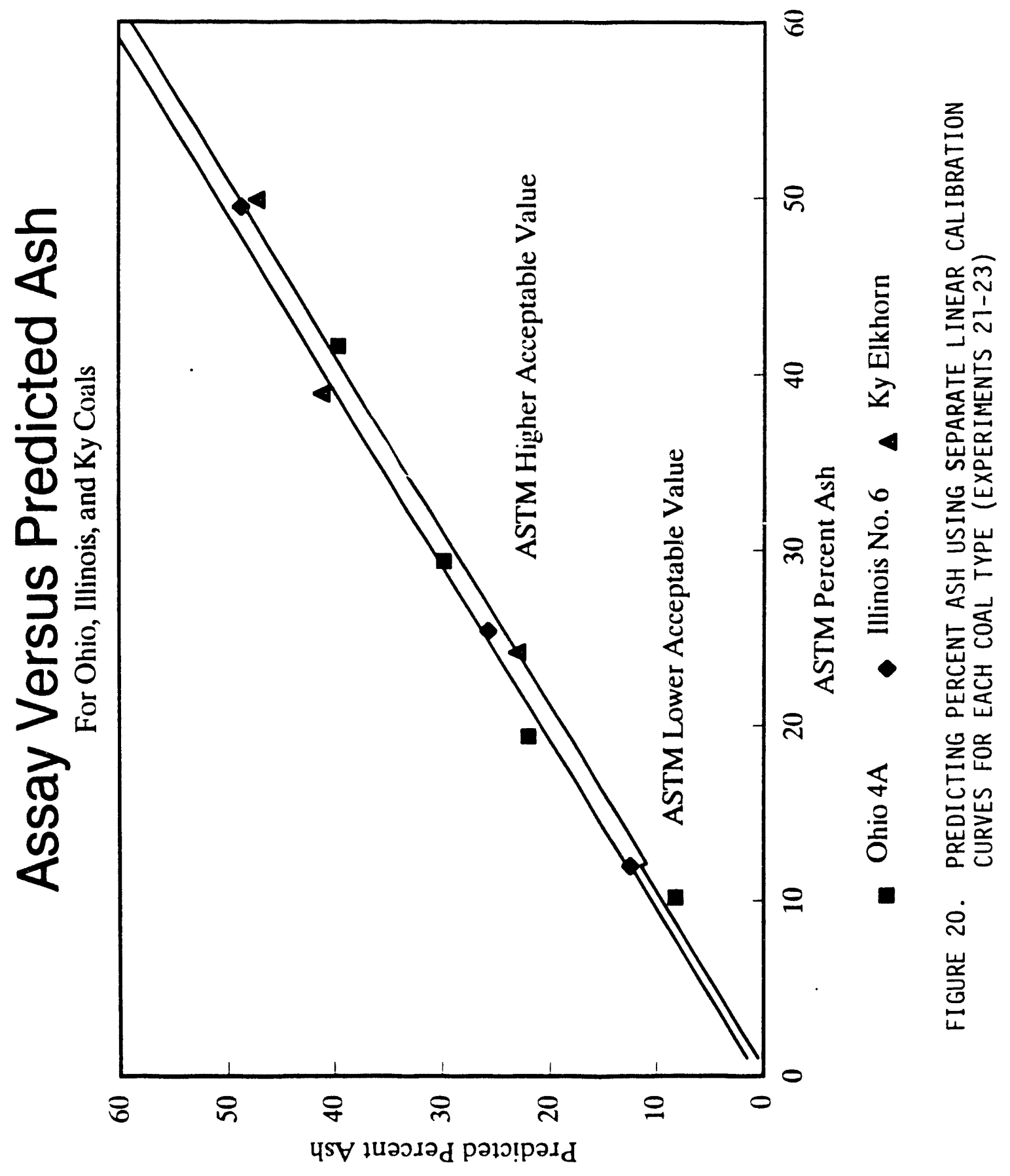


target level. Correlation using Formula No. 3, 4, 5, or 6 (see Table 4) would likely have decreased this composite error.

Run 26. In this run, magnetite, $\mathrm{Fe}_{3} \mathrm{O}_{4}$, was added to a coal slurry. Percent solids were increased from 5 to 13 percent, with associated increases in ash level. The gamma ray attenuation observed with $\mathrm{Fe}_{3} \mathrm{O}_{4}$ was phenomenal. The effect was so vastly different than operation with raw coal, even at ash levels significantly greater than in Run 26 , that it was rapidly concluded that the DEGG was unisuitable for analysis of intermediate heavy-media streams. Further analysis, however, indicated that the product, or refuse stream, after the inagnetite removal rise and drain screens, should be sufficiently low in magnetite to allow accurate analvsis.

Run 27. In this run, low-ash, Bechtel microbubble-floatationcleaned Illinois No. 6 coal, from the DOE-EPRI test program, was studied. Ash levels of 3 to 5 percent at percent solids levels of 3 to 6 percent were planned. However, the test loop apparently was inadequately cleaned and large quantities of residual magnetite remained from the previous run. Ash levels twice those expected and iron levels many times the expected levels were found. Predicted ash levels, based on non-magnetite contaminated coal correlations, were as expected far from the analyzed values. It was again determined that coals with significant magnetite levels could not be successfully analyzed by the DEGG approach.

Runs 34-35. In these tests, high ash refuse was added to Ohio $4 \mathrm{~A}$ coal. Post-run analysis indicated that the preamplifier on the LEGG performed erratically. No new results cold be obtained from this data due to this problem.

Prior to the next run, a new LEGG preamp ifier was installed, and several small modifications made. 
Runs $37-38$. Runs 37 and 38 were extended duration runs made with Ohio 4A coal and Pennsylvania-coal refuse. The ash composition was not totally constant, but varied in a manner consistent with typical coal preparation plant service (i.e., the percent iron in the ash varied from 26 to 42 percent). This provided the data necessary to generate the following new ash prediction equation

$$
\text { Predicted } \% \text { Ash, dry }=-2.1517+2.9806 \cdot\left(S_{L} / S_{H}\right) \text {. }
$$

Figure 21 shows a plot of Run 37 dry ASTM ash content versus predicted ash content based on this equation. The standard error was an excellent 0.44 percent ash. Bias was naturally zero since the data were correlated upon itself.

Run 38 was conducted with the same Ohio $4 \mathrm{~A}$ cleaned coal. Again the test began using only the cleaned coal, then small quantities of Pennsylvaniacoal refuse were added to increase the ash content. Using the Run 37 equation the dry ash content was calculated. The standard error, calculated by adding the maximum bias and the standard deviation of the difference between the assay value and the predicted value, was less than 0.8 percent in the 11 to 17 percent ash range. Figure 22 is a plot of ash content versus time. The solid lines represent target levels (ASTM assay + 1-percent and - 1-percent ash) and the symbols the ash predictions. Note that over the 600 hour test period the data were virtually always within or near the target bands.

Runs 40-42. After Run 38, the project was suspended while a modification to the scope of work was approved. As part of the new approved scope, the LEGG preamplifier was replaced and several of other electronics problems were rectified. In addition, an on-line data acquisition system was installed to allow both data logging and on-line prediction of ash, percent solids, sulfur, and iron. Because of the numerous electronics changes, the same ash and percent solids prediction coefficients developed from the Run 37 data were no longer truly applicable to the Runs 40-43 data. 


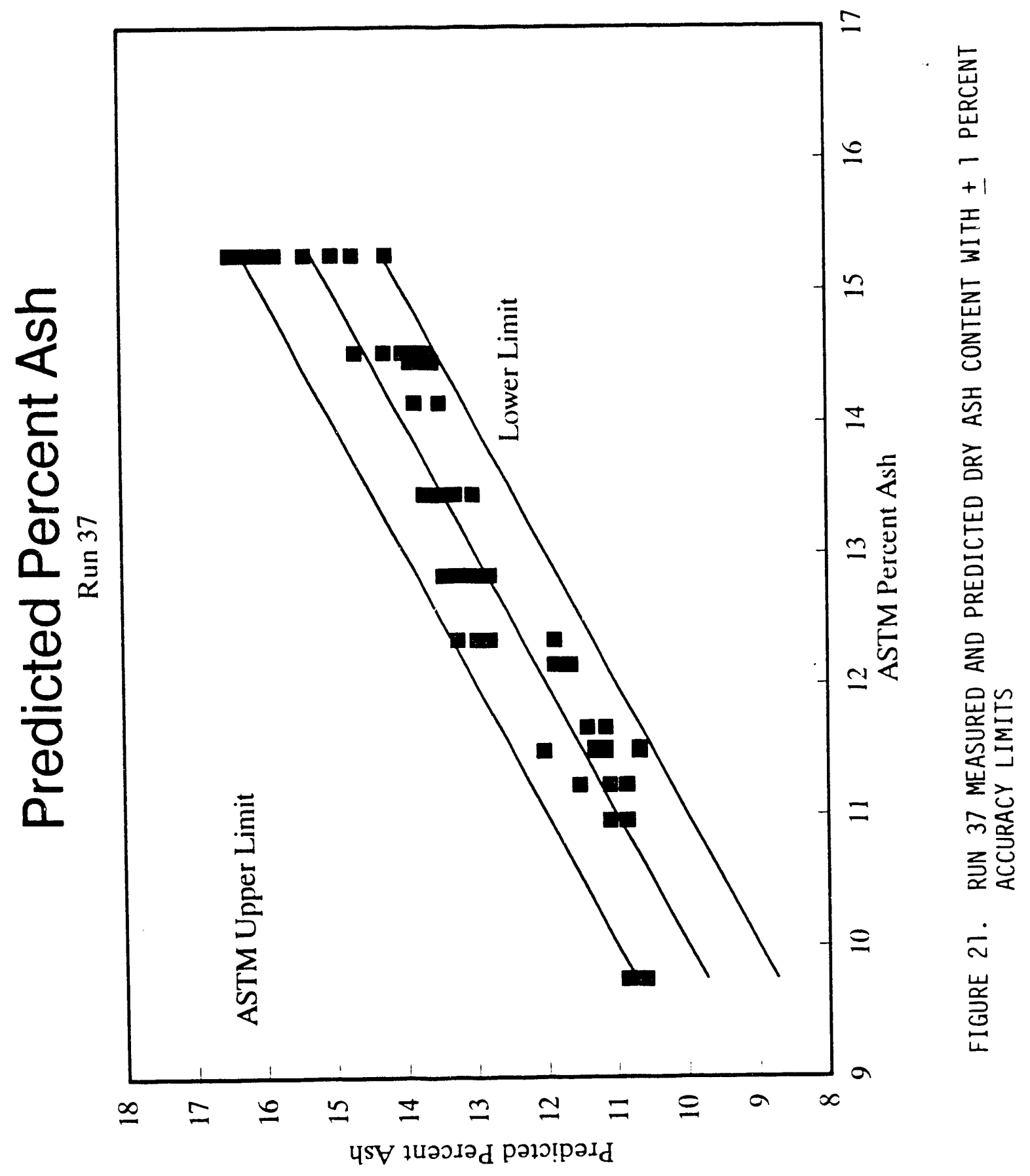




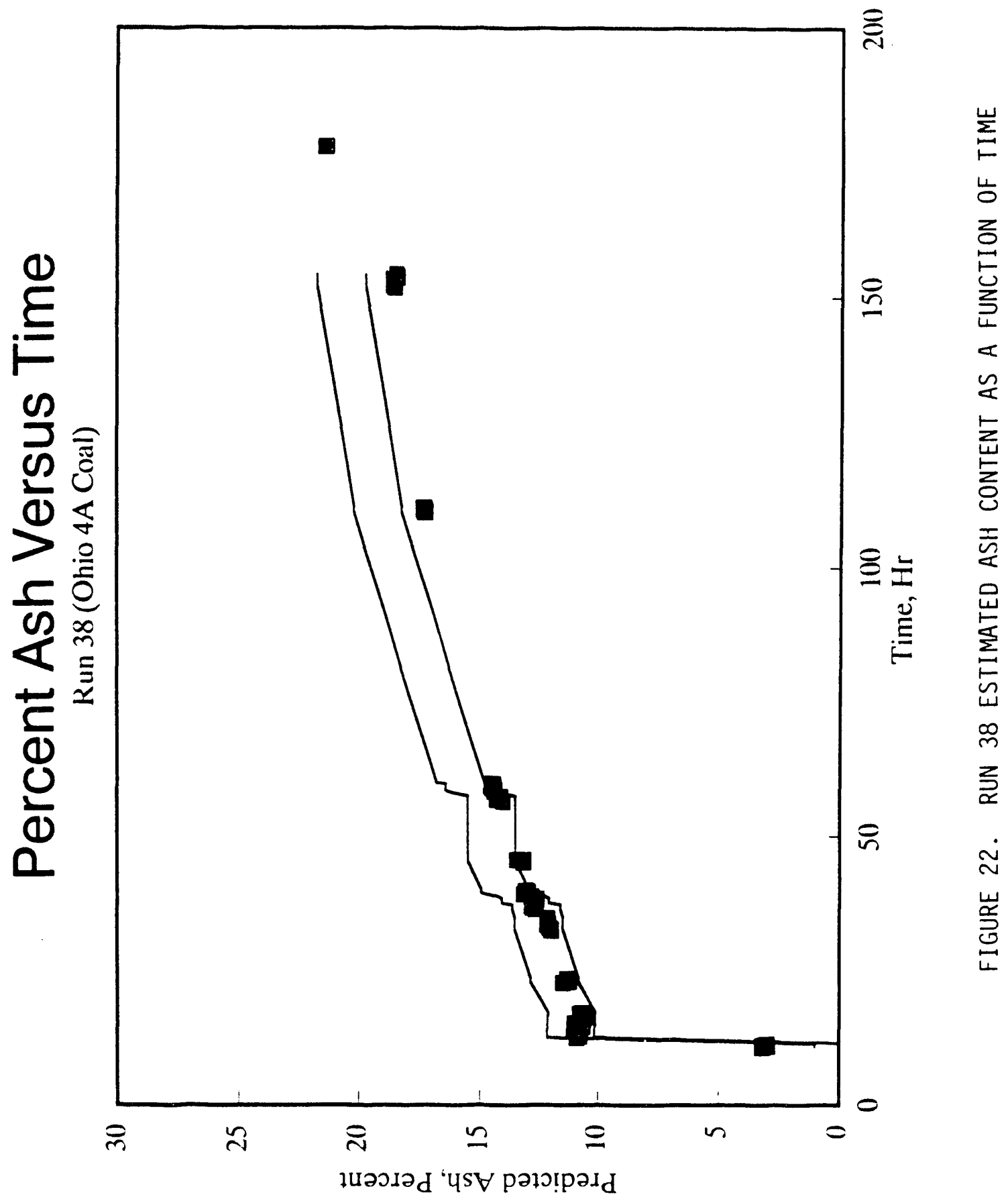


In Runs 40-42, Ohio $4 \mathrm{~A}$ coal was charged to the test loop system. Ash levels ranged from 10 to 16 percent and percent solids 10 to 20 percent. Ash levels were increased by the addition of $\mathrm{Fe}_{2} \mathrm{O}_{3}$. In addition, primarily for PGNAA analysis purposes, sulfur and sodium chloride were also added. The results for those runs were noted in the beginning of this section on ash. Standard error, using the Run 37 coefficients and a prediction equation based on Formula No. 1, was 0.98 percent ash. The bias was -0.04 percent ash. Correlating the Run 40-42 data using Formula No. 1 format, the standard error was reduced slightly to 0.91 percent ash. This indicated that the data were similar to those generated in Runs 37 and 38 .

Through further theoretical evaluation, several additional formulas were devised and evaluated based on the Run 40-42 data (see Table 4). Using the data, prediction standard error of 0.58 and 0.14 percent ash, for an uncorrected and an iron-corrected prediction formula, respectively, were developed.

These results are shown graphically in Figure 23 .

Run 43. Run 43 was conducted with high ash (i.e., 50 percent ash) refuse, referred to as "gob" from the cleaning of Ohio $4 \mathrm{~A}$ coals. This material was first added to the test loop at 5, 10, and 15 percent solids, and then cleaned Ohio $4 \mathrm{~A}$ coal was added to reduce the ash content. Finally, sulfur was added. The purpose of the run to see if an accurate prediction equation could be developed for the broad 10 to 50 percent ash range representing Runs 40-43. As noted in the beginning of this section, the best correlation; including both iron and sulfur corrections, produced a standard error of only 4.6 percent ash. Run 43 data alone, using the same equation, was correlated with an 0.81 percent ash standard error. The results for the Runs 40-43 correlation are shown in Figure 24, and Run 43 is shown in Figure 25 . 


\section{Predicted vs Assay Ash}

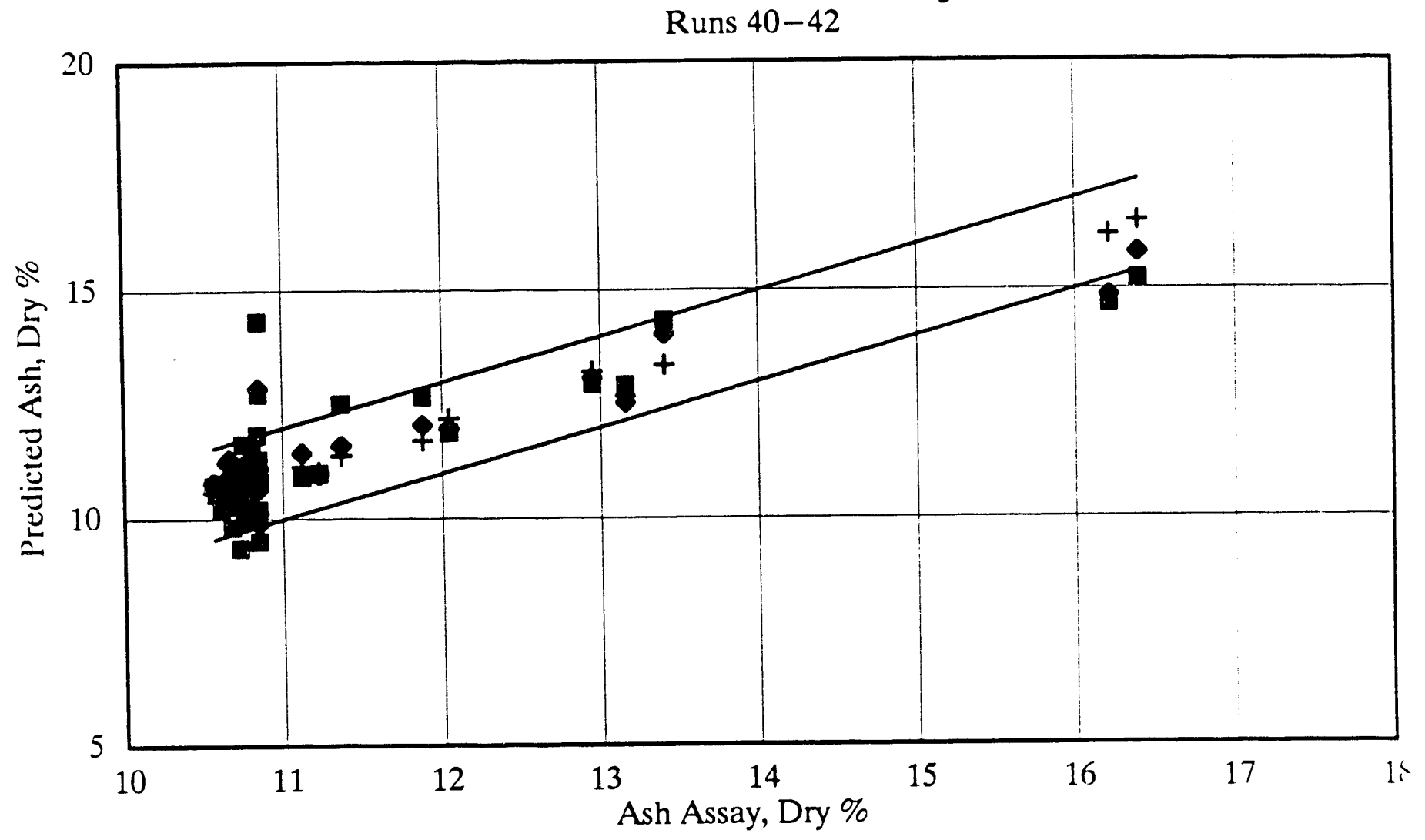

- Basis: Run 37 SL/SH Correlation

- Basis: Best DEGG-Only Prediction

+ Basis: Iron Correction, 6 Constant Correlation

FIGURE 23. RUN 40-4.2 PREDICTED DRY ASH CONTENT 


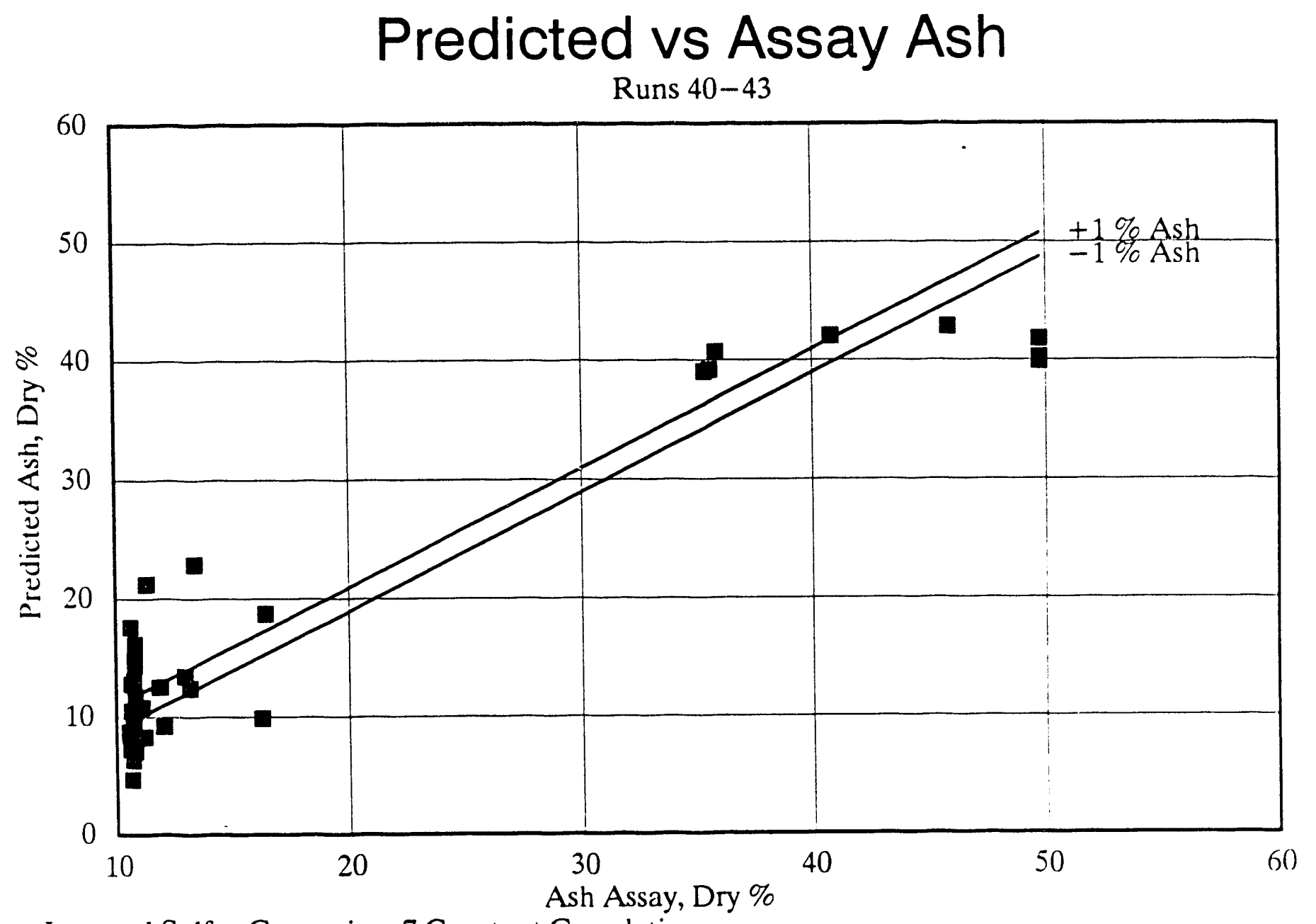

Iron and Sulfur Correction, 7 Constant Correlation

FIGURE 24. RUN 40-43 PREDICTED DRY ASH CONTENT 


\section{Predicted vs Assay Ash}

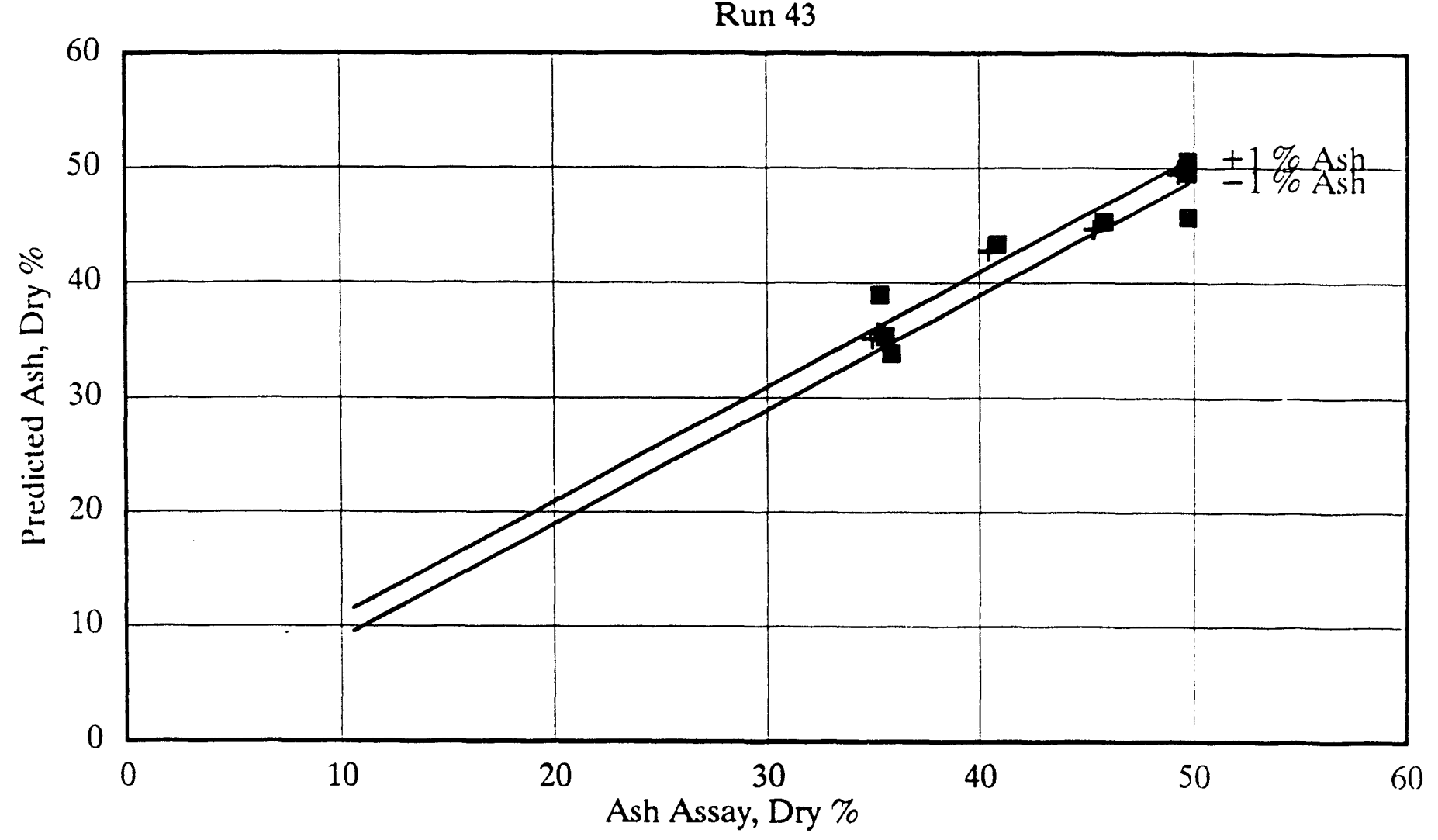

- Basis: Best DEGG-Only Correlation

+ Basis: Iron and Sulfur Correction, 7 Constant Correlation

FIGURE 25. RUN 43 PREDICTED DRY ASH CONTENT 


\section{Conclusions}

This project served to establish the ash instrument accuracy and to determine the (1) effects of major slurry properties on DEGG performance, (2) suitability for heavy-media applications, and (3) applicability for flotation applications. Results are summarized below.

Accuracy. The DEGG can be used to predict ash levels with a standard error of 1 percent or less when restricted to narrow ash and ash composition ranges. This meets the projects ash target. Using correction terms for percent solids, iron and/or sulfur derived from the DEGG and PGNAA devices, ash levels can be predicted with a standard error of less than 5 percent over extremely broad ash and ash composition ranges. Thus ash content can be predicied, for a single coal, over a reasonable ash range (representative of typical coal preparation operations) with acceptable accuracy.

Effect of Slurry Properties. The major slurry properties of interest were:

- Ash Level

- Sulfur Level

- Percent Solids

- Iron Content

- Particle Size

- Coal Type.

The effect of each is summarized in Table 5.

Suitability for Heavy-Media Application. The strong effect of iron on the DEGG makes heavy-media applications difficult. It appears the unit is not suitable for analysis of the slurries directly from heavy-media baths or cyclones. However, after the magnetite has been removed from the product or refuse streams (i.e., after the rinse and drain screens) acceptable analysis 
TABLE 5. EFFECT OF SLURRY PROPERTIES ON ASH PREDICTION

Slurry

Property

Effect

Ash Level

Sulfur Level

Percent Solids

Iron Content

Particle Size

Coal Type
The DEGG and PGNAA could be used to estimate ash content with a standard error less than 1 percent $(0.15$ to 0.9 percent) depending on the correlation method selected) over ash levels typically encountere in advanced and conventional cleaning processes, e.g. 5 to 20 percent ash and 30 to 50 percent ash. Separate ash prediction correlations were required for each ash range to maintain prediction error within the projects error target. A single correlation, over a 5 to 50 percent ash level, resulted in standard error of 5 to 10 percent ash.

Varying suifur levels did not significantly affect ash prediction. Adding a sulfur correction term resulted in a slight improvement in ash prediction.

Percent solids levels ranging from 5 to 20 percent, did not dramatically affect ash prediction accuracy, e.g. standard error 0.8 of ash was achieved over this percent-solids range. However, further improvement to 0.6 percent ash error was possible by including a percent solids correction term. Greater error was encountered with extremely low (< 5 percent) solids levels.

Varying levels of iron ( 0.2 to 0.9 percent iron, wet basis in slurry) could be tolerated while keeping ash standard-error levels below 1 percent. Greater accuracy ( 0.15 percent ash) was possible using prediction equations incorporating an iron correction term. Larger standard errors were encountered when much larger iron variations, as between clean coal ( 10 to 17 percent ash, 10 to 15 percent solids, 0 . to 0.9 percent iron, wet basis) and refuse stream (35 to 50 percent ash, 5 to 20 percent solids, 0.2 to 0.7 percent iron, wet basis) were encountered. Results with slurries doped with magnetite $\left(\mathrm{Fe}_{3} \mathrm{O}_{4}\right)$ to simulate heavy-media operations, showed excessively high error levels

Varying levels of particle size, from -20 mesh to -100 mesh, did not noticeably affect ash prediction. Smaller sizes are not anticipated to cause problems. The upper limit was not established, but coal particles $3 / 4$ inch or larger are anticipated to be unsuitable.

Variations in the coal composition between different coal types resulted in standard errors in the range of 2 to 5 percent ash. Individual correlation by coal type was required to achieve standarderror levels below the 1 percent ash target. 
should be possible. Therefore, DEGG control of a heavy-media system should be possible.

Suitability for Flotation Applications. In limited testing, a small quantity of air was added to the loop to simulate flotation froth. The air allowed excessive levels of gamma radiation to reach the detector. Upon addition of air, both the LEGG and HEGG output voltage instantly rose to their maximum 10 volt value. Therefore, the DEGG cannot be used in froth applications. However, the feed to the flotation cell and the tailings under flow, which do not contain excessive air levels, should be readily analyzed. Therefore, DEGG control of a flotation system should be possible.

\section{Percent Solids Results}

\section{Accuracy Achieved}

The HEGG allowed slurry percent solids to be accurately estimated over a wide range of slurry properties. However, it was observed that as ash content, or ash composition varied, percent solids accuracy decreased.

The results from the accuracy improvement evaluation were less dramatic than in the ash prediction case. The various prediction equations evaluated are shown in Table 6. Runs 40-42 were conducted with Ohio 4A coal (see Table 4 for details). The best standard error achieved, without using corrections terms for iron, ash, or sulfur was 0.90 percent solids. The formula used was percent solids

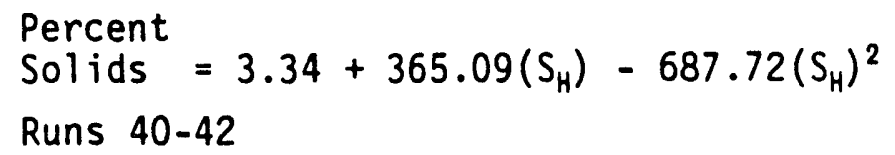

Little improvement was obtained using an iron and/or a sulfur correction formula. Run 43 was made with high ash refuse. It had a much higher overall ash content ( 35 to 50 versus 10 to 16 percent ash). It was, as expected, more difficult to satisfactorily include with the Run 40-42 data base. The best 


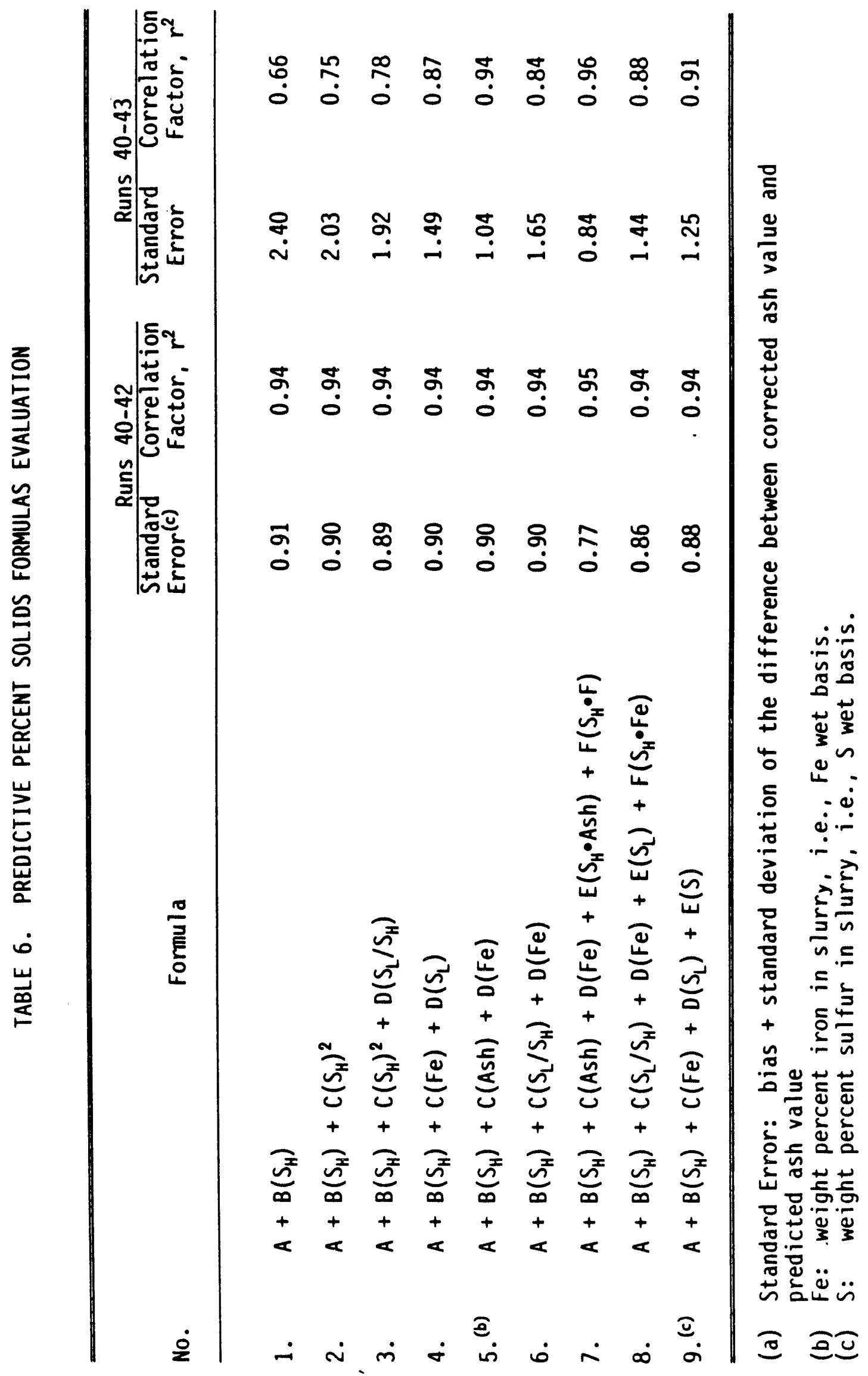


level achieved, without correction terms, was 1.9 percent solids using Formula No. 3:

$$
\begin{aligned}
& \text { Percent Solids }=8.73+454.48\left(S_{H}\right)-2766.16\left(S_{H}\right)^{2}-1.36\left(S_{L} / S_{H}\right) \\
& \text { Runs } 40-43
\end{aligned}
$$

The standard error was improved to 0.84 percent solids, using the ash and iron correction Formula No. 7:

$$
\begin{aligned}
& \text { Percent Solids }=4.09+361.96\left(\mathrm{~S}_{H}\right)-0.13(\text { Ash })+6.50(\mathrm{Fe})-1.17\left(\mathrm{~S}_{\mathrm{H}}\right)(\text { Ash }) \\
& \text { Runs } 40-43 \\
& -145.97\left(S_{H}\right)(\mathrm{Fe})
\end{aligned}
$$

Since ash is not directly available from the DEGG, $\left(S_{L} / S_{H}\right)$ was substituted. This however did not give similar improvements, as the standard error was 1.44 percent solids. The best Run 40-43 equations (with a 1.25 percent standard error), using available outputs from the DEGG and PGNAA, was Formula No. 9:

$$
\text { Percent Solids }=4.02+497.89\left(S_{H}\right)+9.29(F e)-88.49\left(S_{L}\right)+5.94(S)
$$

where $\mathrm{Fe}$ and $\mathrm{S}$ were the percent iron and sulfur in the slurry, wet basis, respectively. Run 43 alone could be correlated successfully, with a standard error of 0.45 percent solids using Formula No. 3.

Thus, the results indicate that the HEGG, or the DEGG, is capable of percents solids prediction within the project's target ( \pm 1 percent solids) when restricted to a reasonable range (10 to 20 percent solids). With iron and ash, or iron and sulfur, corrections, the instrument can achieve acceptable accuracy over even broader ranges. A standard error of 0.8 to 1.2 percent was obtained with widely varying ash content and ash composition over a 5 to 20 percent solids range. Therefore, the unit is well suited to coal preparation plant requirements. 
While accuracy was the most significant single factor, other factors, which could impact the usefulness of the percent solids analyzer were also studied.

\section{Test Conducted}

A series of tests was conducted to determine the effect of slurry properties on percent solids prediction ability, they were:

Runs 0, 2-4, and 10 Effect of percent solids levels, ash
composition, and coal type
Effect of percent solids levels and coal type
Runs 24 and $25 \quad \begin{aligned} & \text { Effect of magnetite } \\ & \text { Effect of percent solids levels, ash } \\ & \text { composition, sulfur content, and chlorine } \\ & \text { content } \\ & \text { Runs } 40-42\end{aligned}$
$\begin{aligned} & \text { Effect of time, percent solids levels and ash } \\ & \text { levels } \\ & \text { Effect of percent solids levels, ash levels, } \\ & \text { composition, and sulfur content. }\end{aligned}$

Each is briefly discussed below.

Runs $0,2-4$, and 10 . In this series of runs, the calibration equation generated in Run 0 , with cleaned Ohio $4 A$ coal, was applied to a new test with Otio 4A cleaned coal (Run 2), Illinois No. 6 coal (Run 3), Kentucky Elkhorn coal (Run 4), and the higher ash raw Ohio 4A coal (Rur 10). Percent solids levels ranged from 1 to 20 percent while ash levels ranged from 5 percent (Elkhorn) to 10 percent (Ohio and Illinois No. 6) to 20 percent (raw Ohio 4A). The results, shown in Figure 26, show good agreement for all coals based on the correlation equation.

$$
\text { Percent Solids }=0.6364+454.54\left(S_{H}\right)
$$

The standard error for Ohio $4 \mathrm{~A}$ coal alone was about 0.5 percent. Applied to the three other coals over the broad range displayed in Figure 26 , the 


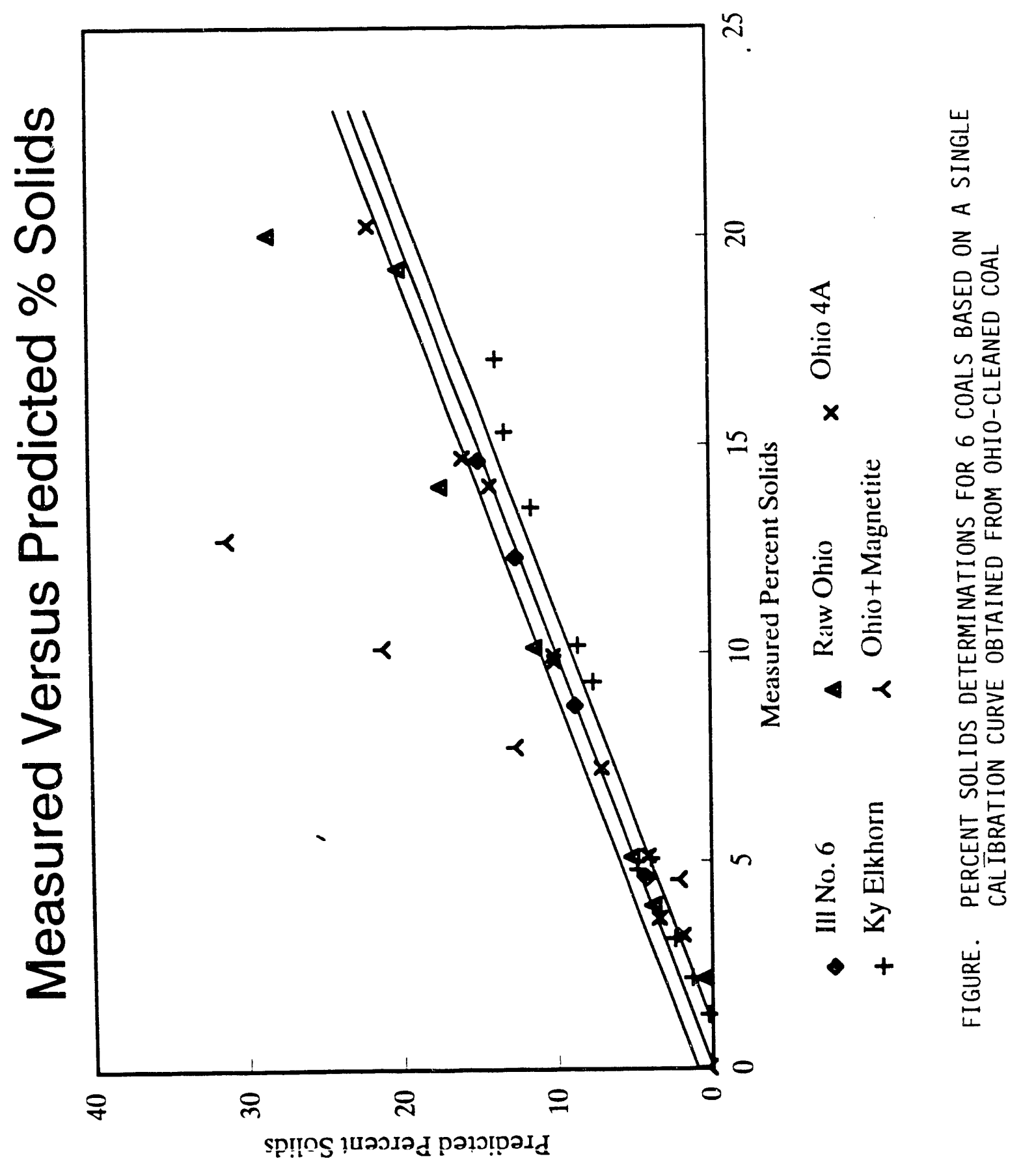


standard error was 1.5 percent. Thus, the percent solids equation is slightly coal (i.e., composition) sensitive.

Run 24 and 25 . Runs 24 and 25 were conducted with Ohio $4 \mathrm{~A}$ and Kentucky Elkhorn coals, respectively. Differing amounts of coal were added to increase the percent solids levels while maintaining the ash levels approximate?y constant ( 1 to 15 percent solids for the 11 percent ash Ohio coal and 3 to 21 percent solids for the 5 percent ash Kentucky coal). Standard errors, using the Run 0 (Ohio 4A) prediction equation, were 0.9 percent ( 0.1 bias plus 0.8 standard deviation) and 1.8 percent ( 1.1 bias plus 0.7 standard deviation) for the Ohio and Kentucky coal, respectively. As found in earlier runs, the lower-ash Kentucky coal resulted in slight over estimation of percent solids. As noted in Figure 27, percent solids were accurately estimated even at the very low 1 to 2 percent solids levels.

Run 26. To evaluate the HEGG for heavy-media applications, a test with added magnetite was conducted. The results, also shown in figure 26 , showed large error in predicted percent solids. Therefore, it was concluded the HEGG was unsuitable for high-magnetite streams.

Runs 37-38. These tests were conducted with Ohio 4A coal with the addition of high-ash Pennsylvania-coal refuse to alter the percent solids and ash levels. Without accounting for ash content the percent solids error was 1.1 percent for Run $37(0.7$ bias +0.4 percent standard deviation of the residuals) and 1.5 for Run 38 ( 1 percent bias and 0.49 percent standard deviation). Shown in Figure 28 are the predicted percent solids for Runs 37 and 38 based on the Run 0-based formula. Figures 29 and 30 show the predicted percent solids as a function of run time. As in the previous figures, \pm 1 percent of assay target lines are included on the iigures. Nearly all the data (except for the very end of Run 38) fall within these boundaries. However, for both sets of test data, a statistically significant bias between the predicted and ASTM measured percent solids was found. This bias was attributed to varying ash levels. Improved results should be possible using an ash and iron-correction equation, such as shown in Table 6 . 


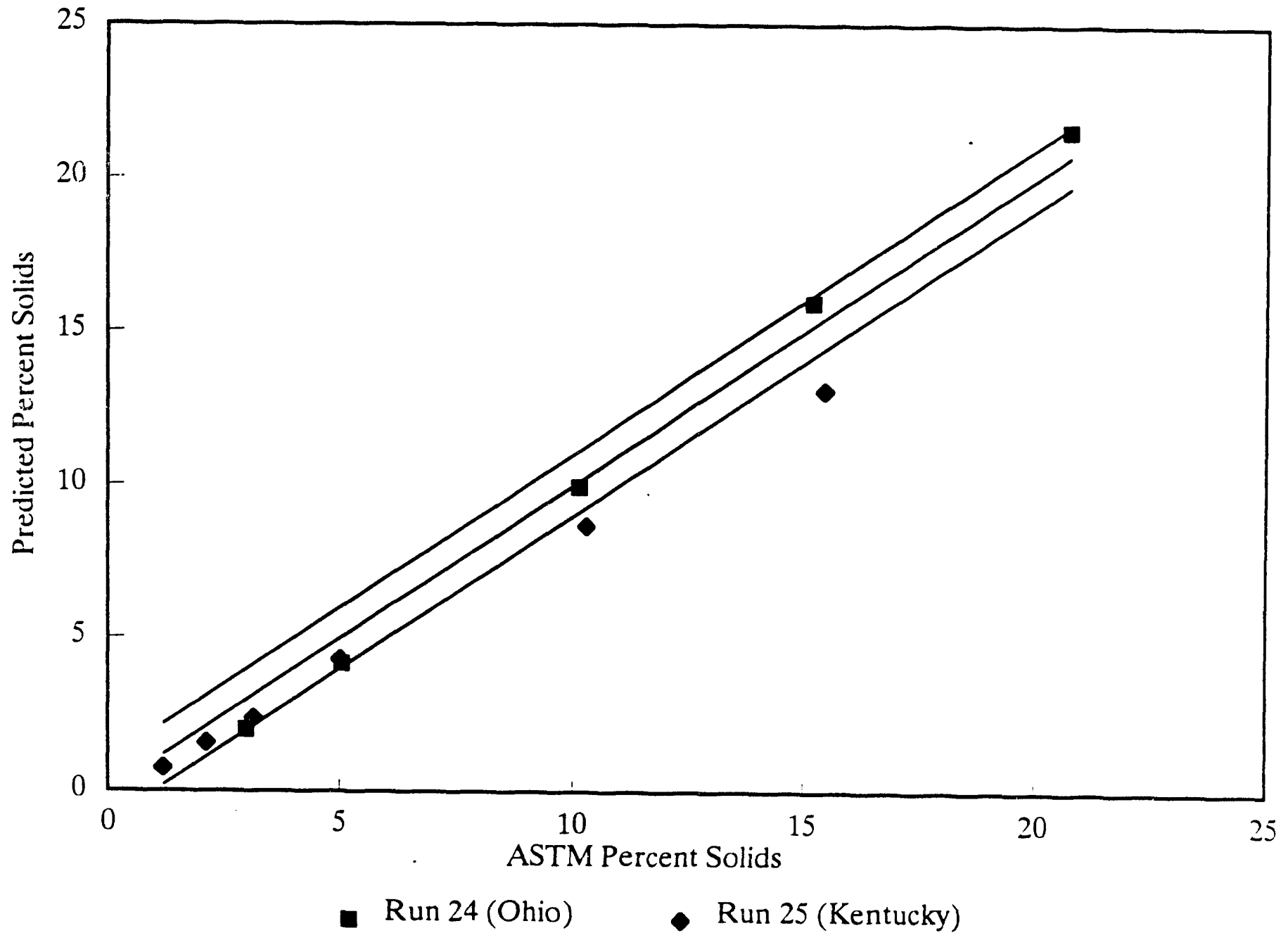

FIGURE 27. PERCENT SOLIDS PREDICTION AT LOW SOLIDS LEVELS 


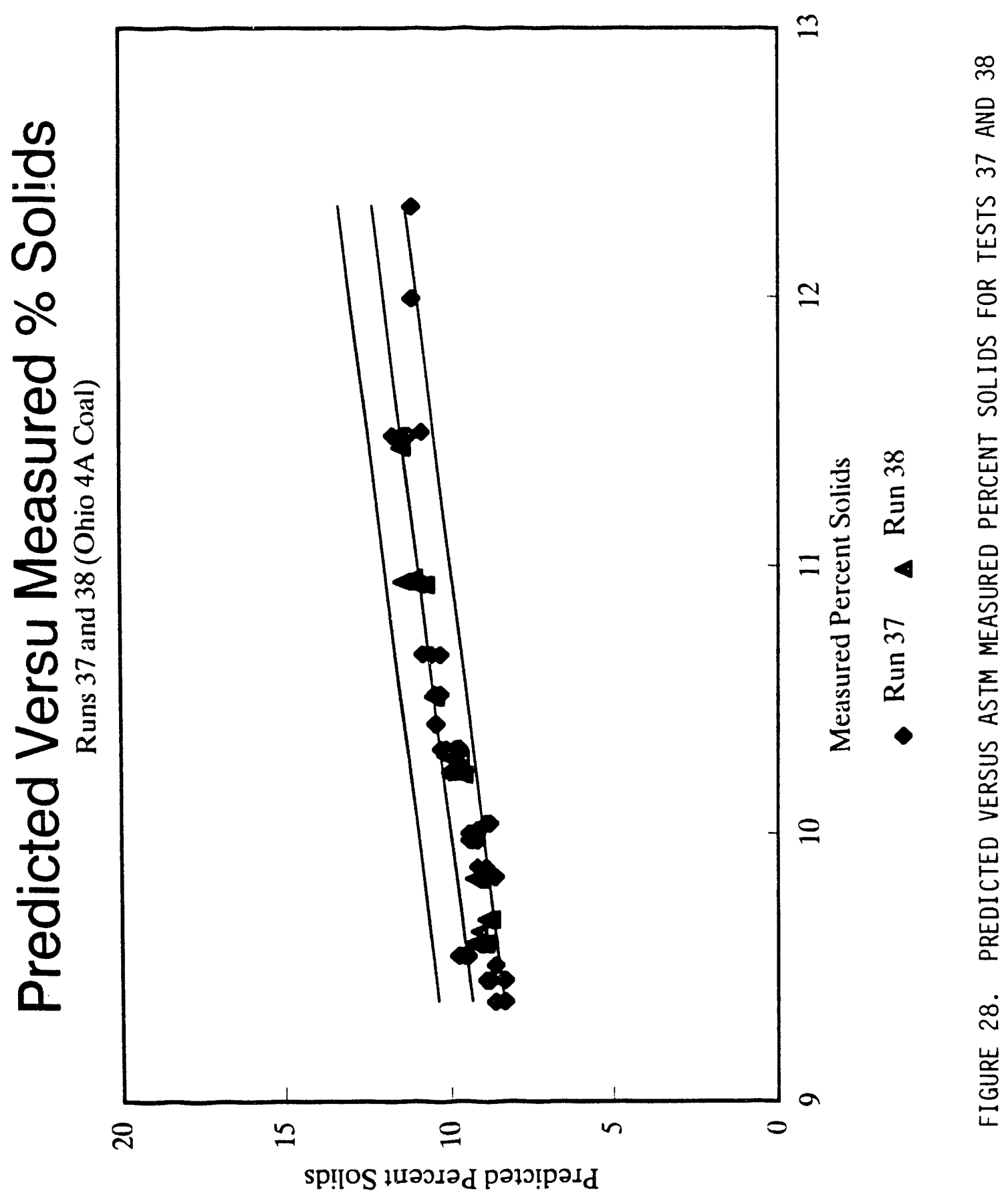




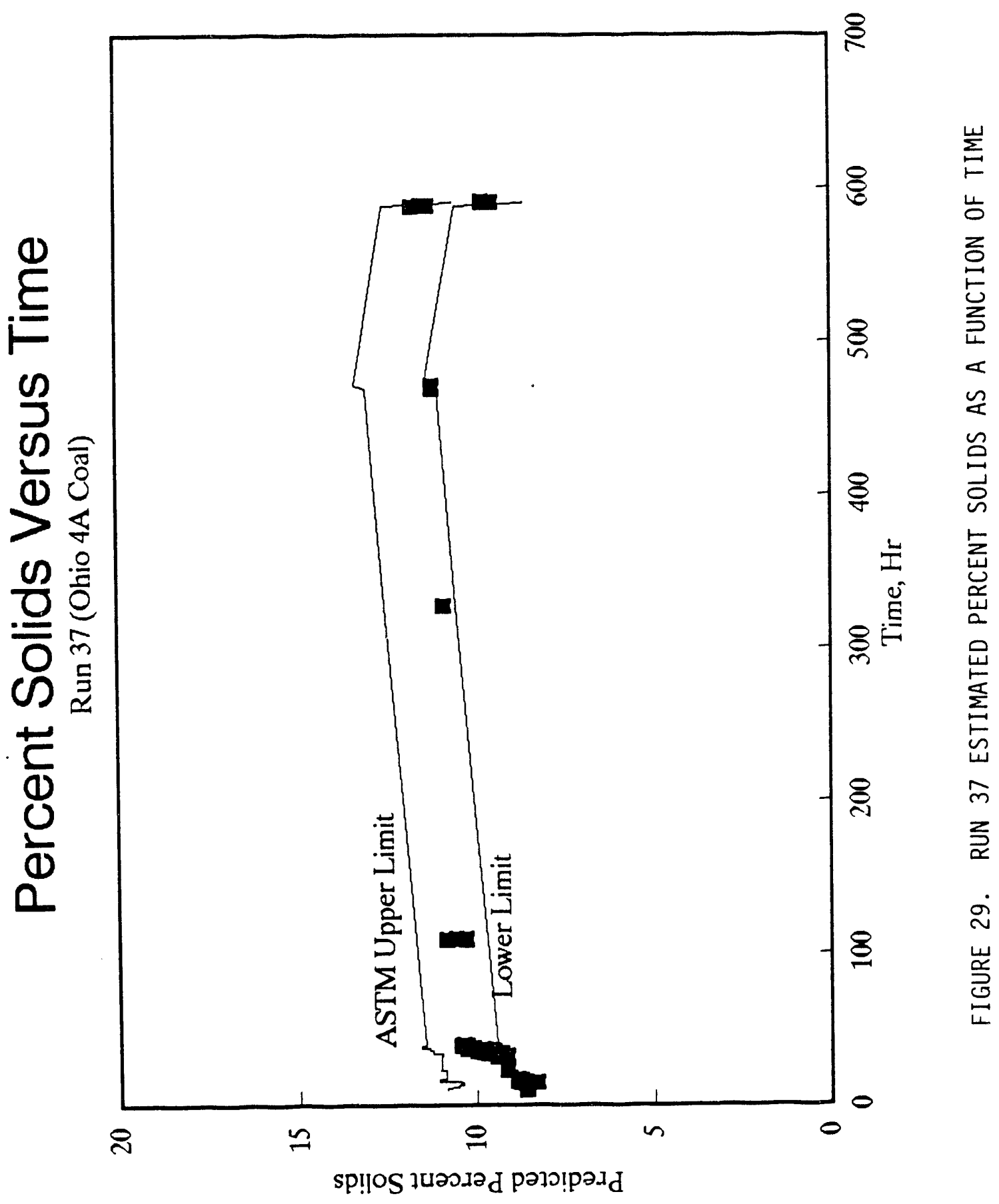




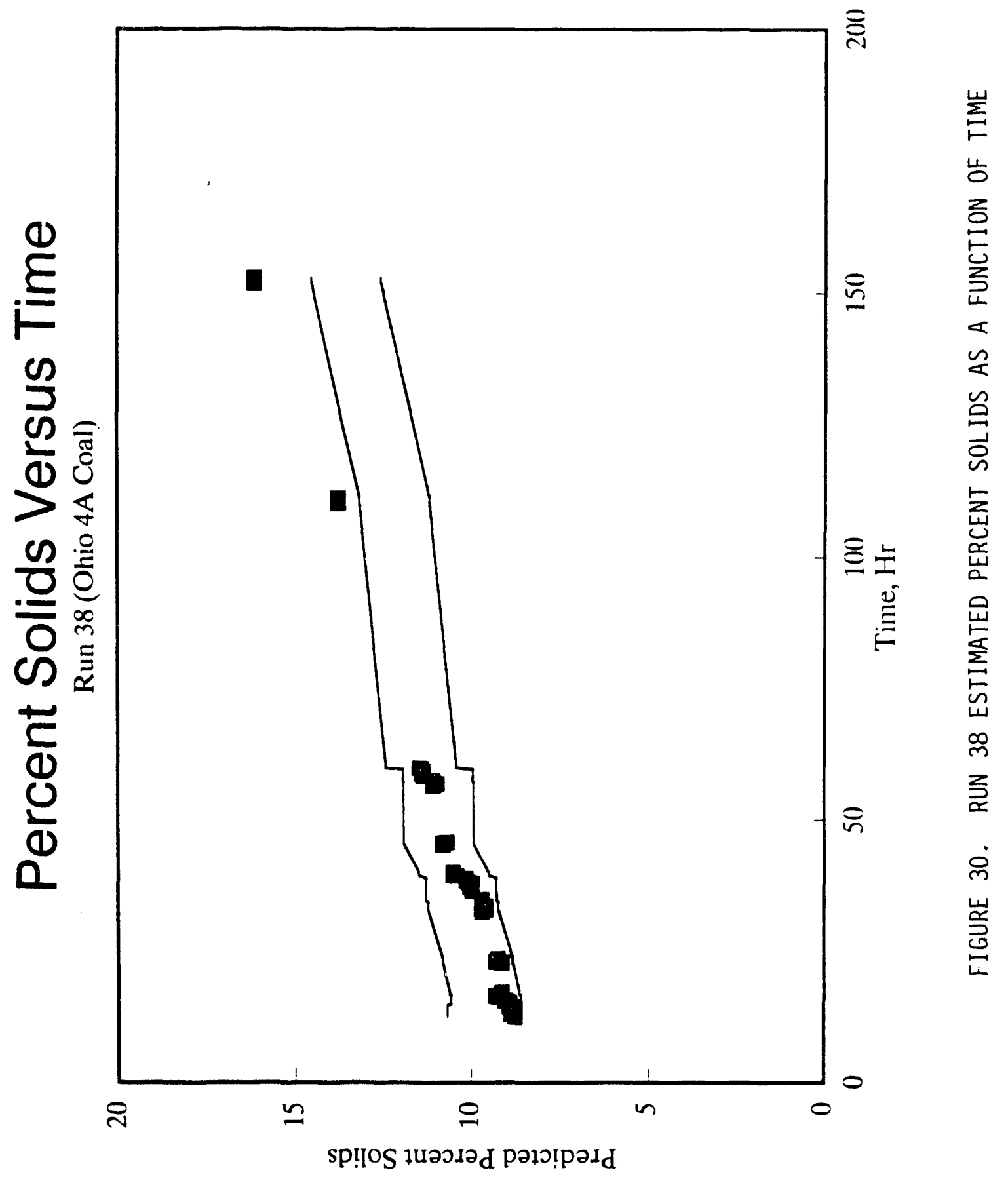


Runs 40-42. These runs were conducted to generate data for accuracy improvement modelling. Thej were conducted with Ohio $4 \mathrm{~A}$ coal at varying percent solids $(5-20)$, ash $(10-16)$, sulfur (3-6), iron (2-7), and chlorine levels. The levels were changed by the addition of coal, sulfur, $\mathrm{Fe}_{2} \mathrm{O}_{3}$, and $\mathrm{NaCl}$. The Run 40-42 correlation results showed that percent solids could be accurately projected from the HEGG, DEGG, or PGNAA. Standard error levels were about 0.9 percent solids over these wide composition ranges. The predicted versus assay values are shown in Figure 31.

Run 43. This run was with high ash refuse (gob) from the cleaning of Ohio $4 \mathrm{~A}$ coal. Percent solids levels ranged from 5 to 20 percent while ash varied from 35 to 50 percent. Results of this run showed the standard error range of 0.45 percent. Correlating Runs 40-43 produced a standard error range of 0.8 to 1.2 percent depending on the form of the correlation equation used (see Table 6 for details). The results for Runs 40-43 were also presented in Figure 31.

\section{Conclusions}

This project served to establish the accuracy of the percent solids instrument and to determine the (1) effect or the major slurry properties on percent solids prediction ability, (2) suitability for heavy-media application, and (3) suitability for flotation applications. Results are summarized belov:

Accuracy. The HEGG device can be used to predict solids level with a standard error of 1 percent or less over reasonable percent solids, ash, and ash composition ranges. This meets the project target for solids. Using corrections for ash, iron, and/or sulfur derived from the DEGG and PGNAA devices, percent solids levels can be predicted with a standard error of less than 1 percent over broad percent solids, ash, and ash composition ranges. 


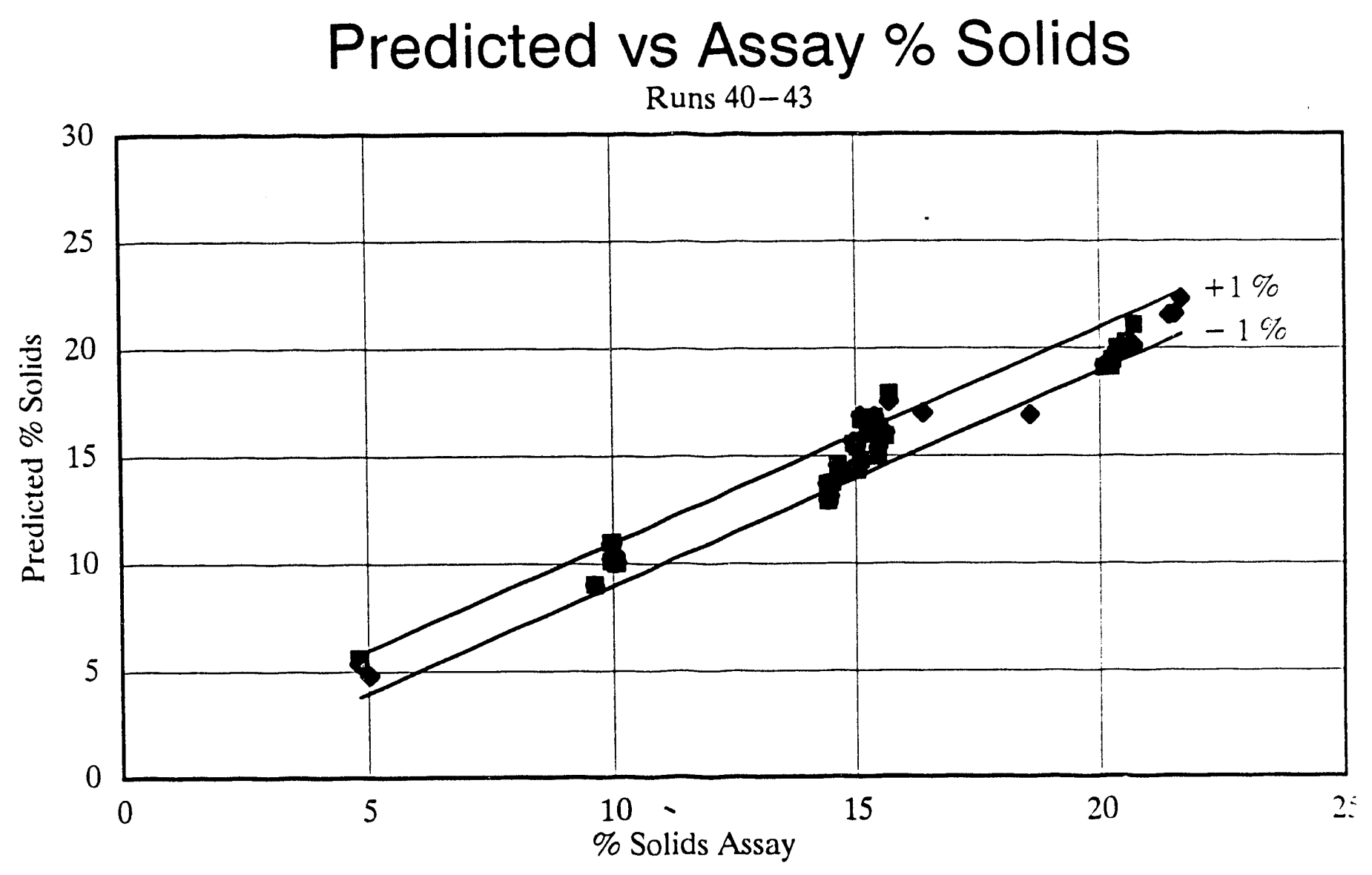

40-42: Best DEGG - Only Correlation

- Run 40-42

- Run 40-43

40-43: Iron Correction with 6 Constant Correlation

FIGURE 31. PREDICTED PERCENT SOLIDS FOR RUNS 40-43 
Effect of Slurry Properties. Of the major slurry properties of interest, only ash composition had a major effect. The unit could be successfully applied over reasonable ash and ash-composition ranges using only the HEGG nutput. This could be expanded to a broader range by including corrections for ash, iron, and sulfur. More details are provided in Table 7.

Suitability for Heavy-Media Application. Like the ash prediction unit, direct analysis of high-magnetite streams produced unacceptably high errors levels. However, by analysis of the product or refuse after magnetite removal, the unit should be able to control heavy-media operations.

Suitability for Flotation Applications. Again, like the ash unit, frothy streams cannot be analyzed. Control should be possible, however, by analysis of the low-air feed and/or tailing streams.

\section{Sulfur Results}

\section{Accuracy Achieved}

The PGNAA unit allowed slurry sulfur levels (dry basis) to be estimated with a standard error within the project's revised sulfur target of \pm 11 percent of true-value sulfur target. (The revised target was defined by the reproducibility limit of ASTM technique D4239.) The unit could not meet the initial \pm 0.2 percent sulfur target based on the ASTM D3177 reproducibility limits. In addition, it was observed that variations in the slurry percent solids, iron, and chlorine levels resulted in reduced sulfur accuracy.

The results of accuracy improvement evaluations were dramatic. The various prediction equation/procedures evaluated are shown in Table 8 . Runs 40-43 (see Table 2 for test details) provided the basis for the final correlation equations. The best standard error achieved was \pm 0.52 percent dry sulfur. The formula was 
$\begin{aligned} & \text { Wet Sulfur, percent }=-0.718-8.89 \times 10^{-5}\left(\mathrm{H}_{\text {counts }}\right)-1.07 \times 10^{-5}\left(\mathrm{~S}_{\text {counts }}\right) \\ &-2.43 \times 10^{-5}\left(\mathrm{Cl}_{\text {counts }}\right)+3.97 \times 10^{-5}\left(\mathrm{Fe}_{\text {counts }}\right) \\ & \text { Sulfur, dry percent }=\text { Sulfur, wet percent } /(\text { percent solids } / 100)\end{aligned}$

TABLE 7. EFFECT OF SLURRY PROPERTIES ON PERCENT SOLIDS PREDICTION

Slurry

Property Effect

Ash Level

Sulfur Level

Percent Solids

Iron Level

Particle Size

Coal Type
Minor effect over 5 to 40 percent range with constant ash compositior levels

Minor effect over 1 to 5 percent sulfur.

The HEGG, DEGG, or PGNAA could be used to predict percent solids with a standard error less than 1 percent $(0.5$ to 0.9 percent, depending $c$ the correlation method selected) over a reasonably broad range of percent solids ( 5 to 20 percent), ash, and ash composition. The rang could be broadened to cover 10 to 50 percent ash level, while maintaining acceptable accuracy, by including correlations for ash, iron, and sulfur levels.

Varying levels of iron ( 0.2 to 0.9 percent iron, wet basis in slurry) had only a minor effect. Larger variations, as experienced with magnetite caused unacceptably large errors.

Varying particle size, -20 mesh, and -100 mesh, had minimal impact. Smaller sizes should also be acceptable. Particle size upper limit has not been identified, but particles larger than $3 / 4$ inch are anticipated to be unacceptable.

Variation in coal type caused minor variations--tied to ash composition differences. Coal-by-coal correlations, or ash and ironcorrection equations, should allow acceptable accuracies. 


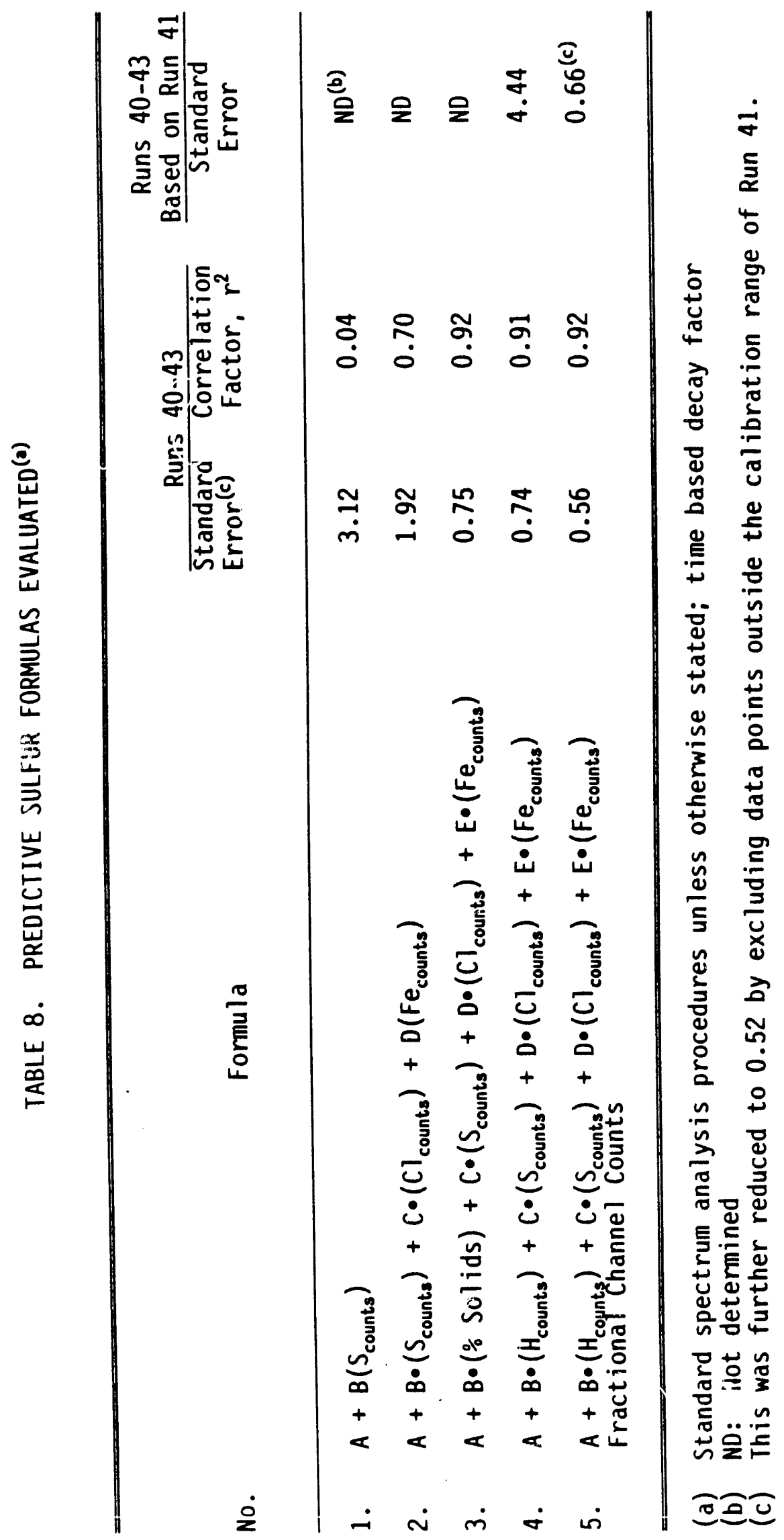


where $\mathrm{H}_{\text {counts, }} \mathrm{S}_{\text {counts, }} \mathrm{Cl}_{\text {counts, }}$ and $\mathrm{Fe}_{\text {counts }}$ were the PGNAA counts obtained for hydrogen, sulfur, chlorine, and iron. The counts were obtained from the "complex" spectral analysis procedure described in Section 2 and expressed on a water-subtracted basis. As noted, several techniques for sulfur correlation were studied. When the coal composition remained constant, $S_{\text {counts }}$ alone were found directly proportional to slurry sulfur content. However, as composition changed, as between coals, or by the addition of additives to the same coal, sulfur counts alone failed to provide an adequate basis for sulfur prediction. The use of hydrogen, chlorine, and iron in addition to sulfur allowed more accurate sulfur predictions. The results indicated that the sulfur analyzer was capable of predicting sulfur within the project target $(0.03+0.11$ true sulfur content) over a dry sulfur range 3 to 6 percent. Further improvement may be required for certain coal preparation applications.

Correlation of iron data lagged that of the sulfur effort. Until a reliable sulfur prediction procedure was developed, efforts to develop a procedure for the more-difficult-to-predict iron were postponed. Using the Run 40-43 data, the best iron standard error was 0.08 percent wet iron in the slurry. The prediction formula was

$$
\begin{aligned}
& \text { Wet Iron, percent }=0.0211-2.51 \times 10^{-6}\left(\mathrm{H}_{\text {counts }}\right)-1.13 \times 10^{-4}\left(\mathrm{~S}_{\text {counts }}\right) \\
& +1.15 \times 10^{-4}\left(\mathrm{Cl}_{\text {counts }}\right)+2.02 \times 10^{-4}\left(\mathrm{Fe}_{\text {counts }}\right) \\
& \text { Iron, dry percent }=\text { Iron, wet percent } /(\text { percent solids } / 100)
\end{aligned}
$$

where $\mathrm{H}_{\text {counts, }} \mathrm{S}_{\text {counts, }} \mathrm{Cl}_{\text {counts, }}$ and $\mathrm{Fe}_{\text {counts }}$ were the PGNAA counts obtained for hydrogen, sulfur, chlorine, and iron using the "complex" spectral analysis procedure and expressed on a water-subtracted basis.

\section{Test Conducted}

A series of tests were conducted to determine the effect of slurry properties on sulfur and iron prediction ability, they were: 
Run 4

Run 15

Run 24

Run 25

Runs 28-33, 36, and 39

Runs 34-35

Runs $37-38$

Runs $40-43$
Effect of slurry sulfur content, Kentucky coal Effect of rapid calibration procedure Effect of slurry sulfur content, Ohio coal Effect of slurry sulfur content, Kentucky coal Effect of $\mathrm{Si}, \mathrm{Al}, \mathrm{C}, \mathrm{Fe}, \mathrm{S}, \mathrm{Cl}, \mathrm{N}$ on PGNAA response

Effect of sulfur and ash content, Ohio coal Effect of variable ash, percent solids and sulfur levels, Ohio level

Effect of variable ash, percent solids, sulfur, iron, and chlorine levels, Ohio coal.

Each is discussed briefly below.

Run 4. In this initial PGNAA test, low-sulfur Kentucky Elkhorn coal was tested by adding progressive amounts of coal into the slurry test loop. As percent solids were increased from 5 to 9 to 14 to 17 percent, so did the slurry sulfur content (while the dry coal sulfur, ash, and dry ash composition levels remained constant). A plot of wet sulfur content versus raw sulfur counts found in Channel 218 is presented in Figure 32. Clearly an excellent inear correlation could be derived from such data. Iron data and iron counts were similarly compared, but with poorer correlation. It appeared that iron would be more difficult to accurately predict. Further testing, to be discussed below, showed that single element correlations were inadequate for both sulfur and iron.

Run 15. In this run a rapid PGNAA calibration procedure was tested. Slim plastic boxes ( 1 -inch $\times 5$-inch $\times 3$ feet long) were filled with varying levels of sulfur, iron, carbon, or chlorine salt and lowered into the test 100p, irradiated, and the PGNAA spectrum obtained. The procedure was not found to be feasible for calibration and abandoned in favor of calibration by charging coal with additives in to the slurry test loop. However, it was learned that a region of the PGNAA spectrum, e.g., 201 to 221 for sulfur, versus the single Channel 218 used in Run 4, provide a better bas is for correlation. 


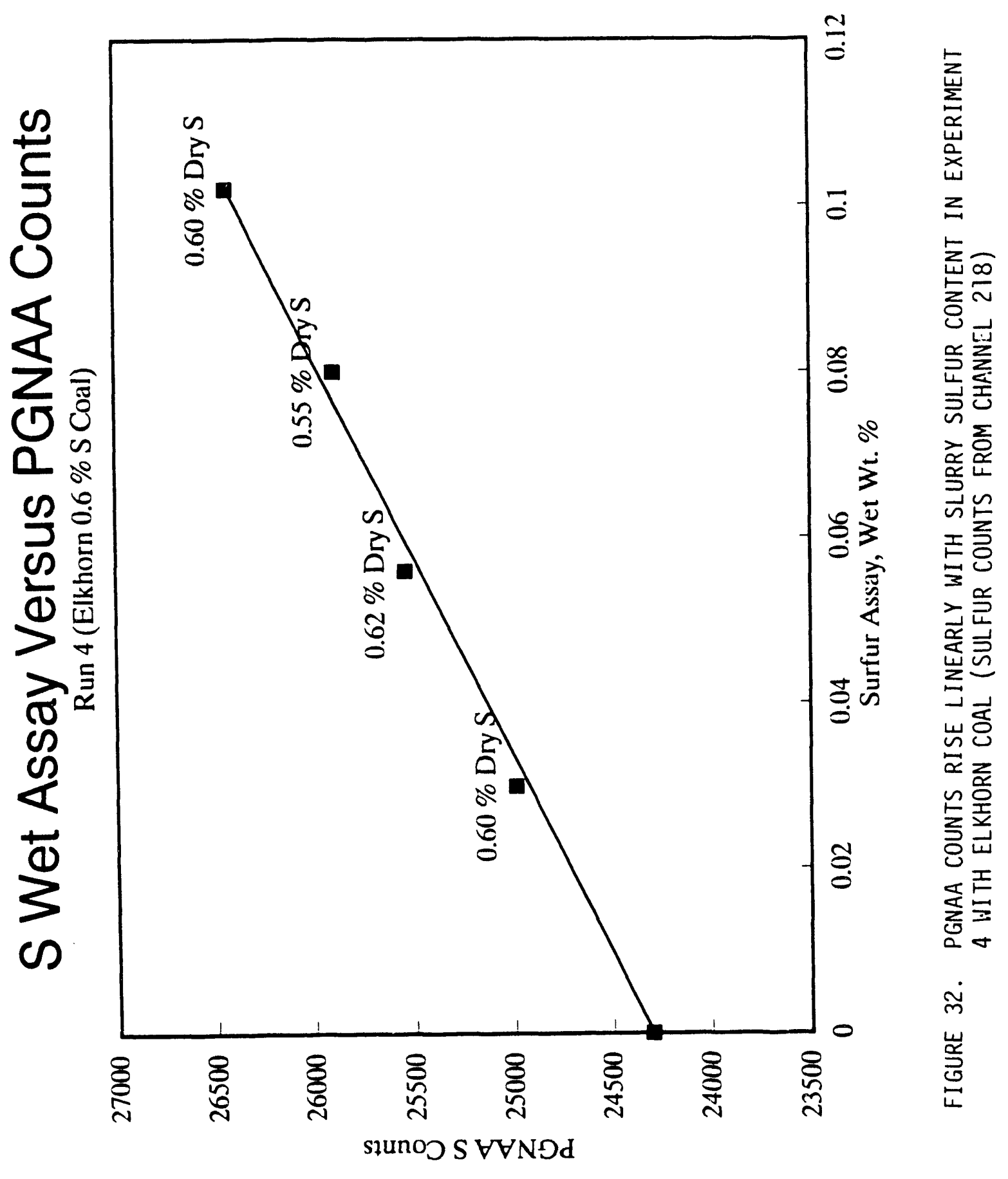


Run 24. In this run, Ohio $4 \mathrm{~A}$ coal was tested at various percent solids levels $(3,5,10,15$, and 20). This allowed the slurry sulfur level to rise while keeping the ash composition in the dry coal constant. Again a good correlation was found between wet sulfur content and sulfur counts determined over the region of interest (ROI) of 201-221. By conditioning the iron data, to account for spectral shift, an improved correlation for iron was also obtained.

Run 25. Run 25 was conducted in a manner similar to Run 4 and 24 , but with Elkhorn coal at 1,2, 3, 5, 10, and 15 percent solids. Again good correlation was found for sulfur. Also, somewhat improved correlation was achieved by conditioning the data to correct for spectral shift. Since both Runs 4 and 25 were conducted with Elkhorn coal, a comparison of their data was of interest. However, due to a change in the way sulfur data was collected, this comparison could not be made. [In Run 4, data was collected from only a single sulfur channel (218) whereas in Run 25, data was collected from a sulfur region (Channels 201-221).]

The correlation constants developed for Run 24 (using the prediction formula: wet sulfur $=A+B \cdot S_{\text {counts }}$ ) were applied to the Run 25 data. No correlation was observed. The broad difference in $S_{\text {counts }}$ and wet sulfur content can be seen in Figure 33. It was determined that a rulti-element correlation would be necessary for accurate sulfur predictions between different coals.

Runs 28-33, 36, and 39. To generate data for providing a multielement correlation, a series of runs was conducted by adding various concentrations of pure elements or compounds into the test loop. Tests 28-33 and 36 were with $\mathrm{SiO}_{2}, \mathrm{Al}_{2} \mathrm{O}_{3}$, graphite (to represent carbon), $\mathrm{Fe}_{2} \mathrm{O}_{3}, \mathrm{H}_{2} \mathrm{SO}_{4}$ (sulfuric acid to generate sulfur data), $\mathrm{HCl}$ (hydrochloric acid for chlorine) and $\mathrm{HNO}_{3}$ (nitric acid for nitrogen), respectively. Run 39 was conducted to establish background spectrum data with the californium source retracted and removed. 


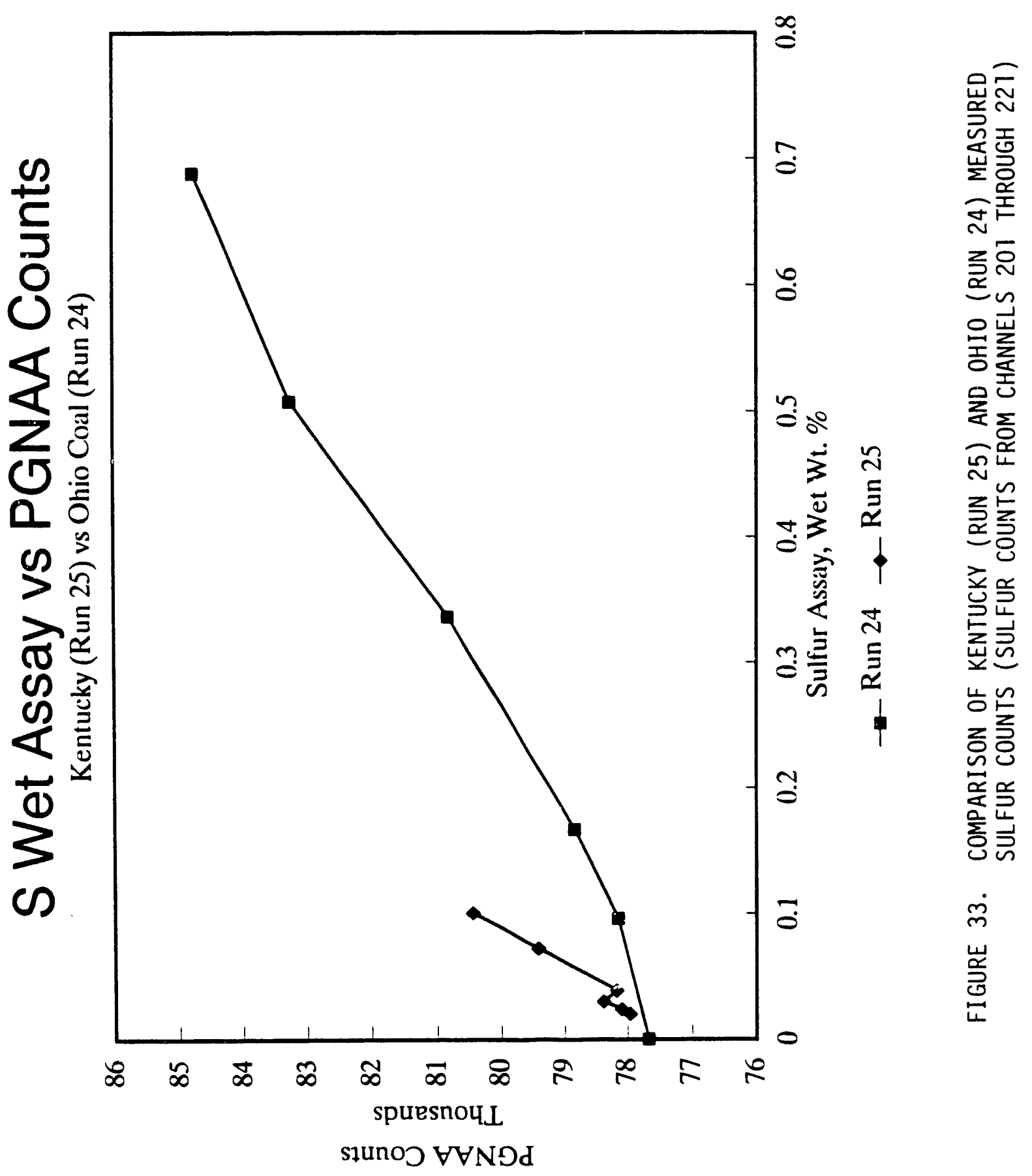


The data indicated a strong PGNAA response with sulfur, iron and chlorine. Little response was observed with carbon, aluminum, silica, or nitrogen. Therefore only $\mathrm{S}, \mathrm{Fe}$, and $\mathrm{Cl}$ were included in subsequent correlations. Based on this new data, sulfur prediction equations were developed and tested with the Run 37 and 38 data. Sulfur prediction accuracy, using only the sulfur-counts data to predict wet sulfur content, was poor. It was concluded that calibration using coal at various ash and sulfur levels would be required.

Runs 34-35. These two runs were conducted with Ohio $4 \mathrm{~A}$ coal to which varying amounts of high-ash refuse were added. In Run 34, the percent solids level was fixed at 5 percent and ash varied from 11 to 25 percent. In Run 35 , the percent solids were allowed to vary $(5,5.5,6$, and 6.5 percent) as a result of the refuse additions which raised the ash from 11 to 25 percent. Using the Run 24 data, based on a prediction formula of wet sulfur = $A+B\left(S_{\text {counts }}\right)$, the dry sulfur contents were predicted. Standard error was 1 to 2 percent dry sulfur, far too high for practical application. It was suspected that the low percent solids level used in those two runs did not provide sufficient signal for accurate analysis (this has been observed in other runs). Therefore, a 10 percent solids levels was set as a minimum slurry concentration for further PGNAA analysis.

Runs 37-38. To provide data for the ash study, Runs 37 and 38 were conducted with Ohiu 4A coal. Refuse was again added to increase the ash and iron levels. The ash ranged from 11 to 21 percent (while percent solids ranged from 9 to 12 percent and sulfur from 3.5 to 3.7 percent). Using the Run 24 correlation $\left[A+B\left(S_{\text {counts }}\right)\right]$, the standard error for Run 37 was 1.1 percent sulfur. It was recognized that while the analyzer could detect changes in the slurry sulfur level (i.e., as the sulfur content increased or decreased so did the sulfur counts) the predicted dry sulfur level was not sufficiently accurate to allow on-line analysis or control. Consultation with others indicated a calibration procedure incorporating wide ranges in sulfur, iron, and chlorine were required. It was concluded that simply varying the slurry wet-sulfur content, by changing the slurry percent solids levels or by 
making only small changes in the sulfur and iron content by adding refuse to the slurry, was inadequate for calibration.

zuns 40-43. In these final four runs, information was gathered to test means of improving the predicted ash, percent solids, sulfur, and iron levels. For Runs 40-42, percent solids were varied from 10 to 20 percent by adding Ohio $4 \mathrm{~A}$ coal; ash from 11 to 16 percent by the additions of $\mathrm{Fe}_{2} \mathrm{O}_{3}$; sulfur from 0.2 to 0.9 percent, wet basis, by the addition of powdered elemental sulfur; and chlorine from 0.006 to 0.017 , wet basis, by the addition of sodium chloride ( $\mathrm{NaCl}$ ). In Run 43, the starting material was 50 percent ash refuse (referred to a gob) from the cleaning of Ohio $4 \mathrm{~A}$ coal. Percent solids were increased by adding gob ( 5 to 15 percent), the ash lowered by adding clean Ohio 4A coal, (ash ranged from 30 to 35 percent), and sulfur increased from 0.1 to 0.9 percent, wet basis, by the addition of powdered sulfur.

Initial correlation of the new data followed the following equation: Wet sulfur, $\%=A+B \cdot\left(S_{\text {counts }}\right)+C \cdot\left(C l_{\text {counts }}\right)+D\left(\mathrm{Fe}_{\text {counts }}\right)$

An improvement in the prediction accuracy was observed, as the standard error dropped to 1.9 percent. However, it appeared that the prediction accuracy dropped for points of low or high percent solids. A further parameter, percent solids was added to the correlation to compensate for this effect. Standard errors dropped significantly to 0.75 percent dry sulfur. However, since percent solids was not directly produced by the PGNAA, hydrogen counts (which were approximately proportional to percent solids) were substituted for percent solids. Similar or better results were obtained. Therefore, the following correlation equation was tested for each of Runs 40-43:

Wet Sulfur, $\%=A+B *\left(H_{\text {counts }}\right)+C *\left(S_{\text {counts }}\right)+D *\left(\mathrm{Cl}_{\text {counts }}\right) *\left(\mathrm{Fe}_{\text {counts }}\right)$ Correlation factors $\left(r^{2}\right)$ of 0.31 to 0.98 were obtained and the standard error (standard deviation of the difference between the assay values and the predicted values) ranged from 0.11 to 0.46 percent dry sulfur. The results are shown in Table 9. 


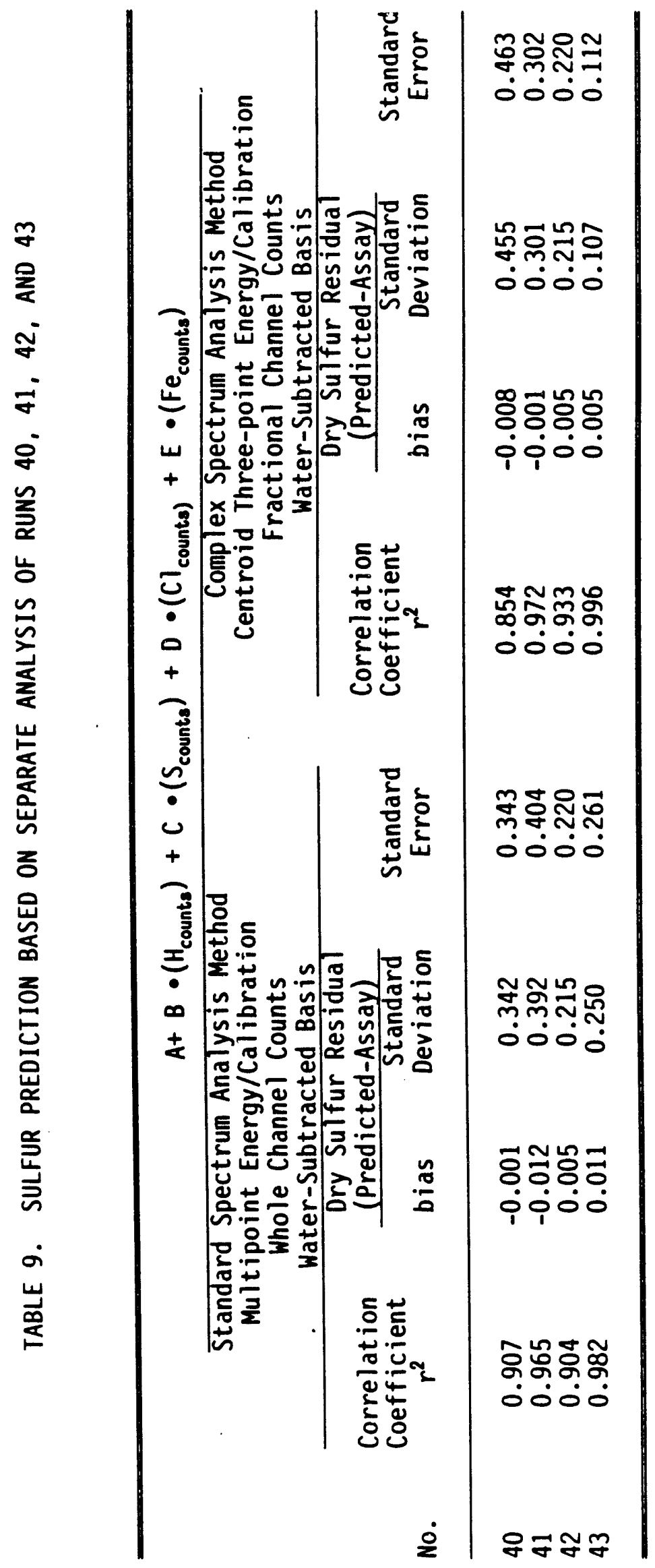


Results using two different spectrum analys is techniques are also shown on Table 9 (see Appendix $B$ for more details of the spectrum analys is techniques). When correlating the data for each run separately, only slight differences in the results obtained.

Next, the data were combined and correlated. Each run was adjusted to a common time basis prior to analysis of the combined data set." In this evaluation, the standard spectrum analys is technique produced a standard error of 0.70 percent dry sulfur using all the data. The complex technique had a standard error of 0.53 percent dry sulfur. In both cases, the bias was negligible, see Table 10.

Finally, the ability to predict unknown values was tested. Run 41 , which had a broad range of sulfur, chlorine, and iron concentrations was selected as the calibration run. (Runs 40 and 43 were not selected as the correlating run since they covered relatively narrow range, and Run 42 was not selected since it was used to test the effect of extreme levels of chlorine and iron.) The wet sulfur content for Runs 40,42 , and 43 were predicted using the following formula:

Wet Sulfur, $\%=-0.718-8.89 \times 10^{-5}\left(\mathrm{H}_{\text {counts }}\right)-1.07 \times 10^{-5}\left(\mathrm{~S}_{\text {counts }}\right)$

$$
-2.43 \times 10^{-5}\left(\mathrm{Cl}_{\text {counts }}\right)+3.97 \times 10^{-5}\left(\mathrm{Fe}_{\text {counts }}\right)
$$

- The PGNAA nuclear source, californium-252, rapidly decays with time. Its half life is about 2.55 years. Therefore, the number of neutrons emitted decreases with time, dropping approximately in half every 2.55 years. Runs conducted on different days were adjusted using a formula based on half life and time since the base run. The initial, water-only hydrogen counts for different runs followed approximately, but not exactly, this relationship. An alternative adjustment technique studied was to ratio the water-only $H_{\text {counts }}$. The methods to adjust for californium decay, one based on elapsed time and half life, and one based on the initial, water-only hydrogen counts ratio, were tested:

Corrected Counts tine basis $=\left\{e^{7.444 \times 10^{-4}} \times t\right.$ (days since base run) $\} \times$ Counts, Corrected Counts H-ratio basis $=\left\{\frac{H_{\text {counts }} \text {-water only for Test } i}{H_{\text {counts }} \text {-water only, for base test }}\right\} \times$ Counts

Results with the two different decay correction techniques were almost identical. 


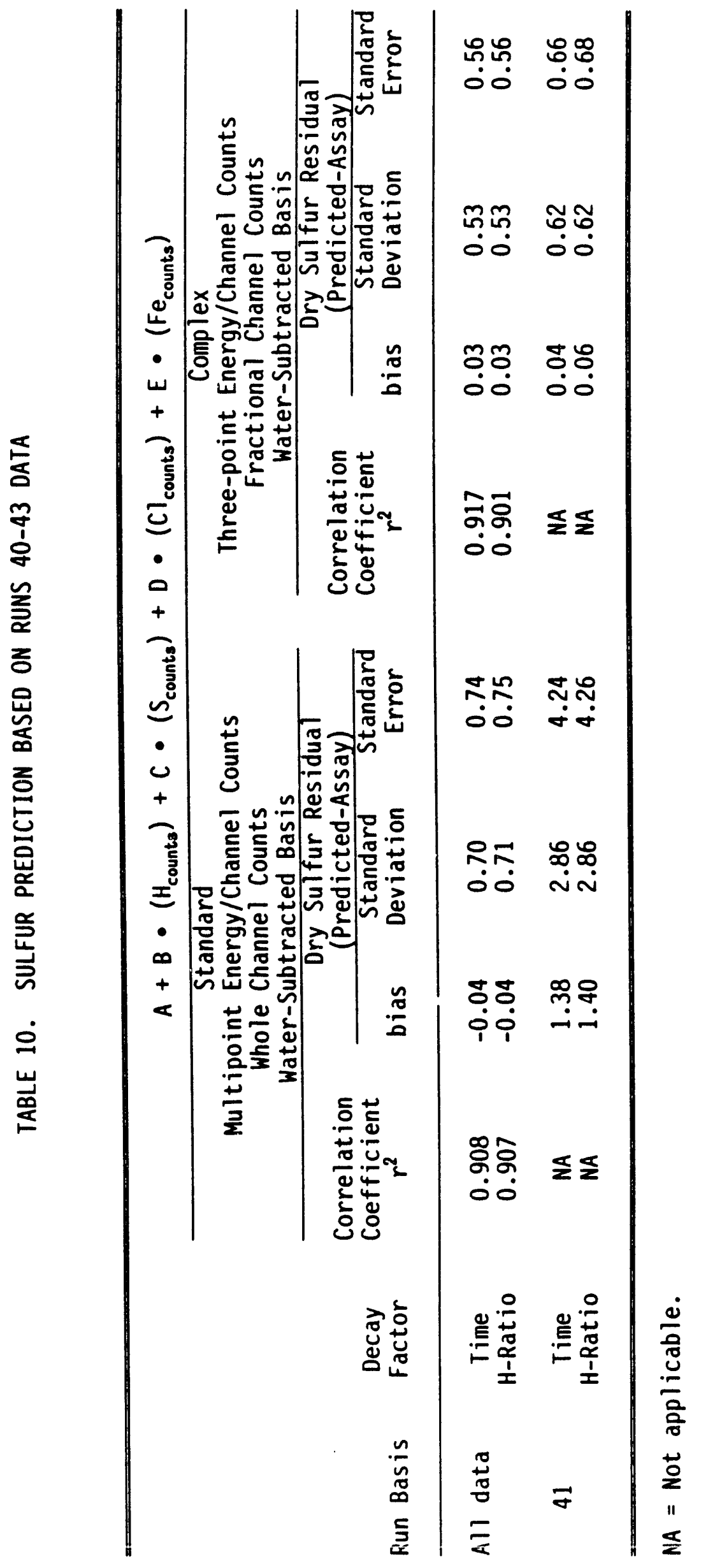


where "counts" data were determined by the complex spectrum analyses technique, and were expressed on a water-subtracted basis. (Note, on this basis $H_{\text {counts }}$ were negative numbers, see Appendix $B$ for details.)

The predicted wet sulfur content was then converted into its dry sulfur value (by dividing by percent solids). As shown in Table 10, the predicted dry sulfur had a bias of 0.04 percent and a standard error of 0.62 percent sulfur (using the complex spectrum analysis technique and a half life/time decay factor). Significantly poorer results (4.44 versus 0.66 percent standard error) were achieved using the standard spectrum-analys is technique. This standard error, 0.66 percent, was slightly below the project sulfur target. Sulfur predictions for Runs 40-43, with error bands noted, are shown on Figure 34. Most of the points fall within the acceptable reproducibility bounds.

Analysis of Figure 34 indicated that while most points fall within the bounds, there were several "outliers." Further analysis indicated that two of these outliers were at low slurry percent solids. Earlier testing indicated that there was insufficient signal present to allow analys is of 1 to 5 percent solids streams. Other outliers corresponded to chlorine or iron levels outside of the calibration run (Run 41) levels. As with most analytical devices which were calibrated using an external standard, results predicted for conditions outside the calibration conditions are unreliable. Therefore, it was reasonable that the PGNAA system should not perform well under extrapolative conditions. These out-of-the-calibration-range points could reasonably be removed from the evaluation. A new plot of the predicted sulfur levels with these points removed from the data base is shown in Figure 35. Under these conditions, the bias was 0.04 percent, and the standard error dropped to 0.52 percent dry sulfur--within the project's sulfur target. All but three points fell within or on the 04239 reproducibility target bounds. 


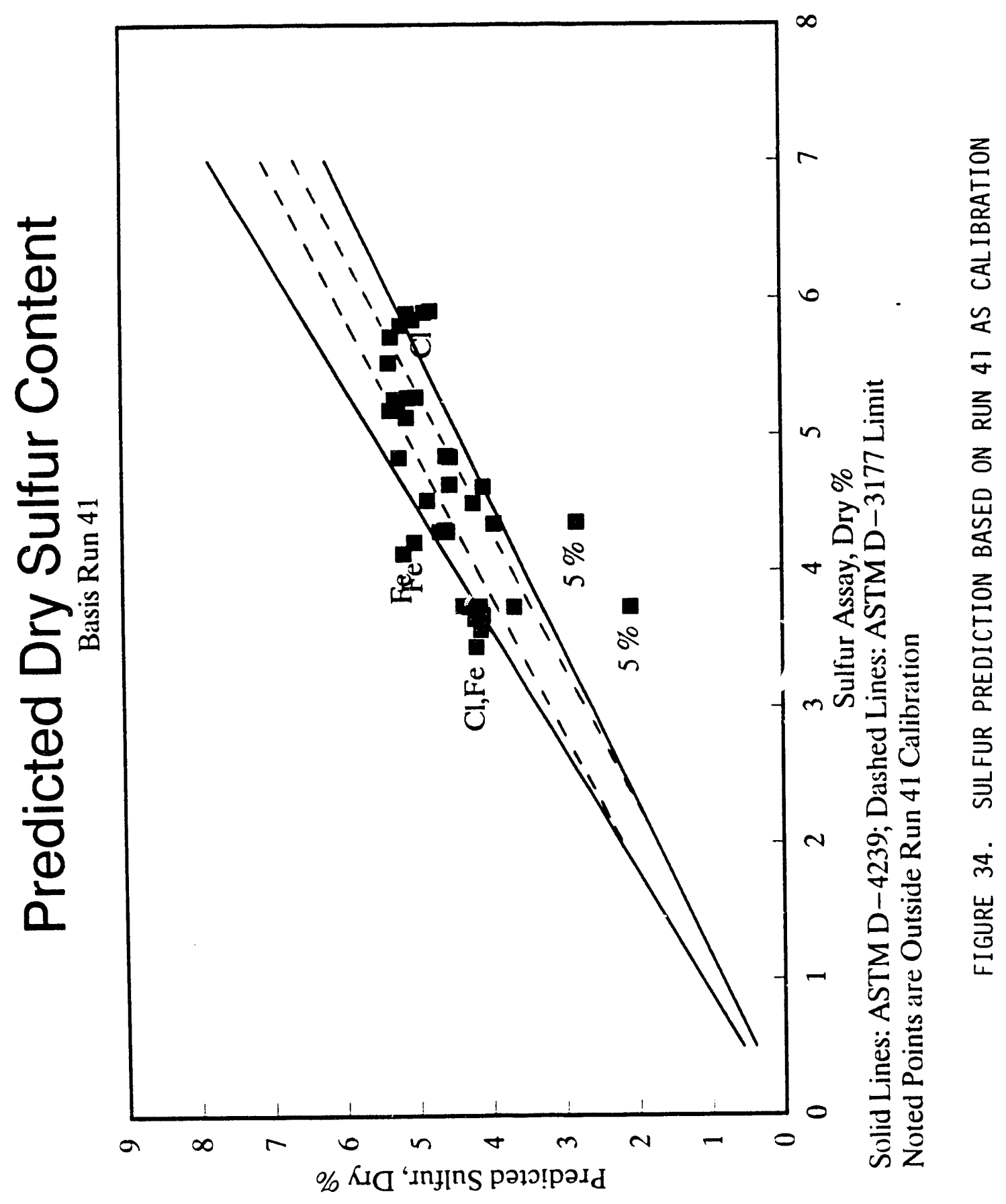




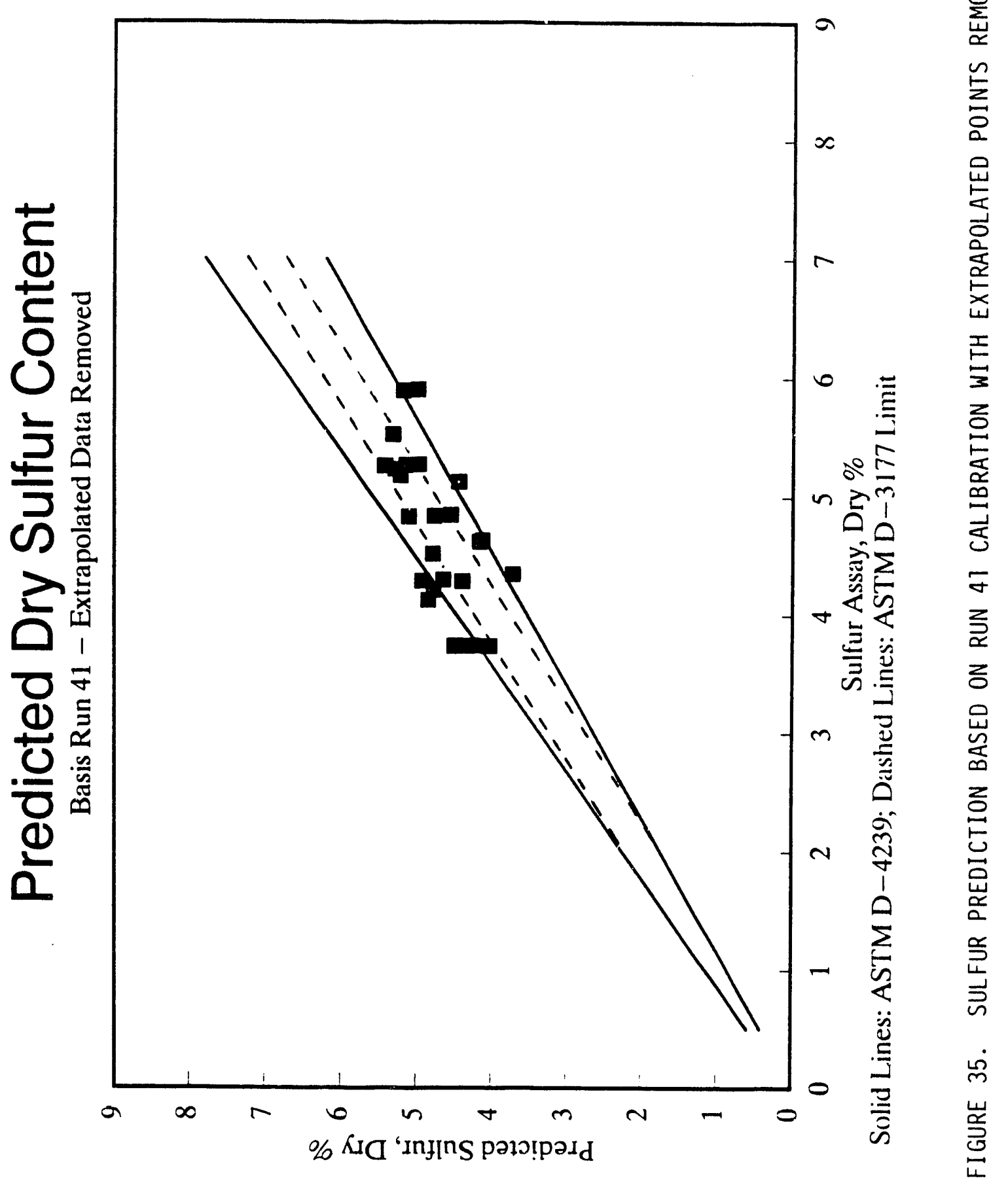


Therefore, it was demonstrated that the PGNAA slurry analyzer could, under reasonable conditions, successfully analyze the sulfur content of bituminous coal slurries. The error level was within the project sulfur prediction target.

Using the lessons learned from the sulfur development, several different iron correlation forms were evaluated. The best results were with formula which included corrections for hydrogen, sulfur, chlorine, and iron, see below

Wet Iron, $\%=A+B \cdot\left(H_{\text {counts }}\right)+C \cdot\left(S_{\text {counts }}\right)+D\left(C l_{\text {counts }}\right)+E \cdot\left(F_{\text {counts }}\right)$

Separate iron prediction for Runs 40-43 are presented in Table 11.

In all cases, the standard error was low, ranging from 0.01 to 0.18 percent wet iron. (Since wet iron is used for the ash-prediction correction, results are discussed for wet iron predictions.) Next, all the data were combined and correlated. Each data set was adjusted to a common time basis using the californium half-life based procedure. The combined data produced a standard error of 0.08 percent wet iron, see Table 12. Finally, the ability to predict unknown iron levels was tested. Using the Run 41 data as the basis, iron levels were predicted for the other runs. (Note as in the sulfur case, data falling outside the Run 41 data base, i.e., requiring extrapolation, were excluded, as well as data at 5 percent solids.) The wet iron conient was predicted using the following formula

Wet iron, $\%=-0.0211-2.51 \times 10^{-8}\left(\mathrm{H}_{\text {counts }}\right)-1.13 \times 10^{-4}\left(\mathrm{~S}_{\text {counts }}\right)$ $+1.15 \times 10^{-4}\left(\mathrm{Cl}_{\text {counts }}\right)+2.02 \times 10^{-4}\left(\mathrm{Fe}_{\text {counts }}\right)$

where "counts" were determined by the complex spectral analys is technique, and expressed on a water-subtracted basis. The correlation worked extremely well for Runs 40 and 42 (conducted under conditions similar to Run 41). Predicted iron values for Run 43 were consistently low. 
TABLE 11. IRON PREDICTION BASED ON SEPARATE ANALYSES OF RUNS $40,41,42$, AND 43 DATA

\begin{tabular}{|c|c|c|c|c|c|}
\hline \multirow[b]{2}{*}{ Run No. } & \multicolumn{5}{|c|}{$\begin{array}{c}A+B\left(H_{\text {counts }}\right)+C\left(S_{\text {counts }}\right)+D\left(\mathrm{Cl}_{\text {counts }}\right)+E\left(\mathrm{Fe}_{\text {counts }}\right) \\
\text { Complex Spectrum Analysis Method } \\
\text { Centroid Three-Point Energy Calibration } \\
\text { Fractional Channel Counts } \\
\text { Wet-Subtracted Basis }\end{array}$} \\
\hline & $\begin{array}{l}\text { Correlation } \\
\text { Factor, } r^{2}\end{array}$ & $\begin{array}{l}\text { Wet Iron Residual } \\
\text { (Assay-Predicted) } \\
\text { Standard Deviation }\end{array}$ & bias & $\begin{array}{l}\text { Dry Iron R } \\
\text { (Assay-Pre } \\
\text { Standard } \\
\text { Deviation }\end{array}$ & $\begin{array}{l}\text { ual } \\
\text { ed) } \\
\text { Standard } \\
\text { Error }\end{array}$ \\
\hline $\begin{array}{l}40 \\
41 \\
42 \\
43\end{array}$ & $\begin{array}{l}0.660 \\
0.952 \\
0.605 \\
0.995\end{array}$ & $\begin{array}{l}0.064 \\
0.035 \\
0.179 \\
0.012\end{array}$ & $\begin{array}{l}0.002 \\
0.007 \\
0.017 \\
0.007\end{array}$ & $\begin{array}{l}0.412 \\
0.179 \\
1.200 \\
0.114\end{array}$ & $\begin{array}{l}0.414 \\
0.186 \\
1.218 \\
0.121\end{array}$ \\
\hline
\end{tabular}




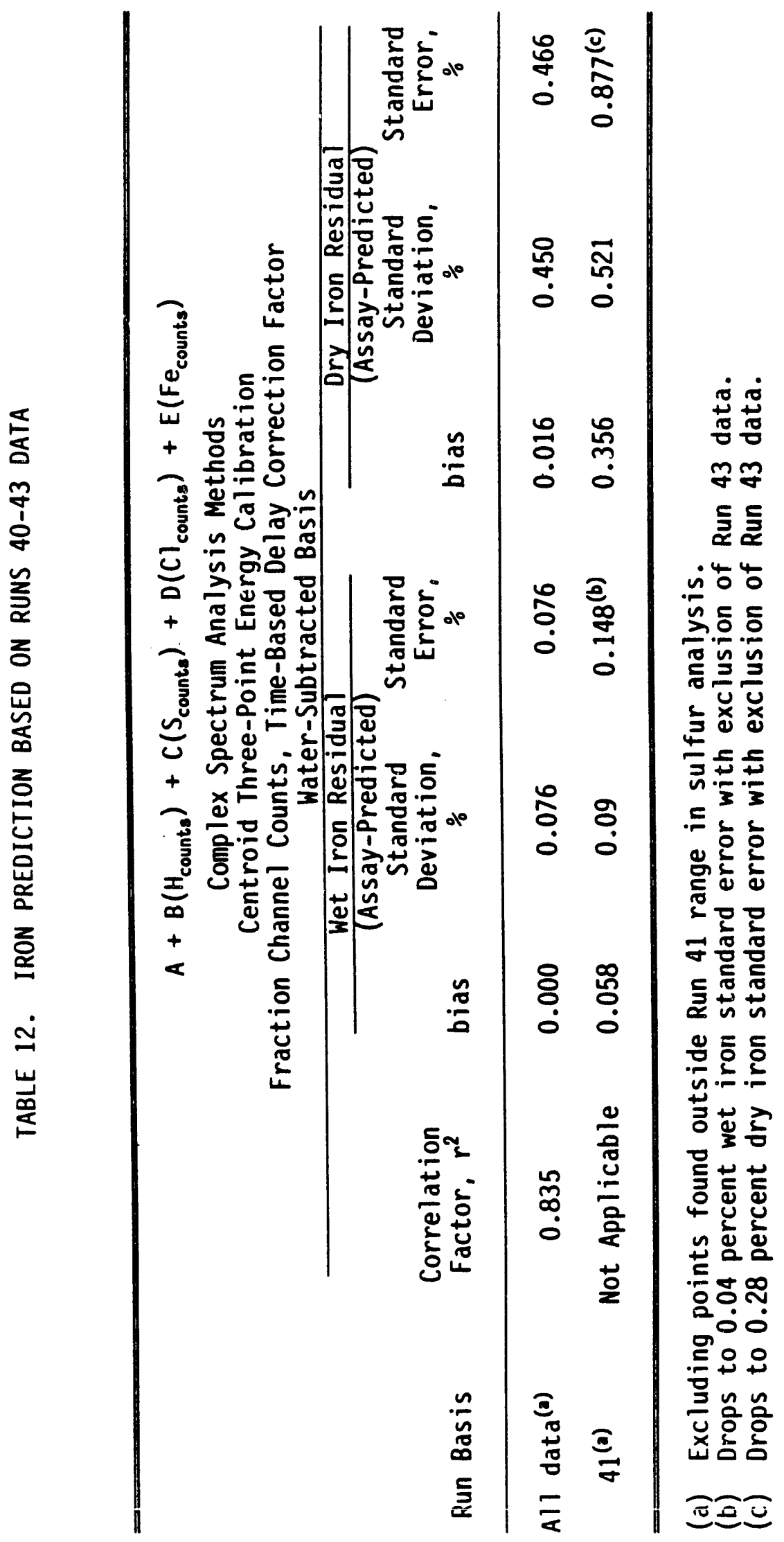


The predicted wet iron content was converted to a dry coal basis by dividing by percent solids. As also noted on Table 12, the dry iron content, predicted from the Run 41-based equation, had a bias of 0.36 percent and a standard error of 0.88 percent iron. This standard error was reduced to 0.28 percent dry iron by exclusion of Run 43 data. Under this basis, the iron prediction fell within the ASTM bounds for iron (there was no formal project target for iron) discussed in Section 3. This target was set by using the ASTM reproducibility limit for determination of iron oxide in ash along with the average ash content of the coal. It equaled 1.4 - weight fraction ash (e.g., with a 10 percent ash coal, the iron target was \pm 0.14 percent dry iron in coal; with 50 ash coal, \pm 0.7 percent dry iron). The iron predictions for Runs 40-43 are shown in Figure 36, with noted target limits expressed on a wet basis. All but 1 point of the 10-20 percent ash (i.e., non-Run 43 data) fell within or on the iron reproducibility target bounds. The iron content of the high-ash refuse used in Run 43 was not as precisely estimated as iron in the other runs. Therefore, a separate calibration was employed for high ash refuse used in Run 43. These data are also shown on Figure 36 .

Therefore, it was demonstrated that the PGNAA slurry analyzer could, under reasonable conditions, successfully analyze the iron content of bituminous coal slurries. The error level was within the ASTM limits for iron in coal.

\section{Conclusions}

The sulfur and iron testing served to determine the analyzer accuracy as well as the (1) effect of major slurry properties on PGNAA performance, (2) suitability for heavy-media applications, and (3) applicability for flotation applications. The results are summarized below.

Accuracy. The PGNAA device can be used to predict sulfur and iron levels with a standard error of 0.52 and 0.28 percent dry sulfur and iron, respectively, over reasonable percent solids, ash, and ash composition ranges. On a relative basis, sulfur predictions were within 11 percent of 


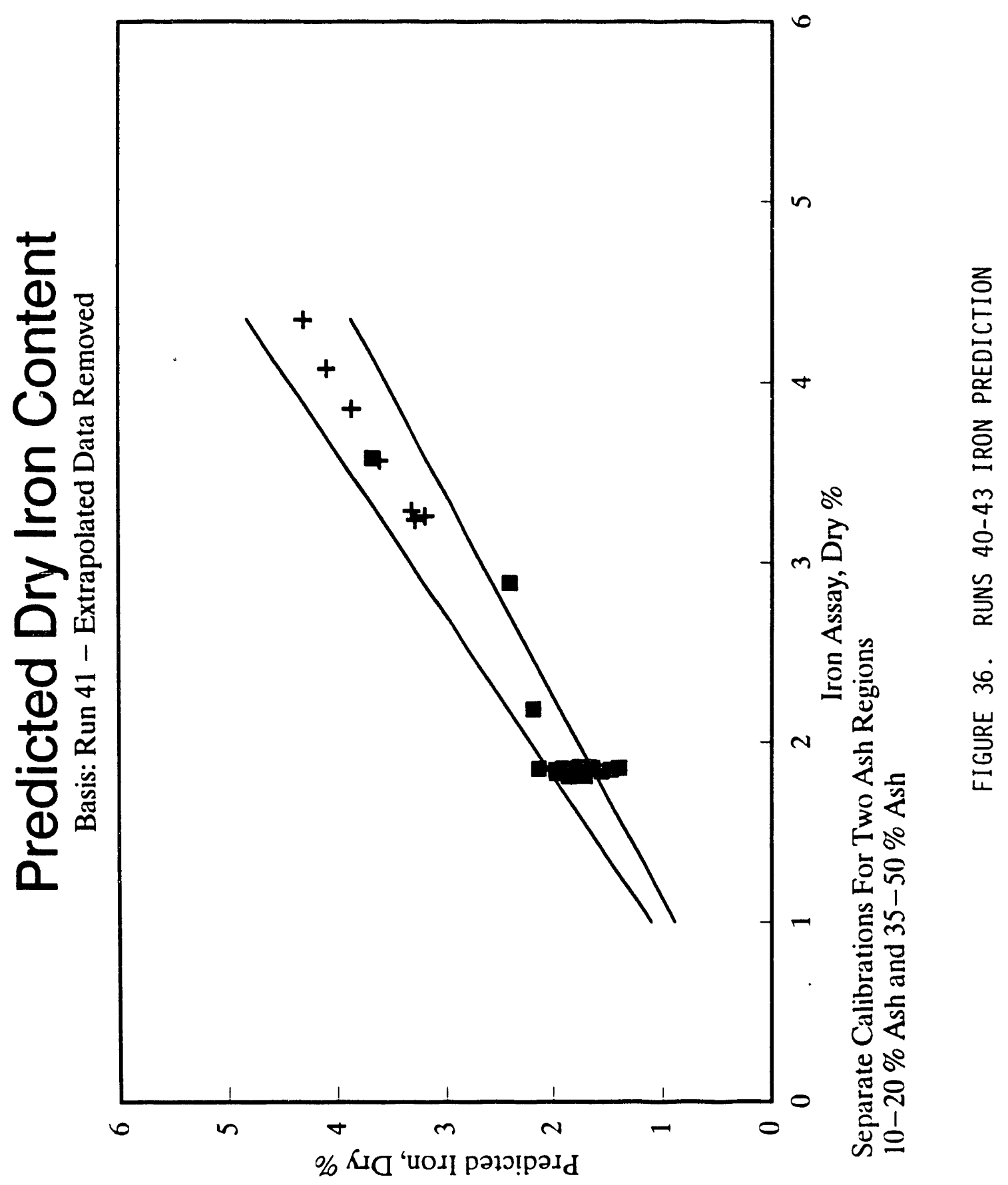


the assay value and iron within 10 percent of assay value. These meet the project's targets.

Effect of Slurry Properties. Of the major slurry properties of interest, only ash composition and percent solids had a major effect on sulfur. Ash level also appeared to affect iron prediction accuracy. Details are provided in Table 13.

Suitability for Heavy-Media Application. The excessively high iron levels found in heavy-media bath and heavy-media cyclone streams make PGNAA analysis unfeasible. However, control of heavy-media operations should be possible by controlling the product or refuse stream after normal magnetite removal.

Suitability for Flotation Applications. The addition of air to the analys is stream adversely affected PGNAA analysis. Although not as serious as with the DEGG analysis, direct analysis of flotation froth is probably not practical. However, flotation control should be possible by analys is of the low-air feed and/or tailings streams. 
TABLE 13. EFFECT OF SLURRY PROPERTIES IN SULFUR AND IRON PREDICTION

Slurry

Property

\section{Effect}

Ash Level

Sulfur Level

Percent Solids

Iron Level

Particle Size

Coal Type
Minor effect over 10 to 50 percent range on sulfur, significant effect in the 35 to 50 percent range on iron.

The PGNAA could be used to predict dry sulfur content with an error less than 11 percent of the assay value over sulfur level typically encountered in advanced and convention cleaning processes, e.g., 3 to 6 percent dry sulfur range. A lower range, 1 to 3 percent dry sulfur should be obtainable with proper calibration.

PGNAA testing indicated that operations should be limited to a 10 percent or greater percent solids range. Testing was only successful over a 10 to 20 percent solids range representative of most conventional cleaning processes. Limited testing indicates that a 1 to 10 percent level may be acceptable if coal composition was reasonably constant.

The PGNAA could be used to predict iron content within 10 percent of assay value over a broad iron range, e.g. 1 to 3 percent dry iron range ( $\mathrm{Fe}_{2} \mathrm{O}_{3}$-in-ash ranges of 12 to 34 percent). Operations with excessive iron levels, as with 50 percent ash "gob", required separate calibration. Operations with magnetite addition were not successful.

Minor effect for -20 mesh and smaller particles. The upper limit was not established. However, particles larger than $3 / 4$ inch will probably not be acceptable.

Variations in the coal composition may require separate calibrations for different coals. 


\section{SECTION 5 PROCESS CONTROL APPLICATIONS}

Presented below is a summary of the evaluation of process control applications using the slurry analyzer. The discussion includes applicable cleaning processes and development of process-control strategies.

\section{Applicable Cleaning Processes}

The DEGG/PGNAA coal-slurry analyzer was designed to allow rapid analysis of fine-coal slurries. Analyses provided included ash, slurry percent solids, sulfur, and iron. The main application of the analyzer was for in-plant optimization of slurry-based, fine-coal cleaning processes. One way to maximize the effectiveness of the analyzer was to integrate it with online process control. The potential value of on-line analysis and control was evaluated by estimating its costs and benefits.

Coal cleaning processes can be divided into two categories: advanced and conventional. The applicability of the coal-slurry analyzer for each cleaning process, and the rationale for this assessment, is listed in Table 14. Based upon this assessment the applicable advanced processes are:

- Flotation

- True heavy-liquid cyclone

- 0 il agglomeration

and the applicable conventional processes are:

- Heavy-media cyclone

- Concentrating tables

- Water-only cyclones

- Froth flotation. 
TABLE 14. APPLICABILITY OF THE COAL SLURRY ANALYZER FOR ADVANCED AND CONVENTIONAL CLEANING PROCESS

\section{Advanced Processes}

Cleaning Process

Advanced flotation

True heavy-

liquid

cyclone

$0 i 1$

agglomeration
Applicability

Yes for feed or refuse: product possibly after de-aeration
Rationale

Particle size (-200 mesh) and composition is acceptable. Existence of air bubbles is a problem. Analys is of froth after de-aeration may be possible. Analys is of feed, or refuse stream, should be acceptable.

Particle size ( -200 mesh) and composition is acceptable. Chlorinated compounds could interfere with sulfur prediction.

Particle size ( -200 mesh) and composition is acceptable. Chlorinated compounds could interfere with sulfur prediction.

\section{Conventional Processes}

Cleaning Process

Jig

Heavy-media
Applicability

No

No
Rationale

Coal particle size, 6 inch $x$ 0 , too large.

Coal particle size, $2-1 / 2 \times$ $1 / 2$ bath inch too large, and product and refuse streams may contain too much iron. 
TABLE 14. APPLICABILITY OF THE COAL SLURRY ANALYZER FOR ADVANCED AND CONVENTIONAL CLEANING PROCESS (Cont inued)

Conventional Processes

(Continued)

Cleaning Process

Heavy-media

cyclone

Concentrating

table

Water-only

cyclone

Froth flotation
Possible

Yes

Yes for feed or refuse, product possible after de-aeration
Rationale

Particle size may be too large: feed sizes range from $3 / 4 \times 28$ mesh (too large) to $1 / 4 \times 28$ mesh (may be acceptable, but not proven). Product and refuse streams can be analyzed only after magnetite removal; direct refuse analysis impossible because of iron content.

Particle size ( $-3 / 8$ incis or $-1 / 4$ inch) may be acceptable (not demonstrated). Coat composition, and iror content, should be acceptable.

Size (-28 mesh) composition, and iron content should be acceptable.

Particle size ( -28 mesh) and composition is acceptable. Existence of air bubbles is a problem. Analys is of froth after de-aeration is possible; feed, or refuse stream analysis should be acceptable. 


\section{Development of Process-Control Strategies}

Control strategies were developed for each of the applicable cleaning processes identified above. Control strategies for one advanced process (froth flotation) and one conventional process (water-only cyclones) are described below. Control strategies for the other applicable processes are presented in Appendix E.

Control strategies will range from the single open loop mode, where the operator uses the analyzer output to manually control the cleaning operation, to closed-loop control. Open loop will be the normal mode to employ initially. It will allow operators to gain faith in the analyzer accuracy and to develop control algorithms (the precise action to follow when analyzer output indicates out-of-specifications coal).

One advanced and one conventional process were selected for detailed control analysis, and for cost/benefit evaluation (presented in the next section). Flotation and water-only cyclones were selected because of interest to the industry and suitability for on-line analysis and control. Control strategies for each is presented below.

\section{Advanced Coal Flotation}

Froth flotation relies on the surface chemistry of the coal for separation. Frothier and collector liquids are added to a dilute slurry (typically 2 to 10 percent solids) of finely ground coal (typically -200 to -500 mesh). The slurry is injected into a cell or column, and fine bubbles of air are passed through the slurry--carrying the carbonaceous fraction upwards to the surface of the vessel. The product consists of a black, foamy froth. It has typically 10 to 25 percent solids and 1 to 5 percent air. (The air level decreases over time, and de-aeration can be accelerated by mechanical means such as the use of baffles or pressurization of the stream.) The slurry moves from cell to cell as the product is skimmed off. The tailings also pass from cell to cell until they reach the far end of the flotation cell, or to 
the bottom of a flotation column. Here they are rejected with the bulk of the vessel's fluid.

In order to automatically control this cleaning operation, it is necessary to:

- Identify which properties must be analyzed

- Identify what control variables are available for adjustment to control cleaning performance

- Determine the mode of control, either feedbac!. feed forward, both feedback and forward, or some other mode advance control scheme.

Property Identification. The most effective coai property found for control of conventional froth flotation cells, and presumably applicable also to advanced flotation system, is the tailings ash content. It has been found by several researchers $(3,4,5,6,7)$ that flotation yield varies directly with tailings ash. An example of this relationship is shown in Figure 37 .

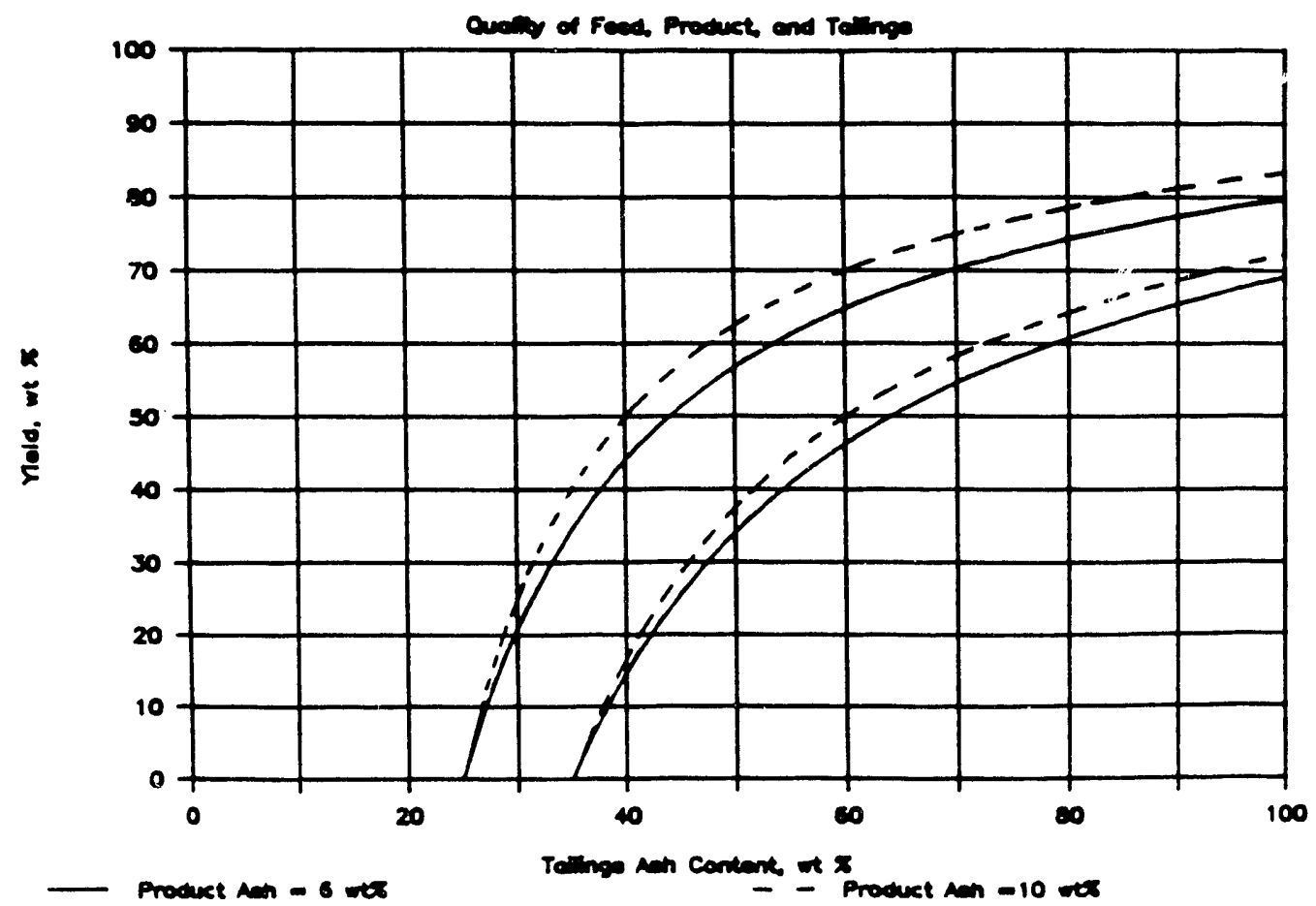

FIGURE 37. EFFECT OF TAILINGS ASH CONTENT ON FLOTATION YIELD AT CONSOLIOATION COAL COMPANYY Reference (3) 
Most eastern bituminous coal cleaning plants try to operate so the tailings stream has approximately 70 percent ash. This is usually manually assessed by the color of the tailings stream. A light gray color indicates acceptable operation while dark gray or black indicates too much coal is being rejected.

Control Variables. Flotation vessel performance is modified primarily by two control variables: (1) the addition levels of frothier and collector, and (2) the flotation cell level. Increasing the frothior and collector will result in increased recovery while sacrificing product quality (i.e., higher ash and sulfur). Changes in the frothier and collector feed pumps can be made very quickly, but to see the effect on the froth quality requires 15 to 30 minutes. The change in the cell height is affected by changing the overflow gate height andior the water makeup rate. As the level in the cell goes up so does the coal's ash content. Thus to decrease ash level, lower the level, i.e., lower the gate and/or decrease the rate of makeup water addition. To increase the ash content, increase the level. Changes in flotation cell height takes 5 to 15 minutes--much slower than modifying the chemical dosage rate. Also, the time to change the froth's quality takes longer--15 to 60 minutes after the start of level height adjustment.

Control Mode. Control systems can use feedback or feed forward control loops. Feedback control monitors a result, compares it with an expected norm, and then adjusts the process based on a control algorithm. It is the most common control mode. It is shown schematically below.

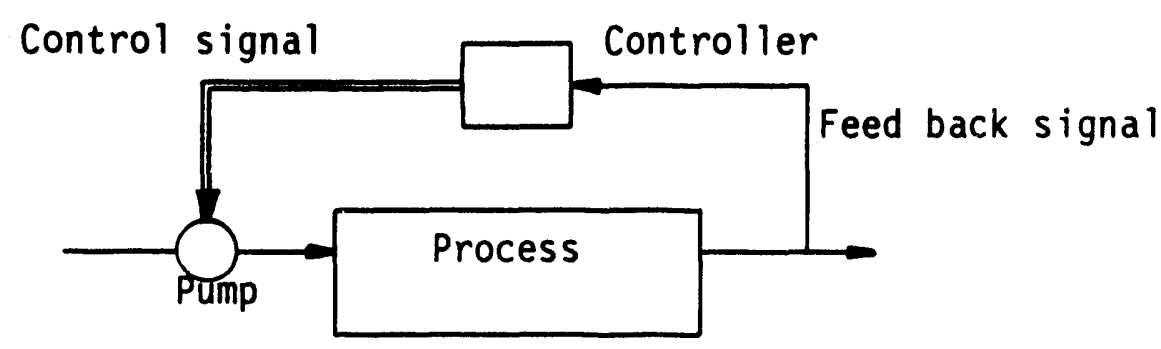


control is relatively slow. This is not a serious problem with coal flotation, since the lag time between action and change in the product is also relatively slow.

The primary alternative is feed forward control. Feed forward control monitors a process before treatment and compares it to an expected model. If the value is different than the expected value, then a change, such as speeding up the feed rate of the frothier and collector pumps, is instituted (see below).

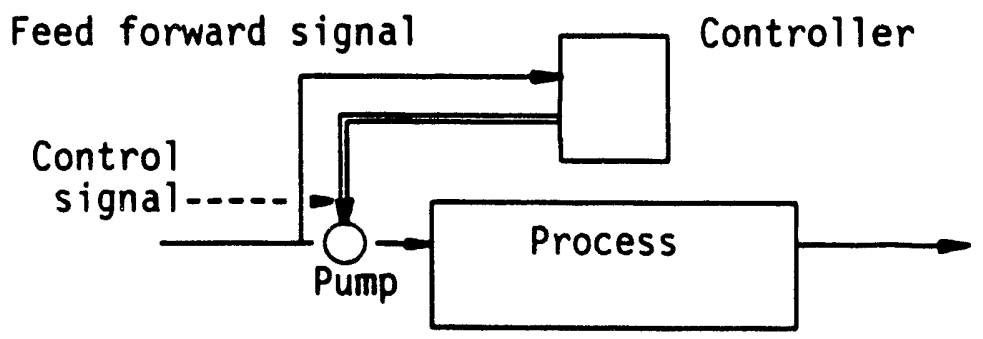

It has the advantage of being faster, control-wise; but again, the control effected is only as accurate as the control algorithm used.

Experience. No advanced flotation processes are currently using online analysis or process control to optimize operations. Therefore, experience is gathered from conventional froth flotation experience which is assumed to be applicable.

The Consolidation Coal Company has installed an opto-electric slurry analyzer in a system to control a conventional froth flotation cell(1). The control system operates by 
- Monitoring the tailings ash content

- Modifying cell performance by adjusting the frothier and collector feed pumps

- Controlling operations using feedback control with a simple updown set point controller (i.e., if the ash is above the set point, the frothier and collector pump rates are reduced, the system waits for a specific period of time, re-analyzes the tailings ash, compares it with the set point, and re-adjusts the pumps up or down).

The system is viewed as somewhat crude in that the analyzer has an accuracy of only \pm 14 percent (at two standard deviations). But with a minimal investment of approximately $\$ 10,000$, the tailings ash content was increased from 51 to 67 wt. percent with a corresponding increase in flotation yield of over $10 \mathrm{wt}$. percent. Estimated payback period was less than two weeks.

Process Technologies is installing a somewhat more sophisticated control system for flotation cell control using a nuclear-based, rapid batch slurry ash analyzer ${ }^{(7)}$. The control strategies are similar to Consolidation Coal company, except that they also measure the flotation feed rate and feed ash content along with the tailings ash content. The control system operates by

- Monitoring the feed and tailings flow rate and both feed and tailings ash content

- Modifying cell performance by adjusting the frothier and collector feed pumps

- Controlling operations using feedback control with an up-down set point controller. 
With knowledge of feed and tailings ash content and feed and tailings flow rate, the product ash content can be calculated by material balance. With the feed, tailings, and ash content, the flotation yield can be calculated (and by relating Btu content to ash content, the Btu recovery can also be estimated). The cell output is compared to a yield/grade set point in the controller and if out of bounds, the frothier and collector feed rates are adjusted. The system is not in operation yet, but significant saving through increased yield is anticipated at a rate of $\$ 7,500$ per week. Payback period is less than a year.

In Australia most of the coal mined is for metallurgical uses, and quality control is very critical. Therefore, use of automated control and online analyzers has received greater interest. The Oaky Creek Coal Co. in Australia uses a nuclear-based slurry ash analyzer to control a froth flotation circuit using a sophisticated control strategy(4). The system uses a highly accurate ash analyzer (better than \pm 1 percent accuracy) and both feed forward and feed back control.

The control system operates by

- Monitoring the feed flow rate and both feed and product ash content

- Modifying performance by adjusting frothier and collector feed pumps based on feed flow rate and feed ash content (primary control) and adjusting cell level based on product ash content (secondary control)

- Controlling operations using feed forward control for primary control and feed back control for secondary control.

The control scheme is shown in Figure 38 below. Information on flotation feed rate (obtained from readily available plant feed rate and the knowledge that flotation feed rate is 25 percent \pm 3 percent of plant feed 
rate) and feed ash content is used in a feed forward mode to set collector feed pumps setting using the following equation(4): $\begin{aligned} \text { Collector dosage, } \mathrm{ml} / \mathrm{min} . & =0.258 * \mathrm{Pl} \text { ant feed rate }(\mathrm{TPH}) \\ + & 0.333 * \text { (feed ash content, } \% \text { ) }\end{aligned}$

The frothier dosage is then set at

Frothier dosage, $\mathrm{ml} / \mathrm{min}=0.23 *$ Collector dosage.

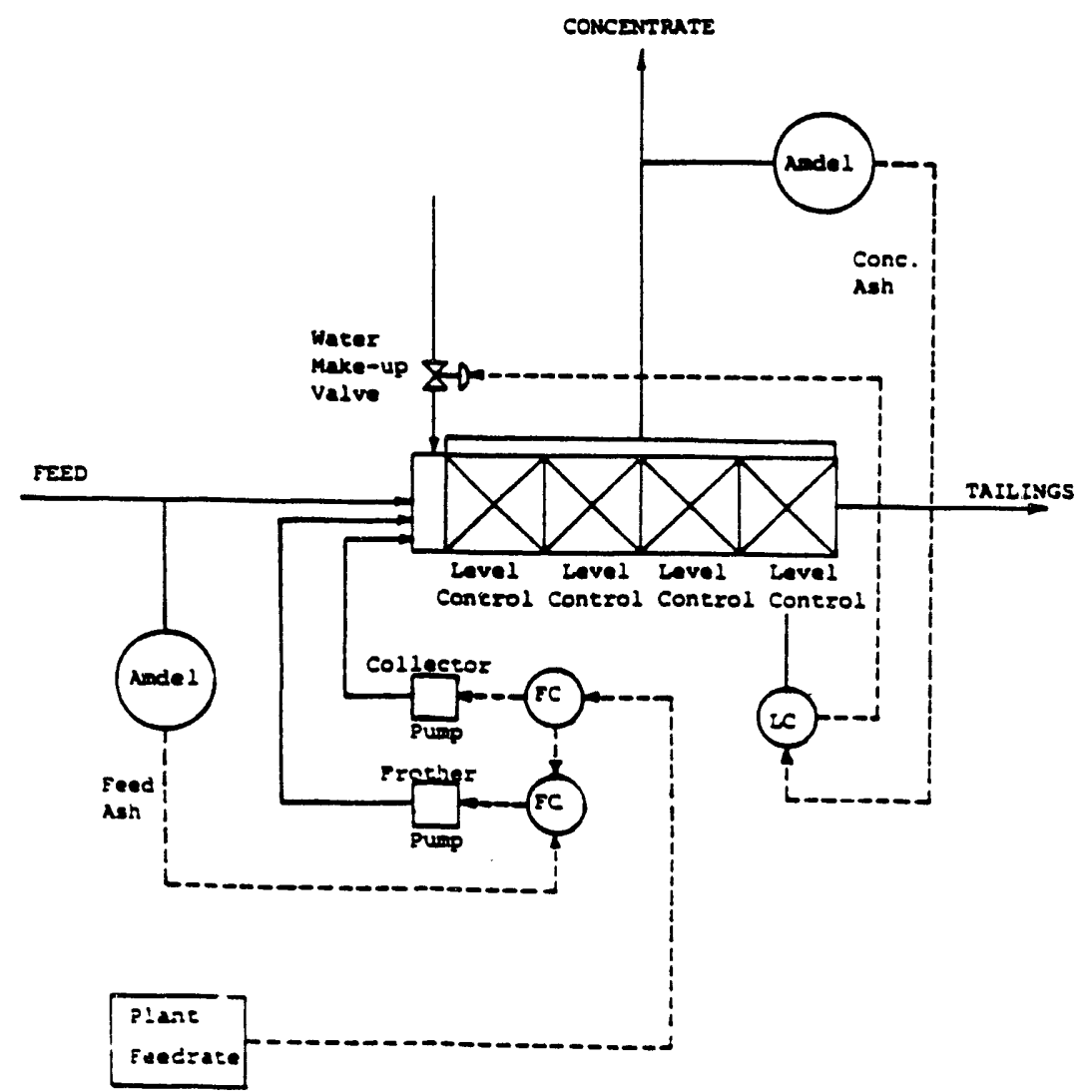

FIGURE 38. CONTROL STRATEGY USED AT OAKY CREEK COAL PTY., LTD

Reference (4)

To allow further control for disturbances in plant feed rate, coal quality, coal type, and particle size, the cell leveis are adjusted based on the product ash content. The controller attempts to keep the ash content with a control band of 8 to 9 percent ash. If the ash content is between 8 and 9 percent, the unit remains in automatic mode attempting to keep the cell level and water rate at their set points. If the ash falls to 7.9 or less the controllers feedback loop drives the cell's weir gate up while simultaneously 
increasing the makeup water flowrate. Once the ash level comes into the acceptable range, the controller returns to automatic and maintains the new set points. Likewise, if the ash content goes above 9 percent the level is lowered and the water makeup rate is reduced until the ash level drops to an acceptable level and the controller can be returned to automatic mode. This system has allowed considerable improvements in plant performance including more consistent product and increased Btu recoveries of over 10 percent. Payback period is estimated at 6 months ${ }^{(4)}$.

Control Strategy Using DEGG/PGNAA Analyzer. The DEGG/PGNAA analyzer has been shown to provide accurate analysis of slurry percent solids, ash, and mass flow rate on streams characteristic of the feed and tailings streams. Frothy streams such as the flotation product are difficult to accurately analyze because of the problems caused by the air bubbles. Therefore, the DEGG/PGNAA analyzer appears well suited to strategies involving feedback control based on (1) monitoring the tailing ash content, or (2) monitoring the feed and tailings flowrate and ash content. Use of de-aeration devices would allow a strategy involving monitoring feed, tailings and product ash content as well as one or more slurry flow rates. Control methods include feedback and feed forward control used to adjust collector and frothier feed rates and cell level.

As noted, current control strategies are built around slurry ash analyzers with control objectives of maintaining ash within acceptable bounds while maximizing yield. Control is not extended to maintaining sulfur within acceptable bounds. This is due partially to the lack of accurate, reasonably priced slurry sulfur analyzers. However, a secondary factor is that conventional froth flotation generally is not an effective sulfur remover--since pyrite is often floated along with the coal. However, in advanced flotation processes, special attention is paid to removal of pyritic sulfur. This can be accomplished by two stage cleaning, where coal is "depressed" and the pyrite floated and removed in the first stage, and clean coal recovered in a second stage. Or special additives can be introduced to make the pyrite more hydrophilic so it can better be separated from the hydrophobic coal. In 
either case a DEGG/PGNAA slurry analyzer could significantly improve the effectiveness of sulfur-control flotation operations.

Presented below are six feasible control modes. The first three use only the DEGG to estimate ash and percent solids in control modes to maintain ash within an acceptable range and maximize yield. The second three use both the DEGG and the PGNAA instrument to control both ash and sulfur.

Control Mode No. 1: Simple Ash/Yield Control for Single Stage

- Monitor the tailings ash content

- Modify cell performance by adjusting the frothier and collector feed pumps.

- Control operations using feedback control with a simple up-down set point controller

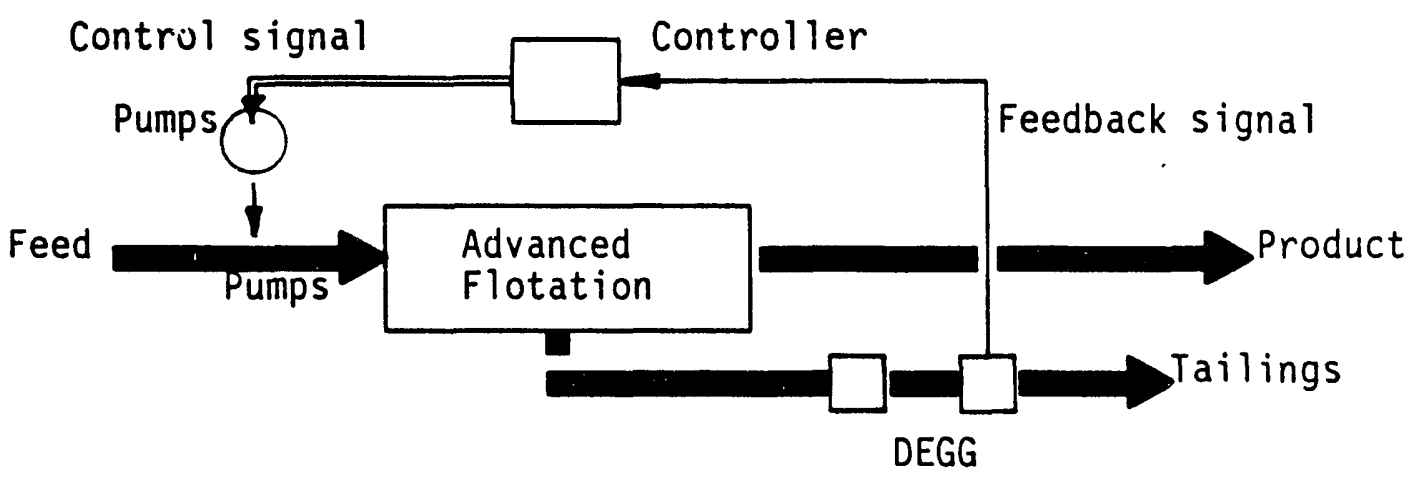

Control Mode No. 2: Moderate Complex Ash/Yield Control for Single Stage

- Monitoring the feed and tailings flow rate and both feed and tailings ash content 
- Modifying cell performance by adjusting the frothier and collector feed pumps

- Controlling operations using feedback control with an up-down set point controller

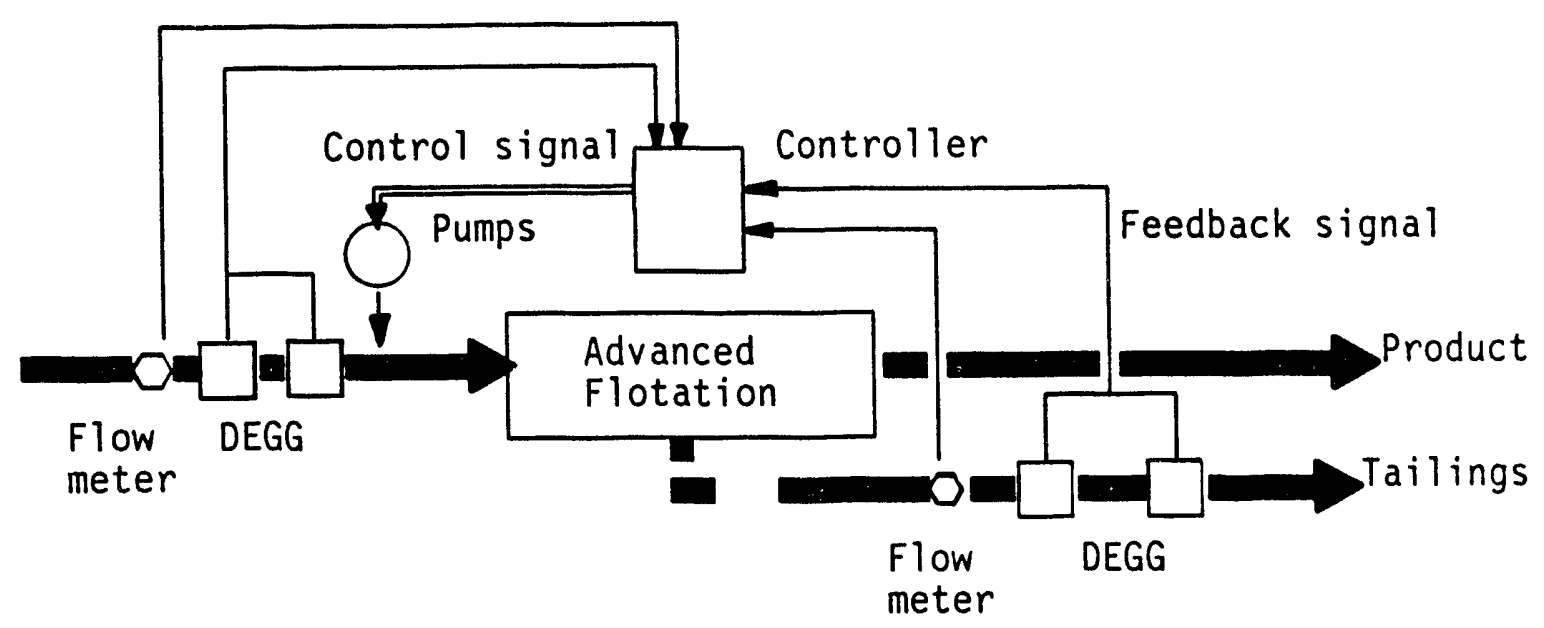

Control Mode No. 3: Complex Ash/Yield Control for Single Stage

- Monitoring both feed and tailings flow rate and both feed and tailings ash content

- Modifying performance by adjusting frothier and collector feed pumps based on feed flow rate and feed ash content for primary control, and adjusting cell level based on calculated product ash content (based on a mass balance using feed and tailings flow rate and feed and tailing ash content) for secondary control

- Controlling operations using feed forward control for primary control, and feedback control for secondary control. 


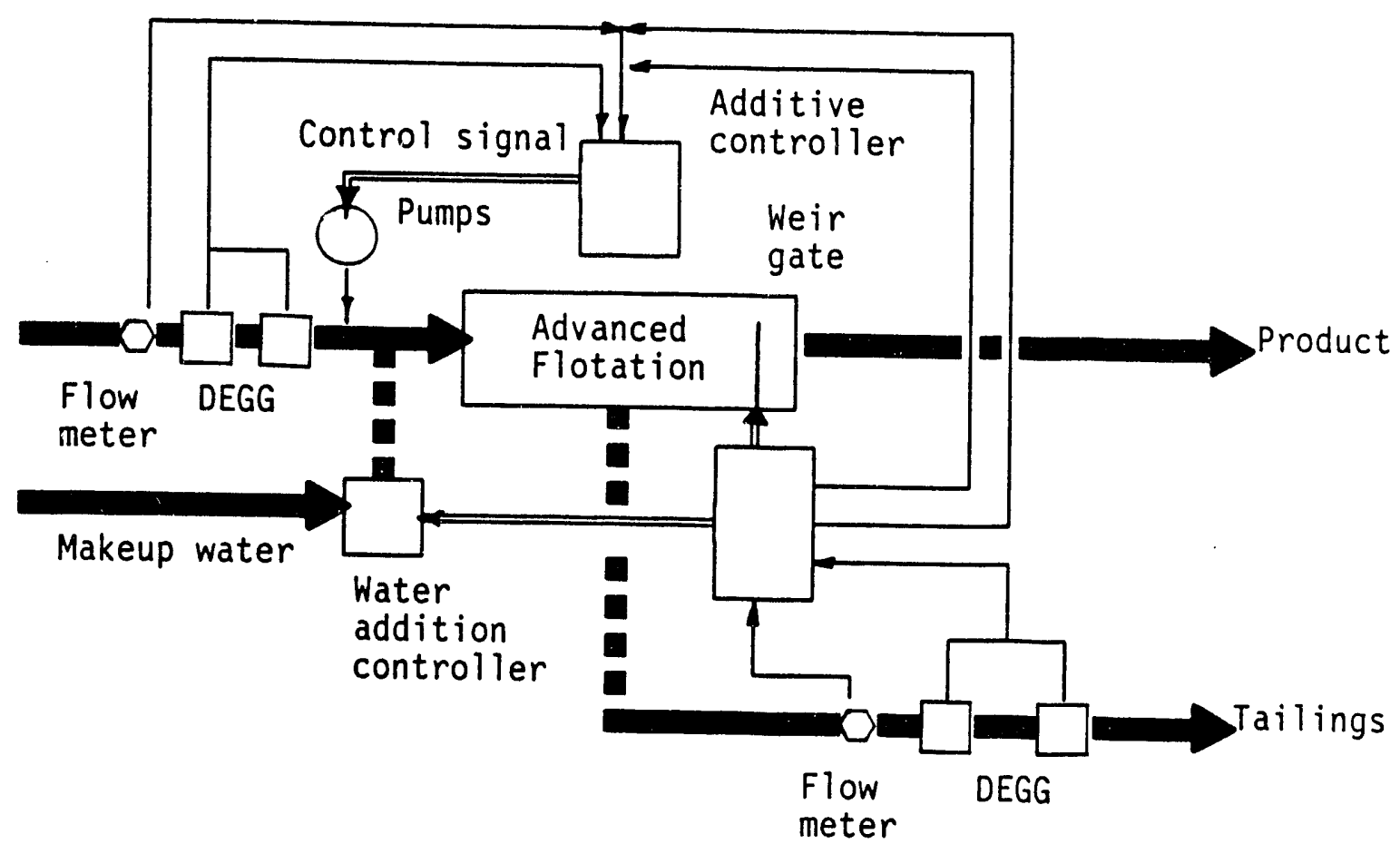

Control Mode No. 4: Simple Sulfur Control for Multiple Stages

- Monitor first stage tailings sulfur and iron content

- Modify first cell performance by adjusting the frothier and coal depressant feed pumps

- Control first stage operations using feedback control with a simple up-down set point controller

- Control second stage following control mode 1 , or 2 , or 3.

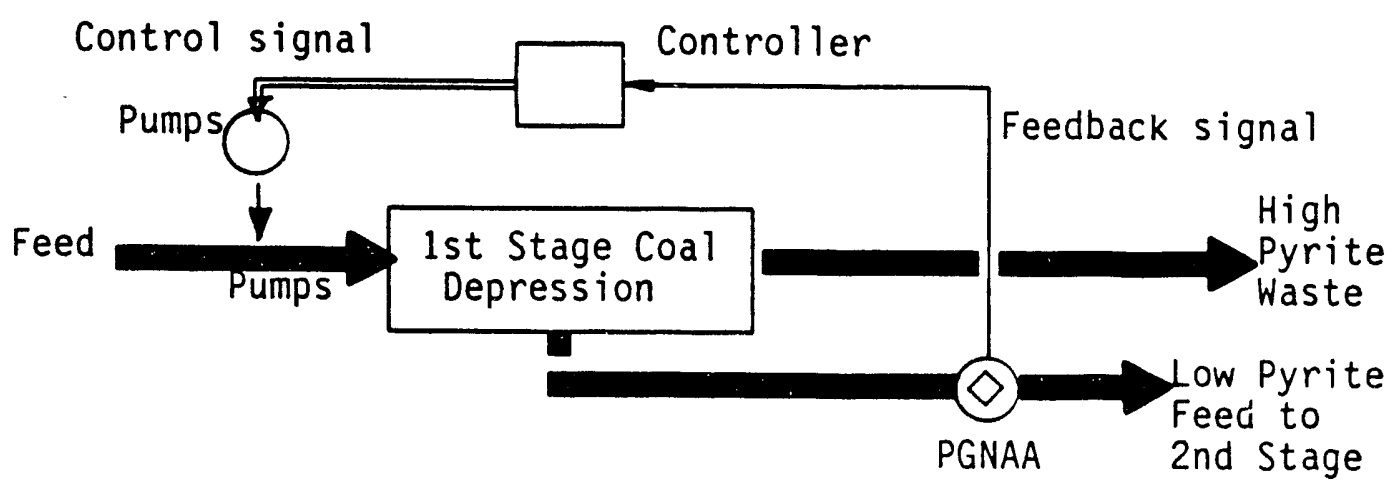


109

Mode 4 is nearly identical to Mode 1, except (1) the ash analyzer has been replaced by the PGNAA sulfur and iron analyzer, (2) the froth represents a high-pyrite waste rather than the product from the flotation cell, and (3) the tailings represent a low-pyrite feed to the second stage rather than the high-ash tailings waste stream. Similarly, sulfur control modes can be made by adapting Control Modes 2 and 3 by making changes (1), (2), and (3).

Another method for sulfur control is to use a pyrite suppressant with the frothier and collector. This makes the pyrite more hydrophilic causing it to sink with the mineral matter and be removed in the tailings stream. Modes 1 and 2 could be modified for pyrite suppression by adding the PGNAA instrument onto the tailings stream and using the sulfur and iron output to control a separate pyrite suppressant feed pump. An advanced form of ash and pyrite control is shown below.

Control Mode No. 5: Complex Ash/Sulfur/Yield Control for Multiple Stages

- Monitoring both first stage feed and tailings flow rate, feed and tailings ash content, and tailings sulfur and iron content second stage control can be based on Control Mode No. 1, or 2, or 3 .

- Modifying first stage performance by adjusting frothier and coal depressant feed pumps based on feed flow rate and feed ash content for primary control, and adjusting cell level based on tailings pyrite content (based on tailings sulfur and iron content) for secondary control; second stage modifications based on the selected Control Mode No. 1, 2, or 3 .

- Controlling operations for the first stage using feed forward control for primary control, and feedback control for secondary control; second stage control loop following the selected Control Mode No. 1, 2, or 3 . 


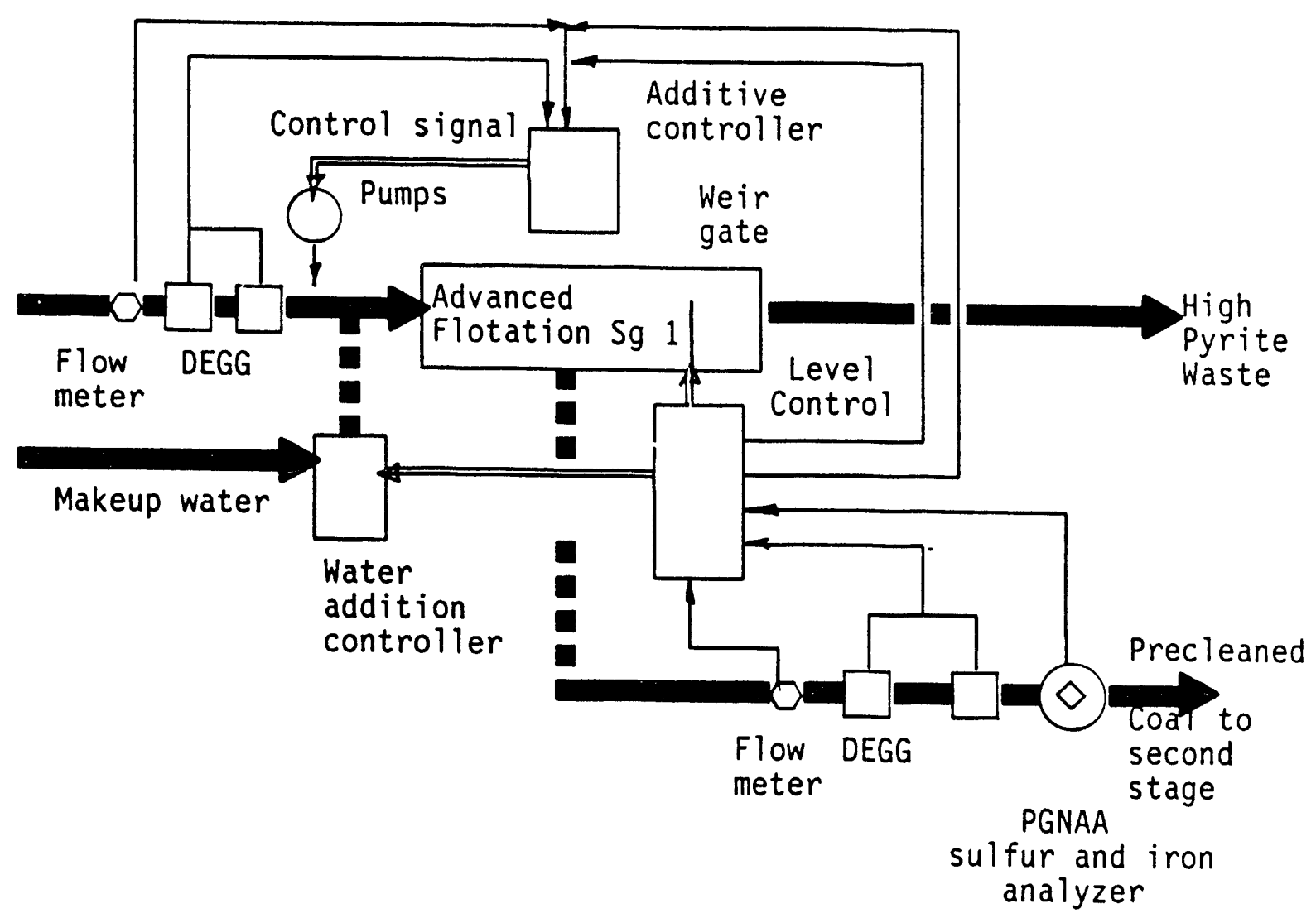

Nater-Only Eyclones

In order to automatically control this cleaning operation it is necessary to:

- Identify which properties must be analyzed

- Identify what control variables are available for adjustment to control cleaning performance

- Determine the mode of control, either feedback, feed forward, both feedback and forward, or some other mode advance control scheme. 
Property Identification. The most effective coal properties found for control of cyclones is the refuse ash content and product ash content. A refuse ash content less than 70 percent ash indicates poor operation. Product ash content greater than 15 percent ash indicates problems with the classifying cyclone upstream of the cyclone.

Control Variables. Water-only cyclone performance is modified primarily by two control variables: (1) position of the vortex finder and feed percent solids. Other factors include diameter of the vortex finder, apex diameter, and pressure at feed inlet. The particular specific gravity is set up originally by varying the dimensions of the discharge orifices; the specific gravity is decreased as the diameter of the vortex finder is decreased or the apex diameter is increased. Neither of these changes, however, lead to simple on-line control options. The specific gravity can also be decreased by raising the vortex finder, i.e., as the vertical clearance between the lower edge of the vortex finder and the cyclone bottom is increased. This change can be made simply, and precisely by use of a hydraulic lift mechanism. Another control variable which can be changed online is feed percent solids. The feed concentration is directly scaled to the cyclone diameter; the smaller the diameter, the lower the desired percent solids input. As the concentration is increased, the specific gravity of separation is also increased. Feed concentration control is limited, since the percent solids must be maintained between 8 to 15 percent. With too concentrated feed, the sebarations are not sharp (more refuse reports to the product stream); with too dilute feed the cyclone act as a classifying cyclone making the separation based on particle size. A third variable which could easily be controlled is inlet pressure. Increasing the pressure results in a slight increase in separating gravity. However, experience shows that as long as there is adequate pressure (usually 8 to 15 psi) there is little impact on performance, and at higher pressures increased wear rates are experienced. ${ }^{(5)}$

Control Mode. Control systems can use feed back or feed forward control loops. The preferred route may be a feed back loop using tailings ash content to control vortex finder position. A more sophisticated circuit would 
include a feed forward loop to control inlet percent solids and a feed back loop using tailings ash content to control the vortex finder location. Since water-only cyclones are quite effective in pyrite removal (generally considered more effective than flotation in the -28 mesh range), tailings ash and sulfur content could be combined to allowed optimized control.

Experience. No water-only cyclones are currently using on-line analysis or process control to optimize operations. However, once initial adjustments have been made, no further adjustments are normally necessary -. assuming the feed coal remains relatively constant. Plants processing frequently changing coal feedstocks should benefit from on-line control.

Control Strategy Using DEGG/PGNAA Analyzer. The DEGG/PGNAA analyzer has been shown to provide accurate analysis of slurry percent solids, ash, and mass flow rate of streams characteristic of the feed and tailings streams.

Presented below are four proposed control modes. The first set uses only the DEGG to estimate ash and percent solids in control modes to maintain ash within an acceptable range and maximize yield. The second set uses both the DEGG and the PGNAA instrument to control both ash and sulfur.

Control Mode No. 1: Simple Ash/Yield Control for Water-Only Cyclone

- Monitor the tailings ash content

- Modify cyclone performance by adjusting the vortex finder position

- Control operations using feedback control with a simple position set point controller 


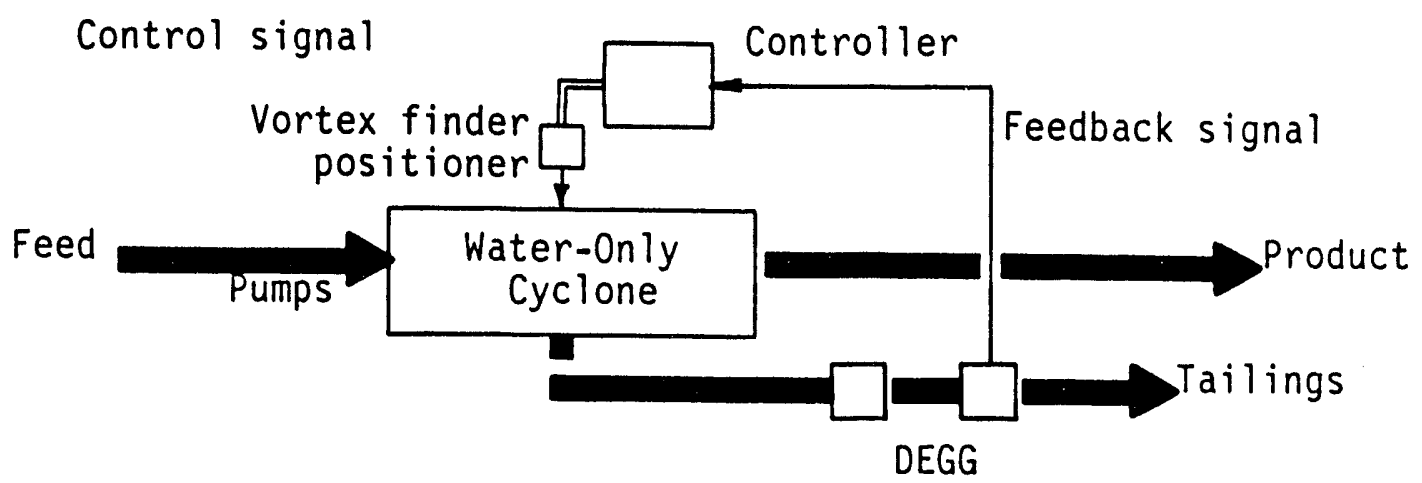

Control Mode No. 2: Moderate Complex Ash/Yield Control for Water-Only Cyclone

- Monitoring the feed and tailings flow rate and both feed and tailings ash content. This configuration would allow calculation of product ash content, cyclone yield, and Btu recovery (by using a Btu prediction based on ash content).

- Modifying cyclone performance by adjusting the vortex finder location (and providing off-line information to the operators on feed percent solids levels which could be adjusted manually)

- Controlling operations using feed back control with an position set point controller

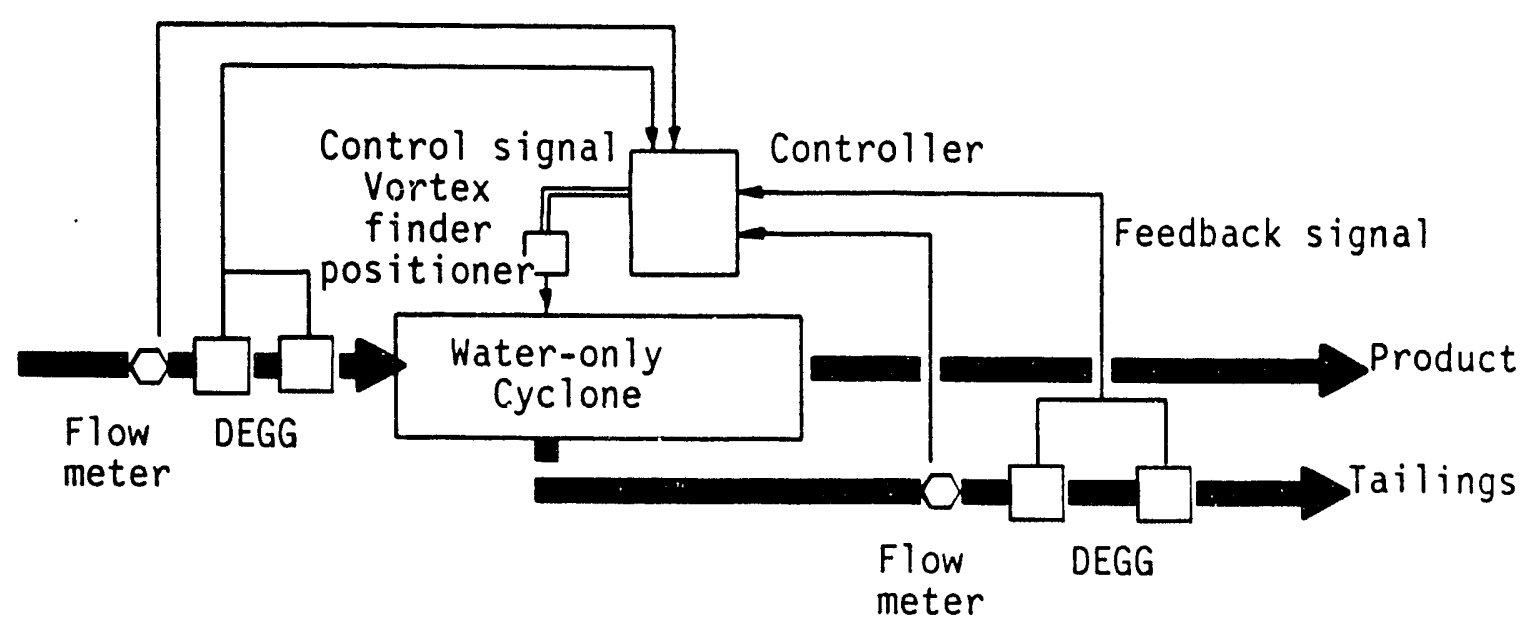


Control Mode No. 3: Complex Ash/Sulfur/Yield Control for Water-Only Cyclone

- Monitor the tailings ash and sulfur content

- Modify cyclone performance by adjusting the vortex finder position

- Control operations using feedback control with a simple position set point controller

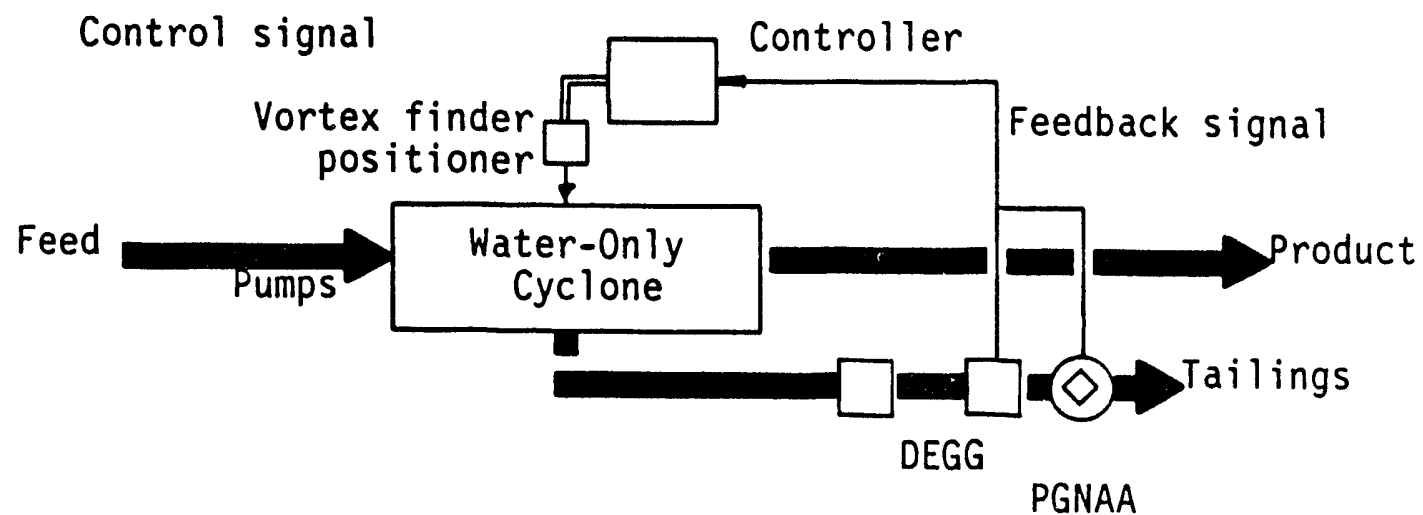

Control Mode Ho. 4: Complex Ash/Sulfur/Yield Control for Water-Only Cyclone

- Monitoring the feed and tailings flow rate and both feed and tailings ash and sulfur content. This configuration would allow calculation of product ash and sulfur content, cyclone yield, and (by using a Btu prediction based on ash content) Btu recovery.

- Modifying cyclone performance by adjusting the vortex finder location (and providing off line information to the operators on feed percent solids levels which could be adjusted manually) 


\section{5}

- Controlling operations using feed back control with a position set point controller

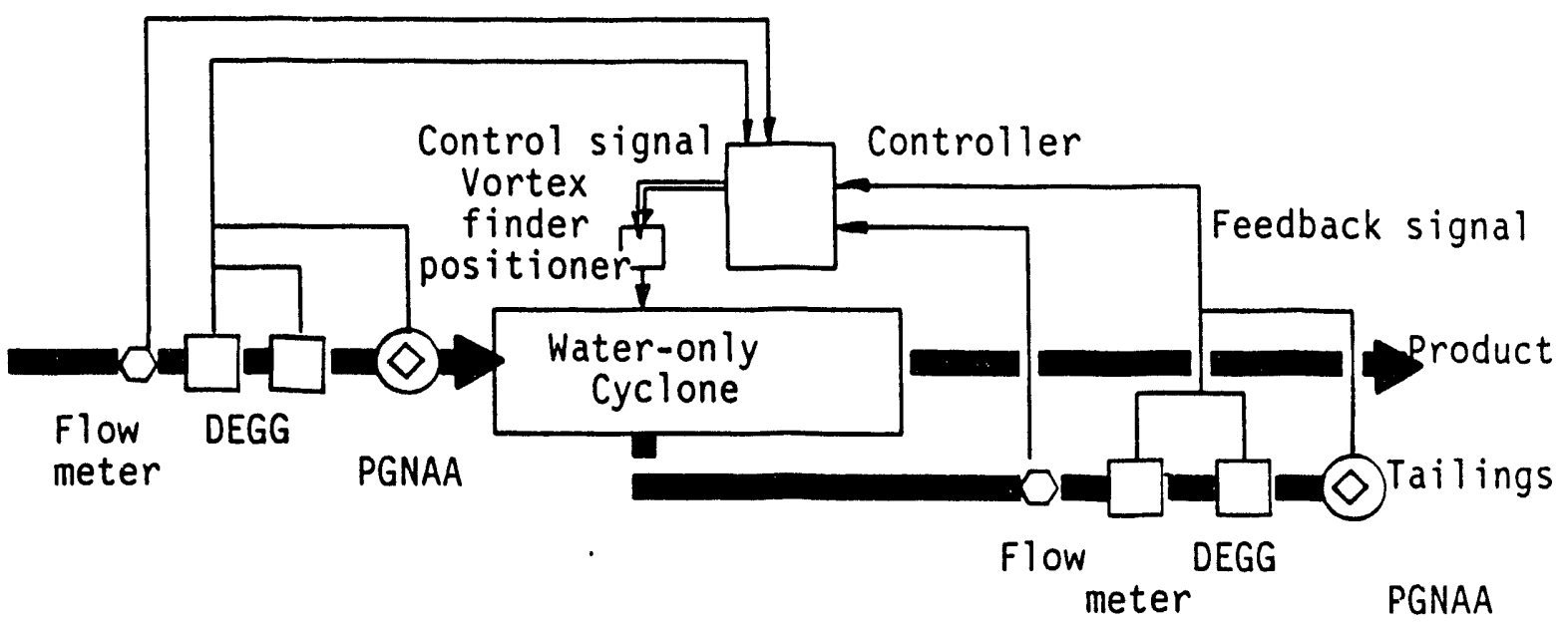




\section{SECTION 6 COST/BENEFIT ANALYSIS}

Presented below is a summary of the cost/benefit analysis for one advanced and one conventional cleaning process using the coal slurry analyzer instruments; discussed are:

- Analyzer costs

- Benefits of on-line analysis and control

- Cost/benefits assessment for advanced froth flotation

- Cost/benefits assessment for conventional water-only cyclones.

\section{Analyzer Costs}

To assess the benefit of on-line analysis and process control, it was necessary to estimate the cost for the slurry analyzer and control system. Costs of purchased equipment were found for (1) the two densitometers and associated equipment necessary for the production of an ash/percent solids analyzer, and (2) the equipment necessary to build a PGNAA sulfur analyzer. The costs were quite modest, compared to typical dry coal analyzers. Approximate selling price (including profit) was estimated at approximately $\$ 27,000$ for the ash/percent solids analyzer and $\$ 44,000$ for the sulfur analyzer. Details are provided below.

\section{Cost for Ash/Percent Solids Analyzer}

An ash/percent solids analyzer would consist of two densitometers and simple computation and display equipment (see below). 


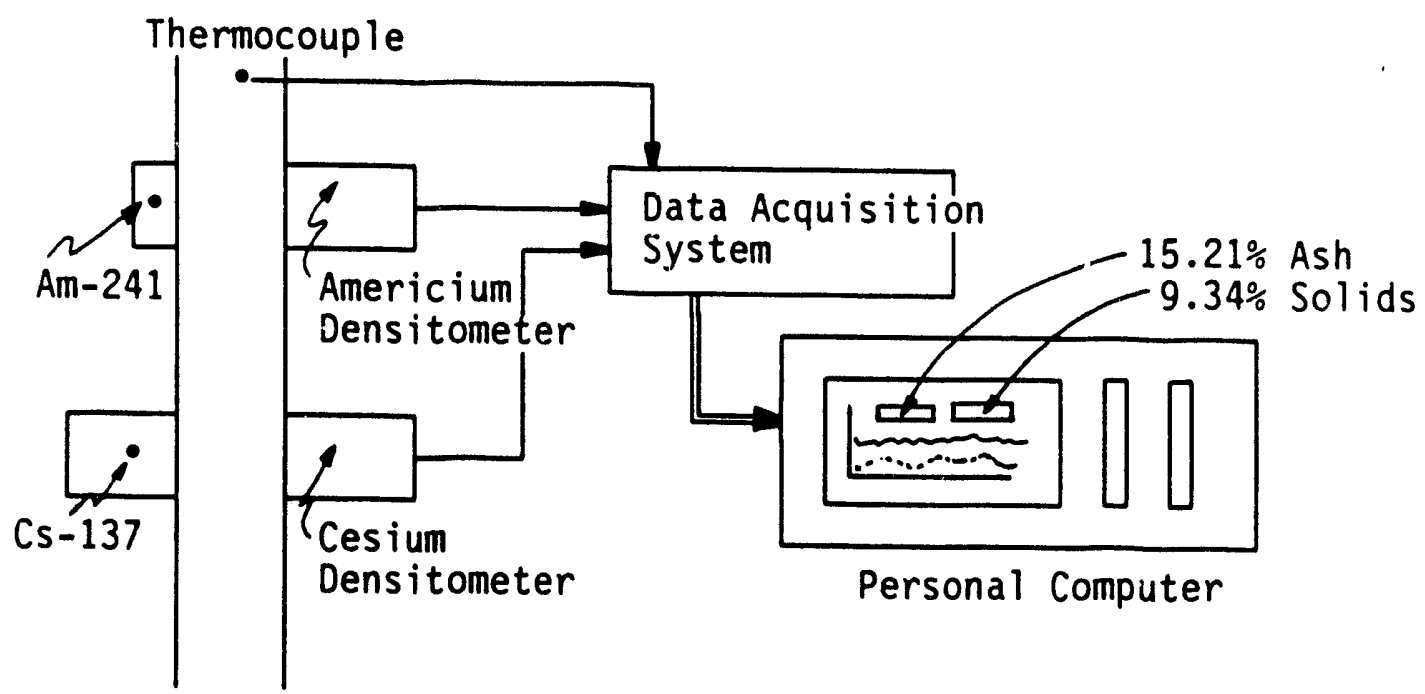

The purchased equipment costs to duplicate the current system and to build a system based on state-of-art equipment are estimated below:

\begin{tabular}{|c|c|c|}
\hline & Current System & New System \\
\hline Cesium-137 Densitometer ${ }^{(8)} \ldots \ldots \ldots \ldots$. & $\$ 6,400$ & 5,675 \\
\hline Americium-241 Densitometer ${ }^{(8)} \ldots \ldots \ldots$ & $\$ 12,165$ & 6,875 \\
\hline Data acquisition system...$\ldots \ldots \ldots$ & $\$ 1,000$ & 1,000 \\
\hline Personal computer ................. & $\$ 1,000$ & 1,000 \\
\hline Software $\ldots . \ldots \ldots \ldots \ldots \ldots \ldots \ldots \ldots \ldots$ & $\$ 1,000$ & 1,000 \\
\hline Other parts $\ldots . \ldots \ldots \ldots \ldots \ldots \ldots \ldots$ & $\frac{\$ 1,000}{\$ 22,565}$ & $\frac{1,000}{\$ 16,550}$ \\
\hline
\end{tabular}

The primary difference between the current system and a new state-of-the-art system is the size of the nuclear sources required and advanced electronics. Currently a 1-curie Cs-137 source and a 5-curie Am-241 source are used. Texas Nuclear, the original densitometer supplier, says that a 100 milli-curie Cs137 source is now standard. This reduction is possible due to improvements in the electronics. Likewise, we assumed a reduction in the americium densitometer source strength is possible. The new system cost is based on decreasing the Am-241 source strength from 5 to 1 curies. 
The system is relatively simple, there are few parts, and the calculation procedures are relatively simple. It is estimated that a new commercial system could be assembled for an additional $\$ 5,000$, making the total before profit, or tax, cost approximately $\$ 22,000$. Assuming a 38 percent tax bracket, the new analyzer selling price is estimated as $\$ 27,000$ with a 15 percent return on investment after tax.

\section{Cost for Sulfur Analyzer}

The PGNAA slurry analyzer is somewhat more complicated, and therefore more expensive (see below).

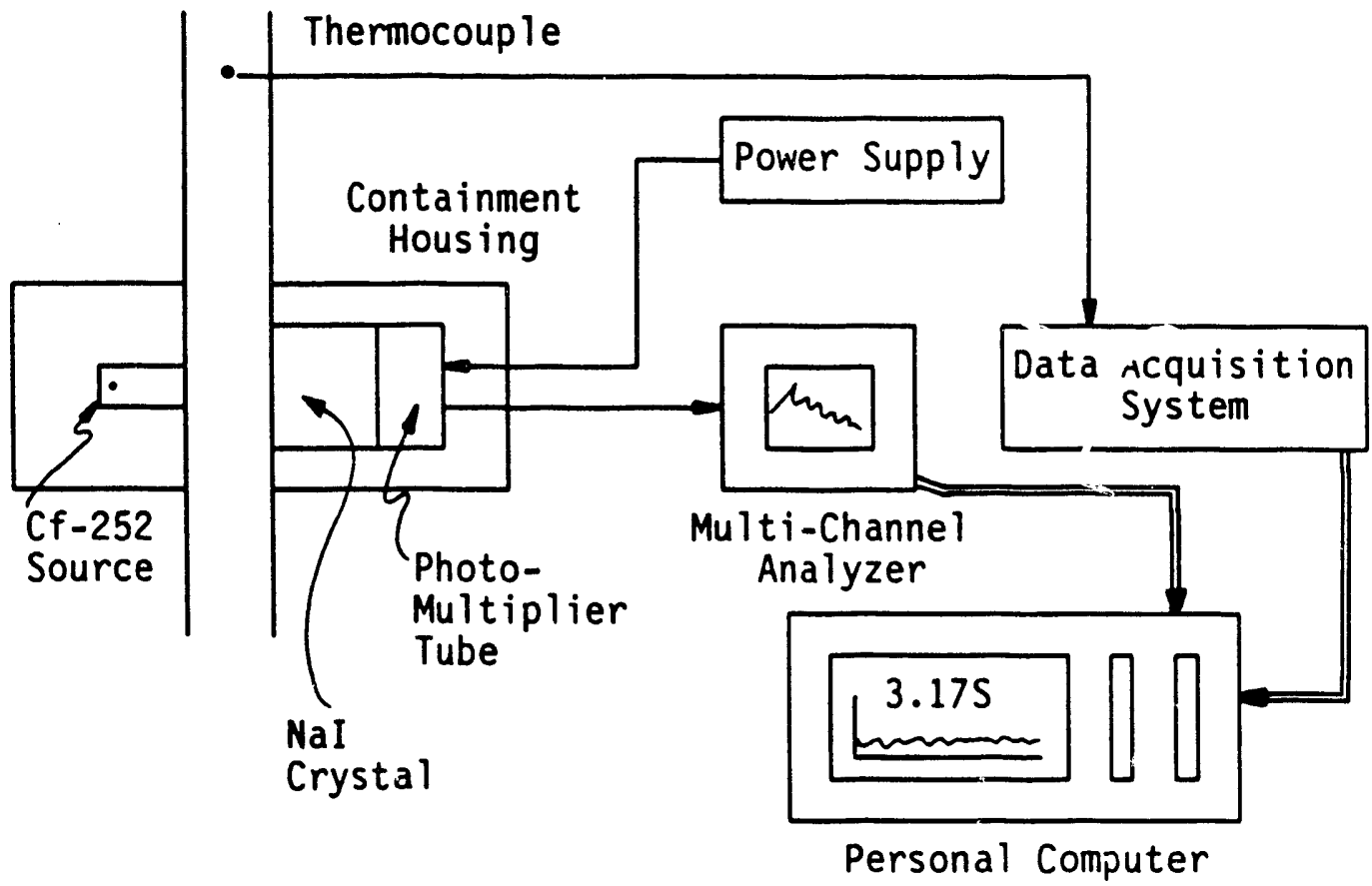

The purchased equipment costs to duplicate the current system are estimated as follows: 


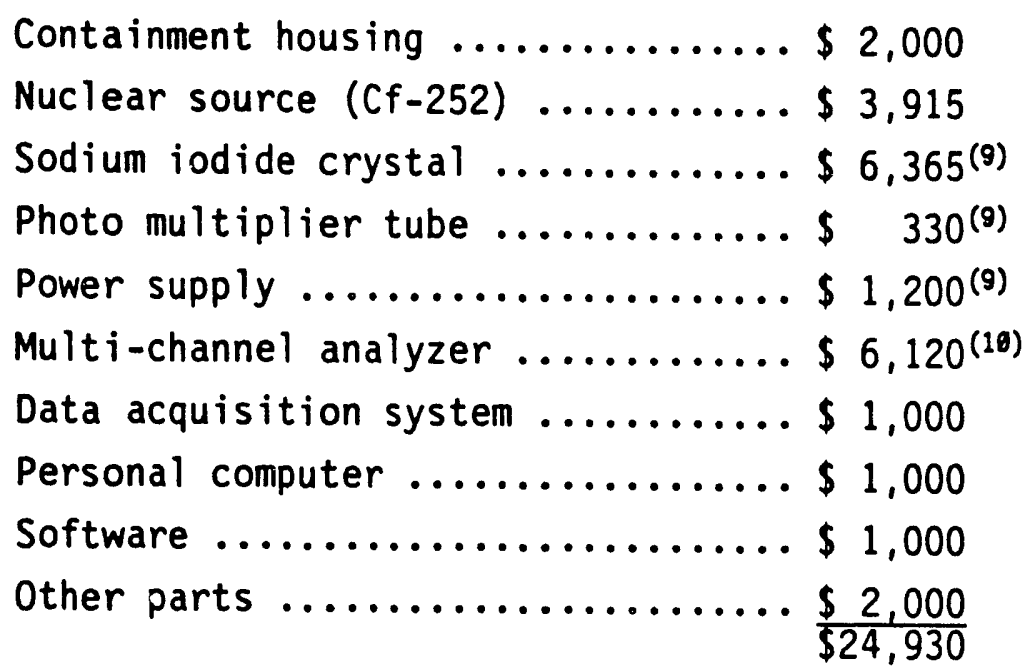

The system is still relatively simple, there are only a limited number of parts, and the calculation procedures can be easily automated. It was estimated that a commercial system could be assembled for an additional $\$ 10,000$, making the total before profit or tax cost around $\$ 35,000$. Assuming a 38 percent tax bracket, the analyzer selling price was estimated at $\$ 44,000$ with a 15 percent return on investment, after tax.

Both estimated selling prices are probably conservative and could be lowered by 20 to 30 percent. However, the overall price seems reasonable as a first estimate, since no additional cost for marketing, service, inventory, nuclear licensing, etc., were included.

\section{Cost of Control Hardware/Software}

The on-line data produced by the DEGG and/or PGNAA could be utilized to manually control the cleaning operations (in which case, control hardware costs would be zero) or automated. The cost for control hardware is dependent on the degree of control sophistication. In general, however, in-plant experience indicates that a simple system can be automated for approximately $\$ 10,000$ per unit ${ }^{(3)}$. Sophisticated control would range up to $\$ 50,000$ to $\$ 100,000$ per cleaning unit ${ }^{(4)}$. 


\section{Benefits of On-Line Analys is and Control}

The economic benefits from an integrated coal cleaning/control strategy for advanced or conventional plants would accrue from improved adherence to coal quality specifications. These benefits could come from improved ash control, sulfur control, or both. Each is discussed separately below.

\section{Ash Control}

Tighter control of product ash content would result in benefits from many factors, including (1) reduced coal give away, (2) reduced mining and waste disposal costs, and (3) penalty avoidance (see below).

Coal "Give Away". Assume that a certain coal preparation plant is contractually bound to deliver 12 percent ash (dry basis) coal to a customer at a rate of 4000 tons/day (or roughly 200 tons/hr from a small to intermediate sized plant which is available at full capacity for 20 hours/day for 200 days/year). Plant operators will actually have to establish a lower target value for end-product ash content, say 10 percent, in order to ensure that excursions above the 12 percent contract value for ash content are minimized. This operation strategy is illustrated graphically in figure 39.

At the contract specification value of 12 percent ash, the coal producer delivers to the customer 800,000 tons/year $(t / y) \times(1-0.12)=704,000$ $(t / y)$ of ash-free coal per year. However, in actual operating conditions, the coal producer is turning over to the customer

$$
800,000 \mathrm{t} / \mathrm{y} \times(1-0.10)=720,000 \mathrm{t} / \mathrm{y}
$$

of ash-free coal per year on the average. The difference between the two above numbers $16,000 \mathrm{t} / \mathrm{y}$, represents the amount of ash-free coal which the producer must "give away" in order to be confident that he is meeting the 12 percent ash figure most of the time. 


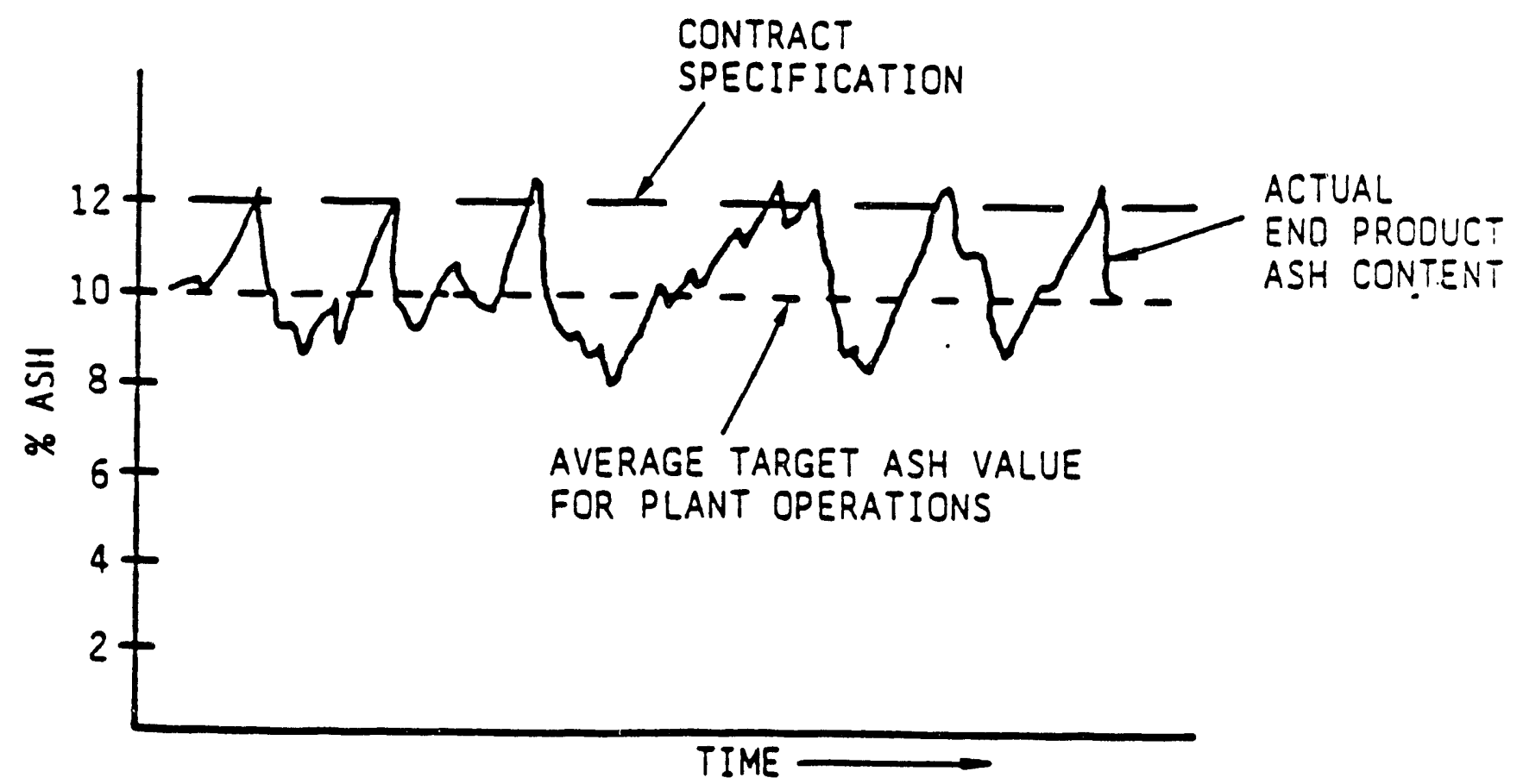

FIGURE 39. VARIATION OF ASH IN CLEANED COAL 
With an integrated coal cleaning control system, it is assumed that the plant operator would increase the target ash content to 11.5 percent, because the product would have much less variability. The amount of ash-free coal in this scenario is:

$$
800,000 t / y \times(1-0.115)=708,000 t / y \text { or } 4,000 t / y \text { coal given away. }
$$

This is $12,000 t / y$ less $(16,000-4,000 t / y)$ than the no control, 10 percent ash case, and is equivalent to $13,636 \mathrm{t} / \mathrm{y}$ of 12 -percent ash coal. Assuming a selling price of $\$ 20 / t$, this difference between integrated control and no control cases translates to a yearly savings of $13,368 \mathrm{t} / \mathrm{y}$ saved $\times \$ 20 / t=$ $\$ 273,000 / y$ saved.

This calculation ignores the costs associated with mining and refuse disposal; they are calculated in the next paragraph.

Mining/Refuse Disposal Incentive. Another benefit of tighter adherence to coal quality specification is that the total tonnage mined is reduced and the total amount of refuse handled is reduced. Using the plant described above, a material balance could be constructed assuming a yield of 77 percent for producing a 10 percent ash coal, and a yield of 80 percent for producing a 11.5 percent ash coal.

Yield)

No Control Scenario. (Producing 10 Percent Ash Coal a 77 Percent

$$
\begin{aligned}
& \text { Tons Mined: } \\
& 800,000 \mathrm{t} / \mathrm{y} \text { sales } 00.77 \text { yield }=1,038,000 \mathrm{t} / \mathrm{y} \text { mined } \\
& \text { Refuse Production: } 1,038,000 \mathrm{t} / \mathrm{y} \text { mined }-800,000 \mathrm{t} / \mathrm{y} \text { sold }= \\
& 238,000 \mathrm{t} / \mathrm{y} \text { refuse. }
\end{aligned}
$$

Integrated Control Employed. (Producing 11.5 Percent Ash Coal at 80 Percent Yield) 
Tons Mined:

$800,000 \mathrm{t} / \mathrm{y}$ sales 0.80 yield $=1,000,000 \mathrm{t} / \mathrm{y}$ mined

Refuse Production: $1,000,000 \mathrm{t} / \mathrm{y}$ mined $-800,000 \mathrm{t} / \mathrm{y}$ sold $=$ $200,000 \mathrm{t} / \mathrm{y}$ refuse.

Assuming a mining cost of $\$ 10 / t$, and a refuse disposal cost of $\$ 5 / t$, the cost savings would be:

Mining Savings: $\$ 10 / t(1,038,000-1,000,000)=380,000 /$ year

Refuse Dispersed Savings: $\$ 5 / t(238,000-200,000)=\$ 190,000 /$ year

Total Mining and Refuse Handling Savings:

$\$ 380,000 / y+\$ 190,000 /$ year $=\$ 570,000 /$ year .

Penalty Avoidance. Although not explicitly stated, this incentive has already been accounted for in the coal giveaway calculations above. The producer has set a 10 percent target to avoid the penalties and potential lost business associated with producing an out-of-specification product. Thus, the operator selects between "giving away" coal by over-cleaning, or severe penalties imposed for missing the target. In today's market, over-cleaning is frequently selected over receiving penalties, so a penalty avoidance cost will not be calculated explicitly. However, in a market with advanced cleaning technologies and advanced conversion processes, the penalty for out-ofspecification coal will be more severe. This might occur because off-spec coal could conceivably reduce the efficiency of the conversion process, or even damage equipment. An example of this would be the effect of high ash coal fed to a combustion turbine. Because of the speculative nature of the costs of an incident of this nature, no control savings are estimated here.

In summary, the cost incentives occur for both conventional and advanced cleaning processes in four major areas outlined in Table 15 . Use of an integrated control strategy is estimated to save a nominal $800,000 \mathrm{t} / \mathrm{y}$ (product) cleaning plant $\$ 843,000 / y$ or about $\$ 1 /$ ton savings. 
TABLE 15. ESTIMATED ANNUAL SAVINGS POSSIBLE WITH COAL SLURRY ASH ANALYZER

\begin{tabular}{lr}
\hline & Savings, \$ \\
\hline Coal GiveAway & 33,000 \\
Mining Reduction & 380,000 \\
Refuse Handling & 190,000 \\
Penalty Avoidance & $(\mathrm{a})$ \\
\hline \multicolumn{1}{c}{ TOTAL } & 843,000 \\
\hline
\end{tabular}

(a) No numerical value is generally accepted, but value is widely recognized.

The savings can be related to the cost of the installed analyzer (estimated at $\$ 100,000$ for a 4-unit DEGG system) in terms of payback period. For this example with a 3 percent yield improvement (yield increase from 77 to 80 percent), the payback period is about 1.5 months. Based on this analysis, it is clear that there are large economic incentives for on-line ash analysis and control. This saving relationship was expanded to include other plant capacities and other yield improvement levels, see figure 40.

\section{Sulfur Control}

Analysis of the benefits of improved sulfur control are more difficult to quantify. Much less work has been done on on-line sulfur analysis. Therefore, less information is available on the possible improvements in pyrite sulfur rejection with on-line control. Two approaches were taken to quantify sulfur-control benefits. The first was an analysis similar to the ash-control case. Savings were based on reduced coal giveaway, 


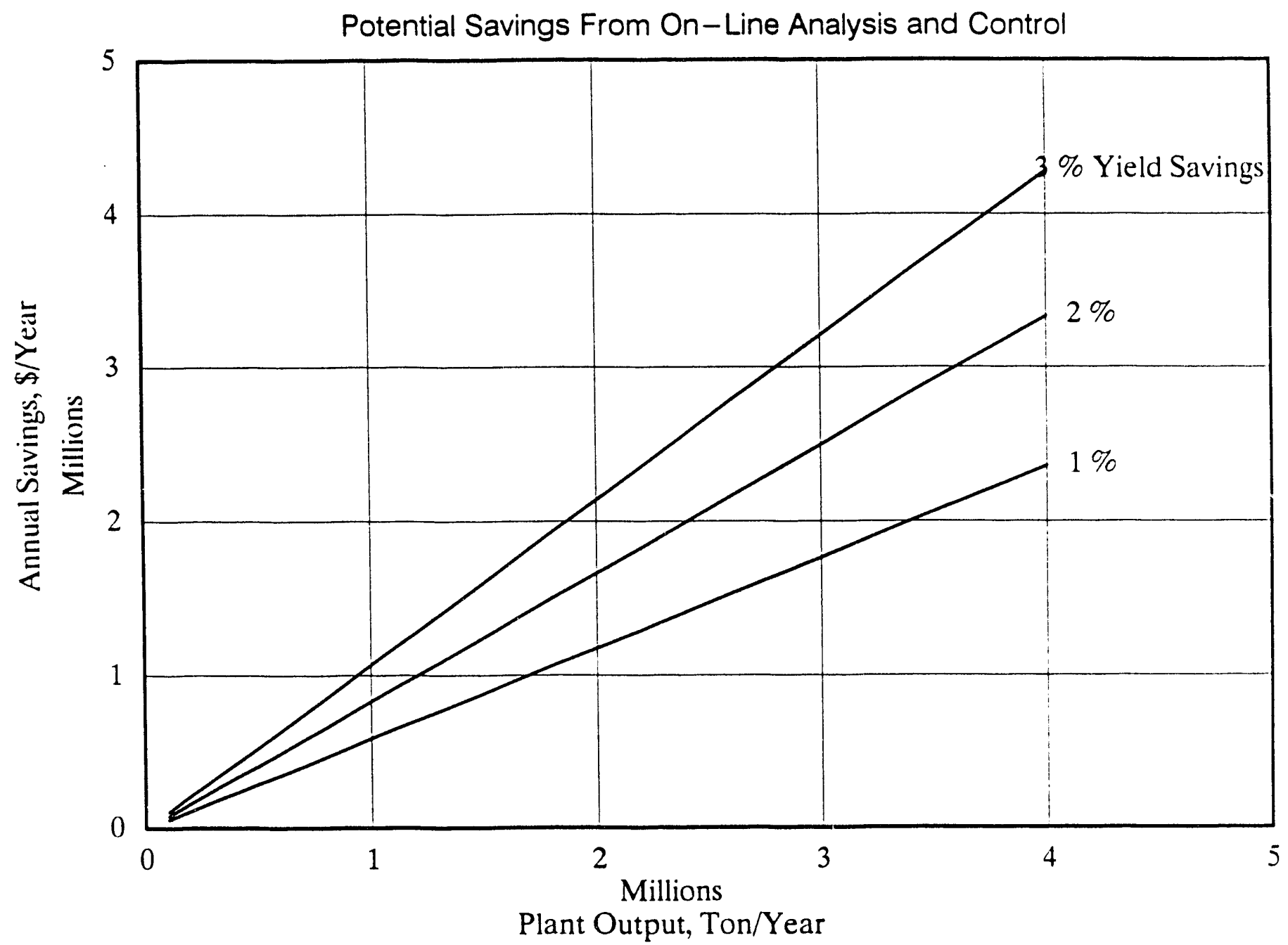

FIGURE 40. POTENTIAL SAVING FROM ON LINE ANALYSIS AND CONTROL 
mining, and refuse-disposal costs. The second approach was based on a higher selling price for lower-sulfur coal. Each is described below.

Coal "Giveaway". Assume that a certain coal preparation plant is contractually bound to deliver 3 percent sulfur (dry basis) coal to a customer at a rate of 4000 tons/day (or roughly 200 tons/hr from a small to intermediate sized plant which is available at full capacity for 20 hours/day for 200 days/year). Plant operators will actually have to establish a lower target value for end-product sulfur content, say 2.6 percent, in order to ensure that excursions above the 3 percent contract value for ash content are minimized.

At the contract specification value of 3 percent sulfur, the coal producer delivers to the customer 800,000 tons/year $(t / y) \times(1-0.03)=776,000$ $(t / y)$ of sulfur-free coal per year. However, in actual operating conditions, the coal producer is turning over to the customer

$$
800,000 t / y \times(1-0.026)=779,200 t / y
$$

of sulfur-free coal per year on the average. The difference between the two above numbers, $3,200 \mathrm{t} / \mathrm{y}$, represents the amount of sulfur-free coal which the producer must "give away" in order to be confident that he is meeting the 3 percent sulfur figure most of the time.

With an integrated coal cleaning control system it is assumed that the plant operator would increase the target sulfur content to 2.8 percent, because the product would have much less variability. The amount of sulfurfree coal in this scenario is:

$800,000 \mathrm{t} / \mathrm{y} \times(1-0.028)=777,600 \mathrm{t} / \mathrm{y}$ or $1,600 \mathrm{t} / \mathrm{y}$ coal given away.

This is $1,600 \mathrm{t} / \mathrm{y}$ less $(3,200-1,600 \mathrm{t} / \mathrm{y})$ than the no-control, 2.6 percent sulfur case, and is equivalent to $1,650 \mathrm{t} / \mathrm{y}$ of 3 -percent sulfur coal. Assuming a selling price of $\$ 20 / t$, this difference between integrated control 
and no control cases translates to a yearly savings of $1,650 \mathrm{t} / \mathrm{y}$ saved $\mathrm{x} \$ 20 / \mathrm{t}$ $=\$ 33,000 / y$ saved.

This calculation ignores the costs associated with mining and refuse disposal; they are calculated in the next paragraph.

Mining/Refuse Disposal Incentive. Another benefit of tighter adherence to coal quality specification is that the total tonnage mined is reduced and the total amount of refuse handled is reduced. Using the plant described above, a material balance could be constructed assuming a yield of 79 percent for producing a 2.6 percent sulfur coal, and a yield of 80 percent for producing a 2.8 percent sulfur coal. (Note: Assuming a small difference in the two yields results in a conservative estimate of the sulfur analysis benefit.)

No Control Scenario. (Producing 2.6 Percent Sulfur Coal a 79 Percent Yield)

Tons Mined:

$800,000 \mathrm{t} / \mathrm{y}$ sales 0.79 yield $=1,013,000 \mathrm{t} / \mathrm{y}$ mined Refuse Production: $1,013,000 \mathrm{t} / \mathrm{y}$ mined $-800,000 \mathrm{t} / \mathrm{y}$ sold $=$ $213,000 \mathrm{t} / \mathrm{y}$ refuse.

Integrated Control Employed. (Producing 2.8 Percent Sulfur Coal at 80 Percent Yield)

Tons Mined:

$800,000 \mathrm{t} / \mathrm{y}$ sales 0.80 yield $=1,000,000 \mathrm{t} / \mathrm{y}$ mined

Refuse Production: $1,000,000 \mathrm{t} / \mathrm{y}$ mined $-800,000 \mathrm{t} / \mathrm{y}$ sold $=$ $200,000 \mathrm{t} / \mathrm{y}$ refuse.

Assuming a mining cost of $\$ 10 / t$, and a refuse disposal cost of $\$ 5 / t$, the cost savings would be:

Mining Savings: $\$ 10 / \mathrm{t}(1,013,000-1,000,000)=130,000 /$ year

Refuse Dispersed Savings: $\$ 5 / \mathrm{t}(213,000-200,000)=\$ 65,000 /$ year

Total Mining and Refuse Handling Savings:

$\$ 130,000 / y+\$ 65,000 /$ year $=\$ 195,000 /$ year. 
Penalty Avoidance. Although not explicitly stated, this incentive has already been accounted for in the coal giveaway calculations above. The producer has set a 2.6 percent sulfur target to avoid the penalties and potential lost business associated with producing an out-of-specification product. Thus, the operator selects between "giving away" coal by overcleaning, or severe penalties imposed for missing the target. In tomorrow's more sulfur-conscience market, over cleaning may frequently be selected over receiving penalties for out-of-sulfur specification coal, so a penalty avoidance cost will not be calculated explicitly. However, in a market with advanced cleaning technologies and advanced conversion processes, the penalty for out-of-specification coal will be more severe. This might occur because off-spec coal would reduce the efficiency of sulfur-emission trade offs. Because of the speculative nature of the costs of an incident of this nature, no control savings are estimated here.

In summary, the cost incentives accrue from both conventional and advanced cleaning processes in four major areas outlined in Table 16 . Use of an integrated control strategy is estimated to save a nominal $800,000 \mathrm{t} / \mathrm{y}$ (product) cleaning plant $\$ 228,000 / y$, or about $\$ 0.30 /$ ton savings.

TABLE 16. ESTIMATED ANNUAL SAVINGS POSSIBLE WITH COAL SLURRY SULFUR ANALYZER

\begin{tabular}{lc}
\hline & Savings, \$ \\
\hline Coal Giveaway & 33,000 \\
Mining Reduction & 130,000 \\
Refuse Handling & 65,000 \\
Penalty Avoidance & $(\mathrm{a})$ \\
\hline
\end{tabular}

(a) No numerical value is generally accepted, but value is widely recognized. 
The savings can be related to the cost of the installed analyzer (estimated at $\$ 300,000$ for a three-unit PGNAA system) in terms of payback period. For this example with a 1 percent yield improvement (yield increase from 79 to 80 percent), the payback period is about 16 months. Based on this analysis, it is clear that there is an economic incentive for on-line sulfur analysis and control.

Selling Price Incentive. The value of low-sulfur coal is anticipated to increase over the next several years, primarily due to the passage of accelerated sulfur-emission control legislation. Currently coal selling price is not highly sulfur dependent. However, if sulfur (and ash) could be eliminated completely, it could sell in the same range as natural gas and oil--or on the order of $\$ 160 /$ ton (based on $\$ 3 / m i l l i o n$ Btu natural gas and $12,000 \mathrm{Btu} / \mathrm{lb} \mathrm{coal})$. If the coal is sufficiently clean to allow combustion with emission levels below $1.2 \mathrm{Ib} \mathrm{SO}_{2}$ per million Btu heat input (i.e., a "compliance" coal), the value of the reduced sulfur could be increased $\$ 10$ to $20 /$ ton the value equal to the cost for flue-gas desulfurization. (11) For higher sulfur-emitting coals, a decrease in sulfur level should be equivalent to at least $\$ 1.00$ for each $1 / 2$ percent sulfur reduction--the equivalent savings from reduced scrubbing costs (1ime $0 \$ 50 /$ ton and 100 percent utilization and sludge disposal e $\$ 10 /$ ton $\left.^{(11)}\right)$.

The level of sulfur reduction with on-line control has not been documented. However, a 25 percent increase in pyrite-sulfur reduction seems a reasonable first estimate. Using the 800,000 tpy plant discussed in the previous example two cases were studied. The first represents a conventional cleaning plant processing 4-percent sulfur coal; the second, an advanced process cleaning 1.9-percent sulfur coal. The following two cases were computed assuming a 25 percent increase in pyrite-sulfur reduction could be achieved, without yield loss, due to on-line sulfur control. 
Conventional Plant

Feed Coal Total Sulfur Content

Pyrites-Sulfur Fraction of Total $50 \%$ Sulfur

Non-Control Pyrite-Sulfur $\quad 30 \%$ Reduction Level

Non-Control Product Sulfur Level $3.42 \%$

( $1 \mathrm{~b} / \mathrm{SO}_{2} / \mathrm{mill}$ ion Btu)

Assumed On-Line Contro! Pyrite Sulfur Reduction Level

On-Line Control Product Sulfur Level ( $\left.1 \mathrm{~b} \mathrm{SO}_{2} / \mathrm{million} \mathrm{Btu}\right)$
$55 \%$

\section{Advanced Plant}

$1.9 \%$

$60 \%$

$65 \%$

1.14

$90 \%$

0.86

For the conventional cleaning-plant case, the sulfur content was decreased by $1 / 2$ percent; therefore, the selling price could be raised by at least $\$ 1 /$ ton. This translated into increased revenue of $\$ 800,000 /$ year.

$(800,000$ tpy $\times \$ 1 /$ ton increased selling price $=\$ 800,000 /$ year $)$

The savings can be related to the cost of the installed analyzer (estimated at $\$ 300,000$ for a three-unit PGNAA system) in terms of payback period. For the conventional plant case, the payback period is about 5 months.

For the advanced process case, improved plant control allowed production of a compliance coal with an increased value of up to $\$ 20 /$ ton. Note, not all of that increased selling price should be associated with the on-line sulfur analysis and control equipment. As a conservative estimate, 10 percent of the potential \$20/ton increased selling price was selected. Therefore, assuming the sulfur-control equipment increased the coal's value by $\$ 2 /$ ton, the payback period is only 2 months. 


\section{Cost/Benefit Assessment for Advanced Froth Flotation}

Flotation control has received considerable attention due to difficulties experienced with current manual control procedures, and the high potential return on investment available from flotation control. $(8,7)$ Therefore, advanced flotation was selected as the advanced process. A typical $300 \mathrm{ft}^{3}$ cell has a coal feed rate of $15 \mathrm{t} / \mathrm{h}$ per cell and a unit is normally composed of four cells. ${ }^{(5)}$ Therefore, a typical flotation unit has a $60 \mathrm{t} / \mathrm{h}$ capacity.

Three levels of control complexity were assessed. The first two employ just simple ash control and moderately complex ash; the third includes complex ash and sulfur control.

\section{Control Mode Mo. 1: Simple Ash/Yield Control for Single Stage} Flotation.

- Monitor the tailings ash content

- Modify cell performance by adjusting the frothier and collector feed pumps

- Control operations using feed back control with a simple up-down set point controller.

A diagram of the analyzer/controller placement is shown below (more details were provided in Section 5 . 


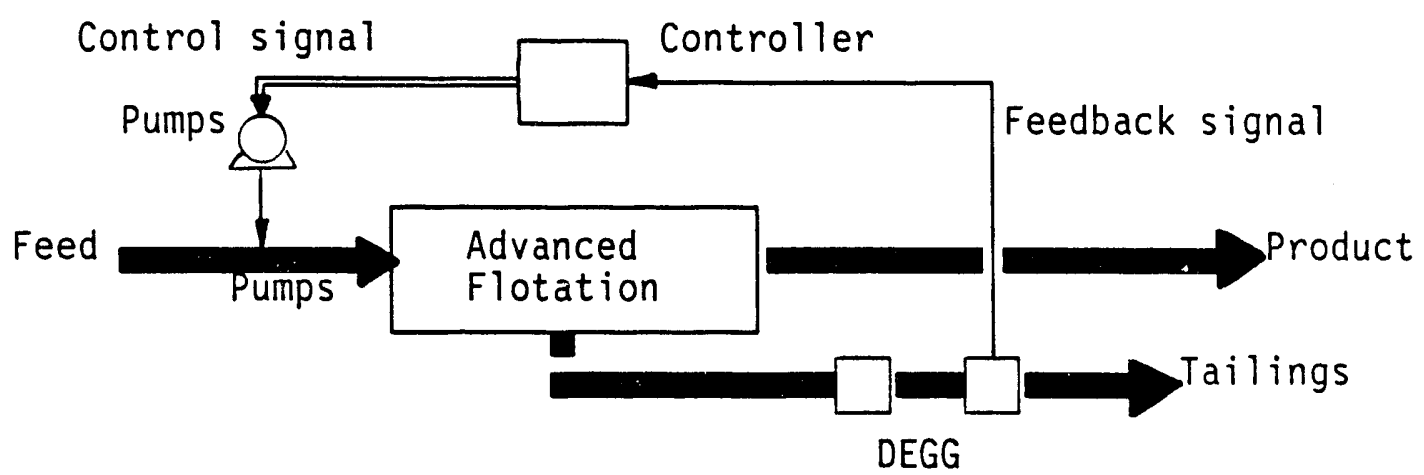

The estimated capital cost for such a system is $\$ 50,000(\$ 27,000$ for the DEGG analyzer, $\$ 10,000$ for the controller and pump system, and $\$ 13,000$ for installation and shakedown). Operating costs are minimal and can be rolled into the normal system operating and maintenance costs. Benefits are estimated at. $\$ 140,000$ per year per unit controlled (based on $15 \mathrm{TPH}$ per flotation ce11, 4 cells per unit, $20 \mathrm{hr} /$ day, 200 day/yr, 1 percent increase in yield through control). Therefore, the estimated payback period is approximately 4 months.

\section{Control Mode Mo. 2: Moderate Complex Ash/Yield Control}

- Monitoring the feed and tailings flow rate and both feed and tailings ash content

- Modifying cell performance by adjusting the frothier and collector feed pumps

- Controlling operations using feed back control with an up-down set point controller.

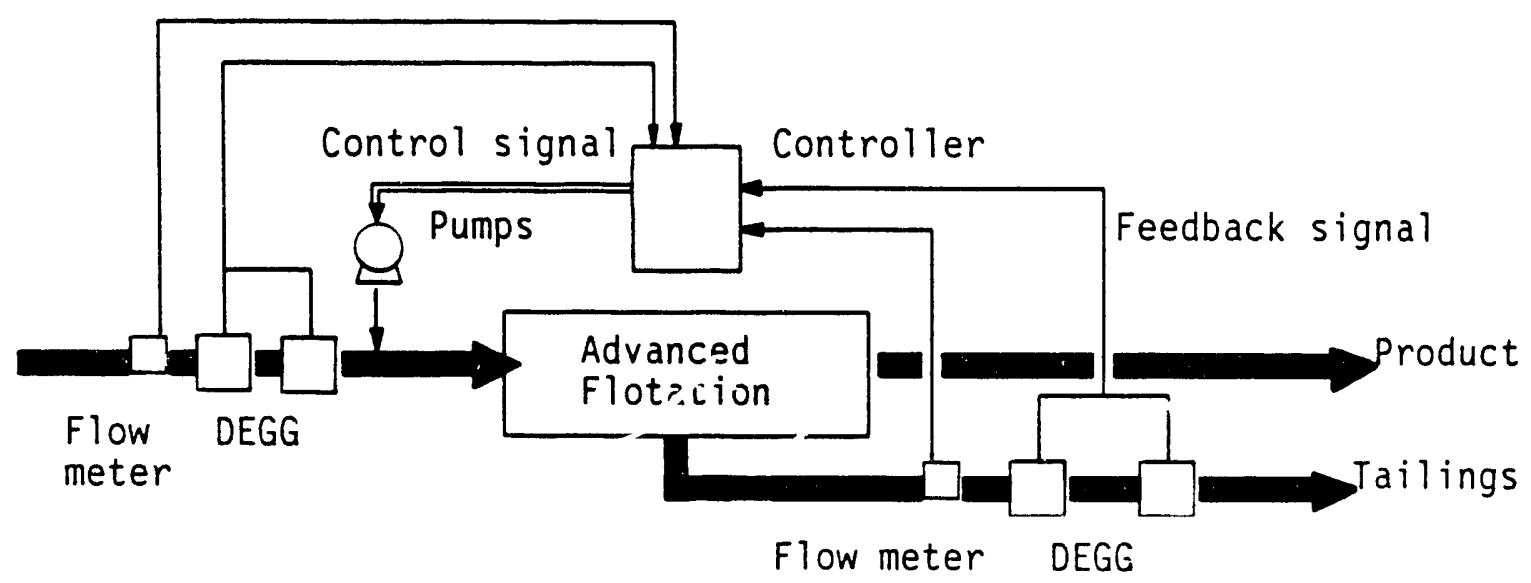


The estimated capital cost for such a system is $\$ 99,000$ ( $\$ 27,000$ for each of the two DEGG analyzer, $\$ 5,000$ for each the two flow meters, $\$ 15,000$ for the controller and pump system, and $\$ 20,000$ for installation and shakedown). Benefits are estimated at $\$ 171,000$ per year per unit controlled (based on 60 TPH per flotation unit, $20 \mathrm{hr} /$ day, 200 day/yr, 1.5 percent increase in yield through on-line analysis and control). Therefore, the estimated payback period is approximately 7 months.

\section{Control Mode Mo. 3: Complex Ash/Sulfur/Yield Control for Multiple Stages}

- Monitoring both first-stage feed and tailings flowrate, feed and tailings ash content, and tailings sulfur and iron content; second siage control can be based on Control Mode No. 1, or 2, or 3 .

- Modifying first-stage performance by adjusting frothier and coal depressant feed pumps based on feed flowrate and feed ash content for primary control, and adjusting cell level based on tailings pyrite content (based on tailings sulfur and iron content) for secondary control; second stage modifications based on the selected Control Mode No. 1, 2, or 3 .

- Controlling operations for the first stage using feed forward control for primary control, and feed back control for secondary control; second stage control loop following the selected Control Mode No. 1, 2, or 3 . 


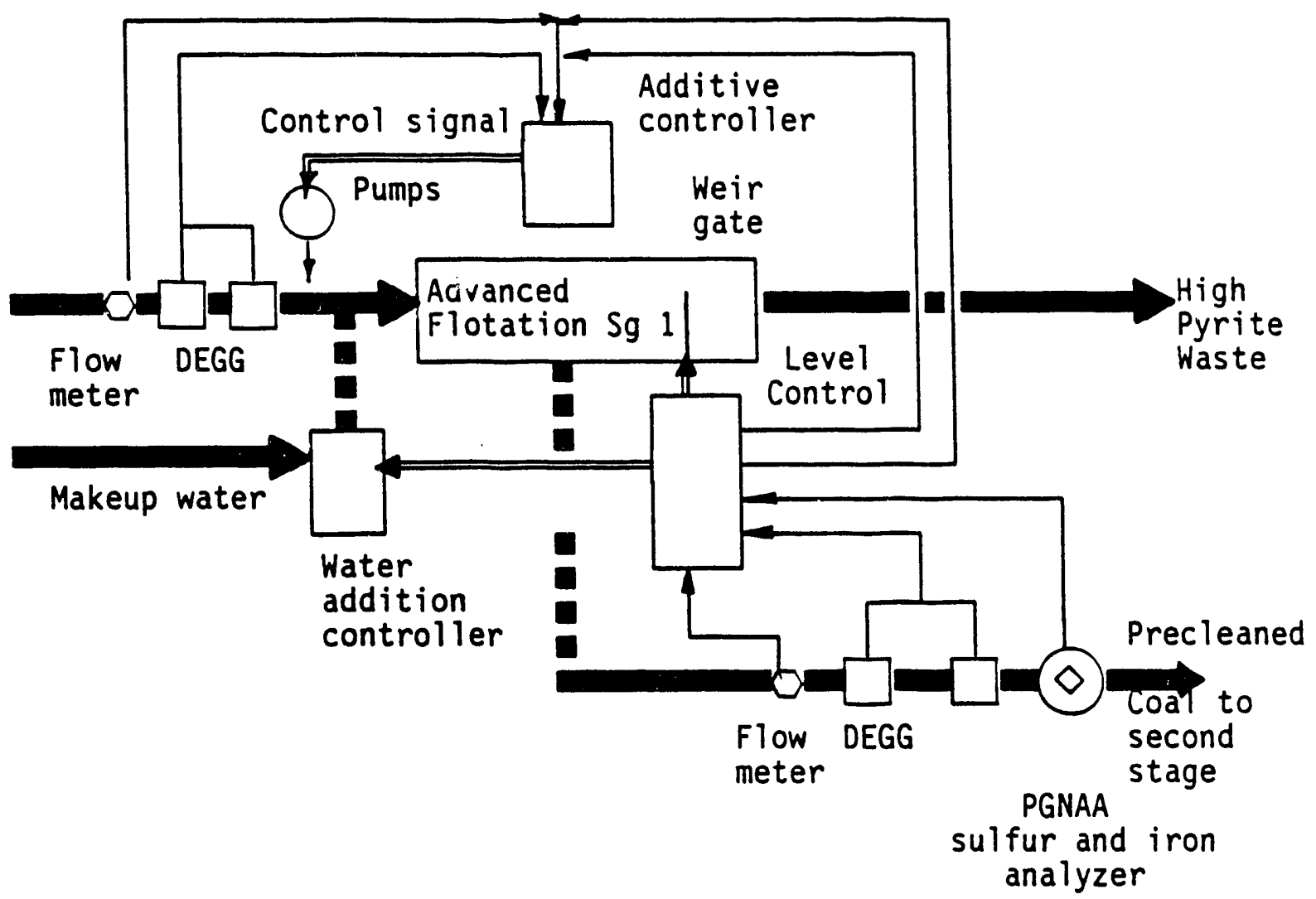

The estimated capital cost for such a system is $\$ 163,000$ ( $\$ 27,000$ for each of the two DEGG analyzers, $\$ 5,000$ for each the two flow meters, $\$ 44,000$ for the PGNAA meter, $\$ 25,000$ for the controller and pump system, and $\$ 30,000$ for installation and shakedown). Benefits are estimated at $\$ 440,000$ per year per unit controlled (the benefit from improved ash control, $\$ 200,000 /$ year, was based on $60 \mathrm{TPH}$ per flotation unit, $20 \mathrm{hr} /$ day, 200 day/yr, 2.0 percent yield increase; the benefit from improved sulfur control, $\$ 240,000 /$ year, was based on an increased coal selling price of $\$ 1 /$ ton). Therefore, the estimated payback period is approximately 10 months.

Therefore, both simple ash/yield control and complex ash and sulfur control are considered excellent investments. 


\section{Cost/Benefit Assessment for Conventional Water-Only Cyclones}

No conventional process, other than froth flotation, has been extensively studied for on-line analys is and control. However, it appears that water-only cyclones represent an excellent choice. The units are simple, inexpensive to operate and have the potential for increased use due to their capability for removal of fine pyrite particles. Therefore, the water-only cyclones were selected as the conventional process. Cyclone capacity depends on cyclone diameter. Typical sizes range from $12-i n c h$ (16 t/h capacity) to 26 -inch $\left(90 \mathrm{t} / \mathrm{h}\right.$ capacity) ${ }^{(5)}$. A $50 \mathrm{t} / \mathrm{h}$ capacity $(24$-inch cyclone) was used for the cost-benefit analysis presented below.

Three levels of control complexity were assessed. The first two employ simple ash control and moderately complex ash control; the third includes complex ash and sulfur control.

Control Mode No. 1: Simple Ash/Yield Control for Water-Only Cyclone

- Monitor the tailings ash content

- Modify cyclone performance by adjusting the vortex finder position

- Control operations using feed back control with a simple position set point controller

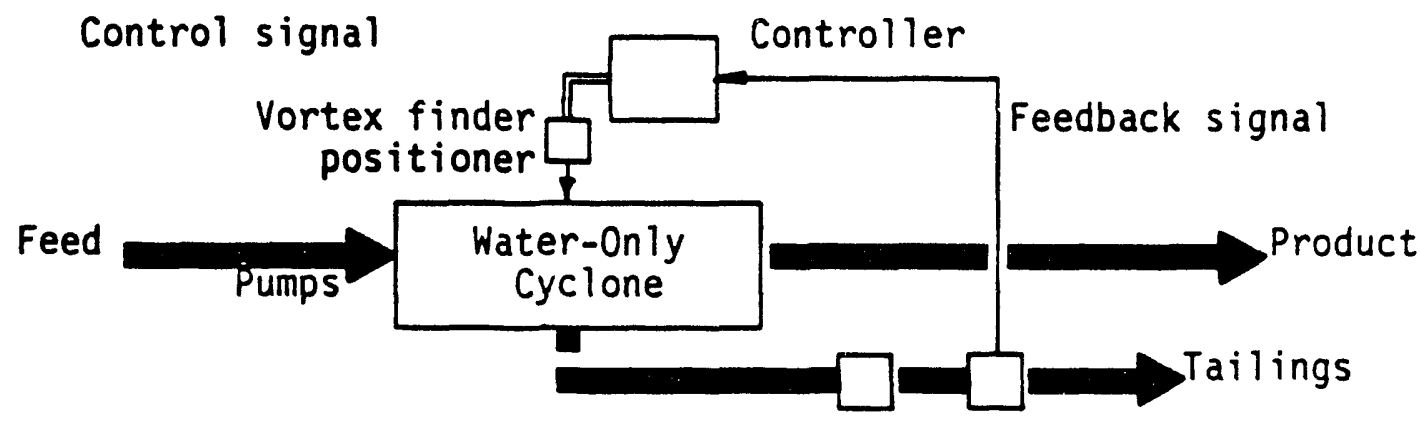

DEGG 
The estimated capital cost for such a system is $\$ 50,000(\$ 27,000$ for the DEGG analyzer, $\$ 10,000$ for the controller and vortex finder mechanism, and $\$ 13,000$ for installation and shakedown). Operating costs are minimal and can be rolled into the normal system operating and maintenance costs. Benefits are estimated at $\$ 120,000$ per year (based on $50 \mathrm{TPH}$ per water-only cyclone controlled, $20 \mathrm{hr} /$ day, $200 \mathrm{day} / \mathrm{yr}, 1$ percent yield increase). Therefore, the estimated payback period is then approximately 5 months.

Control Mode No. 2: Moderate Complex Ash/Yield Control for WaterOnly Cyclone

- Monitoring the feed and tailings flow rate and both feed and tailings ash content. This configuration would allow calculation of product ash content, cyclone yield, and (by using a Btu prediction based on ash content) Btu recovery.

- Modifying cyclone performance by adjusting the vortex finder location (and providing on-line information to the operators on feed percent solids levels which could be adjusted manually)

- Controlling operations using feed back control with a vortex position set point controller.

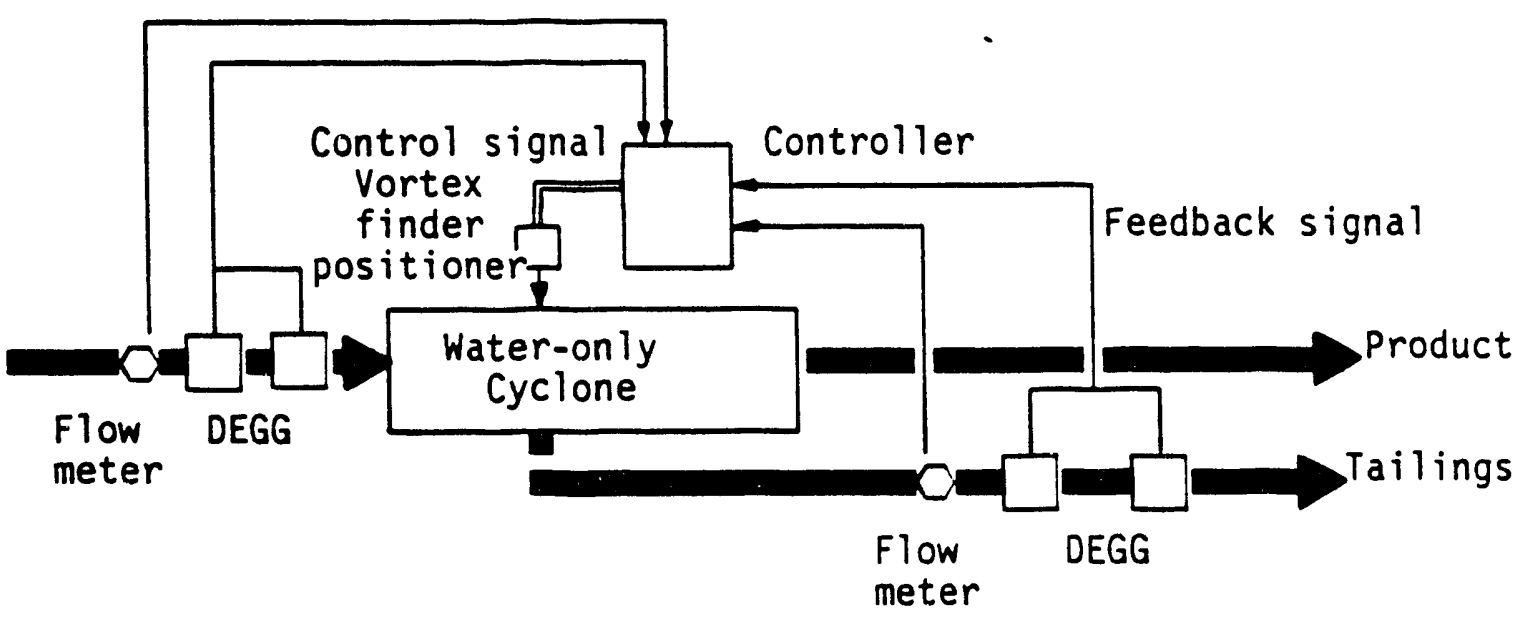


The estimated capital cost for such a system is $\$ 99,000$ ( $\$ 27,000$ for each of the two DEGG analyzer, $\$ 5,000$ for each of the two flow meters, $\$ 15,000$ for the controller and actuator, and $\$ 20,000$ for installation and shakedown). Benefits are estimated at $\$ 140,000$ per year per cyclone controlled (based on $50 \mathrm{TPH}$ per cyclone, $20 \mathrm{hr} /$ day, 200 day/yr, 1.5 percent yield increase). Therefore, the estimated payback period is approximately 8 months.

\section{Control Mode No. 3: Complex Ash/Sulfur/Yield Control for Water-Only Cyclone}

- Monitor the tailings ash and sulfur content

- Modify cyclone performance by adjusting the vortex finder position

- Control operations using feed back control with a simple vortex position set-point controller.

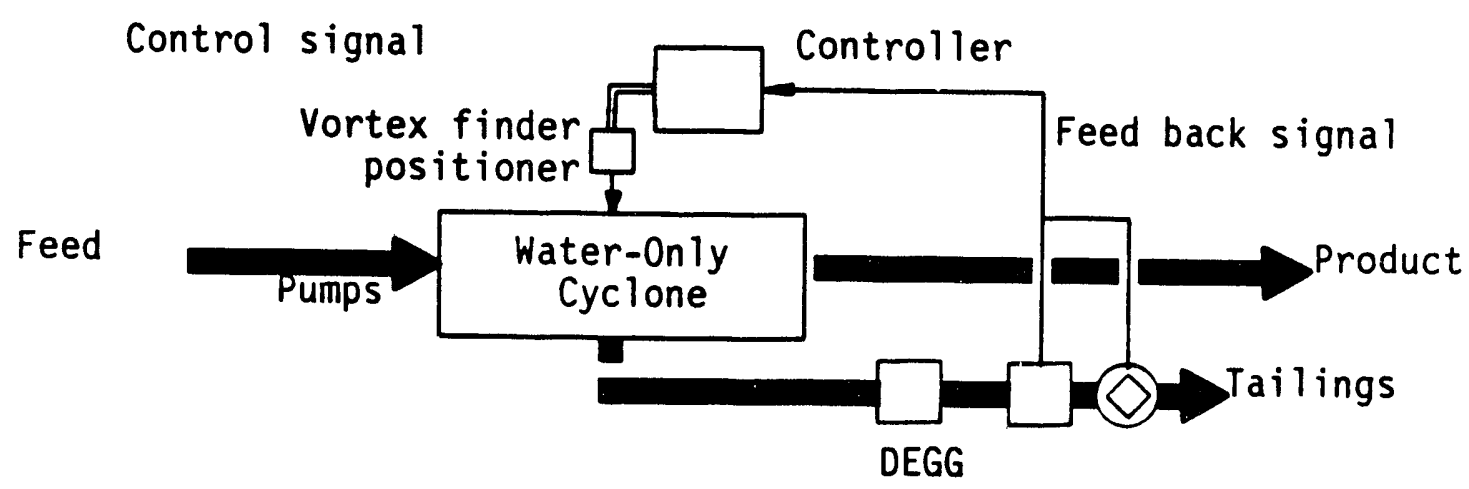

PGNAA

The estimated capital cost for such a system is $\$ 110,000(\$ 27,000$ for the DEGG analyzer, $\$ 44,000$ for the PGNAA analyzer, $\$ 15,000$ for the controller and actuator, and $\$ 24,000$ for installation and shakedown). Benefits are estimated at $\$ 420,000$ per year per cyclone controlled (the ash control benefit, $\$ 170,000 /$ year, was based on $50 \mathrm{TPH}$ per cyclone, $20 \mathrm{hr} /$ day, 200 day/year, 2 percent yield increase; the sulfur control benefit, $\$ 250,000 /$ year was based on an increased coal selling price of $\$ 0.50 /$ ton). Therefore, the estimated payback period is approximately 8 months. 
Again, based on this analysis, both simple and complex control systems are considered excellent investments. 


\section{SECTION 7 CONCLUSIONS AND RECOMMENDATIONS}

\section{Conclusions}

Based on the results obtained from the coal-slurry analyzer instruments testing and process control evaluation, the following conclusions were drawn.

Ash

The DEGG provides an accurate, versatile, easy-to-use, on-line means for estimation of coal-slurry ash content. Over typical ash, ash composition, and percent solids ranges (10 to 25 percent ash, 12 to 34 percent iron oxide in ash, and 5 to 20 percent solids), the ash standard error is less than 1 percent ash. This is within the project's target limit. Use of an iron correlation term in the prediction equation can further lower the ash estimate standard error. Over very broad ash and ash composition ranges (10 to 50 percent ash), error levels increase to around \pm 5 percent ash. Therefore, separate calibrations for feed, product, and refuse streams will probably be necessary to maintain ash error within acceptable levels. Likewise, separate calibration for different coals may be necessary.

The major coal slurry property affecting ash prediction was ash composition and air. Varying sulfur levels, percent solids (above 5 percent), and particle sizes (below 20 mesh) had only minor effects.

The DEGG is well suited to on-line analysis and control. Analysis times were short, allowing nearly instantaneous prediction of ash levels. The unit appears applicable to many major conventional and advanced fine-coal cieaning processes. However, because of extreme sensitivity to high iron levels, or entrapped air, the unit cannot be used for direct analysis of streams containing magnetite or air. However, analysis of product or refuse streams after magnetite-removal in heavy-media applications, or feed or tailings streams from flotation applications, should allow control for these 
critical cleaning operations. Cost/benefit analysis showed excellent potential. Payback periods ranged from 4 to 10 months depending upon the level of analysis, control complexity, and assumed improvements in process yield.

\section{Percent Solids}

The HEGG provides an accurate, versatile, easy-to-use method for online analysis of percent solids. Over typical percent solids, ash, and ash composition ranges ( 5 to 20 percent solids, 10 to 25 percent ash, and 12 to 34 percent iron oxide in ash), the percent solids standard error was less than 1 percent. This was within the project's target limit. Use of signals from both the HEGG and the LEGG (i.e., the DEGG) allow a slight improvement in percent solids predictions. Use of ash and iron correction terms allowed the DEGG to predict percent solids with less than 1-percent standard error over very broad ash and ash composition ranges (10 to 50 percent ash). Therefore, separate calibration for feed, product, or refuse streams might not be necessary if input from the DEGG and PGNAA instruments were available.

The major slurry properties affecting percent solids accuracy were excessively high iron levels (as experienced with magnetite-containing streams) and entrained air. Varying ash (10 to 25), sulfur (1 to 6), particle size (below 20 mesh) had only minor effect.

The HEGG percent solids system is very similar to the DEGG-based ash analyzer. Both were combined for process control and costs/benefits analysis. As noted above, the DEGG is well suited to on-line analys is and control, displaying rapid analysis times, and estimated payback periods from 4 to 10 months.

\section{Sulfur and Iron}

The PGNAA unit provides a versatile, easy-to-use means for on-line analysis of slurry sulfur and iron content. Combined with the HEGG (or DEGG), reasonably accurate dry sulfur and iron estimates can be made. The system 
failed to meet the \pm 0.2 percent sulfur accuracy target original planned. It however, meet the more typical ASTM accuracy level outline in the alternative, \pm 11 percent sulfur target. Over broad ranges of sulfur, ash, ash composition, and percent solids ranges ( 3 to 6 percent sulfur, 10 to 50 percent ash, 12 to 34 percent iron oxide in ash, and 5 to 20 percent solids) the dry sulfur standard error was within the project's revised target. The PGNAA can predict sulfur within 11 percent and iron within 10 percent of their true value, with a bias no greater to 0.03 percent. The sulfur and iron prediction equations contain correction terms for percent solids, chlorine and iron. Since these corrections were adequate to account for very large compositional changes, separate calibrations for different coals may not be necessary.

The major slurry properties affecting sulfur and iron predictions were percent solids, chlorine, and air. Varying ash (10 to 50 percent) and particle sizes (below 20 mesh) had only minor effects on sulfur; but broad ash ranges appeared to adversely affect iron-prediction accuracy.

The PGNAA can be readily employed for on-line analys is and control. Although analysis times, at 5 minutes per analyses, are longer than the DEGG, they are considerably shorter than the lag time associated with most sulfur control actions (e.g., changing cell level, reagent dosage, specific gravity, vortex finder level, etc.). The larger analysis time, however, will make online sulfur somewhat less responsive than the DEGG ash control system. The unit appears applicable to all major fine-coal cleaning processes. But, like the DEGG, can not be applied directly to magnetite-containing streams or froth stream. Cost/benefit analysis showed excellent potential. Payback periods were only 7 to 10 months for combined ash and sulfur control systems. The benefit was based on yield improvement and/or increased selling price. No credit for greater sulfur level stability was included; inclusion would lower the payback periods further. 


\section{Control Strategies}

Control strategies have been successfully developed for advanced fine-coal, slurry-based cleaning processes such as flotation, true-heavy liquid cyclones, and oil agglomeration, and conventional clean processes such as heavy-media cyclones, concentrating tables, water-only cyclones, and froth flotation. The control systems ranged from simple open loop control (analyze and let operator adjust process) to complex, multi-instrument, integrated closed loop control.

\section{Cost/Benefit}

The analyzer appears economically attractive for typical advanced cleaning processes, such as flotation. Savings from on-line analys is and control are due to increased plant yield, reduced mining costs and reduced refuse disposal costs. Saving are projected to be sufficient for payback of the analyzer, control system, and installation within 3 to 8 months. For advanced flotation, payback periods ranged from 4 to 7 months. For conventional water-only cyclones, payback periods ranged from 3 to 8 months. Investments with payback periods less than 18 months are generally considered excellent investment opportunities.

\section{Recommendations}

Based on the experimental data generated and cost/benefits, analyses, the following recommendations are made:

(1) Generate longer-term accuracy data with more coals, over typical slurry processing conditions.

(2) Test the DEGG/PGNAA analyzer in an actual coal cleaning plant control mode. Determine effectiveness, estimate costs for the control system and installation, and document savings achieved. 
(3) Replace the HEGG with a state-of-the-art cesium 137 densitometer, and modify a similar unit as an americium densitometer. Such a replacement should allow greater accuracy (due to improved electronics), lower gamma-ray emissions (due to smaller Am-241 and Cs-137 sources), and lower instrument costs. Test the effectiveness of new electronics, and reestimate DEGG analyzer costs.

(4) Replace the PGNAA amplifier and multi-channel analysis with new state-of-the-art equipment. These replacements should allow greater accuracy, due to more precise division of the PGNAA spectrum (9000 versus 512 divisions), better spectrum stabilization, and improved electronics. In addition, the new equipment should provide directly the corrected hydrogen, sulfur, chlorine and iron counts needed to predict sulfur--this will allow more rapid integration with on-line data acquisition, sulfur prediction, and control systems. Test the effectiveness of new electronics, and re-evaluate PGNAA analyzer costs.

(5) Identify the maximum coal particle size consistent with accurate slurry analysis. 


\section{SECTION 8 REFERENCES}

1. EPRI Report. Reynolds, G., et. al., Nuclear Assay of Coal Volume I: Coal Composition by Prompt Neutron Activation Analysis--Basic Experiments, Final Report prepared by Science Applications, Inc. for the Electric Power Research Institute, EPRI Report No. FP-989, Volume I, January 1979.

2. ASTM Manual. 1987 Annual Book of ASTM Standards, Section 5-Petroleum Products, Lubricants, and Fossil Fuels, Volume 05.05-Gaseous Fuels, Coal and Coke, Publications Code Number 01-050587-13, ASTM, Philadelphia, PA, (pp. 397-401) (D3177-84) and (pp 469-480) (D4239-85).

3. Oblad, H. B. and Nelson, M. G., "Control of Fine Coal Flotation Using An Optoelectronic Tailings Ash Detector," Proceeding of Coal Prep 89, Lexington, KY, May 2-4, 1989 (pp 5-20).

4. Barbagallo, John, "Automatic Process Control of Fine Coal Flotation", Proceeding of Coal Prep 89, Lexington, KY, May 2-4, 1989 (pp 215-234).

5. Holt, Elmer C., An Engineering/Economic Analysis of Coal Preparation Plant OPeration and Cost, Final Report prepared by The Hoffman-Muntner Corp. for the U. S. DOE, Contract No. ET-75-C-01-9025 (February, 1978).

6. Cox, J. H. and Baxter, D. T., "Sampling and Analysis Priorities", Proceeding of Coal Prep 89, Lexington, KY, May 2-4, 1989 (pp 89-102).

7. Brown, Robert J., "Monitoring Ash Content On-Line in Fine Coal Slurry - A Case Study," Proceeding of Coal Prep 89, Lexington, KY, May 2-4, 1989 (pp 235-256).

8. Personal Communication, Chuck Jackson, Texas Nuclear, September 1, 1989, 512-836-0801.

9. Personal Communication, Steve V. Hatoe, EG\&G Ortec, September 1, 1989, 615-986-4212.

10. Personal Communication, Mike Harred, Morland Corp., September 3, 1989, 800-444-8456.

11. Personal Communication, J. H. Oxley, Battelle Memorial Institute, January $31,1990,614-4240-7885$.

12. Lone, M. A., Leavitt, R. A., and Harrison, D. A., "Prompt Gamma Rays from Thermal-Neutron Capture," Atomic Data and Nuclear Data Tables, Vol. 26, No. 6, November 1981 (pp 511-559), Academic Press, Inc. 
APPENDIX A

ASH AND PERCENT SOLIDS ANALYSIS 


\section{APPENDIX A}

\section{ASH AND PERCENT SOLIDS ANALYSIS}

This appendix is divided into two sections, duel-energy gamma gauge DEGG Percent Solids and Ash Prediction Procedures and detailed equipment description. 
The attenuation of gamma rays in a coal-water slurry may be represented by the following relationship

$$
\frac{I}{I_{1}}=e^{-\rho \sum_{i} \omega_{i} \mu_{i}(E) T}
$$

where

$$
\begin{aligned}
\rho= & \text { slurry density, } \mathrm{g} / \mathrm{cm}^{3} \\
\omega_{i}= & \text { weight fraction of component } i \text { in slurry } \\
\mu_{i}(E)= & \text { attenuation coefficient for component } i \text { as a function } \\
& \text { of gamma-ray energy } E, \mathrm{~cm}^{2} / \mathrm{g} \\
T \quad= & \text { thickness of absorber, } \mathrm{cm} \\
I \quad= & \text { attenuated gamma-ray intensity, photons } / \mathrm{cm}^{2} \cdot \mathrm{s} \\
I_{1}= & \text { unattenuated gamma-ray intensity, photon } / \mathrm{cm}^{2} \cdot \mathrm{s} \\
I_{0}= & \text { attenuated genma-ray intensity, with only water, } \\
& \text { photon } / \mathrm{cm}^{2} \cdot \mathrm{s} .
\end{aligned}
$$

For the case where attenuation is due only to water, the above expression reduces to

$$
\frac{I_{0}}{I_{1}}=e^{-\rho w_{w} \mu_{w} T}
$$

where $\omega_{W}$ is the weight fraction of water in the slurry and $\omega_{W}$ is the gamma-ray attenuation coefficient for water. Combining equations $(A-1)$ and $(A-2)$ gives the following relationship

$$
S=\ln \left(\frac{\mathrm{I}}{\mathrm{I}}\right)=\rho \sum_{i} \omega_{i} \mu_{i} \mathrm{~T}-\rho \omega_{w} \mu_{w} \mathrm{~T}=\rho \mathrm{T} \sum_{i} \omega_{i} \mu_{i}
$$


where the prime indicates that water is excluded from the summation. Since the attenuation coefficients vary with gamma-ray energy, equation $(A-3)$ can be written for both high-energy and low-energy gamma rays as

$$
S_{H}=\rho T \sum_{i}^{\prime} \omega_{i} \mu_{i}
$$

and

$$
S_{L}=\rho T \sum_{i}^{\prime} \omega_{i} \mu_{i_{L}}
$$

where the subscript $H$ denotes the $662 \mathrm{keV}$ yamma-ray from Cs 137 and $L$ the $60 \mathrm{keV}$ gamma-ray of Am241. The summations can be written as separate sums over the different classes of components

$$
\sum_{i}^{\prime} \omega_{i} \mu_{i}=\sum_{C, H, O} \omega_{i} \mu_{i}+\sum_{a} \omega_{i} \mu_{i}+\sum_{s, C \ell, . v} \omega_{i} \mu_{i}
$$

where the summation index "a" represents ash components as oxides, and $C$, $\mathrm{H}, \mathrm{O}, \mathrm{S}, \mathrm{Ce}$, and $\mathrm{N}$ represent carbon, hydrogen, oxygen, sulfur, chlorine, and nitrogen as atoms. Each of the above sums can be expressed as

$$
\begin{aligned}
\sum_{C, \mathrm{H}, \mathrm{O}} \omega_{\mathrm{i}} \mu_{\mathrm{i}} & =\omega_{C^{\mu} \mu}+\omega_{\mathrm{H}} \mu_{\mathrm{H}}+\omega_{\mathrm{O}} \mu_{\mathrm{O}} \\
\sum_{\mathrm{a}} \omega_{\mathrm{i}} \mu_{\mathrm{i}} & =\sum_{\mathrm{a}} \cdot{ }^{\prime}{ }^{\prime} \omega_{\mathrm{i}} \mu_{\mathrm{i}}+\omega_{\mathrm{Fe}_{2} \mathrm{O}_{3}} \mu_{\mathrm{Fe}_{2} \mathrm{O}_{3}} \\
& =\frac{\sum_{\mathrm{a}}}{}{ }^{\prime} \omega_{\mathrm{i}}\left(\mathrm{a}_{\mathrm{i}} \mu_{\mathrm{i}}+\beta_{\mathrm{i}} \mu_{\mathrm{o}}\right)+\omega_{\mathrm{Fe}_{2} \mathrm{O}_{3}}\left(\mathrm{a}_{\mathrm{Fe}_{2} \mathrm{O}_{3}} \mu_{\mathrm{Fe}}+\beta_{\mathrm{Fe}_{2} \mathrm{O}_{3}} \mu_{\mathrm{o}}\right)
\end{aligned}
$$




$$
\sum_{\mathrm{S}, \mathrm{Cl}, \mathrm{N}} \omega_{\mathrm{i}} \mu_{\mathrm{i}} \simeq \omega_{\mathrm{S}} \mu_{\mathrm{S}}
$$

where double primes denote that iron oxide is excluded from the summation, $\alpha_{j}$ is the weight fraction of metal and $B_{j}$ the weight fraction of oxygen in the ash metal oxide. In the case of the iron oxide $\mathrm{Fe}_{2} \mathrm{O}_{3}$, the values of

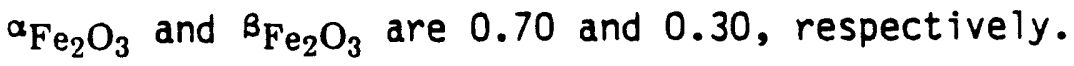

Attenuation coefficients for the two different gamma-ray energies of interest are listed in Table A-1 for major atomic constituents in coal.

TABLE 1. GAMMA-RAY ATTENUATION COEFFICIENTS

\begin{tabular}{rcccccc}
\hline \multirow{2}{*}{$\begin{array}{c}\text { Energy, } \\
\text { keV }\end{array}$} & \multicolumn{6}{c}{ Attenuation Coefficient, $\mathrm{cm}^{2} / \mathrm{g}$} \\
\cline { 2 - 7 } & $\mu_{\mathrm{C}}$ & $\mu_{\mathrm{H}}$ & $\mu_{\mathrm{O}}$ & Hash & $\mu_{\mathrm{Fe}}$ & $\mu_{\mathrm{S}}$ \\
\hline 60 & 0.176 & 0.326 & 0.165 & 0.322 & 1.2 & 0.223 \\
662 & 0.081 & 0.160 & 0.081 & 0.081 & 0.077 & 0.081 \\
\hline
\end{tabular}

TABLE 2. MODEL COALS

\begin{tabular}{|c|c|c|c|c|c|c|c|}
\hline \multirow[b]{2}{*}{ Type Coal } & \multirow{2}{*}{$\begin{array}{c}\text { Density, } \\
\mathrm{g} / \mathrm{cm}^{3}\end{array}$} & \multicolumn{6}{|c|}{ Weight Percent } \\
\hline & & c & H & 0 & $A s{ }^{\star}$ & $\mathrm{Fe}$ & $\mathrm{s}$ \\
\hline Ohio No. $4 \mathrm{~A}$ & 1.45 & 66.02 & 5.03 & 8.82 & 10.49 & 2.627 & 3.54 \\
\hline Illinois No. 6 & 1.47 & 62.31 & 4.33 & 8.16 & 11.45 & 2.78 & 3.83 \\
\hline E]khorn & 1.37 & 78.56 & 4.94 & 7.55 & 4.92 & 0.34 & 0.59 \\
\hline High Ash Refuse & -- & 32.82 & 2.21 & 3.67 & 52.50 & 12.47 & 7.46 \\
\hline
\end{tabular}

*Contains $\mathrm{Fe}$. 
Assuming the coal compositions listed in Table A-2 as covering the range of coals of interest to this program, the following approximations can be used without appreciable error

$$
\sum_{i} \omega_{i} \mu_{i_{H}}=\sum_{C, H, O} \omega_{i} \mu_{i_{H}}+\sum_{a} \omega_{i} \mu_{i_{H}}
$$

and

$$
\sum_{i}^{\prime} \omega_{i} \mu_{i_{L}} \approx \sum_{C, H, O} \omega_{i} \mu_{i_{L}}+\sum_{a}^{n} \omega_{i} \mu_{i_{L}}+\omega_{\mathrm{Fe}_{2} \mathrm{O}_{3}} \mu_{\mathrm{Fe}_{2} \mathrm{O}_{3}}
$$

Taking the ratio of equations $(A-4)$ and $(A-5)$ gives

$$
\frac{S_{H}}{S_{L}}=\frac{\sum_{i}^{\prime} \omega_{i} \mu_{i}}{\sum_{i}^{\prime} \omega_{i} \mu_{i}}
$$

Using the relationship

$$
\omega_{\mathrm{a}}=\sum_{\mathrm{a}} \omega_{\mathrm{i}}=\sum_{\mathrm{a}}^{\prime \prime} \omega_{\mathrm{i}}+\omega_{\mathrm{Fe}_{2} \mathrm{O}_{3}}
$$

the ash summation at the higher energy can be written approximately as

$$
\sum_{i} \omega_{i} \mu_{i_{H}} \approx \bar{\mu}_{a_{H}} \sum_{a} \omega_{i}=\omega_{a} \bar{\mu}_{a_{H}}
$$

where $\bar{\mu}_{a}$ is the average attenuation coefficient for ash, and equation $(A-12)$ can be written as

$$
\frac{S_{H}}{S_{L}}=\frac{\sum_{C, H, O} \omega_{i} \mu_{i_{H}}+\omega_{a} \bar{\mu}_{a_{H}}}{\sum_{C, H, O} \omega_{i} \mu_{i_{L}}+\omega_{a} \bar{\mu}_{{ }_{2}}+\omega_{F_{2} O_{3}}\left|\mu_{\mathrm{Fe}_{2} O_{3}}(L)-\bar{\mu}_{a}(L)\right|}
$$


Solving the above equation for $\omega_{a}$ gives the weight fraction of ash in the slurry as

$$
\omega_{a}=\frac{\sum_{C, H, O} \omega_{i} \mu_{i_{H}}-\frac{S_{H}}{S_{L}}\left\{\sum_{C, H, O} \omega_{i} \mu_{i_{L}}+\omega_{F_{2} o_{3}}\left[\mu_{F e_{2} O_{3_{L}}}-\bar{\mu}_{a_{L}}\right]\right\}}{\left[\frac{S_{H}}{S_{L}} \bar{\mu}_{a_{L}}-\bar{\mu}_{a_{H}}\right]}
$$

As an approximation the above equation can be further approximated by the expression

$$
\omega_{a}=\frac{\tilde{C}_{1_{H}}-\left(\frac{S_{H}}{S_{L}}\right) \tilde{C}_{1_{L}}}{\left(\frac{S_{H}}{S_{L}}\right) C_{2}-C_{2_{H}}}
$$

where

$$
\begin{aligned}
& \widetilde{\mathrm{C}}_{1_{\mathrm{L}}}=\sum_{\mathrm{C}, \mathrm{H}, \mathrm{O}} \omega_{\mathrm{i}} \mu_{\mathrm{i}_{\mathrm{L}}}+\omega_{\mathrm{Fe}_{2} \mathrm{O}_{3}}\left[\mu_{\mathrm{Fe}_{2} \mathrm{O}_{3}}-\bar{\mu}_{\mathrm{a}_{\mathrm{L}}}\right] \\
& \widetilde{\mathrm{C}}_{1_{\mathrm{H}}}=\sum_{\mathrm{C}, \mathrm{H}, \mathrm{O}} \omega_{\mathrm{i}} \mu_{\mathrm{i}_{\mathrm{H}}} \\
& \mathrm{C}_{2_{\mathrm{L}}}=\bar{\mu}_{\mathrm{a}_{\mathrm{L}}} \\
& \mathrm{C}_{2_{\mathrm{H}}}=\bar{\mu}_{\mathrm{a}_{\mathrm{H}}} .
\end{aligned}
$$

The values of the $\tilde{c}_{1_{L}}$ and $\tilde{c}_{2_{L}}$ may be obtained using experimental measurements from the approximation

$$
\frac{S_{L}}{\rho T}=\widetilde{C}_{1_{L}}+C_{2_{L}} \omega_{a}
$$


by plotting $S_{L} / \rho T$ versus wa where $\tilde{c}_{1_{L}}$ is the intercept and $c_{2_{L}}$ the slope. Similarly, using the expression

$$
\frac{S_{H}}{\rho T}=\widetilde{C}_{1_{H}}+C_{2_{H}} \omega_{a} \text {, }
$$

$\tilde{\mathrm{c}}_{1_{\mathrm{H}}}$ and $\tilde{\mathrm{c}}_{2_{\mathrm{H}}}$ can be obtained.

As a further simplification $\mathrm{C}_{2}$, which has a value of only 0.3 , can be assumed to be nearly zero allowing Equation A-9 to be rearranged as

$$
w_{2}=A+B\left(S_{L} / S_{H}\right)
$$
relationship

For correlating data Equation $(A-16)$ can be expanded to give the

$$
\omega_{\mathrm{a}}=\tilde{A}_{0}+\tilde{A}_{1}\left(\frac{S_{L}}{S_{H}}\right)+\tilde{A}_{2}\left(\frac{S_{L}}{S_{H}}\right)^{2}+\tilde{A}_{3}\left(\frac{S_{L}}{S_{H}}\right)^{3}+\ldots
$$


where

$$
\begin{aligned}
& \tilde{\mathrm{A}}_{0}=-\frac{\widetilde{\mathrm{C}}_{1_{\mathrm{H}}}}{\mathrm{C}_{2_{\mathrm{H}}}} \\
& \widetilde{\mathrm{A}}_{1}=\frac{1}{\mathrm{C}_{2_{H}}}\left|\widetilde{\mathrm{C}}_{1_{L}}-\frac{\widetilde{\mathrm{C}}_{1_{\mathrm{H}}} \mathrm{C}_{2}}{\mathrm{C}_{2_{H}}}\right| \\
& \widetilde{A}_{2}=\frac{C_{2}}{\left[C_{2_{H}}\right]^{2}}\left(\widetilde{C}_{1_{L}}-\frac{\widetilde{C}_{1_{H}} C_{2 L}}{C_{2_{H}}}\right) \\
& \tilde{\mathrm{A}}_{3}=\frac{\left[\mathrm{C}_{2_{\mathrm{L}}}\right]^{2}}{\left[\mathrm{C}_{2_{\mathrm{H}}}\right]^{3}}\left[\widetilde{\mathrm{C}}_{1_{\mathrm{L}}}-\frac{\widetilde{\mathrm{C}}_{1_{\mathrm{H}}} \mathrm{C}_{2}}{\mathrm{C}_{2_{\mathrm{H}}}}\right]
\end{aligned}
$$

$\widetilde{\mathrm{C}}_{1_{L}}$ is a strong function of iron composition. Therefore, $\widetilde{\mathrm{A}}_{2}$ and $\tilde{A}_{3}$ will not be constant over varying iron content coals. To account for this, an alternative correlation equation was developed

$$
w_{a}=A+B\left(\frac{S_{L}}{S_{H}}\right)+C\left(w_{F_{0}}\right)+D\left(\frac{S_{L}}{S_{H}}\right)\left(w_{F_{0}}\right)+E\left(S_{H}\right)
$$

\section{Percent Solids}

The weight fractions of water and solids in the coal-water slurry can be expressed as 


$$
\begin{gathered}
A-8 \\
\omega_{w}=\frac{\rho}{\rho} v_{w}
\end{gathered}
$$

- and

$$
\omega_{\text {so }}=\frac{\rho_{\text {so }}}{\rho} v_{\text {so }}
$$

where

$$
\begin{aligned}
& \omega_{w}=\text { weight fraction of water in slurry } \\
& w_{s o}=\text { weight fraction of solids in slurry } \\
& \rho_{w}=\text { density of water, } g / \mathrm{cm}^{3} \\
& \rho_{\text {so }}=\text { density of solids, } \mathrm{g} / \mathrm{cm}^{3} \\
& v_{w}=\text { volume fraction of water in slurry } \\
& v_{\text {so }}=\text { volume fraction of solids in slurry }
\end{aligned}
$$

From the above two relationships the density of the slurry is

$$
\rho=\rho_{w} v_{w}+\rho_{\text {so }} v_{\text {so }}
$$

or in terms of weight fraction as

$$
\rho=\frac{\rho_{w} \rho_{s 0}}{\omega_{s 0} \rho_{w}+\omega_{w} \rho_{s o}}
$$

If $x_{i}$ is the weight fraction of species $i$ in the solids, then the weight fraction of that species in the slurry is given by

$$
\omega_{i}=\omega_{s o} x_{i}
$$


To calculate the density of the slurry, equation $(A-4)$ is used for the higher gamma energies where the linear absorption coefficients are approximately equal

$$
\rho=\frac{S_{H}}{T \sum_{i}^{\prime} \omega_{i} \mu_{i_{H}}} .
$$

The above summation can be expressed approximately as

$$
\begin{aligned}
& \sum_{i}^{\prime} \omega_{i} \mu_{i_{H}}=\sum_{i}{ }^{\prime \prime} \omega_{i} \mu_{i_{H}}+\omega_{H} \mu_{H_{H}} \\
& \approx \mu_{C_{H}} \sum_{i}{ }^{\prime \prime} \omega_{i}+\omega_{H} \mu_{H_{H}} \\
& \approx \mu_{C_{H}}\left(1-\omega_{H}-\omega_{W}\right)+\omega_{H_{H}} \mu_{H_{H}}
\end{aligned}
$$

where the triple prime denotes that hydrogen and water are excluded from the summation. Equation $(A-17)$ can now be approximated as

$$
\begin{gathered}
\rho=\frac{S_{H} / T}{\mu_{C_{H}}\left(1-\omega_{H}-\omega_{W}\right)+\omega_{H} \mu_{H_{H}}} \\
=\frac{S_{H} / T}{\mu_{C_{H}}\left(1-\omega_{W}\right)+\omega_{H}\left[\mu_{H_{H}}-\mu_{C_{H}}\right]}
\end{gathered}
$$

Since

$$
\omega_{\mathrm{w}}+\omega_{\mathrm{so}}=1
$$


the above equation can be written in terms of the weight fraction of solids as

$$
\rho=\frac{S_{H} / T}{\mu_{C_{H}} \omega_{s o}+\omega_{H}\left[\mu_{H_{H}}-\mu_{C_{H}}\right]}
$$

Combining equations $(A-17)$ and $(A-30)$ gives the expression for the weight fraction of solids as

$$
\omega_{s o}=\frac{\left\{\left(\frac{S_{H}}{T}\right)-\rho_{w} \omega_{H}\left[\mu_{H_{H}}-\mu_{C_{H}}\right]\right\}}{\left|\rho_{W^{\mu}} \mu_{C_{H}}+\left(\frac{S_{H}}{T}\right)\left(1-\frac{\rho_{W}}{\rho_{S O}}\right)\right|}
$$

If $\rho_{S O} \approx \rho_{W}$ and $\omega_{H}$ is sma11, the above expression can be written approximately as

$$
\omega_{s o}=\frac{S_{H}}{\rho_{w} \mu_{C_{H}} T}=\frac{S_{H}}{\mu_{C_{H}} T}
$$

since ow $\approx 1 \mathrm{~g} / \mathrm{cm}^{3}$.

To develop an expression for data correlation and instrument calibration, equation $(A-32)$ can be expressed to give

$$
\begin{gathered}
\omega_{\mathrm{so}}=-a \omega_{H}+\left(1+a \beta \omega_{H}\right)\left(\frac{S_{H}}{\rho_{w} \mu_{C_{H}} T}\right)-\beta\left(1+a \beta \omega_{H}\right)\left(\frac{S_{H}}{\rho_{w^{\mu} C_{H}} T}\right)^{2} \\
+\beta^{2}\left(1+a \beta \omega_{H}\right)\left(\frac{S_{H}}{\rho_{W^{\mu} C_{H}} T}\right)^{3}+\ldots \\
\approx \widetilde{B}_{0}+\widetilde{B}_{1} S_{H}+\widetilde{B}_{2} S_{H}^{2}
\end{gathered}
$$


where

$$
\begin{aligned}
& \widetilde{B}_{0}=-a \omega_{H} \\
& \widetilde{B}_{1}=\frac{\left(1+a \beta \omega_{H}\right)}{\rho_{W^{\mu} C_{H} T}} \\
& \widetilde{B}_{2}=-\frac{\beta\left(1+a \beta \omega_{H}\right)}{\left(\rho_{W^{\mu} C_{H}} T\right)^{2}} \\
& a=\frac{\left[\mu_{H_{H}}-\mu_{C_{H}}\right]}{\mu_{C_{H}} T} \\
& \beta=\left(1-\frac{\rho_{w}}{\rho_{s o}}\right) .
\end{aligned}
$$

This relationship can be further expanded, to more explicitly take into account the observed effect of ash and iron on percent solids, as

$$
W_{S O}=A+B\left(S_{H}\right)+C(A s h)+D(F e)+E\left(S_{H} \cdot A s h\right)+F\left(S_{H} \cdot F e\right)
$$

This could also be re-expressed, substituting $\left(S_{L} / S_{H}\right)$ for ash, as

$$
W_{S O}=A+B\left(S_{H}\right)+C\left(S_{L} / S_{H}\right)+D(F e)+E\left(S_{L}\right)+F\left(S_{H} \cdot F e\right)
$$

\section{Sensitivity Analysis}

A brief sensitivity analysis was performed using I1linois No. 6 and Elkhorn coals with percent solids in the slurries of 5 and 20 percent. Equation (A-33), which calculates the solids fraction in the slurry, ${ }^{\omega_{s o}}$, is accurate to within 6 percent. Neglecting the hydrogen correction and the density term increases the error to about 10 percent. 
Assuming that $\tilde{c}_{1_{H}}$ and $\tilde{c}_{1_{L}}$ are constants can introduce errors of over 50 percent in the determination of the ash fraction, wa, from equation $(A-17)$. The error introduction by fitting calibration data to plots of $R / \rho T$ versus $w_{\text {a }}$ to determine the constants $C_{1}$ and $C_{2}$ has inherent errors of at least 10 percent. The best calculational accuracy was obtained using the expansion of $\omega_{a}$ in terms of $S_{L} / S_{H}$ where the $A^{\prime}$ 's were determined by linear regression using data for a specific coal. 


\section{DETAILED EQUIPMENT DESCRIPTION}

\section{High-Energy Gamma Gauge}

The high energy gamma gauge (HEGG) is a modified Texas Nuclear SGH densitometer. The standard SGH densitometer is composed of four major components, the source head (which holds a 0.1 to 0.2 milli-currie source of cesium-137), the holding bracket, the ionization chamber-based radiation detector, the amplifier and transmitter, and display unit.

The source emits a colluminated beam of gamma-ray energy. The beam is directed through the pipe where the rays are absorbed in proportion to the density of the material in the pipe. The non-absorbed (not attenuated) rays are detected in an ion chamber, see Figure $A-1$.

The ion chamber detector is compromised of a hermetically sealed chamber filled with a high molecular weight gas. Radiation ionizes the gas and polarized electrodes collect the ions producing a proportional output current. This current is typically in the range of a few pico-amps to a nanoamp. To eliminate the problems inherent in sending such a low current signal through a cable, the detector incorporated a high stability preamp which amplifies the signal to the milliamp range. This milliamp signal is then sent via inexpensive shielded pair cable to the transmitter to be processed and filtered providing a linear, real-time output reflecting density changes. To insure maximum stability, the ion chamber and preamp are held at constant temperature in a closely controlled isothermal shell. The signal is then sent to the SGH transmitter through an inexpensive shielded, two-wire cable. Ion chambers are precise, extremely reliable, and very rugged.

The following changes were made to the basic SGH densitometer.

1. The 0.2 millicurie cesium source was replaced with an Amersham Model CDC.91, 1.0 curies cesium-137 source. The source head, however, was not modified. 
A- 14

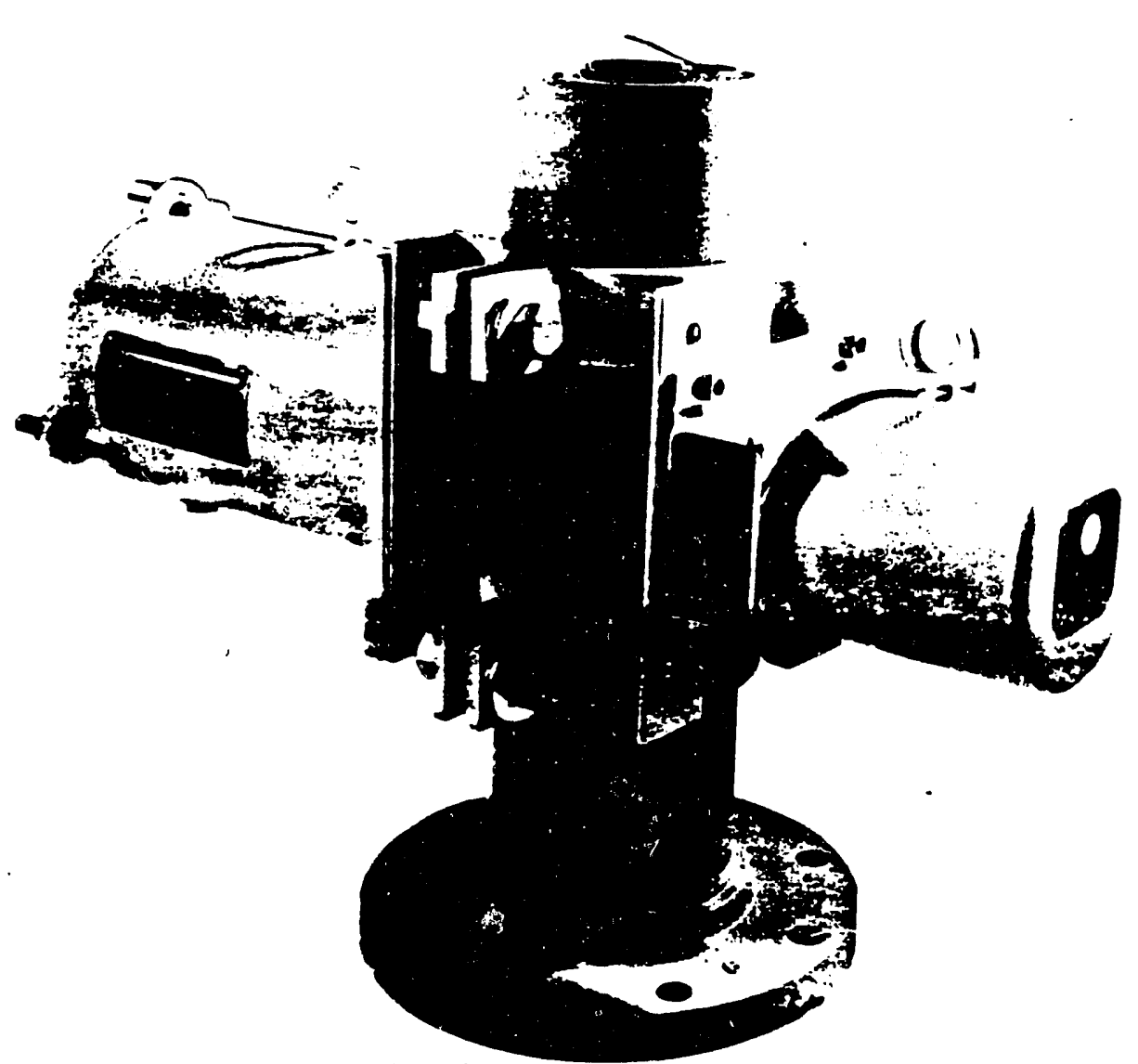

Source head, bracket, and detector

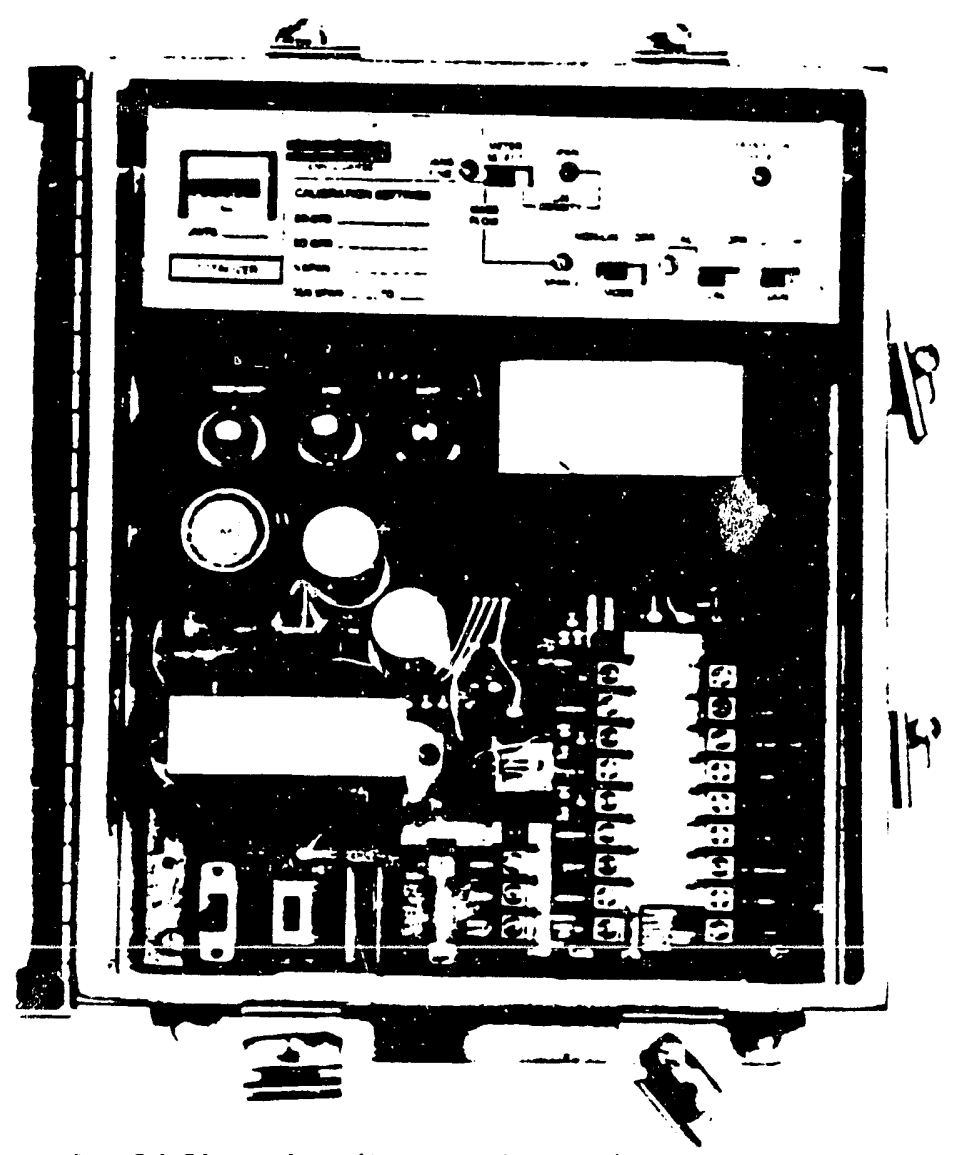

Amplification/Transmitter/Readout

FIGURE A-1. STANDARD DENSITOMETER

Source: Texas Nuclear SGH Densitometer Manual, Publication 710-717340, February, 1982 
2. The ion chamber preamplifier was modified to output a 0 to 10 volt signal rather than the normal milliamp signal. This was accomplished by inserting a high neg (1.0. $\times 10^{10}$ ohoms) resister.

3. The ion chamber preamplifier was modified by replacing the " 66 " and "C7" capacitors to change the dead time. The new capacities were C6: 22 P-farrad and C7:330 P-farrad.

4. The amplifier/transmitter unit was completely bypassed. The only components utilized were the power supply which provided a -700 volt source to the ion chamber, +28 and -5 volt sources to the preamplifier, and a 110 volt source to the constant temperature blanket.

\section{Additional HEGG Information}

\section{DEVICE TYPE: Gamma Gauge}

MODEL: Model Source Head

MANUFACTURER/MODIFIER: Texas Nuclear/Science Applications International Corporation

SEALED SOURCE MODEL DESIGNATION: Amersham Model CDC.91

ISOTOPE: Cesium-137 MAXIMUM ACTIVITY: 1 Curies

LEAK TEST FREQUENCY: 6 months

PRINCIPAL USE: Gamma Gauges - Code D

CUSTOM DEVICE: $\quad X$ YES NO 


\section{Description}

The HEGG is a low-energy gamma gauge source head incorporating a sliding shutter ON/OFF mechanism. It is mounted on a 6-inch pipe carrying a dilute coal/water slurry as part of the system to measure the properties of the slurry. A padlock, through holes in the shield frame and shutter, secures the shutter in either the ON or OFF position.

\section{Labeling}

The unit is appropriately labeled. The radiation symbol is magenta on a yellow background. Labels are attached directly to the shield assembly with screws. The labels are made of aluminum.

\section{Diagram}

The unit is shown schematically in Figure A-2, and the preamplifier is shown in a cioseup photo in Figure $A-3$.

\section{Conditions of Normal Use}

The device will be mounted onto a 6-inch pipe carrying a dilute coal-water slurry as part of a slurry test loop used for tests of coal cleaning processes which reduce the sulfur and ash content of the coal. The general environment is an industrial laboratory. The immediate vicinity of the device will be largely filled with slurry piping and its support structure. Personnel will not be in the immediate area of the device except for infrequent maintenance activities or briefly to open or close valves.

The environment is indoors but not heated or cooled; temperatures are expacted to fall within $0^{\circ} \mathrm{F}$ to $100^{\circ} \mathrm{F}$. No significant vibration impact, corrosion, puncture, or compressive loads are expected. Flooding is unlikely. No special fire hazards are expected. The device will be stationary in normal use. 


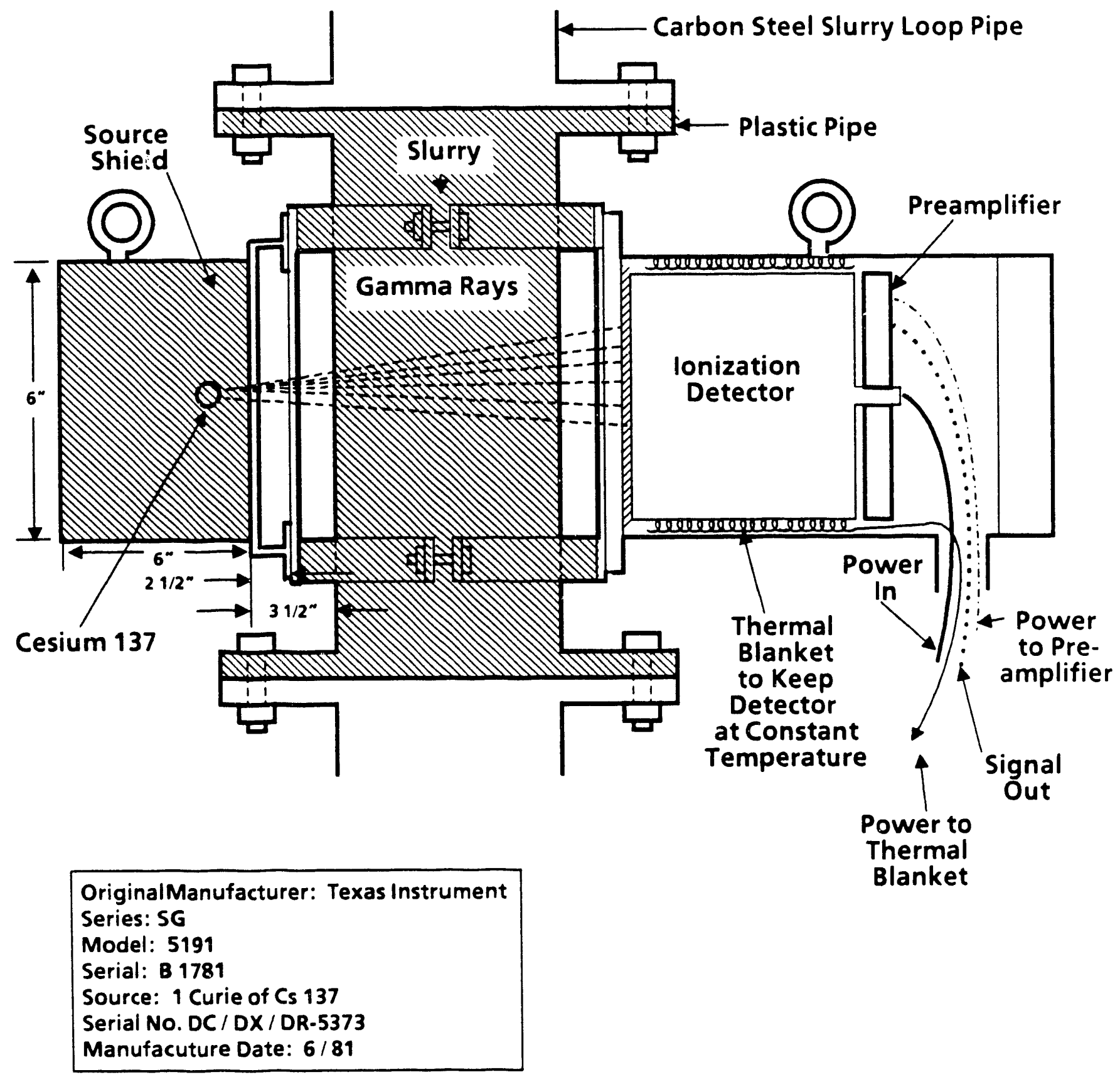

Figure A-2. HEGG Schematic (Cesium 137) 


\section{A-18}

High Mleg

Resistor

$4.7 \times 10^{11} \Omega$

\section{Capacity}

$\mathrm{C}_{6}: 22 \mathrm{p}$ Farrad

Capacitator for

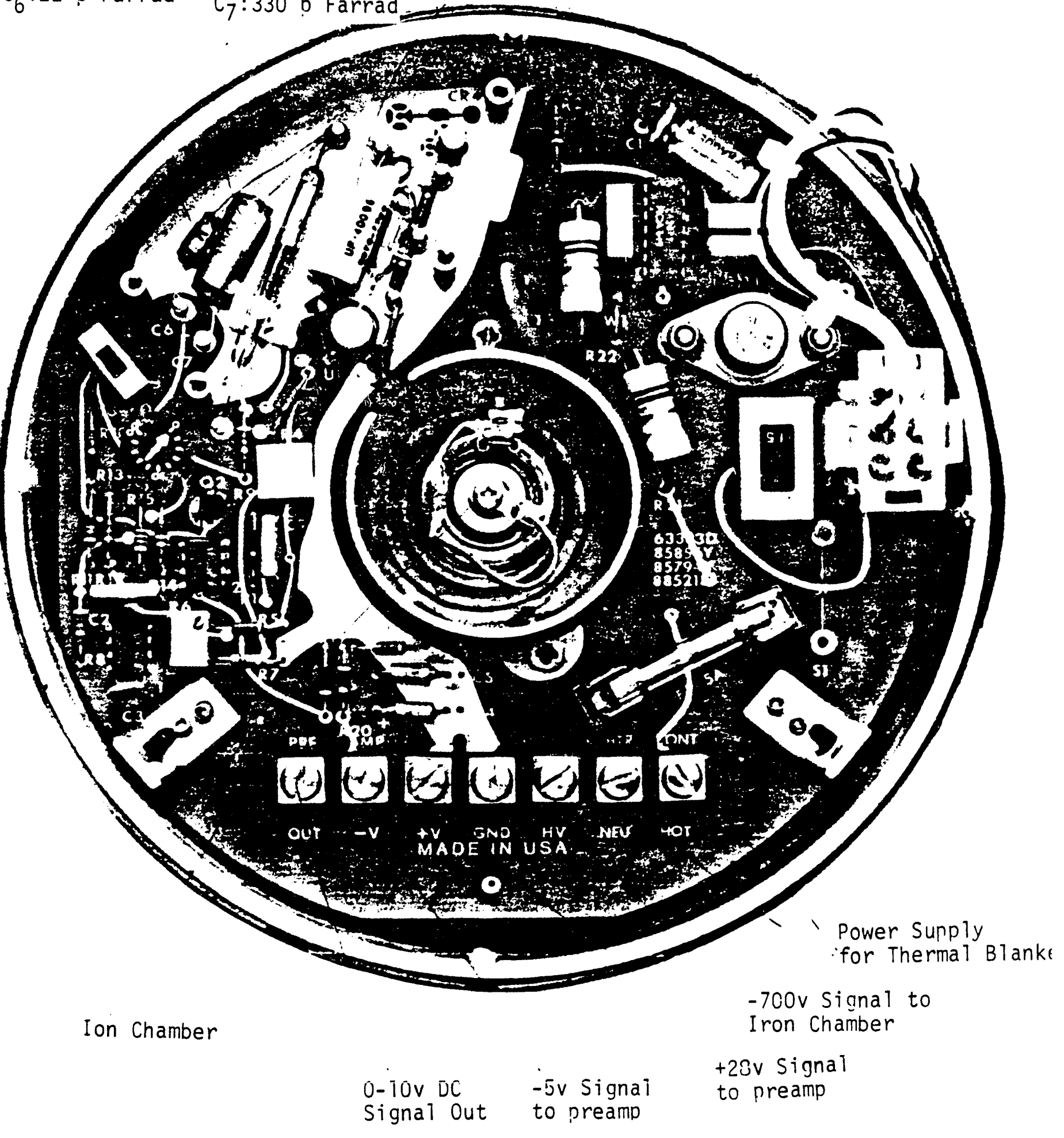

FIGURE A-3. HEGG PREAMP 


\section{Testing and Evaluation}

The inherent simplicity and ruggedness of the device assure reliable operation. The custom device has been tested for proper operation of the ON/OFF mechanism and a leak test has been performed.

\section{External Radiation Levels}

Twenty-one measured gamma-ray dose levels for the HEGG slurry analyzer showed all levels below $1 \mathrm{mrem} / \mathrm{hr}$ gamma radiation.

\section{Quality Assurance and Control}

Most source quality control is performed by Amersham Corporation, the source supplier. Amersham performs a wipe test, a bubble test, and an immersion test of the source in accordance with ANSI standards. Amersham measures the activity to -10 to +20 percent. After the source is installed, the shield will be surveyed for unusual leakage and conformance with the external radiation levels given above. Due to deliberate over-design, no further controls on the device are needed.

\section{Safety Analys is Summary}

Engineering analysis of the device and certification of the special form source by its supplier assure that the device will perform safely. The shield is ruggedly constructed of welded steel and completely contains the source. Based on experience with this type of construction, it will withstand all normal conditions of handling, use and storage including abrasion, vibration, impact, puncture, and compressive levels. 


\section{Instruction to Users}

There is no recommended service for the device except leak testing every six months (instructions follow), and source replacement when decay requires it (not expected in view of source life). Source replacement is not to be done by the user. Refer source replacement, any apparent problems with the source ON/OFF mechanism, relocation, etc. to Battelle Memorial Institute.

In case service is required on the valves or piping near the device, place the source in the OFF position until the work is complete.

\section{Source Head Test Procedure}

Leak or wipe tests of sealed sources are required by Nuclear Regulatory Commission and/or applicable state regulations. These test: ensure that the sources have not begun to leak radioactivity. The wipes should be taken as specified below. Analys is of the wipes requires a specific license to do so by the appropriate regulatory agency. The required interval between tests is normally six months but varies with regulatory jurisdiction. The sources were wipe tested prior to delivery and a dated certification provided. Leak test records must include the date and the signature of the individual certifying the test results.

Negligible radiation exposure will occur while taking the wipes. The following materials are required:

1) Wipes (filter papers, 2 minimum) or "Q-tips" (cotton swabs)

2) Envelopes or plastic bags

3) Tweezers/Tongs.

Take at least two wipes as follows:

1) Set out tweezers, wipes, and envelopes.

2) Wipe the exterior of the shield, especially at the weld joints.

3) Place wipes in the envelopes as they are taken.

4) Seal and submit to an authorized leak-test agency. 
If a leak is discovered, it must be reported to the appropriate regulatory agency promptly (w:thin 5 days normally). In this very unlikely event, tape a plastic sheet around the entire source and contact Battelle for assistance.

\section{Low Energy Gamma Gauge}

The low-energy gamma gauge (LEGG) is a more extensively modified Texas Nuclear SGH densitometer. The unit is identical to the HEGG except for modification to the source head and detector preamplifier.

The following changes were made to the standard SGH densitometer:

1. The original 0.2 millicurie cesium source was replaced with an Amersham Model AMN.24, 5.0 curie americium 241.

2. The source head was completely replaced with a new, smaller, custom constructed unit.

3. The source head-bracket assembly was modified to move the source approximately 1 -inch closer to the slurry pipe.

4. The ion chamber preamplifier was modified to output a 0 to 10 volt signal rather than the standard milliamp signal. (A $4.7 \times$ 10 " ohm high meg resistor was used.)

5. The ion chamber preamplifier was modified by replacing the standard "C6" and "C7" capacitors. The new capacitor values were: $C 6=100 \mathrm{P}$-farrad, $C 7=10 \mathrm{P}$-farrad.

6. The amplifier/transmitter unit was completely bypassed. Only the power supply was used to provide $-700 \mathrm{~V},+28 \mathrm{~V},-5 \mathrm{~V}$, and $110 \mathrm{~V}$ voltage sources, as described in the HEGG description. 
DEVICE TYPE: Gamma Gauge

MODEL: Model CLEG Source Head

MANUFACTURER/MODIFIER: Texas Nuclear/Science Applications International Corporation

SEALED SOURCE MODEL DESIGNATION: Amersham Model AMN.24

ISOTOPE: Americium-241 MAXIMUM ACTIVITY: 5 Curies

LEAK TEST FREQUENCY: 6 months

PRINCIPAL USE: Gamma Gauges - Code D

CUSTOM DEVICE: $\quad \longrightarrow$ YES NO

\section{Description}

The SAIC Model CLEG is a low-energy gamma gauge source head incorporating a sliding shutter ON/OFF mechanism. It is mounted on a 6-inch pipe carrying a dilute coal/water slurry as part of the system to measure the properiies of the slurry. A padlock, througn holes in the shield frame and shutter, secures the shutter in either the ON or OFF position.

\section{Labeling}

The unit is labeled appropriately. The radiation symbol is magenta on a yellow background. Labels are attached directly to the shield assembly with screws. The labels are made of aluminum. 
Diagram

The unit is shown schematically in Figure A-4.

\section{Conditions of Normal Use}

The device will be mounted onto a 6-inch pipe carrying a dilute coal-water slurry as part of a slurry test loop used for test; of coal cleaning processes which reduce the sulfur and ash content of the coal. The general environment is an industrial laboratory. The immediate vicinity of the device will be largely filled with slurry piping and its support structure. Personnel will not be in the immediate area of the device except for infrequent maintenance activities or briefly to open or close valves.

The environment is indoors but not heated or cooled; temperatures are expected to fall within $0^{\circ} \mathrm{F}$ to $100^{\circ} \mathrm{F}$. No significant vibration impact, corrosion, puncture, or compressive loads are expected. Flooding is unlikely. No special fire hazards are expected. The device will be stationary in normal use.

\section{Testing and Evaluation}

The inherent simplicity and ruggedness of the device assure reliable operation. The custom device has been tested for proper operation of the ON/OFF mechanism and a leak test has been performed.

\section{External Radiation Levels}

Twenty-one measured gamma-ray dose levels for the LEGG slurry analyzer showed all levels below $1 \mathrm{mrem} / \mathrm{h}$ incorporating the Model CLEG. 


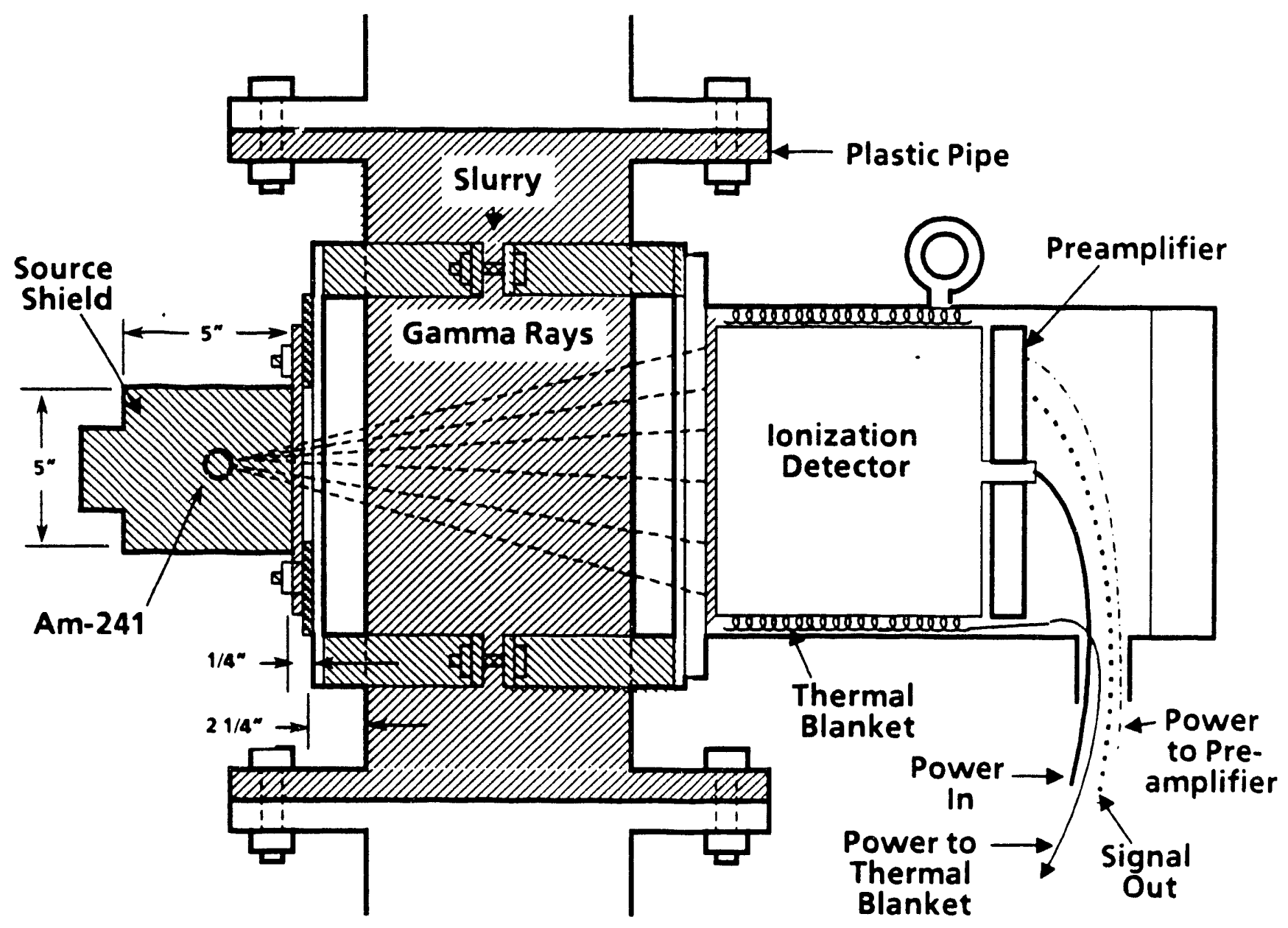

Figure A-4. LEGG Schematic (Americium 241) 


\section{Quality Assurance and Control}

Most source quality control is performed by Amersham Corporation, the source supplier. Amersham performs a wipe test, a bubble test, and an immersion test of the source in accordance with ANSI standards. Amersham measures the activity to -10 to +20 percent. After the source is installed, the shield will be surveyed for unusual leakage and conformance with the external radiation levels given above. Due to deliberate over-design, no further controls on the device are needed.

\section{Safety Analysis Summary}

Engineering analysis of the device and certification of the special form source by its supplier assure that the device will perform safely. The shield is ruggedly constructed of welded steel and completely contains the source. Based on experience with this type of construction, it will withstand all normal conditions of handling, use, and storage including abrasion, vibration, impact, puncture, and compressive loads.

\section{Instruction to Users}

There is no recommended service for the device except leak testing every six months (instructions are provided in the HEGG description), and source replacement when decay requires it (not expected in view of source life). Source replacement is not to be done by the user. Refer source replacement, any apparent problems with the source ON/OFF mechanism, relocation, etc. to Battelle Memorial Institute.

In case service is required on the valves or piping near the device, place the source in the OFF position until the work is complete. 
APPENDIX B

SULFUR AND IRON ANALYSIS 
APPENDIX B

\section{SULFUR AND IRON ANALYSIS}

This appendix is divided into two sections, Prompt Gamma Neutron Activation Analysis (PGNAA) Sulfur and Iron Prediction Procedure and Detailed Equipment Description.

\section{PGNAA SULFUR AND IRON PREDICTION PROCEDURE}

The PGNAA instrument produces a histogram of "counts" broken down into 512 divisions or channels. These form an energy spectrum of count number versus channel number, see figure 5 in text. In order to use the spectrum to predict sulfur contents, the spectrum must be divided into one or more Regions of Interest (ROI).

The gamma-ray energy levels, for all elements, are tabulated in standard nuclear assay books ${ }^{(12)}$. From these standards, it is clear that most elements should produce many energy peaks. By looking at the tabulated PGNAA energy-element data, the energy levels of the most significant peaks can be identified. Initially, it was assumed that there was a linear relationship between energy channel number and gamma-ray energy. When evaluations of predicted sulfur levels showed poorer than expected accuracy levels, this relationship was determined experimentally, see Figure B-1. Clearly there is a slight bow to the relationship. Regions of interest around hydrogen, sulfur, chlorine, and iron were estimated as follows:

\begin{tabular}{ccc} 
Element & Energy Level, meV & Region of Interest \\
\cline { 1 - 2 } $\mathrm{H}$ & 2.223 & $91-99$ \\
$\mathrm{~S}$ & 5.421 & $215-225$ \\
$\mathrm{Cl}$ & 6.110 & $237-247$ \\
$\mathrm{Fe}$ & 7.638 & $284-296$
\end{tabular}




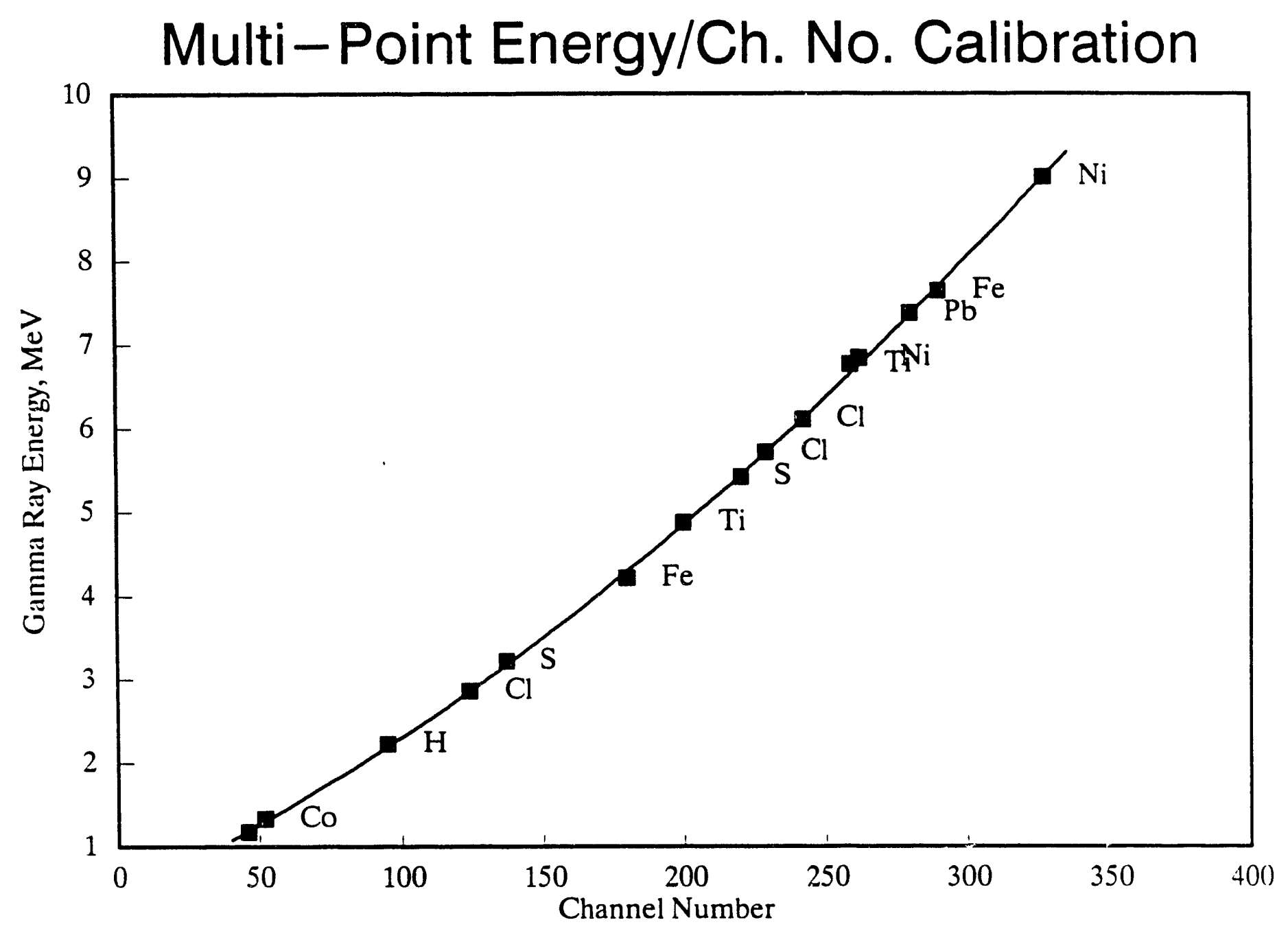

FIGURE B-1. ENERGY-CHANNEL NUMBER RELATIONSHIP

(WITH HYDROGEN SET AT CHANNEL 95) 
These ROI's formed the basis of the "standard" spectrum analysis technique used in the latter part of the project. In this technique, the hydrogen peak was adjusted, at the start of the run, to have its peak (greatest number of counts) in Channel 95. The counts in Channels 215 through 225 were then totalled and this sum referred to as the sulfur counts. A typical level was between 33,000 and 35,000 counts. This technique, while simple and straightforward, did not result in good run-to-run prediction accuracy.

It was clear that slight shifting in the spectrum, due to instrument drift, was a significant contributor to analyzer inaccuracy.

A more precise determination of the hydrogen, sulfur, chlorine, and iron ROI, possible by accounting for the spectrum shift, led to improved prediction performance. The correction procedure was based on the hydrogen peak around Channel 95 (at $2.223 \mathrm{meV}$ ), the chlorine peak around channel 239 (at $6.110 \mathrm{meV})$, and iron around Channel 255 (6.818 meV).

Subsequently, a "complex" spectrum analysis technique was derived consisting of the following four steps.

(1) Centroid Calculation: The centroids for the hydrogen (over Channels 91-99), chlorine (225-250), and iron escape peak (250260) regions were calculated. The centroid was calculated by equation B-1 below, where the summation is over the channels in the ROI.

$$
\text { Centroid }=\frac{\sum_{i=\text { Start }}^{\text {Stop }}\left(\text { Channe } l_{i}\right) *\left(\text { Counts }_{i}\right)}{\sum_{i=\text { Start }}^{\text {Stop }} \text { Channe } l_{i}}
$$


"Start" is the initial channel number, and "stop" the final channel number defining the range over which the centroid is calculated.

(2) Energy/Channel No. Fit. The three centroids were fit, using multiple linear regression, as a second order polynomial with the corresponding energy levels:

\begin{tabular}{lc}
\multicolumn{1}{c}{ Channel No. } & Energy, meV \\
\cline { 2 - 2 } H Centroid & 2.223 \\
Cl Centroid & 6.110 \\
Fe-Escape Centroid & 6.818
\end{tabular}

to produce an equation of the form:

Channel No. $=A+B *($ Energy $)+C *(\text { Energy })^{2}$

typical values (Run 41, 10 percent solids) were:

Channel No. $=-49.95+74.98 *($ Energy $)-4.44 *(\text { Energy })^{2}$

(3) Calculate Counts. Using the defined energy range for the ROI's for each element, the appropriate starting and stopping channel for each ROI was computed following equation B-2. For example, using the coefficients in the typical equation presented in B3, the following ROI's were calculated:

\section{Element}

$\begin{array}{ll}\mathrm{H} & 2.123-2.323 \\ \mathrm{~S} & 5.300=5.600 \\ \mathrm{Cl} & 5.950=6.260 \\ \mathrm{Fe} & 7.440=7.840\end{array}$

Calculated ROI Channels Based on Equation B-3

$$
\begin{array}{r}
89.60-100.69 \\
222.67-230.64 \\
238.92-245.35 \\
262.02-264.86
\end{array}
$$


(1) Calculate ROI Counts. The fractional-channel counts for each element were computed. For example, the H-ROI is computed below. To assist in the explanation, a counts versus channel number histogram, in the hydrogen region, is shown in Figure B2 below.

Hydrogen Counts Versus Channel Number

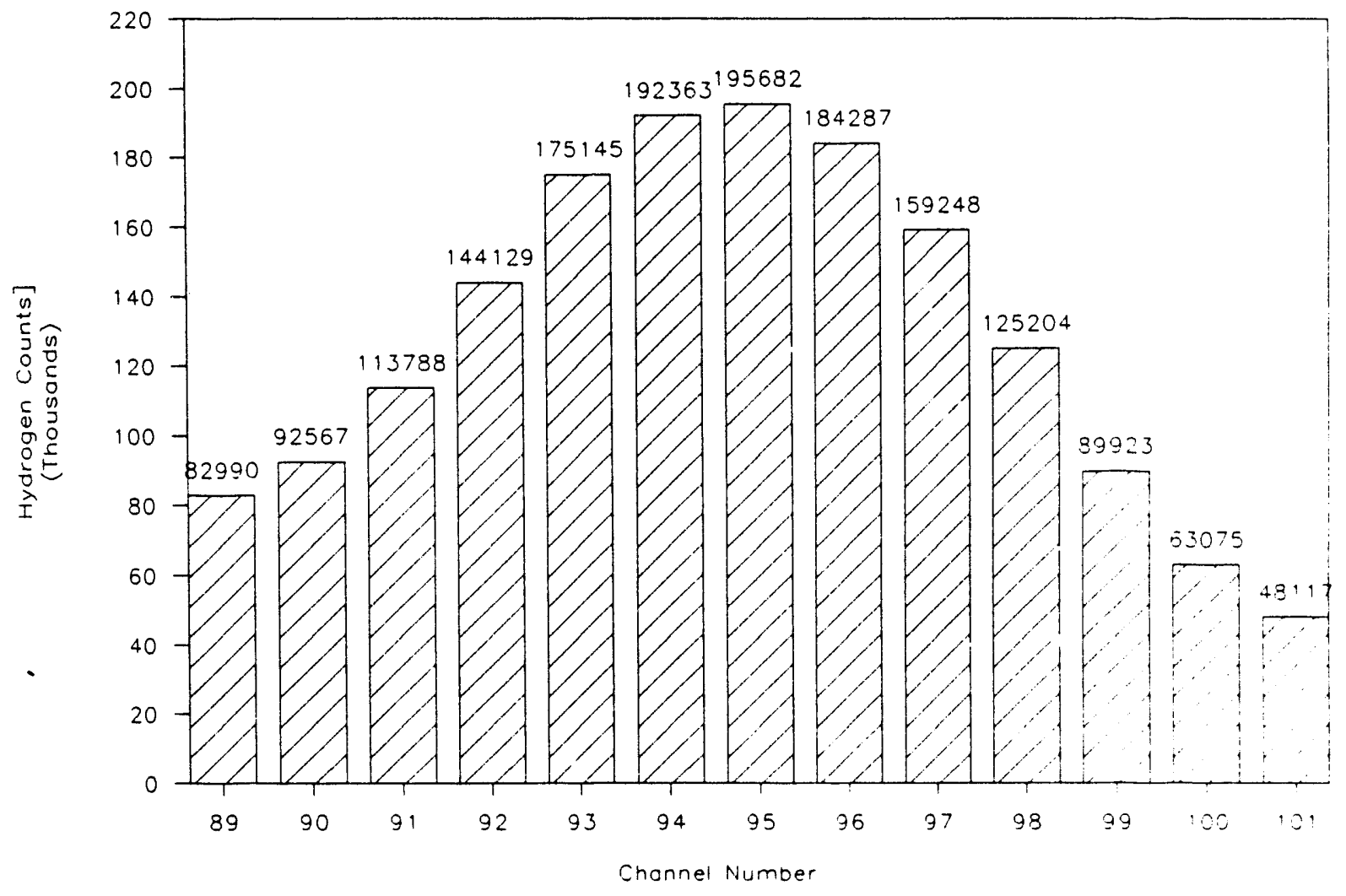

FIGURE B-2. HYDROGEN ROI HISTOGRAM 
The $H$ counts over fractional channels 89.60 to 100.69 were calculated as:

$$
\begin{aligned}
H & =(1-0.60) * \mathrm{CH}_{89}+\sum_{=98}^{109} \mathrm{CH}_{i}+0.69 * \mathrm{CH}_{101} \\
& =\{(1-0.60) *(82,990)\}+1,535,411+\{0.69 *(48,117)\} \\
& =1,601,808
\end{aligned}
$$

The same procedure was repeated for the sulfur, chlorine, and iron regions of interest. For purposes of analysis, these count values were placed on a water-subtracted basis. Under typical test conditions, three spectra were taken; the counts determined and averaged. Then the fractional, water-only counts for each element (determined when the test loop contained only water, determined earlier in the run) was subtracted from the determined counts for that element. Since the concentration of hydrogen is the highest when only water is in the test loop, the hydrogen count drops with each addition of coal, sulfur, chlorine, iron, etc. This means that the water-subtracted sulfur counts increase with added coal, but water-subtracted hydrogen courits become a negative number and become more negative with each coal addition. For example:

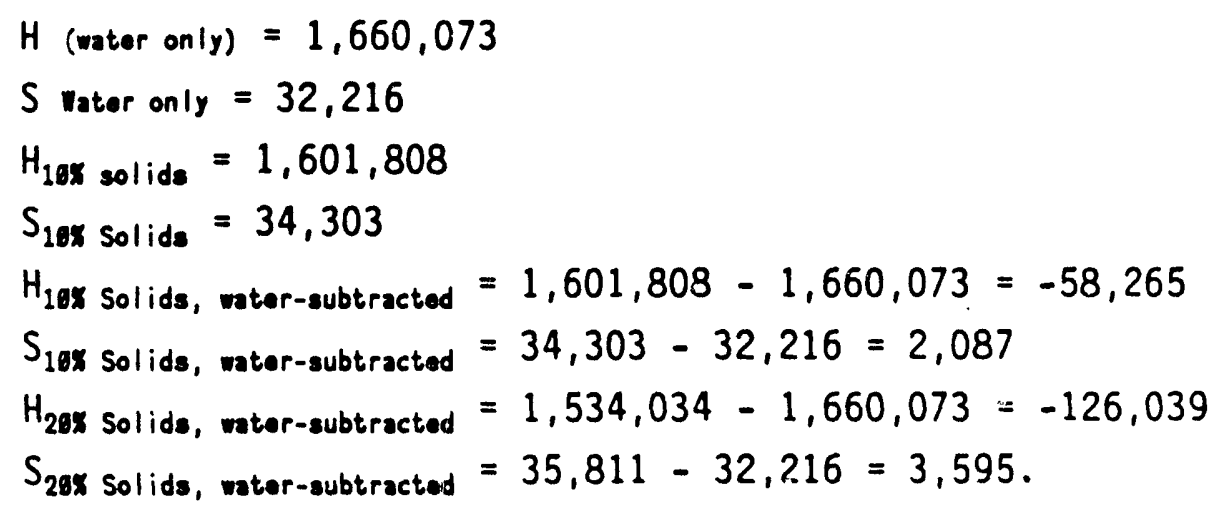

This "complex" spectrum-analysis procedure produced good run-to-run sulfur predictions. The standard error, as noted in the body of the report, was just within the sulfur standard error target. 


\section{DETAILED EQUIPMENT DESCRIPTION}

The PGNAA unit tested in this experimental program was designed and built by SAIC under contract to EPRI. The unit is composed of the following seven items:

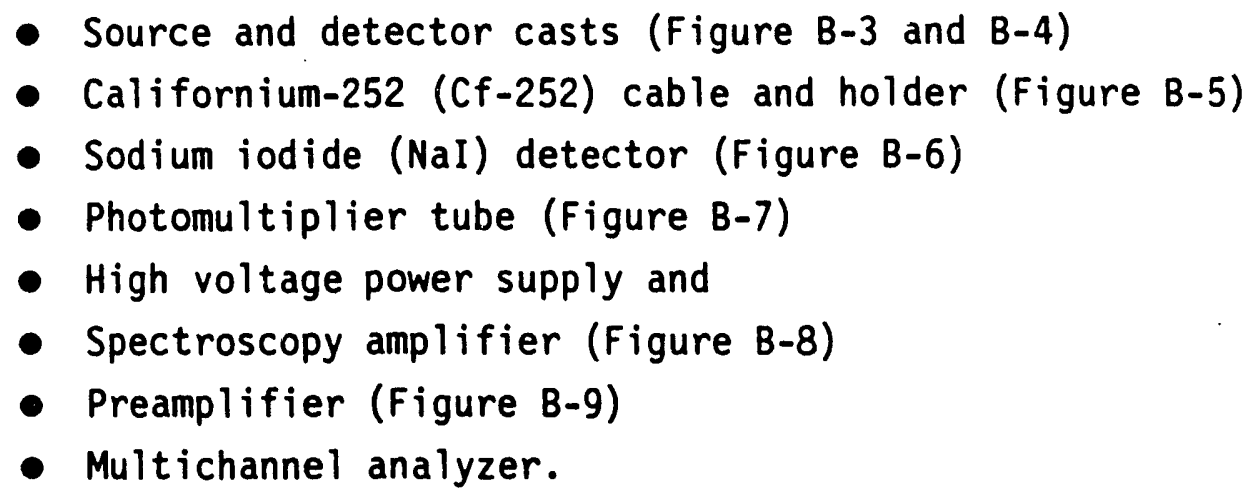

The source holder is a large hollow cylinder filled with borated wax for neutron and gamma-ray shielding, see photo in Figure 15 in the body of the report and Figures B-3 and B-4. The holder is made in a two part "clam shell" arrangement, which allows it to surround the slurry pipe. The source side is 27 inches in diameter and 26 inch long (Figure B-2). A 3/4-inch tube welded into the unit, along the centerline of the cylinder, allows the $C f-252$ source to be inserted or retracted. The source is an Amersham CVN.7 seaied source containing $20 \mu \mathrm{g}$ of $\mathrm{Cf}-252$ with 10.72 millicurie activity and $396.64 \mathrm{mBq}$. The double sealed source is a cylinder approximately $1 / 4$ inch in diameter and $1 / 4$ in. long. The source was enclosed in a 2-inches long, 1/2-inch diameter aluminum holder and screwed onto a 12-inch long, 1/2-inch diameter shaft, see Figure B-5. Replacement of the californium source was done remotely in a "hot cell" at Battelle's nuclear materials laboratory. After loading the source into the holder and onto the cable connection, it was manually pushed into place with a 24-inches long, 1/8-inch cable attached to the shaft. The "source in" location was approximately $3 / 4$ in. from the 6 in. plastic slurry pipe. The detector side of the shield is also 27 inches in diameter but only 20 inches long. This section of the clam shell encloses the slurry pipe, see Figure B-4. A 7-inch I.D., 12-inch long pipe, extends from the shield and provides access to the detector equipinent. 


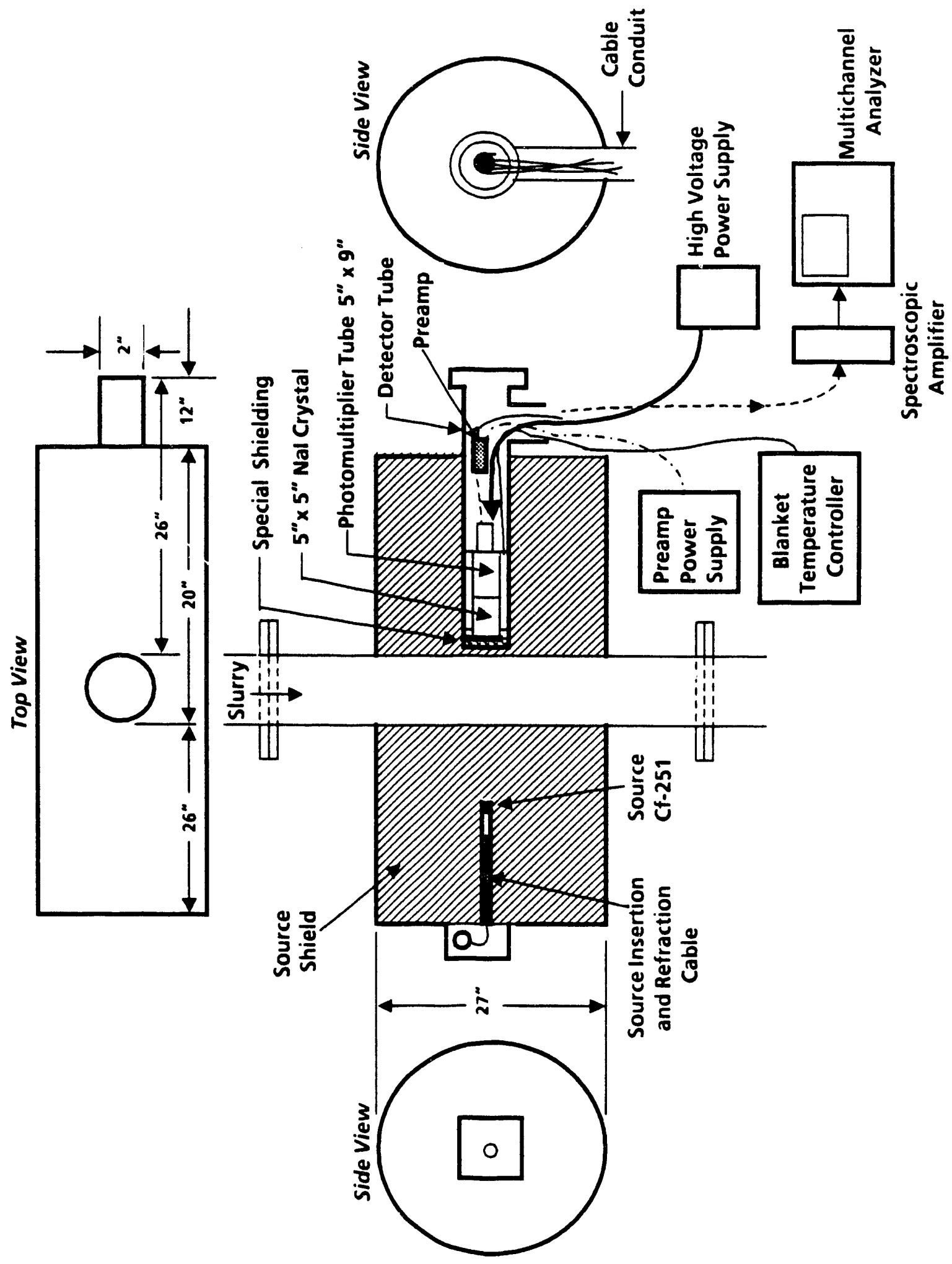




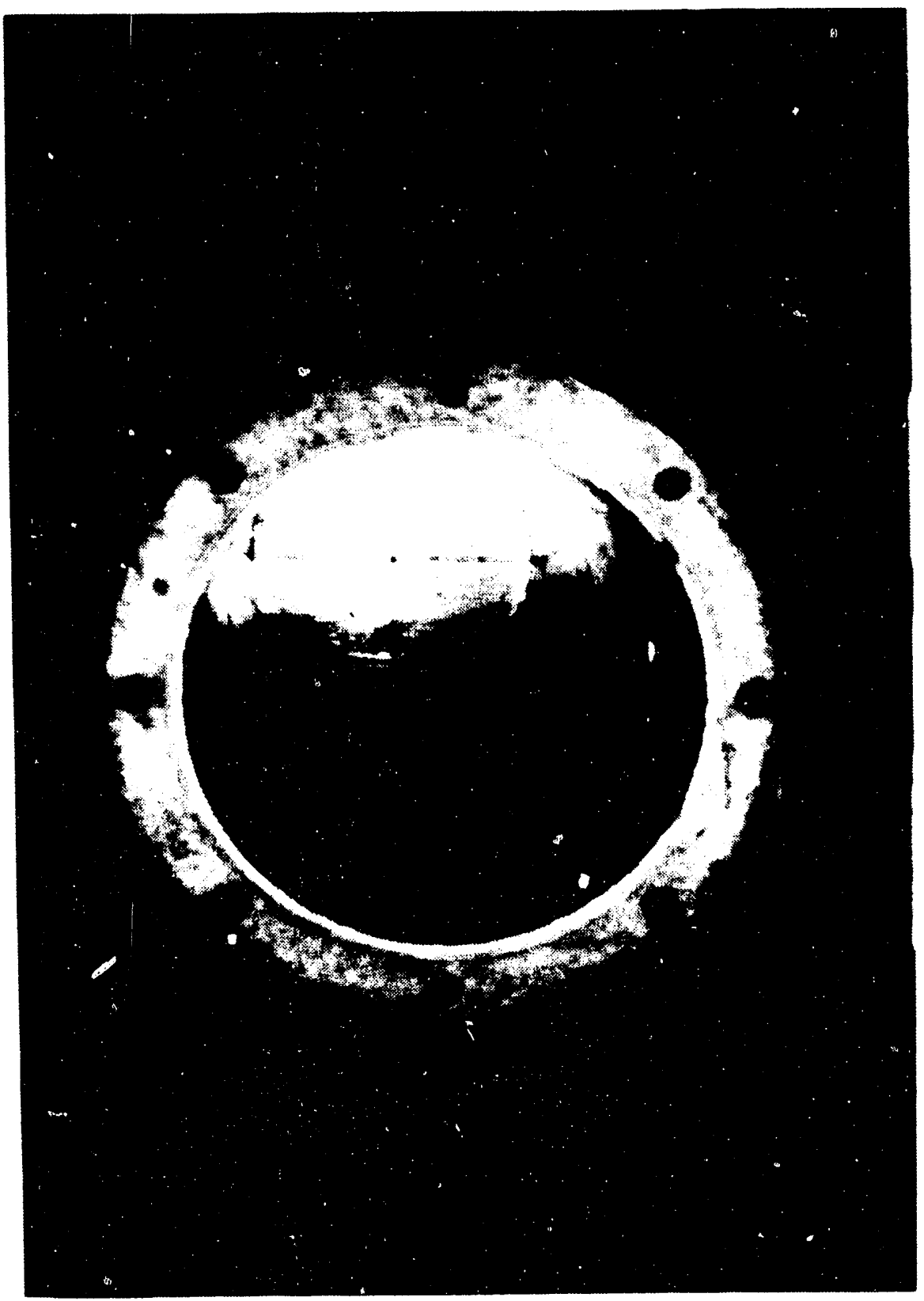

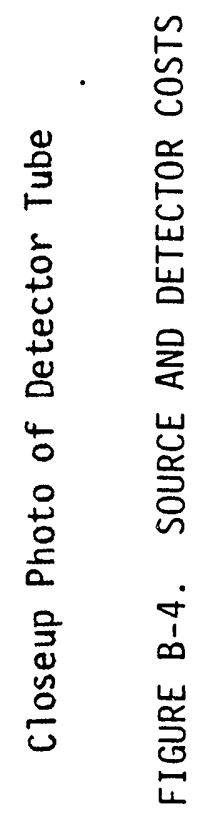




\section{B -10}

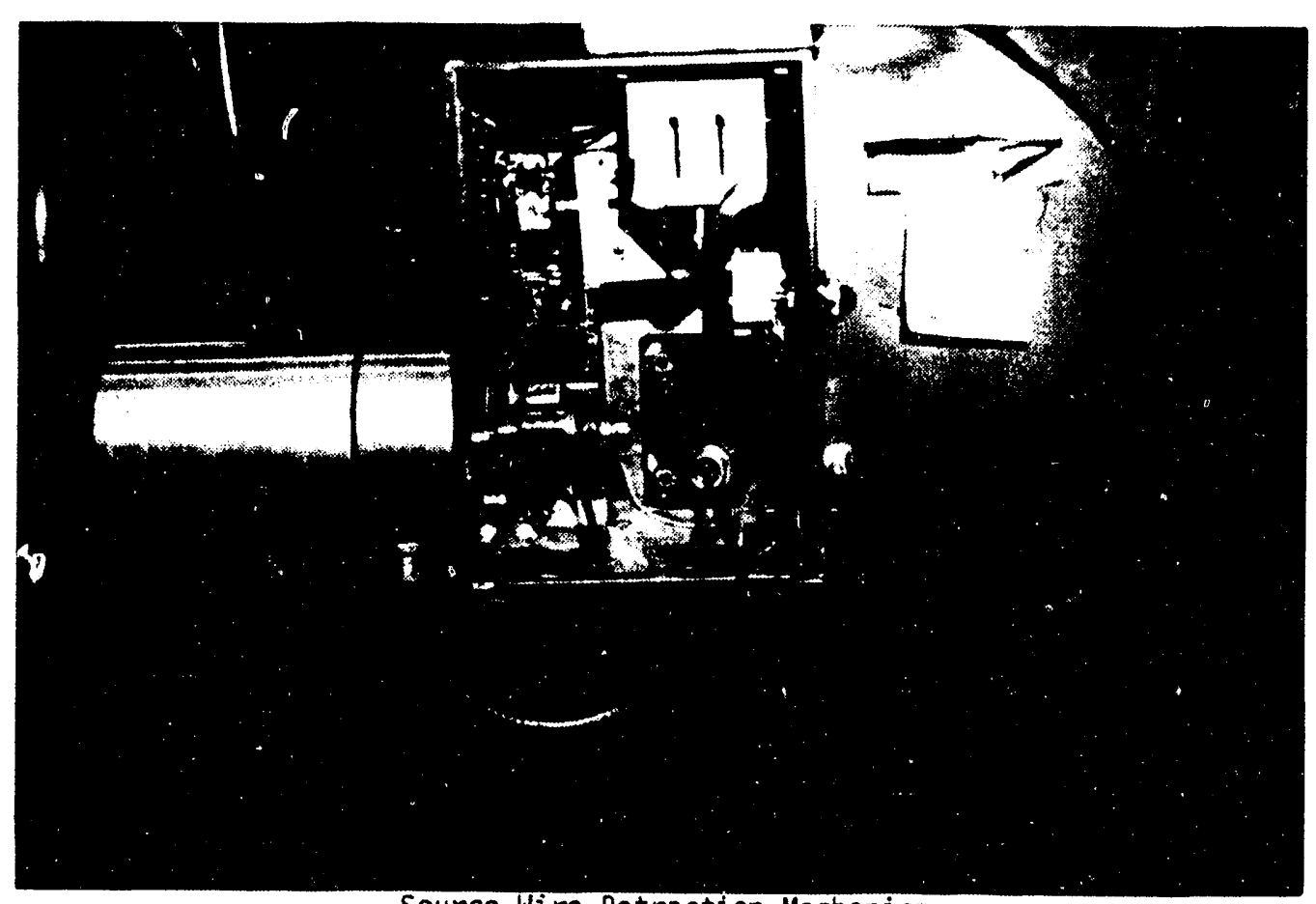

Source Wire Retraction Mechanism

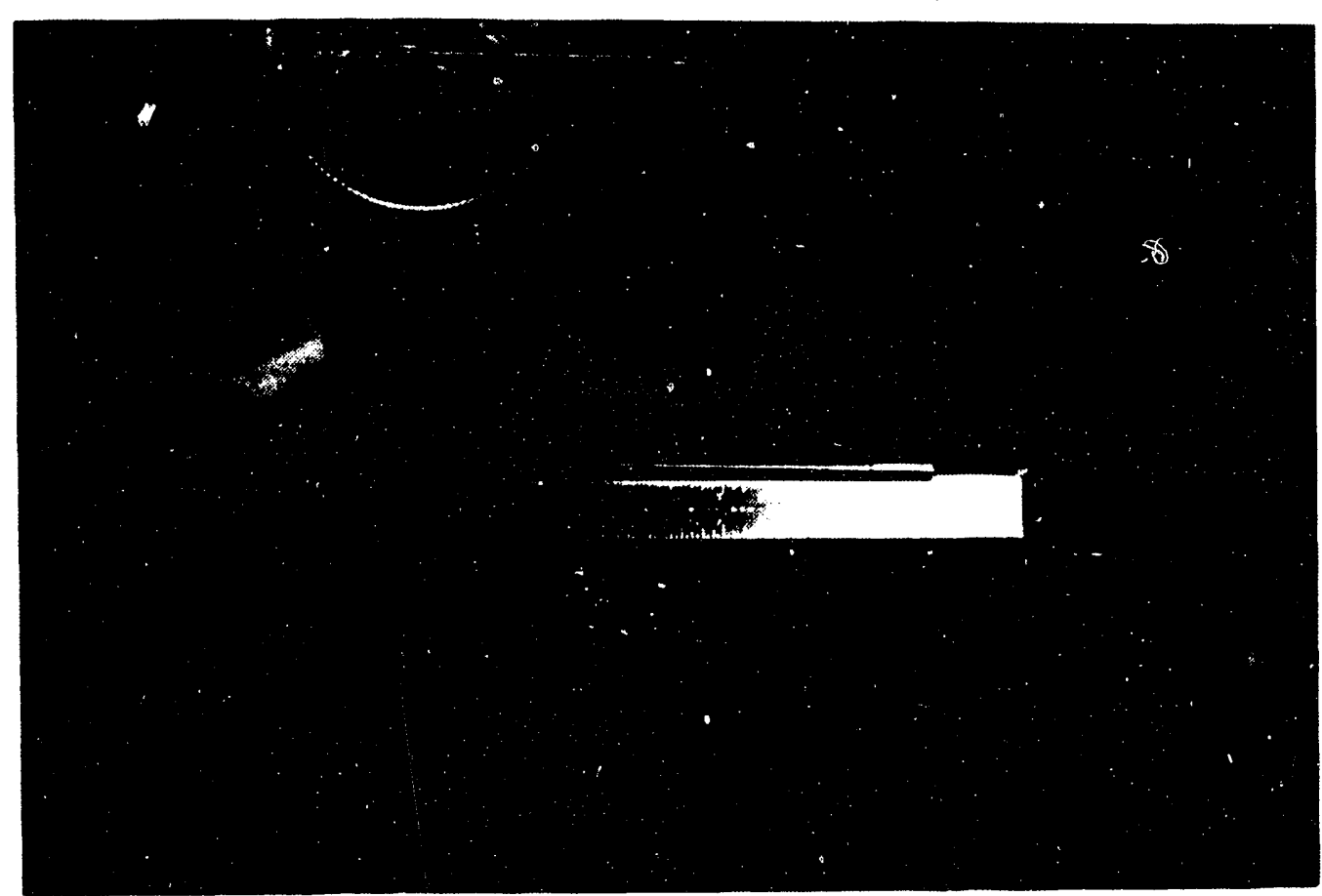

Source Cable with Source Tube and Source Holder

FIGURE B-5. CALIFORNIUM CABLE AREA HOLDER 


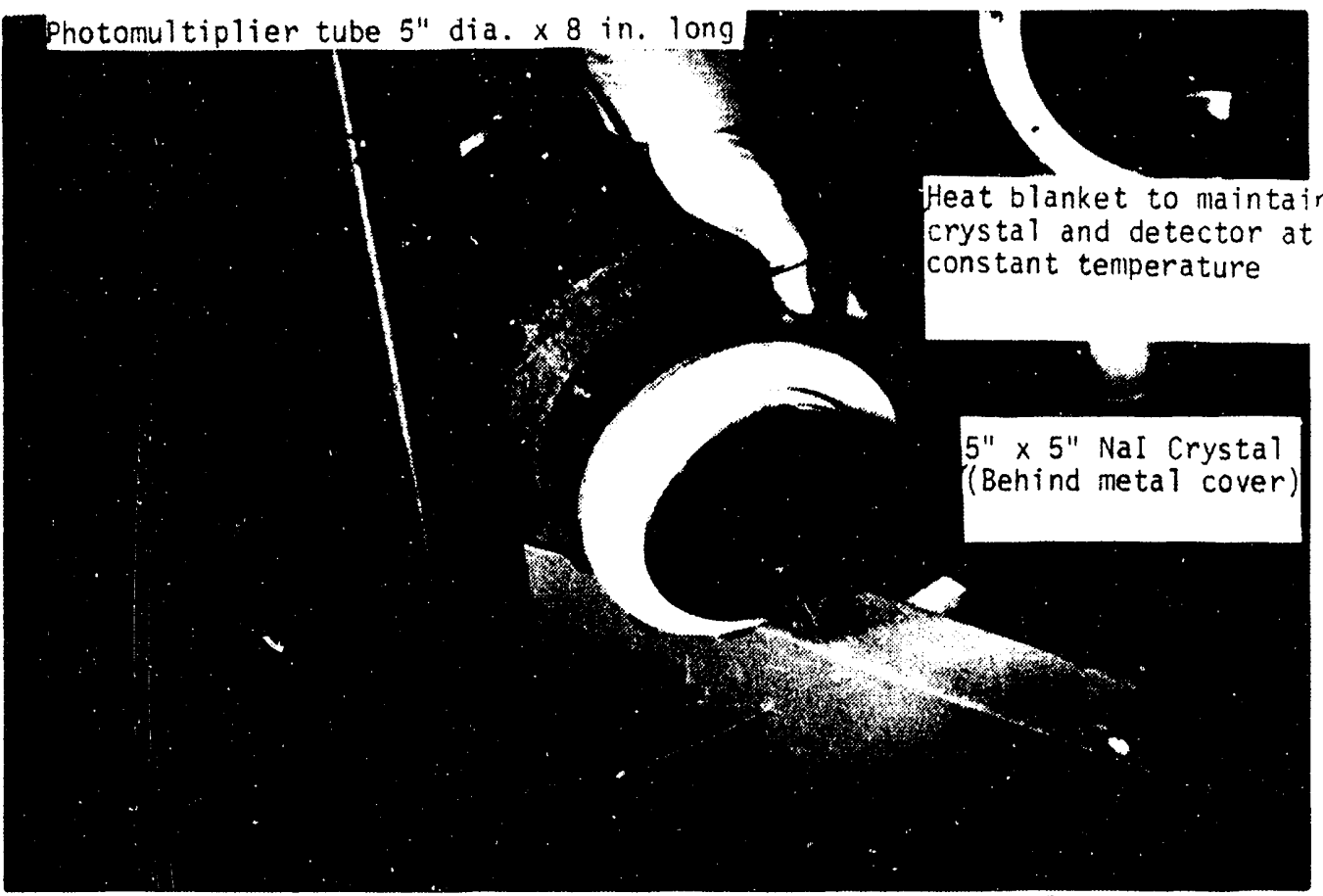

Sodium Iodide Crystal/Photomultiplier Tube Assenbly

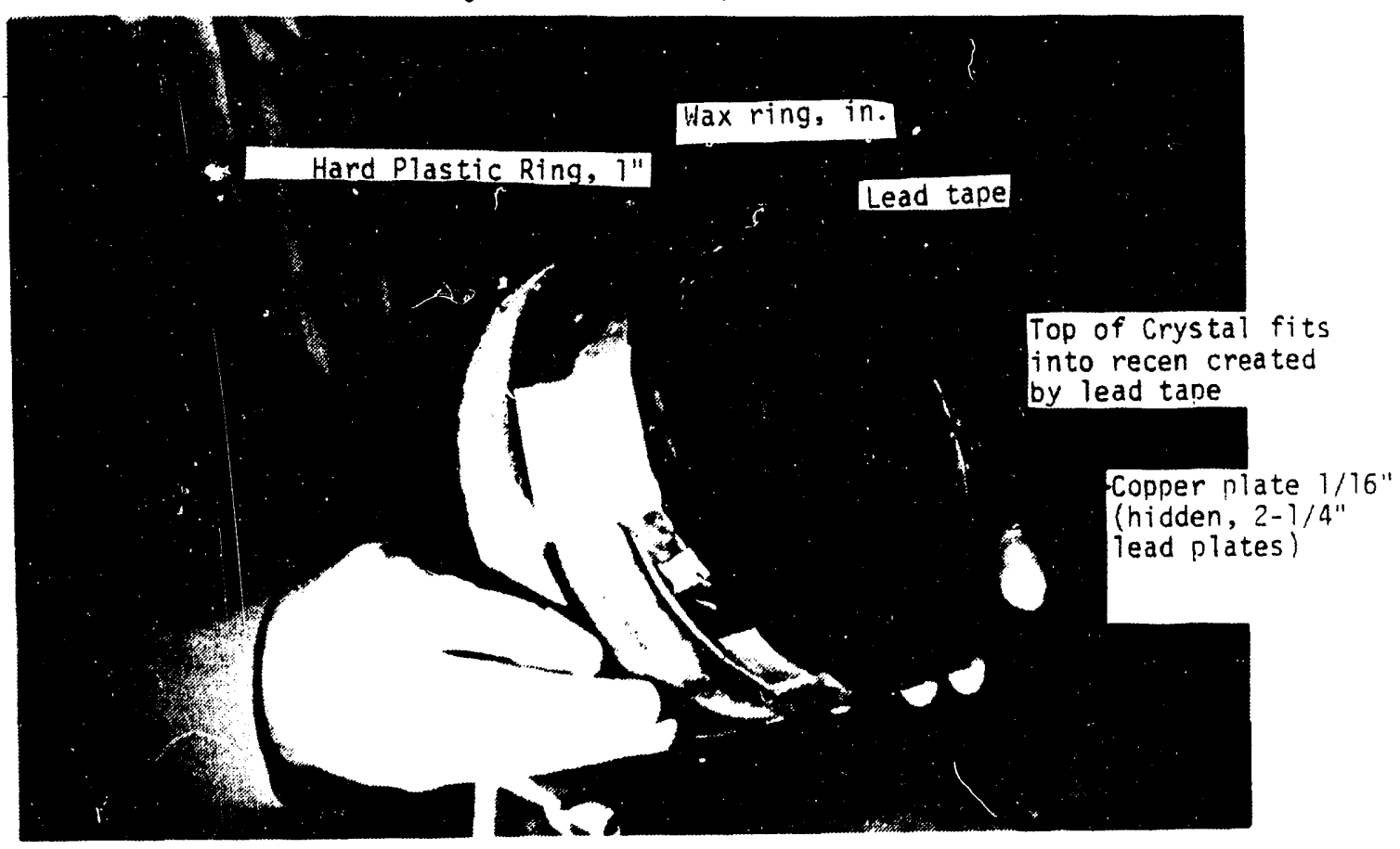

Special Shielding Placed over End of Nal Crystal

FIGURE B-6. SODIUM IODIDE CRYSTAL 

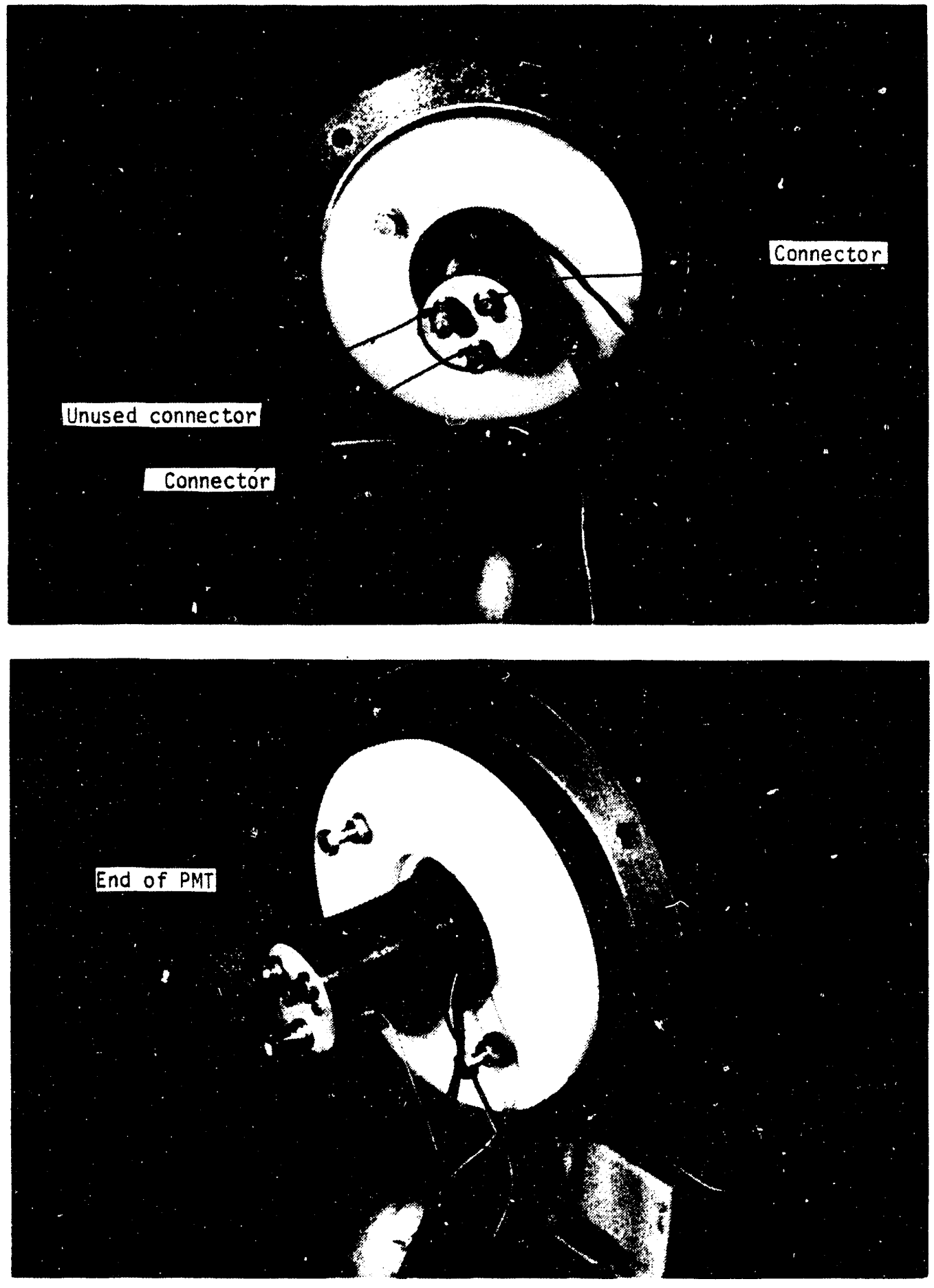

FIGURE B-7. PHOTOMULTIPLIER TUBE 


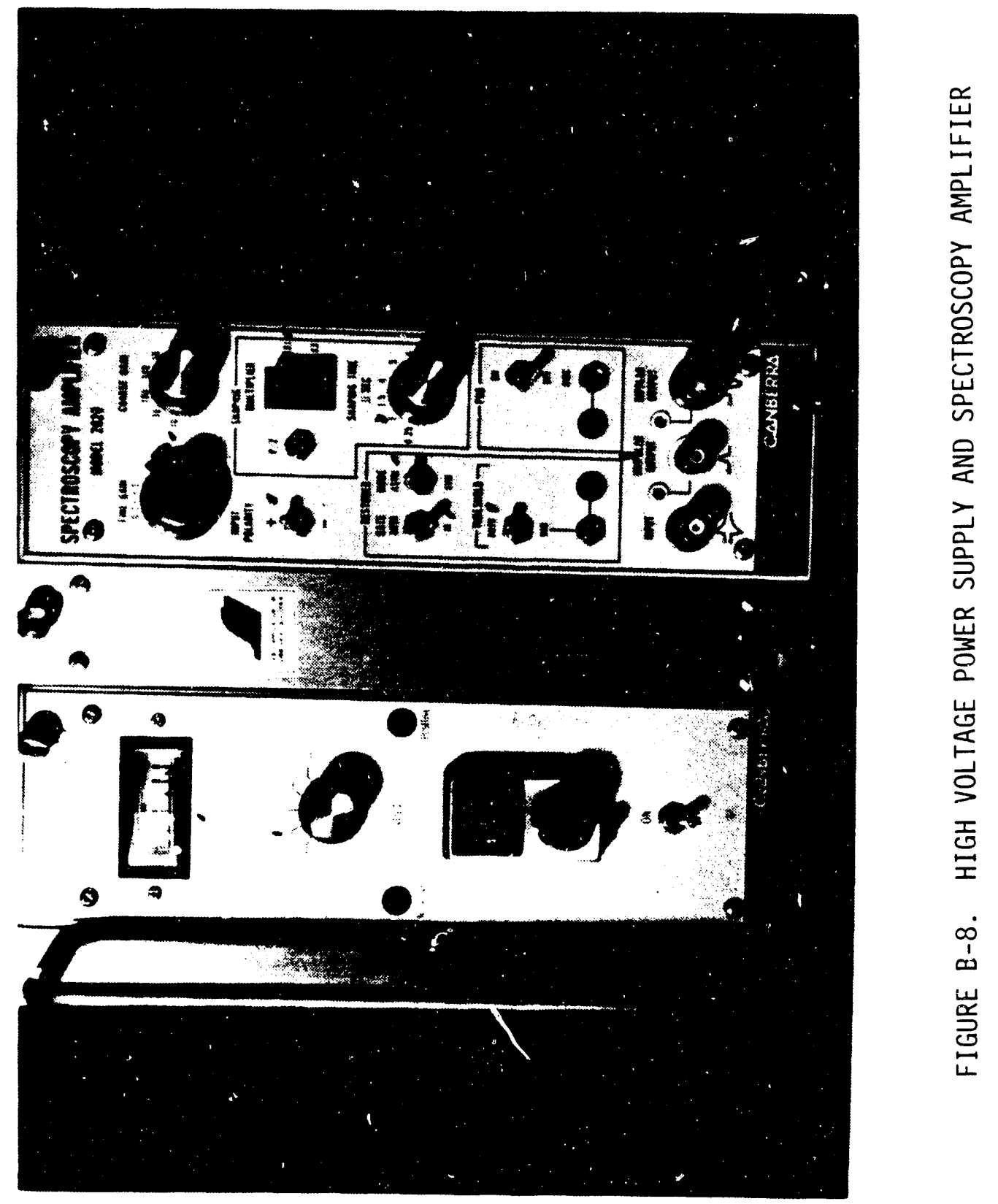




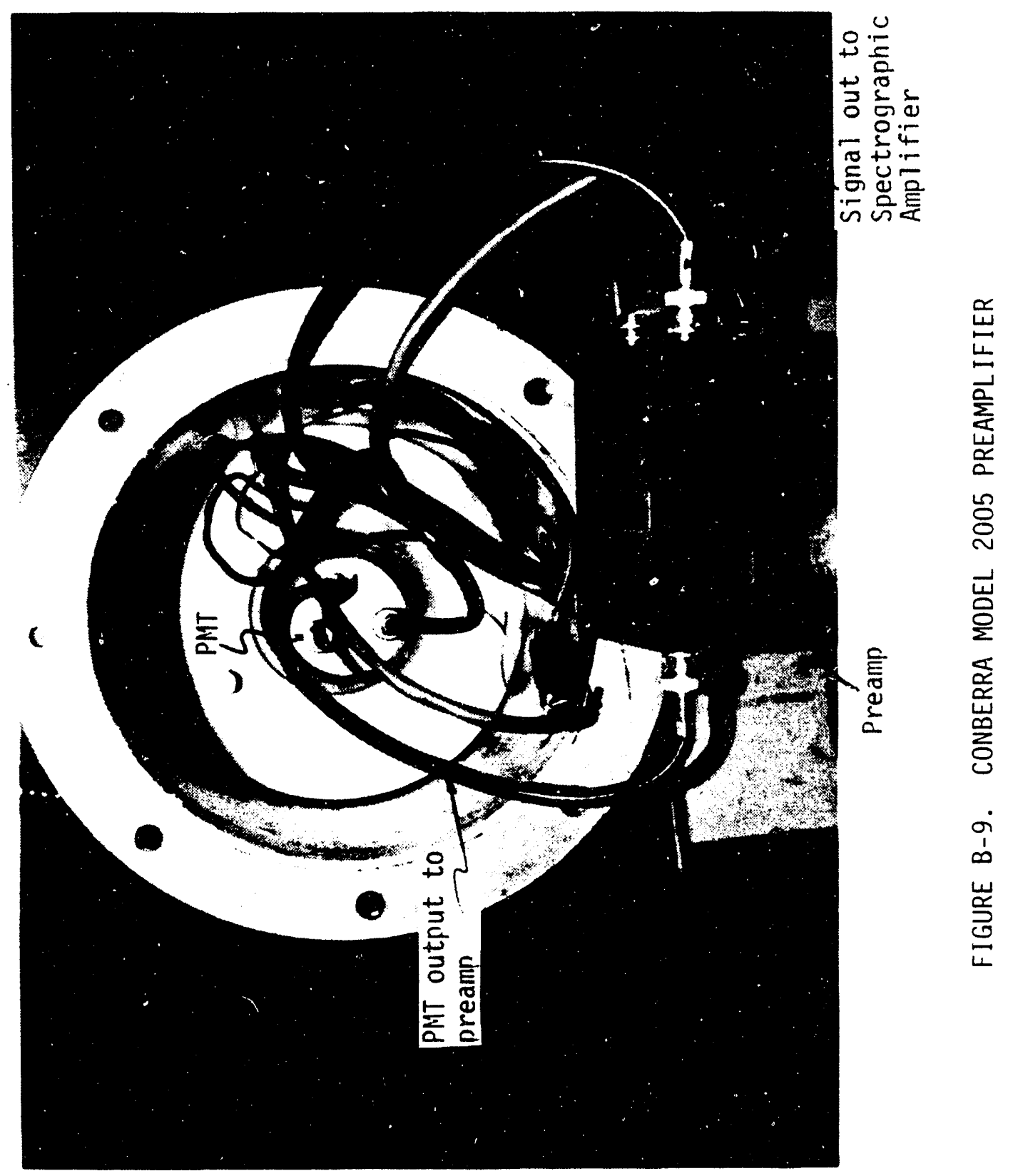




\section{B-15}

The characteristic gamma-rays produced by the thermalized neutrons passed through the slurry and the plastic pipe and then through the front edge of the containment shield. The rays passed through $1 / 2$ inch of aluminum (the containment vessel wall) and chrough some shielding material. This material, see Figure B-6, consisted of 1-inch of hard plastic, 1-inch of wax, 1/4-inch of lead, 1/8-inch of lead, and finally a thin (1/32-inch) copper plate. This shielding served to absorb some of the radiation and reduce background interference. The rays were detected by a 5 -inch diameter by 5 -inch long $\mathrm{NaI}$ crystal. A 1-inch layer of lead sheet surrounded the edge of the crystal in order to reduce interference. Located directly behind the crystal was 5-inch diameter by 8-inch long photomultiplier tube (PMT), see Figure B-7. Both the crystal and the PMT were surrounded with a heated "blanket." A Fenwal temperature controller measured the temperature and adjusted a 120 volt input source to maintain the crystal and PMT at a preset temperature of $99 \mathrm{~F}$. To activate the PMT a high voltage was applied. The voltage, around 942 volts, was generated in a Canberra Model 3002 High Voltage Power Supply, see Figure B-8. The voltage was user adjustable (in order to keep the hydrogen peak at spectrum channel 95). The PMT output was sent to a Canberra Model 2005 preamplifier where the signal was amplified by a factor of 10 , see Figure $B-9$. The preamplifier output was sent by special high voltage cable to a Canberra Model 2020 Spectroscopy Amplifier (see Figure B-8) located in the control room. Here the signal was further amplified and "shaped." The Spectroscopy Amplifier settings were:

Fine Gain: 0.40

Coarse Gain: 10

Input Polarity: +

Restore Mode: ASTM

Restore Rate: $\mathrm{Hi}$
Shaping Multiplier: $x 1$

Shaping Time: $0.25 \mu \mathrm{s}$

Threshold: Auto

PUR: off

These settings were not changed throughout the test program. 


\section{B-16}

The unipolar output from the rear of this amplifier was sent to the "Input" port on the front of the EG\&G Ortec Model 7100 Multi-channel Analyzer (MCA). (Details provided in Appendix C.) Here the gamma-ray spectrum was broken into 512 separate "channels" and then umber of "counts" detected in the set $300 \mathrm{sec}$. counting period was displayed. Initially the number of counts in the region, or regions, thought to represent the different elements, e.g., channels 215 to 225 for sulfur, were manually recorded. Therefore, information about the rest of the 512 channels was lost. Subsequently, a data acquisition system was set up and all data was recorded for on-line sulfur and iron prediction and for off-line analysis. 


\section{B-17}

Additional Information

DEVICE TYPE: Neutron Gauge

MODEL: Model CPNA Source Holder/Shield Assembly

ORIGINAL MANUFACTURER: Science Applications International Corporation

SEALED SOURCE MODEL DESIGNATION: Savannah River Operations SR-CF-Series Amersham Model CVN.6

ISOTOPE: Californium 252 MAXIMUM ACTIVITY: 20 millicuries

(37 micrograms)

LEAK TEST FREQUENCY: 6 months

PRINCIPAL USE: General Neutron Source Applications - Code H

CUSTOM DEVICE: $X$ YES

\section{Description}

The PGNAA unit was a neutron activation device for analyzing a coal water slurry. It consisted of a californium-252 sealed source mounted in a two-piece shield assembly surrounding the pipe containing the slurry. Both halves consist of an outer shell of welded aluminum filled with borated paraffin. The slurry pipe fits in a vertical channel cut out of the detector side of the shield. The Cf-252 source was mounted on a zircalloy holder which slides in a zircalloy tube, centered in the shield. The holder was attached to a Teleflex cable. In the "Source-In" position, the source was close to the slurry pipe and contained within a bismuth cap which reduces the direct gammaray flux. In the "Source Out" position, the source was near the center of the source half of the shield. 


\section{Labeling}

The unit was appropriately labeled. The radiation symbol is magenta on a yellow background. Labels are attached directly to the shield assembly with screws. The labels are made of aluminum.

\section{Conditions of Normal Use}

The device was mounted onto a 6-inch pipe carrying a dilute coalwater slurry as part of a slurry test loop used for tests of coal cleaning processes which reduce the sulfur and ash content of the coal. The general environment was an industrial laboratory. The immediate vicinity of the device was largely filled with slurry piping and its support structure. Personnel were not in the immediate area of the device except for infrequent maintenance activities or briefly to open or close valves.

The environment was indoors but not heated or cooled; temperatures are expected to fall within $0^{\circ} \mathrm{F}$ to $100^{\circ} \mathrm{F}$. No significant vibration impact, corrosion, puncture, or compressive loads are expected. Flooding is unlikely. No special fire hazards are expected. The device was stationary in normal use.

\section{Testing and Evaluation}

At the time of installation the source holder/shield assembly was tested for proper operation and a leak test was made.

\section{External Radiation Levels}

Radiation levels measured indicated the gamma-ray and neutronemission levels are generally low (in the range of $1 \mathrm{mrem} / \mathrm{hr}$ at 30 to $100 \mathrm{~cm}$ from the device). 


\section{Quality Assurance and Control}

Most source quality control was performed by the seaied source suppliers although a leak test will be performed by Battelle prior to installation into the device. Savannah River measures the activity to \pm 3 percent and Amersham measures the activity to -10 to +20 percent. After the source was installed the shield was surveyed for unusual leakage and conformance with the external radiation levels given above. Due to deliberate over-design, no further controls on the device were needed.

\section{Safety Analysis Summary}

Engineering analysis of the device and certification of the special form source by its supplier assure that the device will perform safely. The shield is cast in a welded 1/4-inch-thick aluminum housing and completely contained. Based on experience with this type of construction, it will withstand all normal conditions of handling, use, and storage including abrasion, vibration, impact, puncture, and compressive loads.

\section{Instruction to Users}

There were no recommended service for the device except leak testing every six months (instructions are presented in Appendix A), and source replacement when decay requires it (approximately every 2.5 years). Source replacement is not to be done by the user. Refer source replacement, any apparent problems with the source ON/OFF mechanism, relocation, etc. to Battelle. 
APPENDIX C

DATA ACQUISITION SYSTEM 
APPENDIX C

\section{DATA ACQUISITION SYSTEM}

A general description of the data acquisition system was provided in the body of the report. Additional details are provided below on each major subsystem.

\section{Data Inputs}

The system consists of the following five data input signals:

High-energy gamma gauge voltage (0-10 v)

Low-energy gamma gauge voltage $(0-10 \mathrm{v})$

Micro-Motion mass flowmeter $(0-10 \mathrm{v})$ [not currently installed]

Slurry temperature (0-50 2mv)

Prompt gamma-neutron activation spectrum (up to 512 values).

\section{Keithley System 500 Data Acquisition and Control System}

The data acquisition hardware system selected was a Keithley series 500 Data Acquisition and Control System. It consists of a series 500 interface board which is installed inside the personal computer (PC), an expansion chassis which can be fitted with up to 11 specialized input/output (I/O) data acquisition cards, and a communication cable which connects the chassis to the interface board, see next page.

The Keithley chassis is configured with an AMM1 (Analog Measurement Module, type 1) in slot number 1. This card can accommodate 8 single-ended, 12-bit analog (i.e., voltages) inputs. It is configured to the 0 to 10 volt mode by setting "dip" switches on the AMM1 card. The HEGG and LEGG 0 to $10 \mathrm{v}$ positive lead inputs are hardwired to positions 0 and 7 (the Micro-Motion 0 to 


\section{C-2}

$10 v$ signal could be wired to positions $1,2,3,4,5$, or 6 ), and the grounds are combined and attached to the common ground terminal.

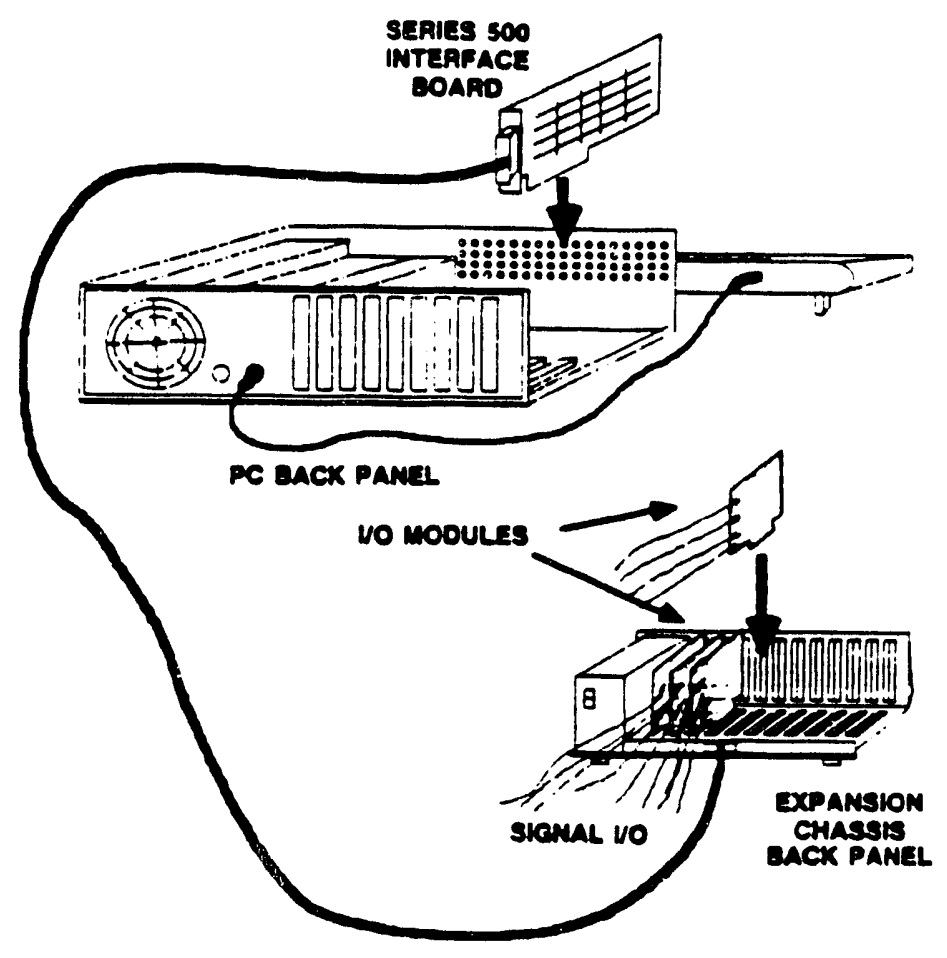

Figure C-1. Typical Expansion Chassis Configuration Source: Keithley Instruments Inc.

The third slot is fitted with an AIM3 (Analog Input Module, type 3). This high sensitivity module can accommodate 16 differential (i.e., isolated) voltage inputs. It is configured to the $\pm 100 \mathrm{mv}$ mode to accommodate the low voltage input provided by the Chromel-Alumel (Type $K$ ) thermocouple. Since only one thermocouple is used, it is hardwired to position 0. 
Multi-Channel Analyzer

Gamma radiation detected by the sodium-iodide detector on the PGNAA instrument is sent to the EG\&G Ortec Company, Model 7100 Multi-Channel Analyzer. This relatively sophisticated unit is shown schematically in Figure C-2 below.

\section{\& eara artac}
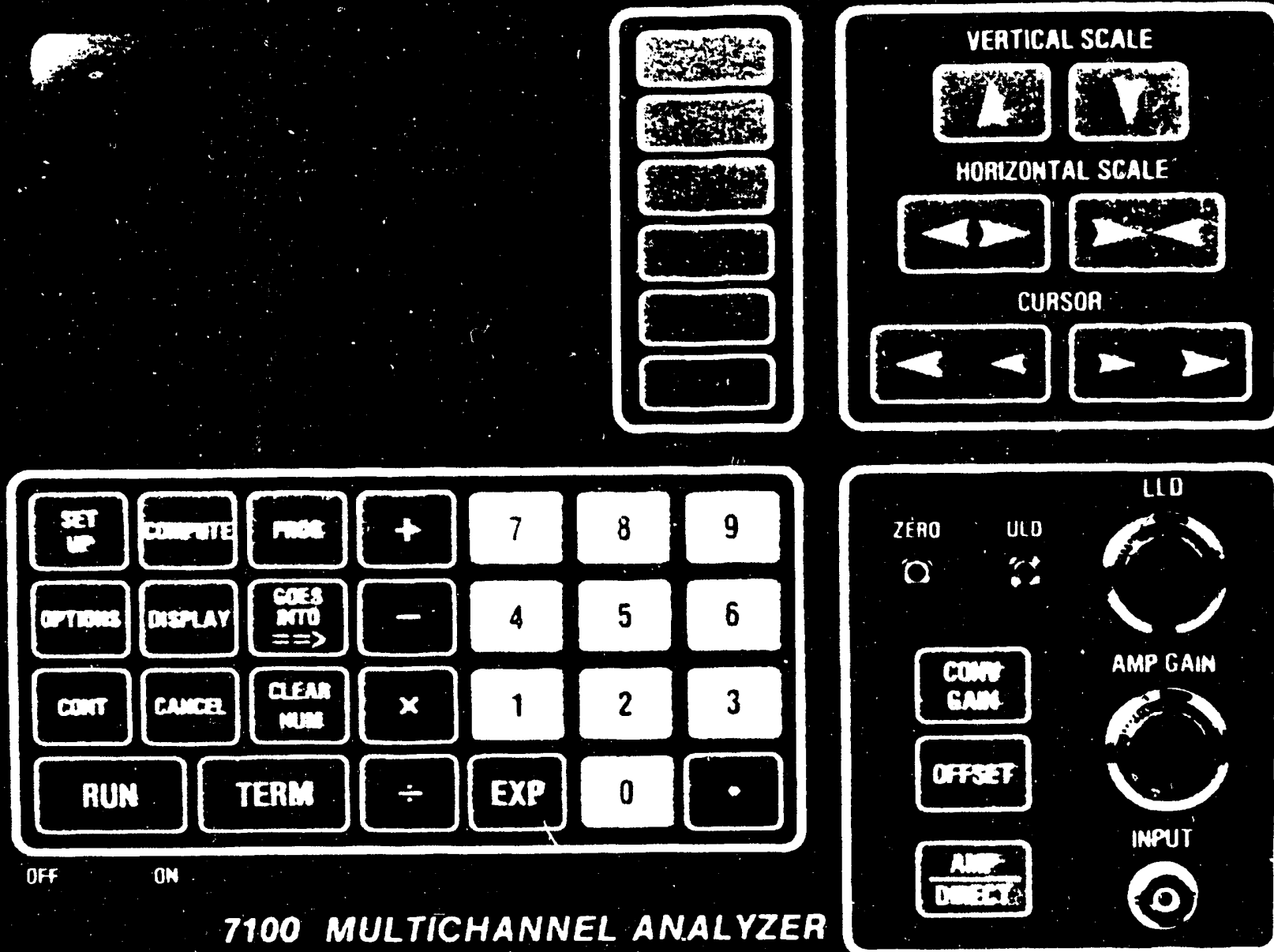

7100 MULTICHANNEL ANALYZER

FIGURE C-2. MULTI-CHANNEL ANALYZER 


\section{C -4}

The incoming gamma-ray energy is divided by energy level into two halves, $H 1$ : channels 0-511, and H2: channels 512-1013. For our work H1 provides all the useful information necessary to characterize the PGNAA spectrum. Each element is found in one or more regions in the spectrum. Depending on an element's susceptibility to activation, a peak of varying height and width is produced. The area under this peak is related to the volume of that element in the slurry sample under analysis. A typical PGNAA, sodium-iodide detector spectrum of Ohio $4 \mathrm{~A}$ coal is presented in Figure $\mathrm{C}-3$. To obtain the information to predict sulfur and iron, all 512 channel values could be inputted, transferred to magnetic medium, and then the relatively small fraction of useful information extracted. A more efficient route would be to cull the useful information from the spectrum first, and process and store it. The MCA has this ability. Up to 25 separate ROI's, ranging from a single channel to a contiguous range of channels (e.g., Channel 213, or Channel range 92 to 97), can be manually set up. The MCA can be instructed to automatically output this ROI data via a serial communication link with the data acquisition system. This is how the current data acquisition system is set up. The software program (LabTech Notebook) instructs the MCA to run an internal-MCA program. This user inputted program tells the MCA to "zero out" all data storage registers, acquire the PGNAA spectrum for a specified period of counting time ( $300 \mathrm{sec}$ has been used for all testing), then output the ROI's. The output data is sent to the PC using a "universal" data communication protocol referred to as RS-232. The physical connection is made between the MCA "Serial Port 1" output and the serial port on the PC using a "null modem" cable. The output is a long stream of numbers referred to as a synchronous serial transfer. Unfortunately, along with the desired values representing the number of counts in each ROI, there is extraneous information such as the channel numbers encompassing each ROI, blank spaces, "carriage returi", "line feed," "erid-of-line delimiters," symbols, etc. The valuable information can be extracted by a process called "parsing". Basically, a starting point and 


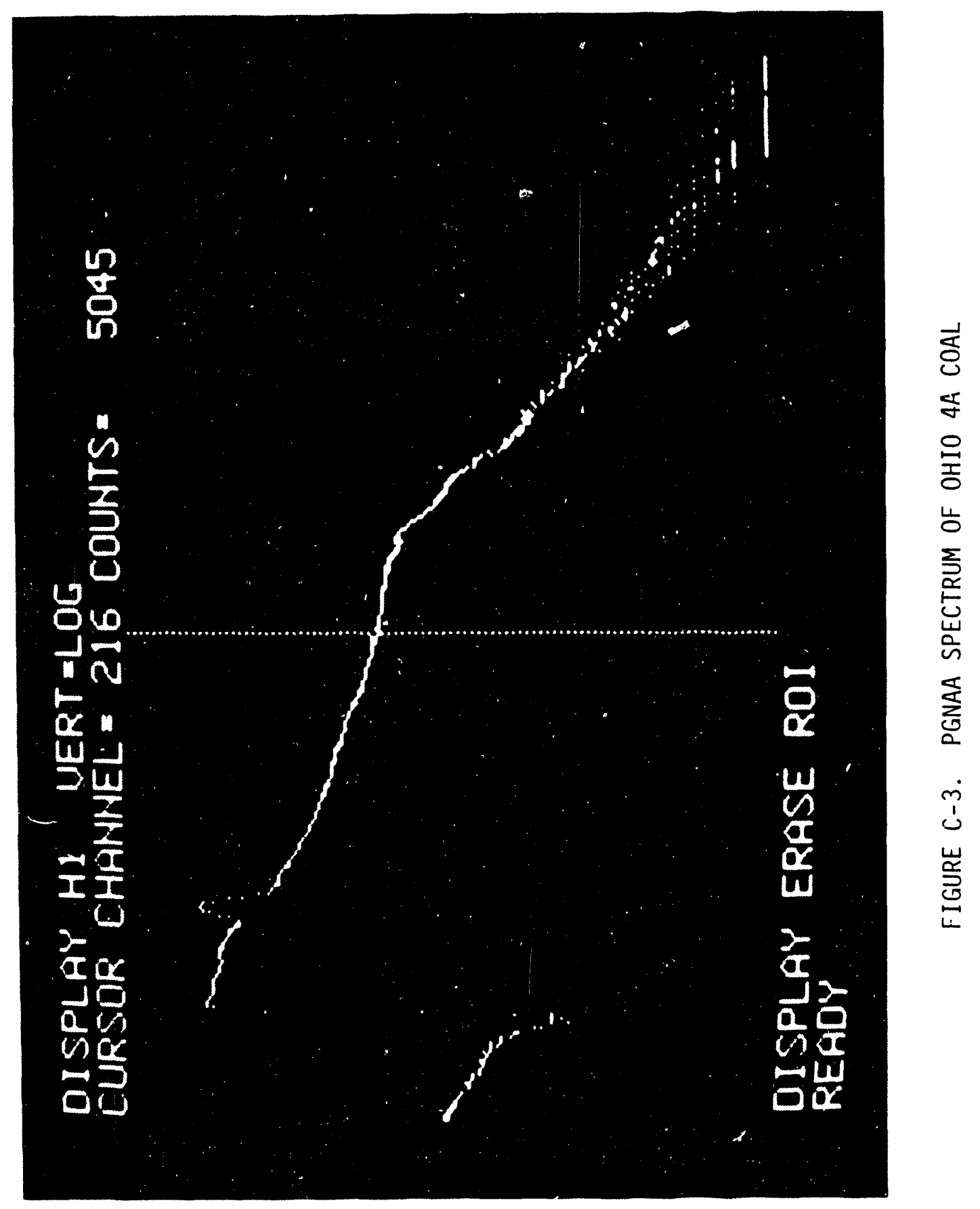


an ending point, measured from the "end-of-line delimiter" is inputted by the user. The data acquisition software automatically extracts the data from what the computer views as a long, continuous line of characters. Part of a typical output is presented below. First, the output as displayed on the MCA screen is presented, then the output sent to the data acquisition system (boxes and space numbers have been added to simplify the discussion) is presented.

Output displayed on MCA

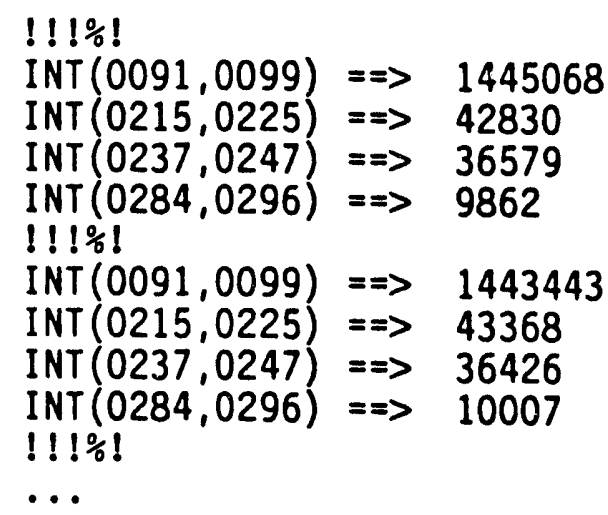

Here is the output sent to the data acquisition system (note: $C R=$ carriage return; $L F=1$ ine feed; $\%=$ end of line, EOL, delimiter):

$+\mathrm{EOL}$ Space numbers added to assist discussion $\downarrow$

\begin{tabular}{|c|c|c|c|c|c|c|c|c|c|c|c|c|c|c|c|c|c|c|c|c|c|c|c|c|c|c|}
\hline & & & 1 & 2 & 3 & 4 & 5 & 6 & 17 & 8 & 9 & 10 & 11 & 12 & 13 & 14 & 15 & 16 & 17 & 18 & 19 & 20 & 21 & 22 & 23 & 24 \\
\hline$! !$ & $!$ & $\%$ & $!$ & & $C R$ & LF & I & $N$ & $T$ & 1 & 0 & 0 & 9 & 1 & , & 0 & 0 & 9 & 9 & ) & & $=$ & $=$ & $>$ & & \\
\hline
\end{tabular}

$\uparrow$ EOL Delimiter

$\uparrow$ Characters sent

\begin{tabular}{|l|l|l|l|l|l|l|l|l|l|l|l|l|l|l|l|l|l|l|l|l|l|l|l|l|}
\hline 25 & 26 & 27 & 28 & 29 & 30 & 31 & 32 & 33 & 34 & 35 & 36 & 37 & 38 & 39 & 40 & 41 & 42 & 43 & 44 & 45 & 46 & 47 & 48 & 49 \\
\hline 1 & 4 & 4 & 5 & 0 & 6 & 8 & & & & & CR & LF & I & N & T & ( & 0 & 2 & 1 & 5 &. & 0 & 2 & 2 \\
\hline
\end{tabular}

$\uparrow$ start in 25, go to 35

$\uparrow$

\begin{tabular}{|l|l|l|l|l|l|l|l|l|l|l|l|l|l|l|l|l|l|l|l|l|l|l|l|l|}
\hline 50 & 51 & 52 & 53 & 54 & 55 & 56 & 57 & 58 & 59 & 60 & 61 & 62 & 63 & 64 & 65 & 66 & 67 & 68 & 69 & 70 & 71 & 72 & 73 & 74 \\
\hline 5 & 1 & & $=$ & $=$ & $>$ & & & 4 & 2 & 8 & 3 & 0 & & & & & & & CR & LF & I & N & T & ( \\
\hline
\end{tabular}




\begin{tabular}{|l|l|l|l|l|l|l|l|l|l|l|l|l|l|l|l|l|l|l|l|l|l|l|}
\hline 75 & 76 & 77 & 78 & 79 & 80 & 81 & 82 & 83 & 84 & 85 & 86 & 87 & 88 & 89 & 90 & 91 & 92 & 93 & 94 & 95 & 96 & 97 \\
\hline 0 & 2 & 3 & 7 & & 0 & 2 & 4 & 7 & ) & & $=$ & $=$ & $>$ & & & 3 & 6 & 5 & 7 & 9 & & \\
\hline
\end{tabular}

$\uparrow$ start in 91 , go to 101

\begin{tabular}{|l|l|l|l|l|l|l|l|l|l|l|l|l|l|l|l|l|l|}
\hline 98 & 99 & 100 & 101 & 102 & 103 & 104 & 105 & 106 & 107 & 108 & 109 & 110 & 111 & 112 & 113 & 114 & 115 \\
\hline & & & & CR & LF & I & N & T & ( & 0 & 2 & 8 & 4 &. & 0 & 2 & 9 \\
\hline
\end{tabular}

\begin{tabular}{|l|l|l|l|l|l|l|l|l|l|l|l|l|l|l|l|l|l|}
\hline 116 & 117 & 118 & 119 & 120 & 121 & 122 & 123 & 124 & 125 & 126 & 127 & 128 & 129 & 130 & 131 & 132 & 133 \\
\hline 6 & 1 & & $=$ & $=$ & $>$ & & & 9 & 8 & 6 & 2 & & & & & & \\
\hline
\end{tabular}

$\uparrow$ start in 124 , go to 134

\begin{tabular}{|l|l|l|l|l|l|l|l|l|l|l|l|l|l|l|l|l|l|}
\hline 134 & 135 & 136 & 137 & 138 & 139 & 1 & 2 & 3 & 4 & 5 & 6 & 7 & 8 & 9 & 10 & 11 & 12 \\
\hline & CR & LF & $!$ & $!$ & $\%$ & $!$ & & CR & LF & I & N & T & ( & 0 & 0 & 9 & 1 \\
\hline
\end{tabular}

$\uparrow+$ EOL delimiter

\begin{tabular}{|l|l|l|l|l|l|l|l|l|l|l|l|l|l|l|l|l|l|}
\hline 13 & 14 & 15 & 16 & 1.7 & 18 & 19 & 20 & 21 & 22 & 23 & 24 & 25 & 26 & 27 & 28 & 29 & 30 \\
\hline & 0 & 0 & 9 & 9 & ) & & $=$ & $=$ & $>$ & & & 1 & 4 & 4 & 3 & 4 & $\ldots$ \\
\hline
\end{tabular}

Thus, the parse start and stop positions are:

25, 35: for the first number which represents hydrogen counts

58, 68: for the second set, representing sulfur counts

91,101: for the third set, representing chlorine, and

124,134: for the fourth set, representing iron.

\section{Personal Computer}

Any of a variety of IBM, or compatible, personal computers could be used in the data acquisition system. A Compaq PC was selected because of its rugged construction and availability. 


\section{LabTech Notebook Software}

The data acquisition software is the vital link between the data signals, the acquisition hardware, and the user. This widely used software package allows relatively rapid setup of the acquisition software, while eliminating the need for specialized programming skills and minimizing setup time.

Each data input is assigned a "channel" number. Communication information is inputted. For example, is the channel signal coming from the Keithley chassis or from the RS-232 source? If from the Keithley, from which I/O card and which position is the signal wired onto the card? If temperature, which type of thermocouple? (The internal software.can convert the thermocouple millivolts to temperature in the desired scale.) If from the RS-232, then is the information to be parsed, and if so what are the starting and ending positions? Calculated channels can also be created. These channels take the information from one or more other channels and perform a mathematical manipulation (such as taking the logarithm) or dividing one signal by another.

Next, the display options are inputted. The display monitor area can be divided into a maximum of 30 different "windows." The location, type, and size of each window must be specified. The window types include analog (such as a voltage versus time plot), digital (a numeric readout of the channel value), or bar chart (horizontal or vertical) showing the relative magnitude of the channel value. Information on each window axis label can also be added. The display design is presented in Figure C-4.

Next, "traces" showing the channel values are assigned to the desired windows. Trace 1, which could represent the dry ash content calculated in charinel 7, could be displayed as a light-blue dashed line versus time in window 7 , and digitally as a numeric value of $12.13 \%$ in window 4 . 


\begin{tabular}{|c|c|c|c|}
\hline Am Voltage & 7.1337 & Cs Voltage & 8.1248 \\
\hline$\%$ solids & 15.02 & $\%$ Ash & 12.13 \\
\hline AVG $\%$ Solids & 14.91 & AVG $\%$ Ash & 12.21 \\
\hline 1362364 & 45998 & 38560 & 12187 \\
\hline$S$, wet 0.47 & S, dry 3.14 & Fe, wet .24 & $\mathrm{Fe}$, dry 1.61 \\
\hline
\end{tabular}

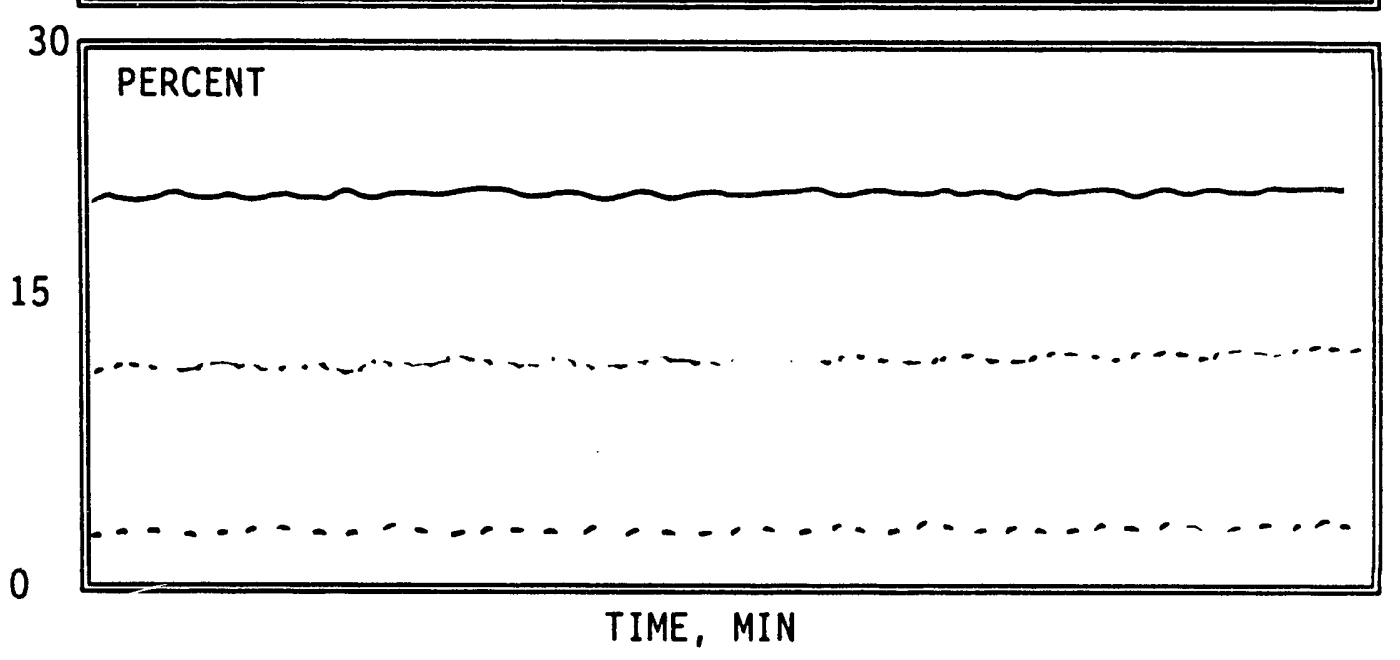

FIGURE C-4. MONITOR DISPLAY DESIGN 


\section{APPENDIX D}

\section{CHEMICAL ANALYSES OF TEST COALS}




$$
\text { D-1 }
$$

APPENDIX D

\section{CHEMICAL ANALYSES OF SELECTED COALS}

Included in this appendix are chemical analyses of the five selected coals, as presented in Tables $D-1$ through $D-5$. 
TABLE D-1. CHEMICAL ANALYSIS OF OHIO NO. 4A COAL OBTAINED FROM THE WATERLOO COAL COMPANY (JACKSON COUNTY, OHIO)

COMMERCIAL TFSTING \& ENGINEERING CO.

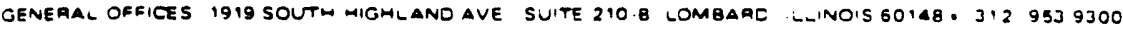

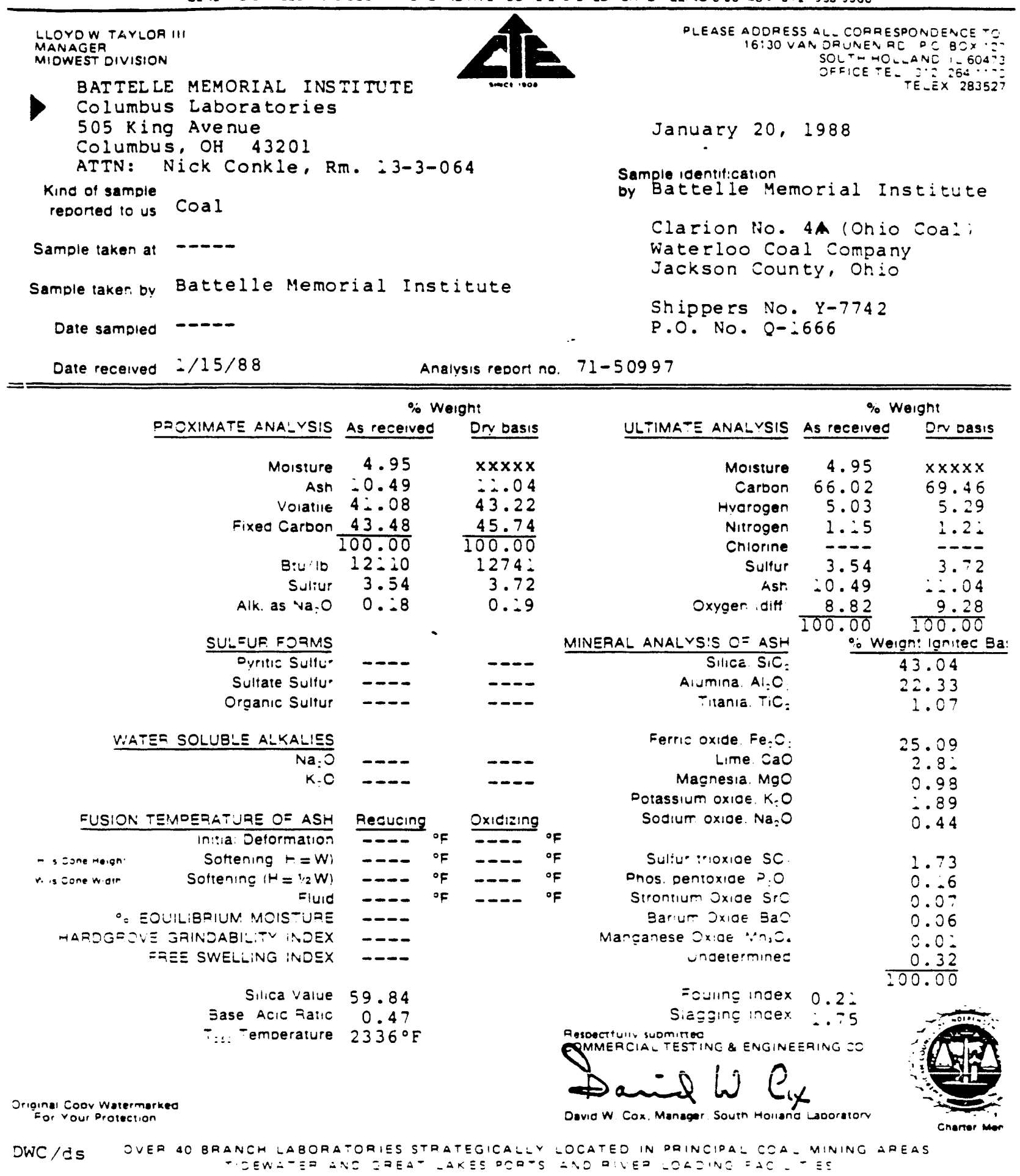


TABLE D-2. CHEMICAL ANALYSIS OF ILLINOIS NO. 6 COAL OBTAINED FROM THE PEABODY NO. 10 MINE (CHRISTIAN COUNTY, IL)

COMMERCIAL TESTING \& ENGINEERING CO. GENERAL OFFICES 1919 SOLTH HIGMLAND AVE SUITE 210.8 LOMBARD LLINOIS 60148 . 212 9539300

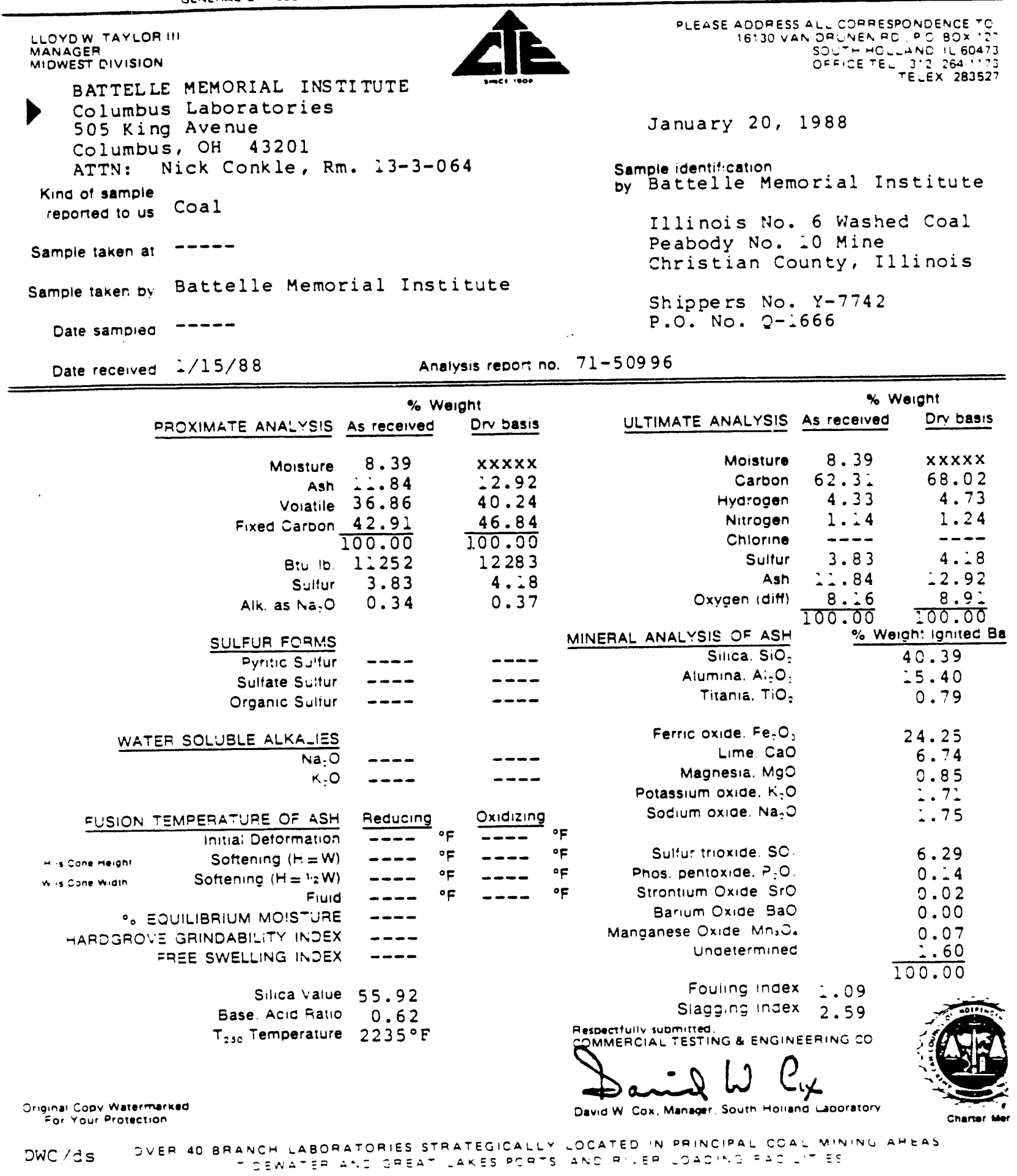


TABLE D-3. CHEMICAL ANALYSIS OF ELKHORN COAL OBTAINED FROM BETHLEHEM MINES (PIKE COUNTY, KENTUCKY)

COMMERCIAL TESTING \& ENGINEERING CO.

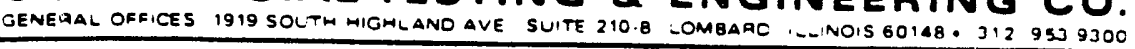

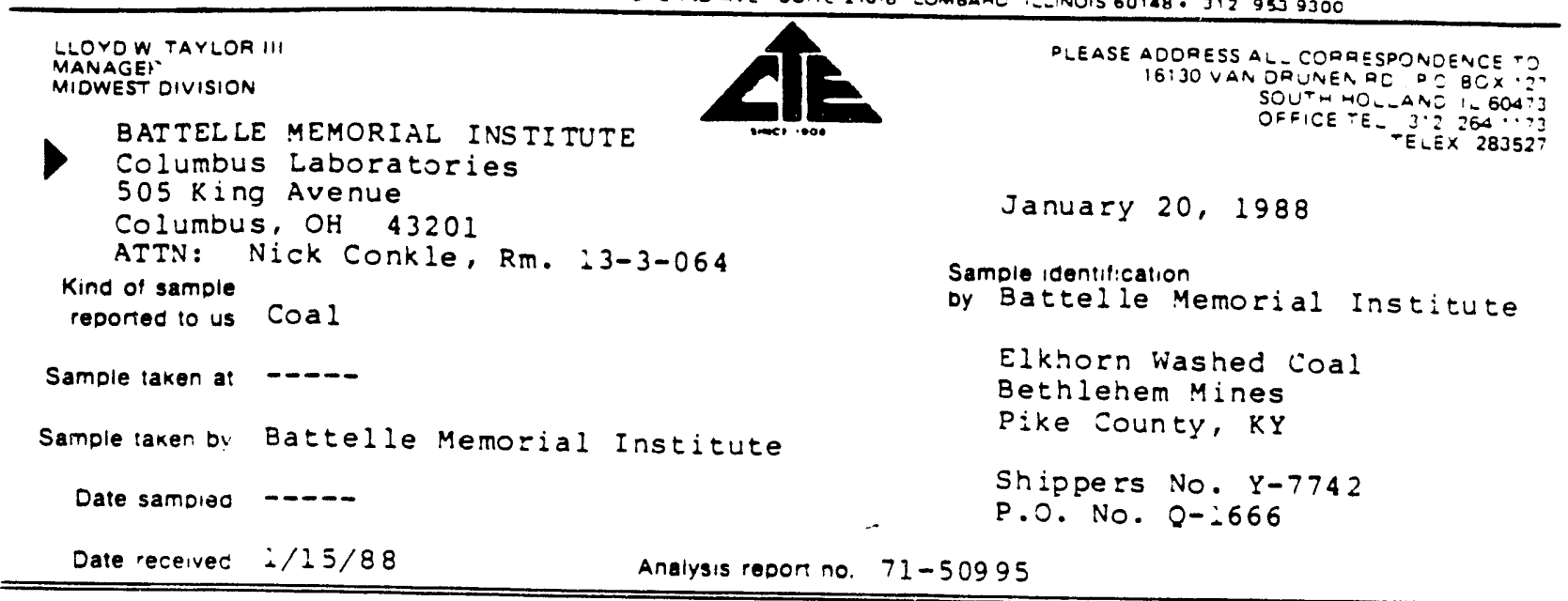

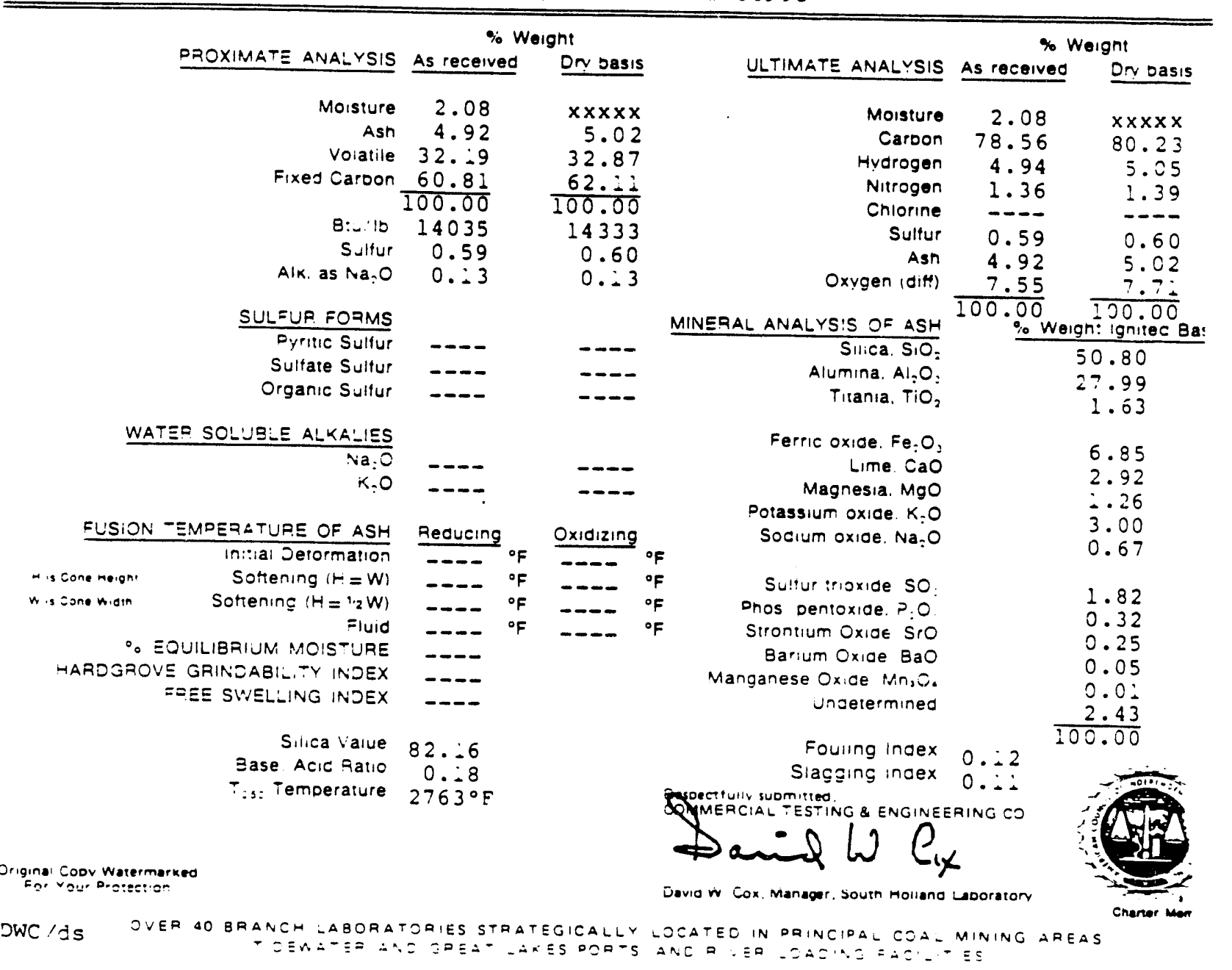


TABLE D-4. CHEMICAL ANALYSIS OF OHIO MA COAL

\section{COMMERCIAL TESTING \& ENGINEERING CO.}

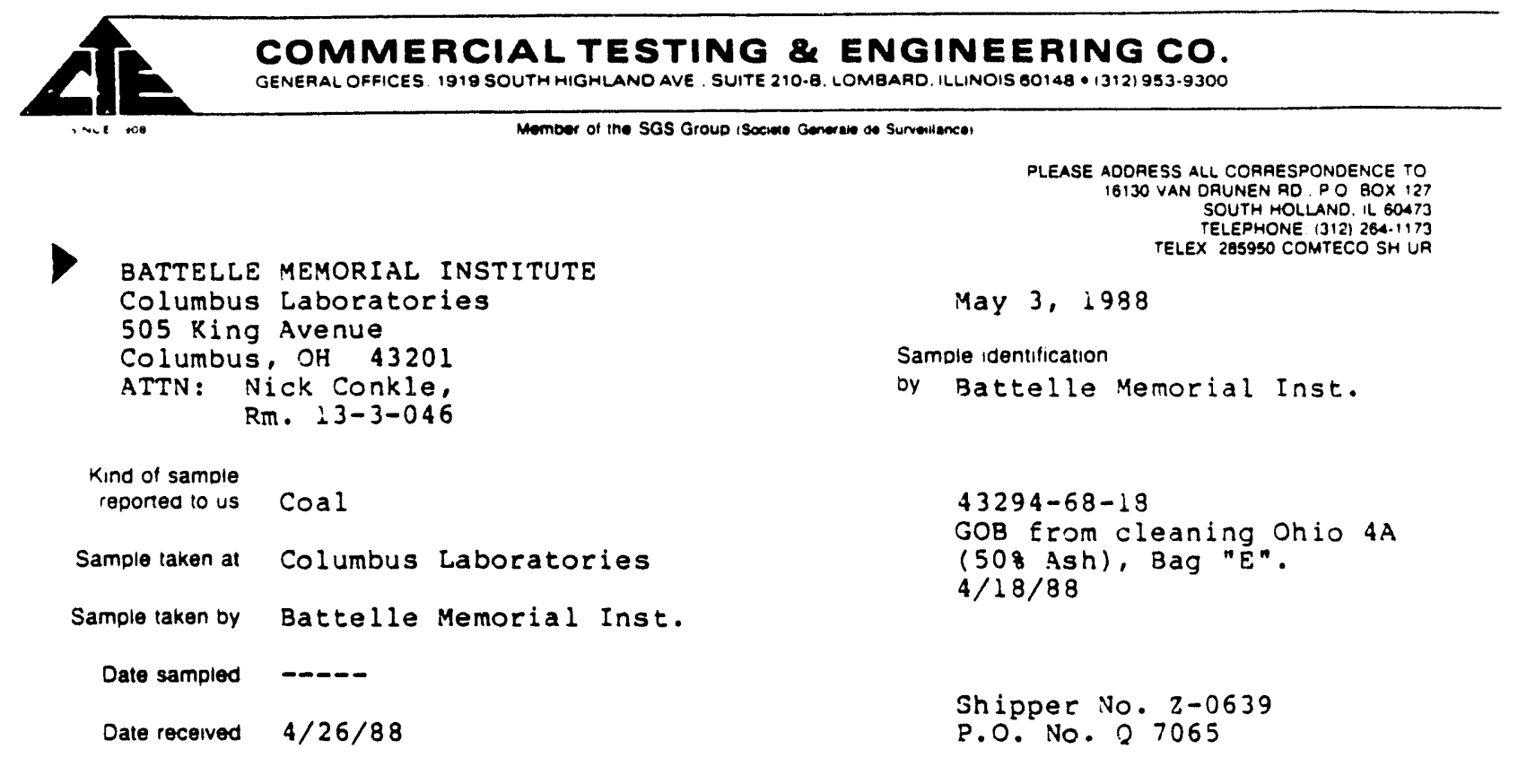

Analysis repor no. $71-55494$

ULTIMATE ANALYSIS

$\begin{array}{rrrr} & \text { As Received } & \text { Dry Basis } \\ \text { 8Moisture } & 3.78 & & \text { xxxxx } \\ \text { 8Carbon } & 36.10 & & 37.52 \\ \text { 8Hydrogen } & 2.02 & 2.10 \\ \text { 8Nitrogen } & 0.75 & 0.78 \\ \text { 8Chlorine } & 0.10 & 0.10 \\ \text { 8Sulfur } & 3.70 & 3.85 \\ \text { 8Ash } & 47.14 & 48.99 \\ \text { soxygen (DifE) } & 6.41 & 6.66 \\ & & 100.00 & 100.00 \\ \text { Btu/lb. } & 5961 & 6195\end{array}$

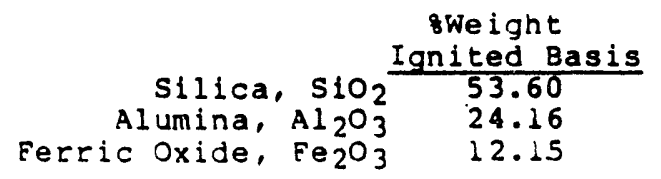

8 We ight

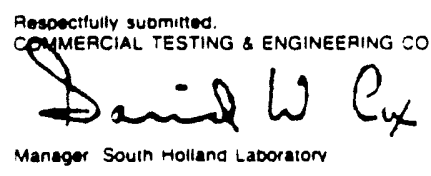
TIDEWATER AND GREAT LAKES PORTS. AND RIVER LOAOING FACILITIES

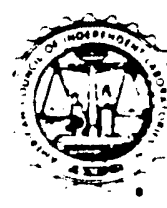

Cnarrer Memoer 
APPENDIX E

PROCESS-CONTROL STRATEGIES 


\section{APPENDIX E}

\section{PROCESS-CONTROL STRATEGIES}

Control strategies for each of the following applicable cleaning processes are presented below:

- True Heavy Liquid Cyclones

- 0il Agglomeration

- Heavy Media Cyclones

- Concentrating Tables

- Froth Flotation.

Note advanced flotation and water-only cyclone control strategies were discussed in the body of the report.

\section{True-Heavy Liquid Cyclone}

The cyclone is a hydraulic centrifuge working on the vortex principle. As a cleaning device it accelerates the separation of coal from mineral matter based on their gravity differences. In "true" heavy liquids the gravity difference is due to the specific separating liquid chosen, in contrast to conventional heavy media which is a mixture of water and dense, magnetic iron oxide (magnetite). Methylene crloride and freon compounds have been the most commonly tested liquids.

The DEGG should perform acceptably with these heavy liquids, and Process Technology Inc.'s (PTI) recent experience with a somewhat similar, nuclear based coal slurry analyzer with methylene chloride provides experimental support for this claim. The PGNAA instrument, however, is sensitive to chlorine. Interpretation of the PGNAA spectrum, for quantitative analysis of the coal slurry, is based on a linear relationship between "counts" recorded for a specific counting period over a specific gamma energy range. Elements such as chlorine, which appear throughout the PGNAA spectrum, 
including in the vicinity of sulfur and iron, make spectrum interpretation less reliable. Therefore, the accuracy of sulfur and iron predictions with chlorine-based heavy liquids may not be acceptable (although no test data are available to verify the analyzer's accuracy or inaccuracy with these types of liquids). Experience at DOE with methylene chloride indicates that this liquid will not likely be pursued as a THL cycloning fluid. Other nonchlorine based liquids are preferred to avoid the excessive corrosive problems experienced with methylene chloride. Therefore, the PGNAA analyzer may be acceptable for future THL-cycloning applications.

Many different THL-cycloning configurations have been studied. One common arrangement uses a three cyclone set up. Coal and separating liquid are mixed and fed to the primary cyclone inlet. The lighter coal stream exits from the top of the cyclone, is mixed with more liquid, and sent to a cleaning cyclone. The primary cyclone underflow, containing mineral matter, coal, and liquid, is mixed with more liquid and sent to a scavenging cyclone. The cyclones' overflows, and underflows, are combined and separately filtered and dried.

In order to automatically control this cleaning operation it is necessary to:

- Identify which properties must be analyzed

- Identify what control variables are available for adjustment to control cleaning performance

- Determine the mode of control, either feedback, feed forward, both feed back and feed forward, or some other mode advance control scheme.

Property Identification. The most effective coal property found for control of cyclones is the refuse ash content. Analysis of the product stream may show little change, even if the yield has dropped significantly. THL cyclones can be very effective in pyritic sulfur removal. Therefore, a 


\section{E-3}

secondary control property of interest in advanced THL cycloning processes is the sulfur content of the tailings.

Control Variables. THL cyclone circuit performance is modified primarily by the slurry specific gravity. Other possible control variables include the location of the vortex finder (i.e., distance from the bottom of the overflow orifice to the bottom of the cyclone), and the size of the underflow orifice. These latter two items are not normally subject to automatic adjustment on line. However, an adjustable vortex finder is technically feasible and is often found with conventional water-only cyclones $^{(5)}$.

Control Mode. Control systems can use feedback or feed forward control loops. Feed forward may be preferred in this cleaning process. The slurry specific gravity of each cyclone is monitored. If outside the acceptance band, the flowrate of the liquid addition pump feeding the cyclone feed sump is adjusted. A lower specific gravity leads to lower ash and sulfur levels, but also poorer recovery.

Experience. No advanced THC cyclone processes are in commercial operation. However, Process Technologies Inc. (PTI) recently completed construction of a $1 \mathrm{TPH}$ integrated pilot plant. The unit was equipped with six semi on-line, batch type, coal slurry ash analyzers. The intent was to in iegrate these with on-line process control. However, technical problems related to the dewatering circuit led to a premature shut down of the pilot plant. Only limited data was obtained--not enough to clearly prove the benefits of their control strategy.

Control Strategy Using DEGG/PGNAA Analyzer. The DEGG/PGNAA analyzer has been shown to provide accurate analysis of slurry percent solids, ash, and mass flow rate on aqueous-coal slurries. Work at PTI using a somewhat similar nuclear based slurry ash analyzer has shown the unit capable of acceptable operation with methylene chloride THL cyclones. Therefore, it is reasonable 


$$
E-4
$$

to assume that the DEGG and possibly the PGNAA analyzer should also be able to work under these conditions (although this has not been demonstrated).

Presented below are three proposed control modes. The first uses only the DEGG to estimate ash and percent solids to maintain ash within an acceptable range and maximize yield. The second and third use both the DEGG and the PGNAA instrument to control both ash and sulfur.

\section{Control Mode No. 1: Simple Ash/Yield Control for a Primary,} Cleaning, and Scavenging THL Cyclone Circuit

- Monitor the tailings ash content

- Modify each cyclone performance by adjusting slurry specific gravity controller setpoint (the specific gravity is determined by a nuclear densitometer). Actual adjustment of the specific gravity is accomplished by increasing or decreasing the flowrate of the liquid addition feed pump

- Control operations using feed forward specific gravity controller. The setpoint is modified by feedback signal from the tailings ash analyzer.

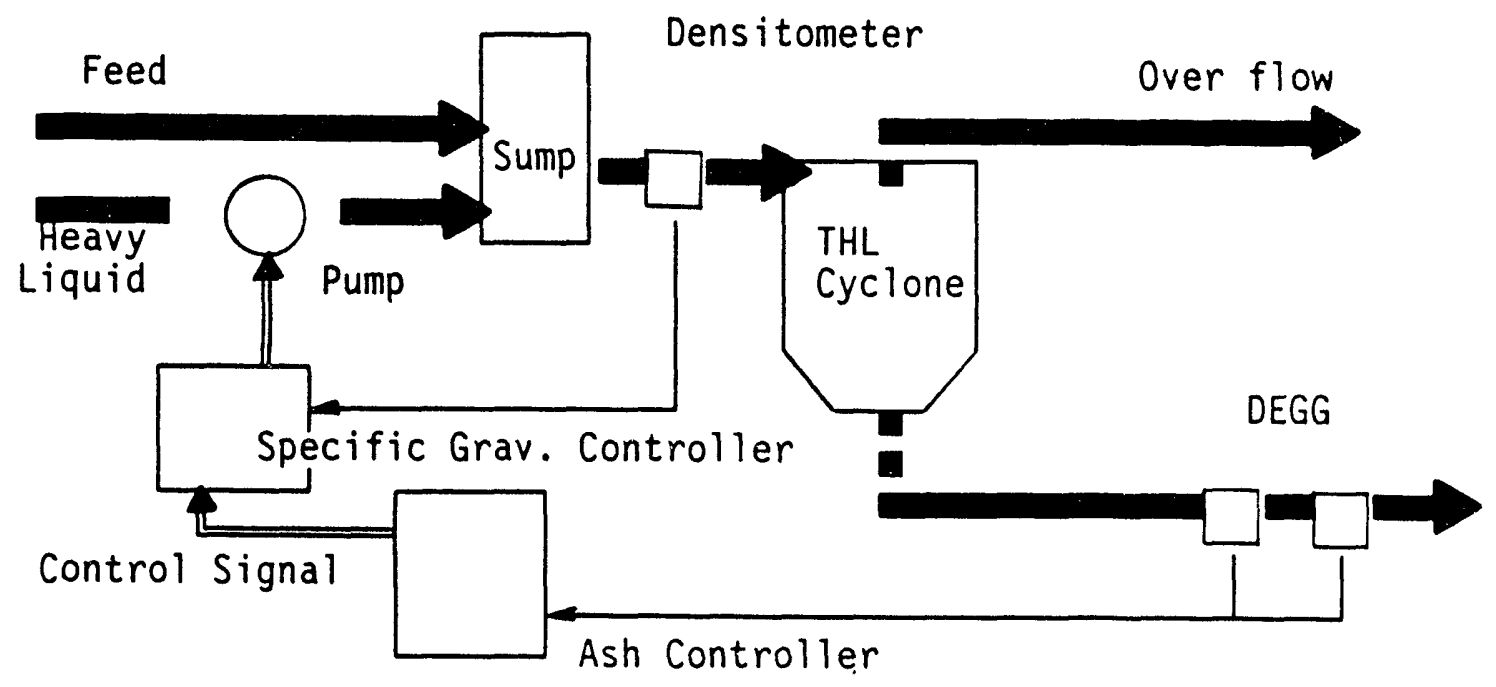


Control Mode No. 2: Simple Ash/Sulfur/Yield Control for a Primary, Cleaning, and Scavenging THL Cyclone Circuit

- Monitor the tailings ash and sulfur content

- Modify each cyclone performance by adjusting slurry specific gravity controller setpoint (the specific gravity is determined by a nuclear densitometer). Actual adjustment of the specific gravity is accomplished by increasing or decreasing the flowrate of the liquid addition feed pump.

- Control operations using feed forward specific gravity controller. The setpoint is modified by feedback loop from an ash/sulfur controller fed by a signal from the tailings ash DEGG analyzer and the PGNAA sulfur analyzer.

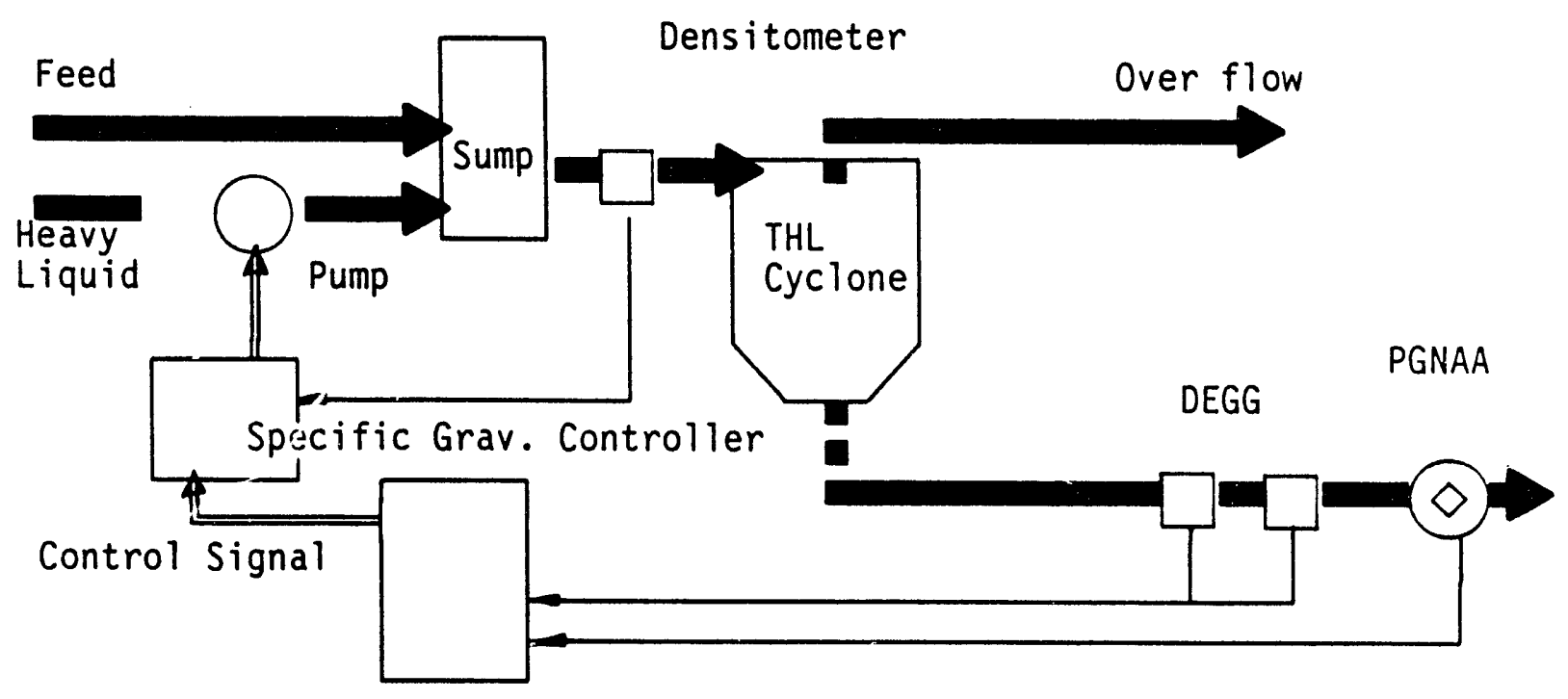

Control Mode No. 3: Complex Ash/Sulfur/Yield Control for a Primary, Cleaning, and Scavenging THL Cyclone Circuit

- Monitor the feed and tailings flowrates and ash and sulfur contents

- Modify each cyclone performance by adjusting slurry specific gravity controller setpoint (the specific gravity is determined 


\section{$E-6$}

by the cesium densitometer half of the DEGG). Actual adjustment of the specific gravity is accomplished by increasing or decreasing the flowrate of the liquid addition feed pump.

- Control operations using feed forward specific gravity concroller. The setpoint is modified by feedback loop from an ash/sulfur controller fed by a signal from the DEGG tailings ash analyzer and the PGNAA tailings sulfur analyzer. With the flowrate and ash and sulfur data, it is possible to calculate product ash and sulfur content and cyclone yield and recovery. These could be used in alternative control algorithms for control of the dense liquid feed pump flowrate.

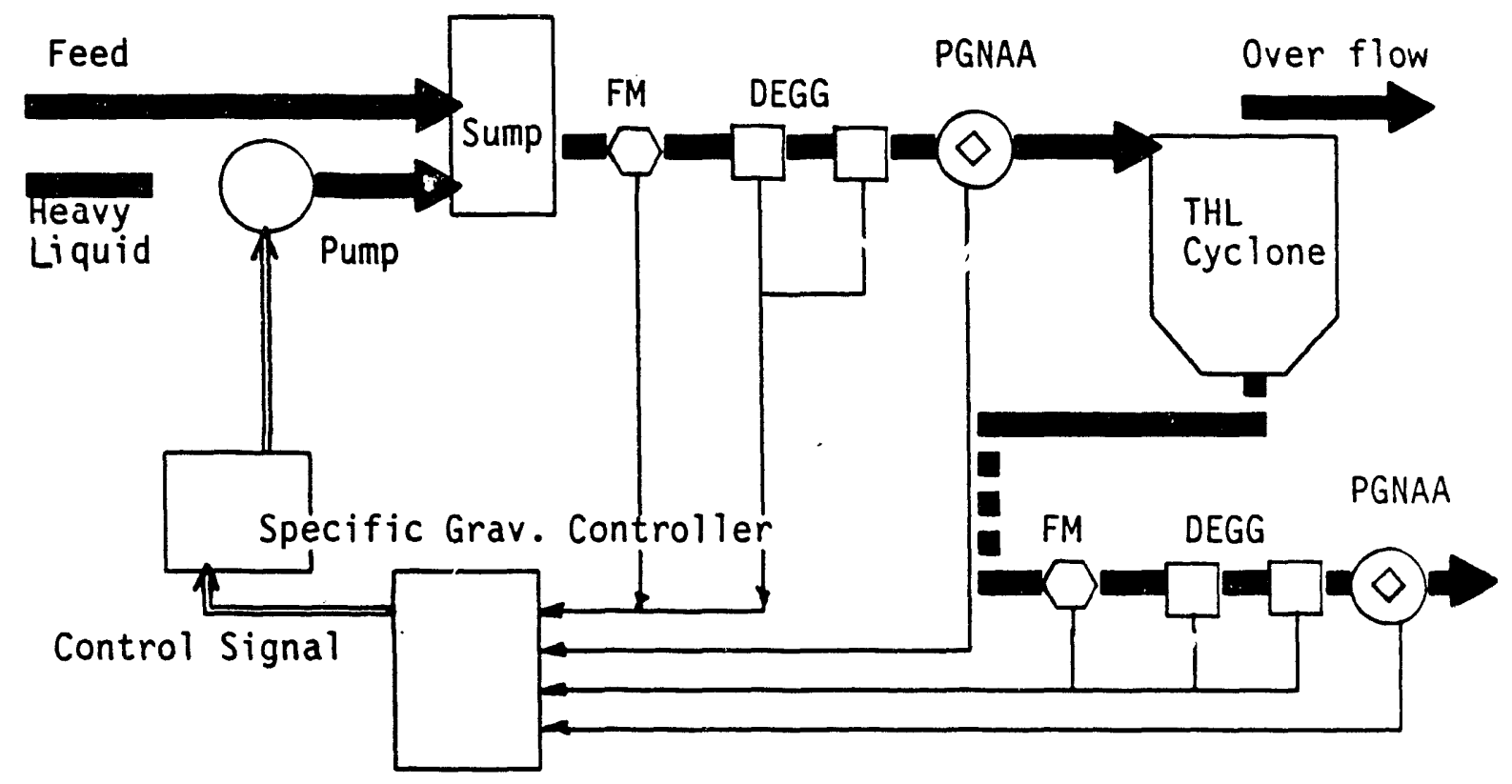

\section{0il Agglomeration}

$0 i l$ açglomeration is a surface-chemistry related cleaning process. The coal is mixed with water, ground to a fine size ( -100 mesh or smaller) and mixed with a bridging agent (such as fuel oil, heptane, hexane, etc.) and agitated in a high-shear mixer. The intermediate product may be screened to remove mineral matter from the product before additional processing, or it may 
be sent directly to a second low-shear mixer. The slurry is then screened to separate the larger clean-coal product from the water-mineral matter tailings stream. The bridging agent may be left in the coal, or removed by drying and recycled within the process. The tailings stream is filtered, the water recycled, and the tailings sent for disposal.

In order to automatically control this cleaning operation, it is necessary to:

- Identify which properties must be analyzed

- Identify what variables are available for adjustment to control cleaning performance

- Determine the control mode(s).

Property Identification. The most effective coal property found to characterize agglomeration performance are the product and tailings ash contents.

Control Variables. Agglomeration vessel performance is modified primarily by the oil addition rate. Secondary control variables include water addition rate (which controls the slurry fulp density) and slurry feed rate.

Control Mode. Control systems can use feedback or feed forward control loops. The oil addition rate could be controlled by a feedback loop based on tailings and/or product ash content or a feed forward loop based on the slurry pulp density. Water feed rate could be controlled by a feed forward loop based on the inlet slurry pulp density.

Experience. No advanced oil agglomeration processes are currently using on-line analysis or process control to optimize operations. Although the oil agglomeration technique has been studied for years, no reference of on-line control has been identified. 
Control Strategy Using DEGG/PGNAA Analyzer. The DEGG/PGNAA analyzer has been shown to provide accurate analysis of slurry percent solids, ash, and mass flow rate on aqueous slurries with similar coal and ash characteristic as oil agglomeration feed, product, and tailings streams. The use of hydrocarbon bridging agents should not theoretically affect either the DEGG or the PGNAA analyzer. PTI's successful experience with their nuclear-based ash analyzer with methylene chloride provides additional evidence that, at least, the ash and percent solids analyzers should perform acceptably with added hydrocarbon liquids.

Presented below are two proposed control modes. The first uses only the DEGG to estimate ash and percent solids in a control mode designed to maintain ash within an acceptable range and maximize yield. The second uses both the DEGG and the PGNAA instrument to control both ash and sulfur.

\section{Control Mode No. 1: Simple Ash/Yield Control for a Two-Stage 0il Agglomeration Circuit}

- Monitor the tailings ash content and feed pulp density

- Modify performance by adjusting bridging liquid feed rate. Actual adjustment of the feed rate is accomplished by increasing or decreasing the settings on the liquid addition feed pump. Feed pulp density is also independently controlled by modifying the water feed rate.

- Control operations use a feed forward water addition controller. 0il addition is adjusted by a feedback controller. The set point is adjusted based on the tailings ash analyzer signal. 
$E-9$

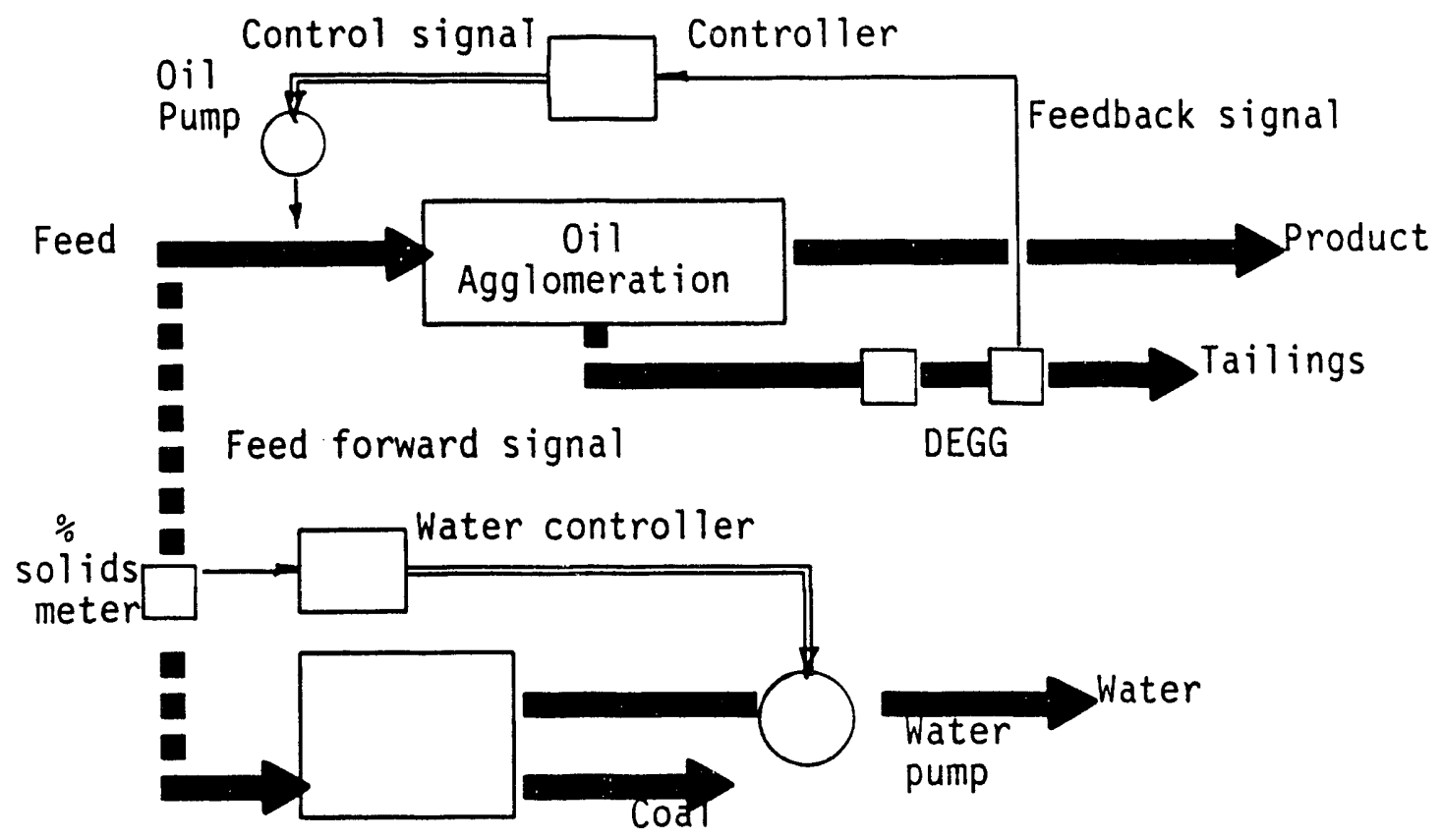

Control Mode No. 2: Simple Ash/Sulfur/Yield Control for a Two-Stage 0il Agglomeration Circuit

- Monitor the tailings ash and sulfur content and feed pulp density

- Modify performance by adjusting bridging liquid feed rate. Actual adjustment of the feed rate is accomplished by increasing or decreasing the settings on the liquid addition feed pump. Feed pulp density is also independently controlled by modifying the water feed rate.

- Control operations use a feed forward water addition controller. 0 il addition is adjusted by a feedback controller. The set point is adjusted based on the tailings ash and sulfur analyzers signals. 


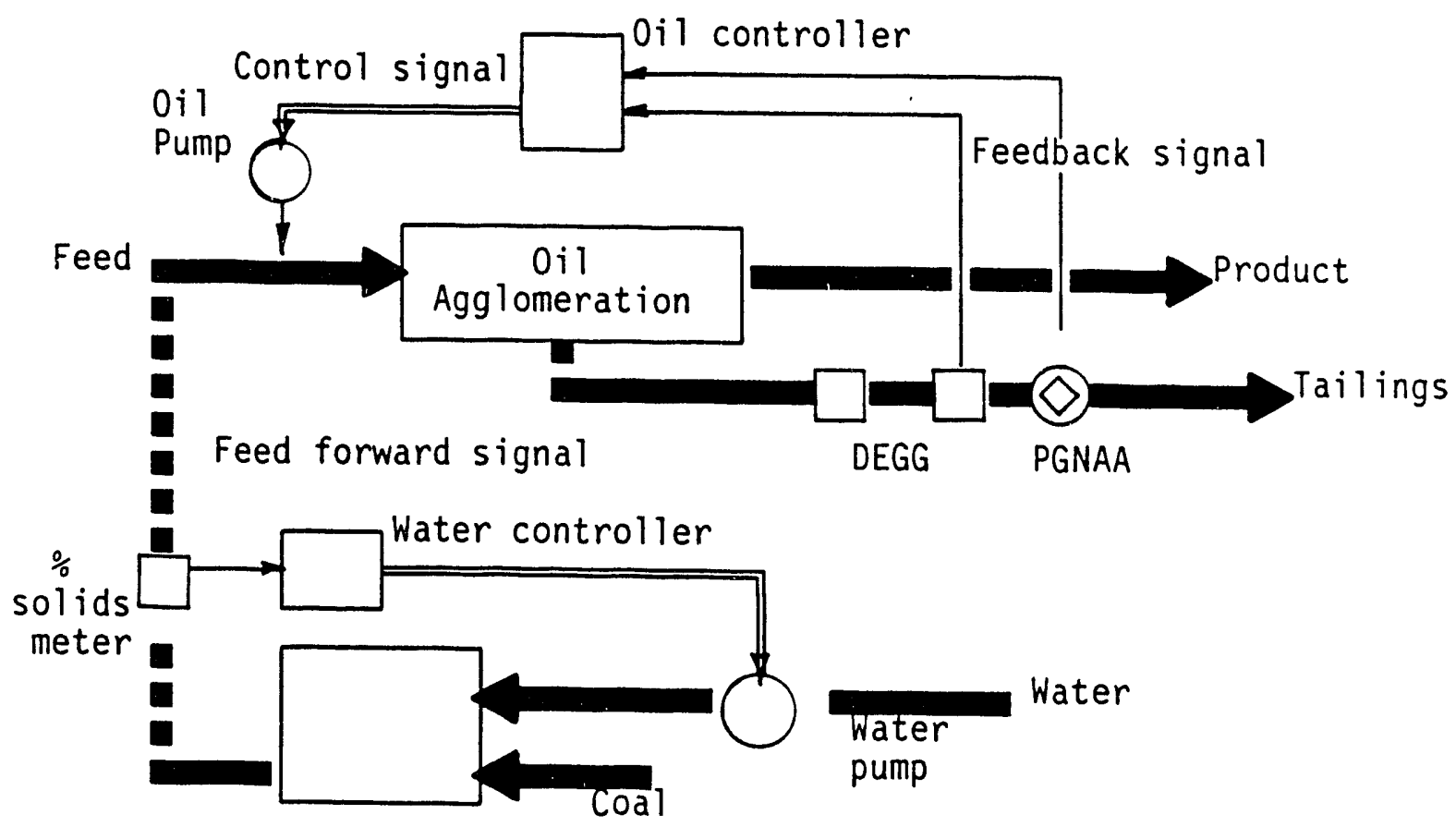

\section{Heavy-Media Cyclones}

A heavy-media (H.M.) cyclone is a hydraulic centrifuge similar in principle, if not actual shape, to a THL cyclone or a water-only cyclone. As a cleaning device, it accelerates the separation of coal from mineral matter based on their gravity differences. The heavy media used is a mixture of water and magnetite, an iron oxide compound $\left(\mathrm{Fe}_{3} \mathrm{O}_{4}\right)$.

The DEGG and PGNAA instruments are both strongly affected by the high iron content characteristic of the feed, product and tailings streams associated the H.M. cyclones. However, after cycloning, the coal and refuse are separated from the magnetite in a succession of "rinse and drain" screens. Both the product and tailings undergo this treatment and should have sufficiently low residual iron contents to allow control of the heavy-media process. (However, this has not been demonstrated.) 
In a standard H.M. cyclone configuration, the raw coal is screened to limit the oversize material and mixed with water and magnetite. It is then pumped to a desliming screen where the $3 / 8$ inch $\times 28$ mesh fraction is separated. The coal/water/magnetite slurry is next sent to a cyclone feed sump. Here additional water and/or magnetite is added to give the proper slurry specific gravity and the proper percent solids. The adjusted slurry is then pumped to the cyclone. The cyclone overhead product is sent to a twostage rise and drain screen. In the first compartment, the product is sprayed with water and the screen drains are routed to a recycle sump. The coal passes to a second compartment where it is again washed with spray water. The washed coal is dewatered and sent to the clean-coal conveyor belt. The screen drains from the second-compartment are sent first to a dilute media sump and then to a magnetic separator. The recovered magnetite is sent to an "overdose medium" storage sump and is then metered back into the cyclone feed sump. A similar wash and recover procedure is conducted on the tailings stream, except that the washed, dewatered material is sent to the refuse belt.

In order to automatically control this cleaning operation it is necessary to:

- Identify which properties must be analyzed

- Identify what control variables are available for adjustment to control cleaning performance

- Determine the best control mode.

Property Identification. The most effective coal property found for control of cyclones is the refuse ash content. Like other cyclones, analysis of the product stream may show little change, even if the yield has dropped significantly. The H.M. cyclones can be effective in pyritic sulfur removal. Therefore, a second control property of interest is the sulfur content of the tailings. 
Control Variables. The H.M. cyclone circuit performance is modified primarily by the slurry specific gravity. Other possible control variables include the location of the vortex finder and the size of the underflow orifice. These latter two items are not normally subject to automatic adjustment on line. However, an adjustable vortex finder is technically feasible and is often found with conventional water-only cyclones.

Control Mode. Control systems can use feedback or feed forward control loops. Feed forward may be preferred for this cleaning process. The slurry specific gravity is monitored; if outside the acceptance band, the flowrate of the heavy media makeup pump feeding the cyclone feed sump is adjusted. A higher specific gravity leads to higher ash and sulfur levels, but also greater recovery.

Experience. Heavy media cycloning is a commercial operation employed in many intermediate to complex cleaning plants. Virtually all plants use on-line specific gravity control. However, no plants use on-line slurry ash or sulfur analyzers to control the process.

Control Strategy Using DEGG/PGNAA Analyzer. Presented below are two proposed control modes. The first uses only the DEGG to estimate ash and percent solids in control modes to maintain ash within an acceptable range and maximize yield. The second uses both the DEGG and the PGNAA instrument to control both ash and sulfur.

\section{Control Mode Mo. 1: Simple Ash/Yield Control for a Heavy-Media Cyclone}

- Monitor the tailings ash content

- Modify cyclone performance by adjusting slurry specific gravity controller setpoint (the specific gravity is determined by a nuclear densitometer). Actual adjustment of the specific gravity is accomplished by increasing or decreasing the flowrate of the heavy media makeup fed to the cyclone feed sump. 
- Control operations using feed forward specific gravity controller. The setpoint is modified by feedback loop from an ash controller fed by a signal from the tailings ash analyzer.

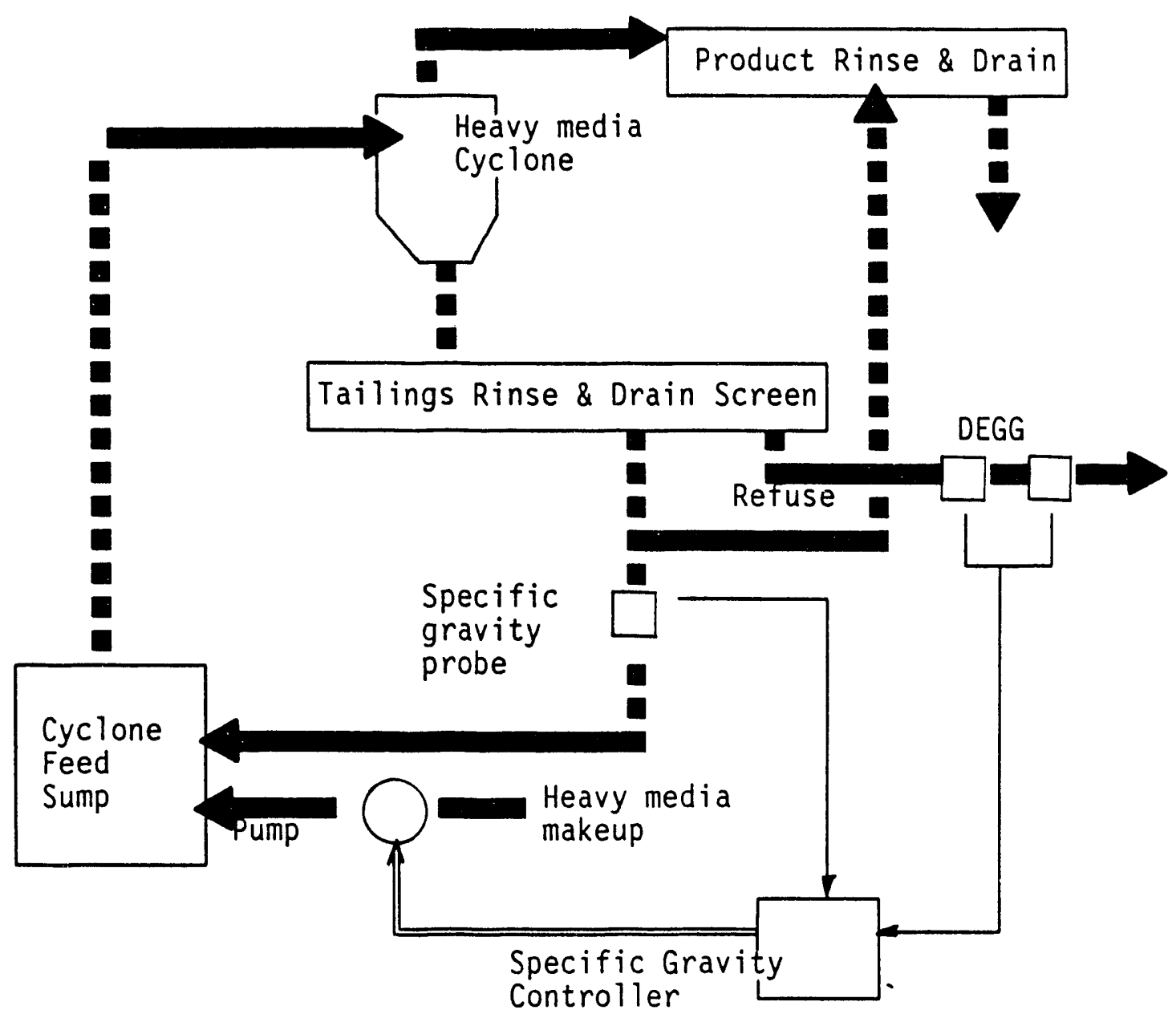

Control Mode No. 2: Simple Ash/Sulfur/Yield Control for a HeavyMedia Cyclone

- Monitor the tailings ash and sulfur content

- Modify cyclone performance by adjusting slurry specific gravity controller setpoint. Specific gravity adjustment is related to the level of heavy media makeup.

- Control operations using feed forward specific gravity controller. The setpoint is modified by feedback loop from a controller fed by signals from the tailings ash analyzer and tailings sulfur analyzer. 


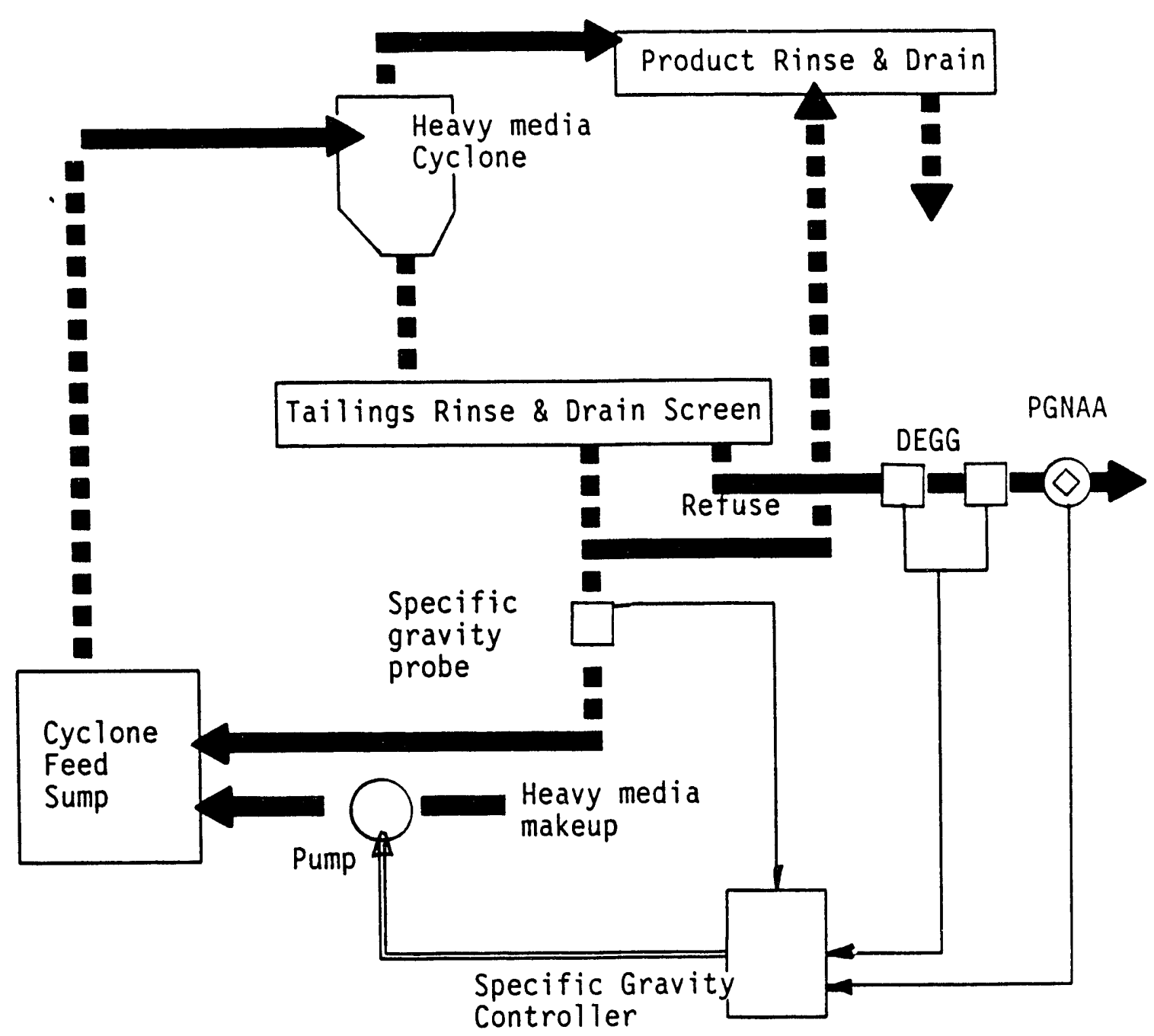

\section{Concentrating Tables}

The concentrating table effects a separation of $1 / 4$ inch $\times 0$ coal from refuse by size and by specific gravity. Water and coal are passed over a vibrating table having a series of riffles. The large, rubber-covered, rhomboid-shaped deck is fitted with a differential motion drive which gives it a quick return conveying motion. This moves the material lying on the deck surface away from the drive end. The nearly horizontal table is fitted with a system of rubber riffles tapered toward the refuse end of the table. Between each set of body riffles are high "pool" riffles. Low density coal particles 
ride over the riffles and report to the clean coal side of the table; highdensity particles are carried behind the riffles to the refuse end. The majority of the water goes with the finer, heavier refuse stream. It flows by gravity, or can be pumped to a refuse screen. Here the water is separated and recycled back to the plant.

The DEGG and PGNAA equipment should perform satisfactorily on this stream since no high-iron components have been introduced. The $-1 / 4$ inch material should be small enough to not cause a problem (although this has not been experimentally verified).

In order to automatically control this cleaning operation it is necessary to:.

- Identify which properties must be analyzed

- Identify what control variables are available for adjustment to control cleaning performance

- Determine the preferred control mode.

Property Identification. The most effective coal property found for control of concentrating tables is the product and refuse ash. Since the refuse stream is smaller and contains more water, it may be the preferred stream for analysis.

Control Variables. Table performance can be modified by several control variables, including reciprocating speed, length of stroke, feed rate, amount and distribution of water, feed percent solids, side tilt, and end elevation. The easiest to accomplish, and those amenable to on-line, control are, in order of preference (1) end elevation, (2) length of stroke, and (3) reciprocating speed.

\section{Control Mode. Control systems can use feed back or feed forward} control loops. Feed back seems the most logical based on the limited state of on-line control information with this cleaning technique. 


\section{$E-16$}

Experience. No tabling operations are currently using on-line analysis or process control to optimize operations.

Control Strategy Using DEGG/PGNAA Analyzer. The DEGG/PGNAA analyzer has been shown to provide accurate analysis of slurry percent solids, ash, and mass flow rate on streams characteristic of the feed and tailings streams. Since the refuse stream contains the most water and is smaller in size, it seems a logical stream for control. Presented below are two proposed control modes. The first uses only the DEGG to estimate ash and percent solids in control modes to maintain ash within an acceptable range and maximize yield. The second use both the DEGG and the PGNAA instrument to control both ash and sulfur.

\section{Control Mode No. 1: Simple Ash/Yield Control for a Concentrating Table}

- Monitor the feed and tailings ash content

- Modify table performance by adjusting table elevation and motor length of stroke

- Control operations using feed forward control of table elevation on the feed ash content, and feed back control of the motor stroke based on the tailings ash content. 


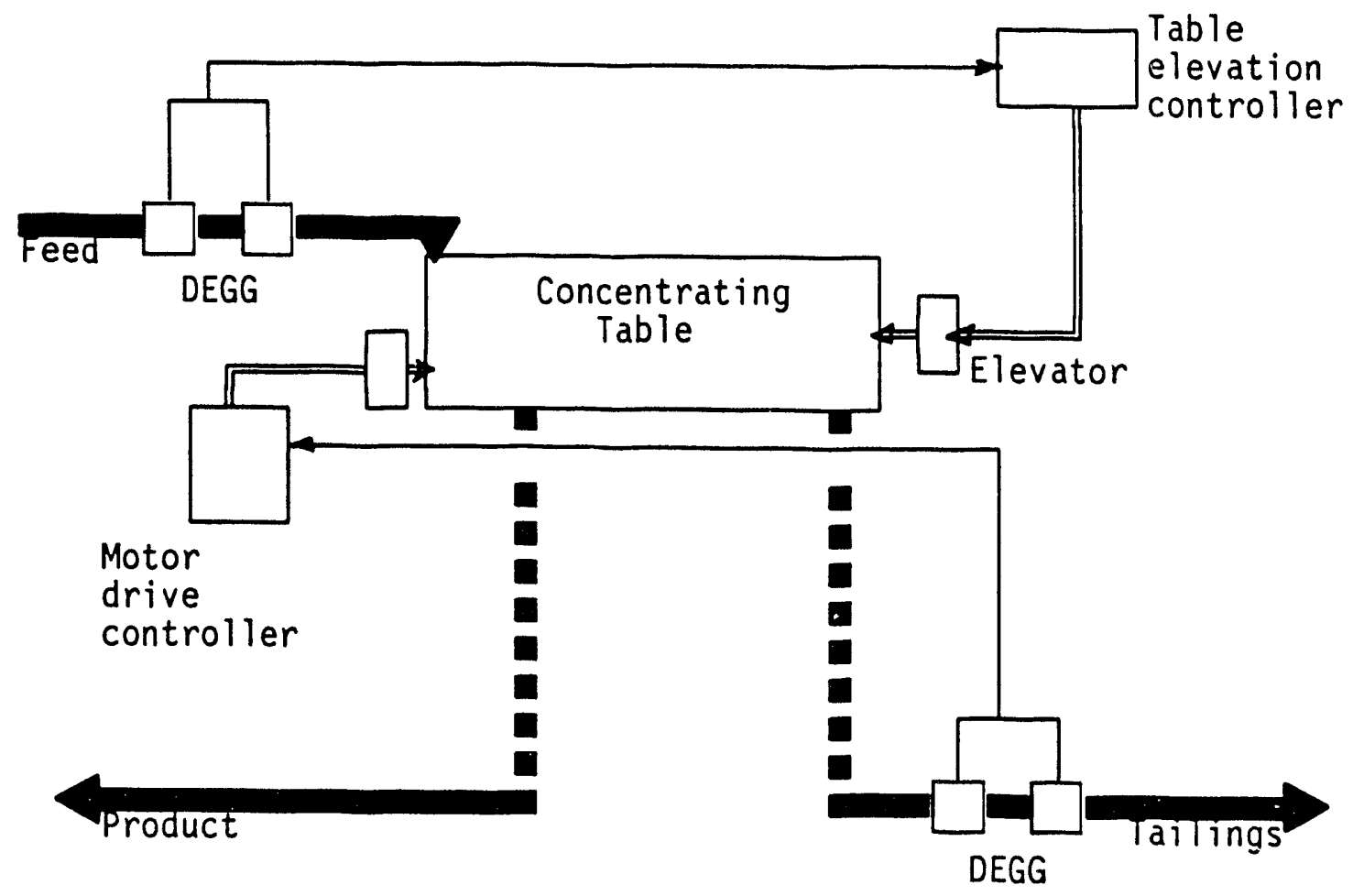

Control Mode No. 2: Simple Ash/Sulfur/Yield Control for a Concentrating Table

- Monitor the feed and tailings ash and sulfur contents

- Modify table performance by adjusting table elevation and motor length of stroke

- Control operations using feed forward control of table elevation based on the feed ash and sulfur contents and feed back control of the motor stroke based on the tailings ash and sulfur contents. 


\section{$E-18$}

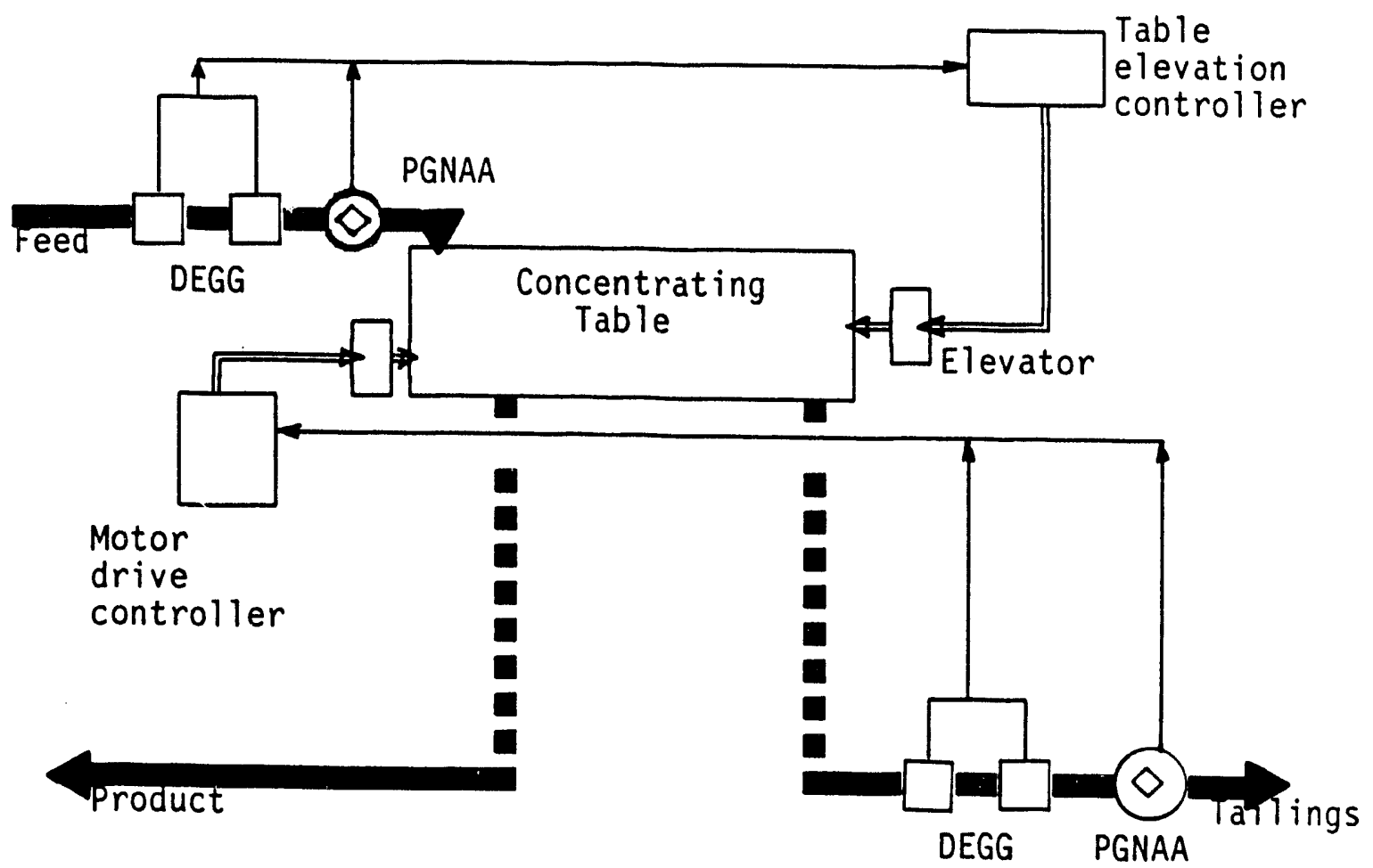

\section{Froth Flotation}

Control options for conventional flotation were covered under control modes discussed under the section on advanced flotation. 

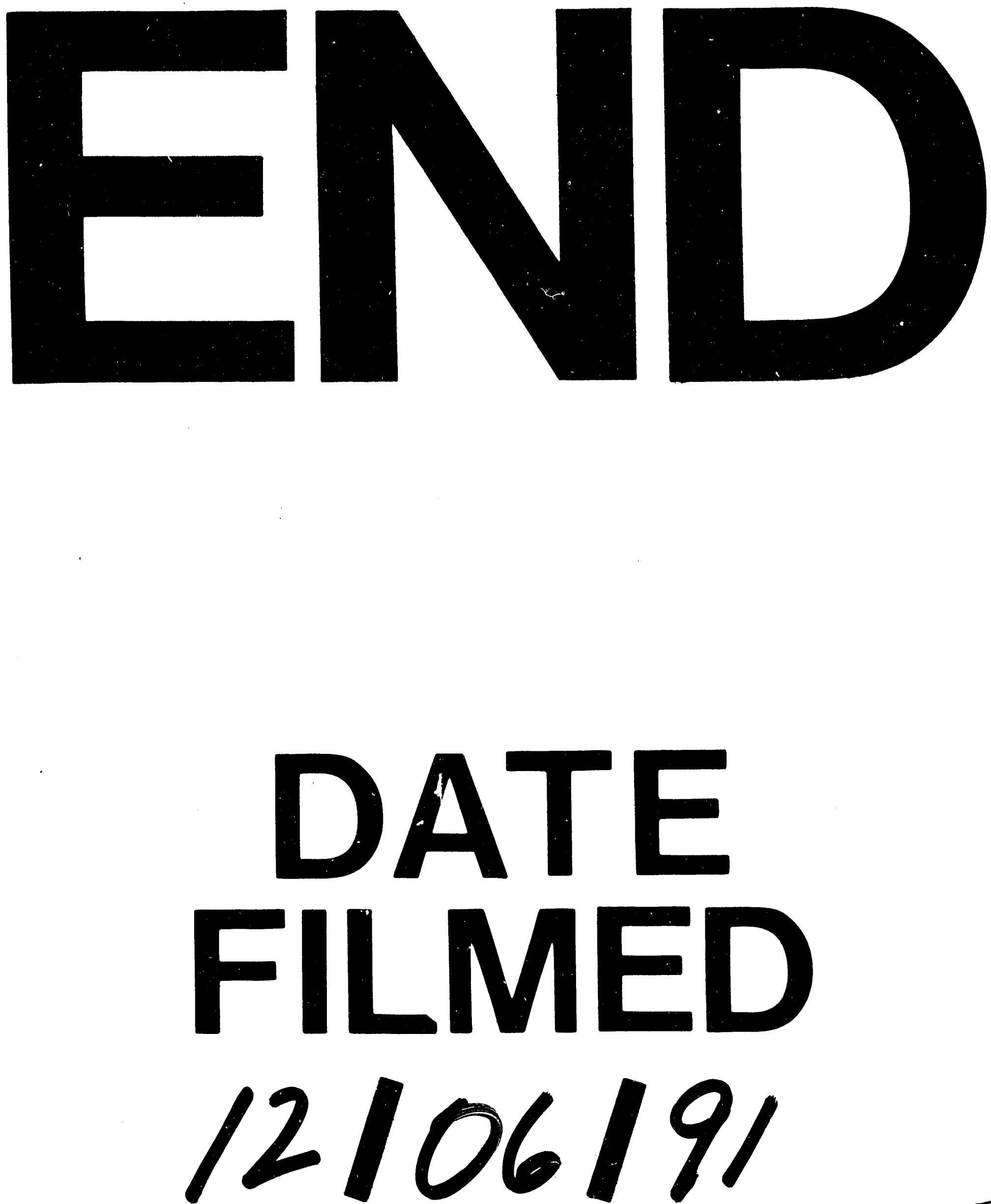